\title{
Noninvasive prenatal screening and diagnosis
}

Citation for published version (APA):

Mersy, E. (2016). Noninvasive prenatal screening and diagnosis: from bench to clinic. [Doctoral Thesis, Maastricht University]. Maastricht University. https://doi.org/10.26481/dis.20161207em

Document status and date:

Published: 01/01/2016

DOI:

10.26481/dis.20161207em

Document Version:

Publisher's PDF, also known as Version of record

\section{Please check the document version of this publication:}

- A submitted manuscript is the version of the article upon submission and before peer-review. There can be important differences between the submitted version and the official published version of record.

People interested in the research are advised to contact the author for the final version of the publication, or visit the DOI to the publisher's website.

- The final author version and the galley proof are versions of the publication after peer review.

- The final published version features the final layout of the paper including the volume, issue and page numbers.

Link to publication

\footnotetext{
General rights rights.

- You may freely distribute the URL identifying the publication in the public portal. please follow below link for the End User Agreement:

www.umlib.nl/taverne-license

Take down policy

If you believe that this document breaches copyright please contact us at:

repository@maastrichtuniversity.nl

providing details and we will investigate your claim.
}

Copyright and moral rights for the publications made accessible in the public portal are retained by the authors and/or other copyright owners and it is a condition of accessing publications that users recognise and abide by the legal requirements associated with these

- Users may download and print one copy of any publication from the public portal for the purpose of private study or research.

- You may not further distribute the material or use it for any profit-making activity or commercial gain

If the publication is distributed under the terms of Article $25 \mathrm{fa}$ of the Dutch Copyright Act, indicated by the "Taverne" license above, 
Noninvasive prenatal screening and diagnosis:

from bench to clinic

Elke Mersy 


\section{Noninvasive prenatal screening and diagnosis: from bench to clinic}

The research presented in this thesis was conducted within GROW School for Oncology and Developmental Biology, at the Department of Clinical Genetics of the Maastricht University Medical Center (MUMC+).

The studies described in this thesis were funded by The Netherlands Organisation for Health Research and Development (ZonMw Prevention Fund; projects 120510006 and 200320009).

ISBN 978-94-6233-439-7

(C) Copyright Elke Mersy, Maastricht 2016

Cover: Petal Wijnen, Maastricht

Lay-out: Elke Mersy, Maastricht

Printed by: Gildeprint Drukkerijen, Enschede 


\title{
Noninvasive prenatal screening and diagnosis:
}

\author{
from bench to clinic
}

\author{
PROEFSCHRIFT \\ ter verkrijging van de graad van doctor aan de Universiteit Maastricht, \\ op gezag van de Rector Magnificus, Prof. dr. Rianne M. Letschert, \\ volgens het besluit van het College van Decanen, \\ in het openbaar te verdedigen \\ op woensdag 7 december 2016 om 10.00 uur
}

door

Elke Mersy

Geboren op 18 augustus 1986, te Kortrijk, België 


\section{Promotores}

Prof. dr. ir. J.A. Veltman

Prof. dr. C.E.M. de Die-Smulders

\section{Copromotor}

Dr. S.G.M. Frints

\section{Beoordelingscommissie}

Prof. dr. J.G. Nijhuis (voorzitter)

Prof. dr. M.P. van Dieijen-Visser

Dr. W.J. Dondorp

Dr. K.D. Lichtenbelt (UMC Utrecht)

Prof. dr. ir. J.R. Vermeesch (KU Leuven, België) 
"I look at myself doing science and I am almost like a tourist. Going places I have never been before - that I might be the first to see."

Yuk Ming Dennis Lo, the Guardian, 2013 discovered fetal cell-free DNA 



\section{Table of contents}

$\begin{array}{ll}\text { Abbreviations } & 8\end{array}$

Chapter 1 General introduction and outline of the thesis

Part I Design of noninvasive prenatal diagnostic tests

Chapter 2 Cell-free RNA is a reliable fetoplacental marker in noninvasive fetal sex determination $\quad 45$

Chapter 3 Noninvasive prenatal diagnosis of myotonic dystrophy type 167

Part II Noninvasive prenatal screening for fetal chromosome disorders

Chapter 4 Noninvasive detection of fetal trisomy 21: Systematic review and report of quality and outcomes of diagnostic accuracy studies performed between 1997 and 2012

Chapter 5 Advantages and disadvantages of different implementation strategies of noninvasive prenatal testing in Down syndrome screening programs

Chapter 6 Noninvasive prenatal testing for sex chromosome trisomy: exploring opinions of pregnant women

Chapter 7 General discussion and future perspectives

Summary 201

Samenvatting 207

Addendum: valorization

Dankwoord 223

Curriculum vitae

Publications 229 


\section{Abbreviations}

45,X Turner syndrome

47,XXX Triple X syndrome

47,XXY Klinefelter syndrome

$95 \% \mathrm{Cl} \quad 95 \%$ confidence interval

AC amniocentesis

AD

autosomal dominant

ADHD

attention deficit hyperactivity disorder

AFP

alpha-fetoprotein

AMELX

$X$-linked amelogenin gene

AMELY

Y-linked amelogenin gene

AR

autosomal recessive

ASHG

American Society of Human Genetics

BMI

body mass index

C21orf105

chromosome 21 open reading frame 105 gene

$\operatorname{cf}(f) D N A$

cell-free (fetal) DNA

$\operatorname{cf}(f) R N A$

cell-free (fetal) RNA

$C G B$

chorionic gonadotropin, beta polypeptide gene

CGB1

chorionic gonadotropin, beta polypeptide 1 gene

CGB2

chorionic gonadotropin, beta polypeptide 2 gene

CGB5

chorionic gonadotropin, beta polypeptide 5 gene

CGB7

chorionic gonadotropin, beta polypeptide 7 gene

CGB8

chorionic gonadotropin, beta polypeptide 8 gene

Co negative controls (non-trisomy 21 samples)

$\mathrm{CSH} 1$

chorionic somatomammotropin hormone 1 (placental lactogen) gene

$\mathrm{CSH} 2$ chorionic somatomammotropin hormone 2 gene

CSHL1 chorionic somatomammotropin hormone-like 1 gene

CVS chorionic villus sampling

(CYP21) CAH congenital adrenal hyperplasia (due to 21-hydroxylase deficiency)

DANSR digital analysis of selected regions

DM1 myotonic dystrophy type 1

$D M P K$ dystrophia myotonica protein kinase gene

DS Down syndrome

EDTA ethylenediaminetetraacetic acid 


\begin{tabular}{|c|c|}
\hline ESHG & European Society of Human Genetics \\
\hline FCT & first trimester combined test \\
\hline FISH & interphase fluorescence in situ hybridization \\
\hline free- $\beta$ hCG & free beta human chorionic gonadotropin \\
\hline$H B B$ & hemoglobin beta gene \\
\hline hCG & human chorionic gonadotropin \\
\hline IGV & integrative genomics viewer \\
\hline IVF/ICSI & in vitro fertilization/intracytoplasmic sperm injection \\
\hline KT & karyotyping \\
\hline MAF & minor allele frequency \\
\hline MeDiP & methylated DNA immunoprecipitation \\
\hline MIPVAR & MIP-based variant calling \\
\hline miRNA & microRNA \\
\hline mRNA & messenger RNA \\
\hline MLPA & multiplex ligation-dependent probe amplification \\
\hline Mpa & only paternal mutation detected \\
\hline MPS & massively parallel sequencing \\
\hline NGS & next-generation sequencing \\
\hline NIPD & noninvasive prenatal diagnosis \\
\hline NIPT & noninvasive prenatal testing \\
\hline NPV & negative predictive value \\
\hline PAPP-A & pregnancy-associated plasma protein-A \\
\hline PCR & polymerase chain reaction \\
\hline PDE9A & phosphodiesterases gene $9 \mathrm{~A}$ \\
\hline PGD & pre-implantation genetic diagnosis \\
\hline $\mathrm{PL}$ & placental lactogen \\
\hline PLAC4 & placenta-specific 4 gene \\
\hline PND & prenatal diagnosis \\
\hline PPV & positive predictive value \\
\hline QF-PCR & quantitative fluorescent polymerase chain reaction \\
\hline qMSP & quantitative methylation-specific polymerase chain reaction \\
\hline qPCR & real-time quantitative polymerase chain reaction \\
\hline QUADAS-2 & quality assessment of diagnostic accuracy (revised tool) \\
\hline RAD & rapid aneuploidy detection \\
\hline RASSF1A & Ras association domain family member 1 isoform $A$ gene \\
\hline
\end{tabular}


RHD Rh blood group, D antigen gene

RhD rhesus D

$\mathrm{RT}(-\mathrm{PCR}) \quad$ reverse transcription (polymerase chain reaction)

SCA sex chromosome aneuploidy

SCT sex chromosome trisomy

SD standard deviation

SERPINB2 serpin peptidase inhibitor, clade B (ovalbumin), member 2 gene

(sm)MIPs (single molecule) molecular inversion probes

SNP single nucleotide polymorphism

$S R Y \quad$ sex-determining region $Y$ gene

sub substitution

T13 trisomy 13, Edwards syndrome

T18 trisomy 18, Patau syndrome

T21 trisomy 21, Down syndrome

TOP termination of pregnancy

uE3 unconjugated estriol

UI unmethylation index

UTY ubiquitously transcribed tetratricopeptide repeat containing, Y-linked

WES whole exome sequencing

WGS whole genome sequencing

WT wild-type nucleotide

XL X-linked 


\section{Chapter 1}

General introduction and outline of the thesis 
In Western countries the health of the pregnant woman and the unborn child are monitored in routine prenatal care. Prevention and early detection of birth defects are part of prenatal care. To prevent birth defects, pregnant women are taught to avoid known teratogens, for example alcohol. Furthermore, they are screened through blood tests for infections and a potential maternal immune response against fetal blood cells. Many birth defects become apparent during gestation because of reduced fetal growth or abnormalities, visible on ultrasound scan. Therefore, pregnant women are offered regular ultrasound examinations and a fetal anomaly ultrasound scan at 18 to 20 weeks of gestation. Additionally, prenatal screening and diagnostic tests for prenatally detectable genetic disorders are offered. In this thesis, I focus on the latter group of tests.

\subsection{Prenatal screening and diagnosis: definitions}

Before describing the research upon which this doctoral dissertation is based, it is necessary to clarify exactly what is meant by the different terms referring to prenatal screening and diagnosis in this thesis.

First and foremost, the terms screening and diagnostic will be used to describe the character of the test itself. The term prenatal diagnostic test will be used for any test providing a definite answer to a clinical question, not requiring a follow-up test to confirm the result. The term prenatal screening test will be applied for any test that offers a risk-assessment and requires a follow-up diagnostic test to clarify abnormal screening results.

Secondly, the concepts of prenatal screening and prenatal diagnosis are described. The term prenatal diagnosis will be used solely when referring to pregnant women with increased risk undergoing a prenatal diagnostic test to investigate the presence of any genetic disorder in the fetus. Women can have an a priori increased risk for a fetus with a genetic disorder, e.g. because they have the genetic disorder themselves, or can have an increased risk after a prenatal screening test, e.g. an ultrasound examination. In other words, women have a medical indication to undergo the diagnostic test.

In this thesis, the term prenatal screening will be used in its broadest sense to refer to pregnant women undergoing a prenatal screening test. Prenatal screening can be followed by prenatal diagnosis in the case of abnormal screening results. In other areas of medicine, the term screening tends to be used to refer to tests offered to people 
without symptoms nor another reason to seek medical help. However, it would not be correct to simply extrapolate this definition and therefore assume that prenatal screening is only offered to women without a medical indication. Women undergoing prenatal screening can also have an increased risk for the tested genetic disorder, but this is not obligatory.

Prenatal testing is a term frequently used in the literature, and is used in general as a synonym for prenatal screening.

Finally, the term prenatal screening program will be used to describe an organized program comprising prenatal screening tests usually followed by a prenatal diagnostic test to confirm any abnormal result of the first risk-assessment. A prenatal screening program can be offered to all pregnant women or only to high-risk pregnant women.

\subsection{An a priori increased risk for a genetic disorder in the fetus}

Future mothers and fathers can have an a priori increased risk for a chromosome disorder or for a single-gene disorder in their unborn child.

In chromosome disorders the birth defect is due to an excess or deficiency of the genes in a part of a chromosome, or a whole chromosome. ${ }^{1}$ Future mothers and fathers have an a priori increased risk for a chromosome disorder in the fetus if they had a previous child with a chromosome abnormality or if they have a structural chromosome abnormality themselves. Mothers over the age of 35 (advanced maternal age) also have an increased risk of fetal chromosome disorders. The effect of progressing maternal age on the risk of chromosome disorders is well known by prenatal care providers and pregnant women. ${ }^{2}$ During the last decades, advanced maternal age was used as a sole criterion for further prenatal diagnosis of fetal chromosome disorders, but this is no longer recommended by the International Society for Prenatal Diagnosis. ${ }^{3}$ Recently, in 2015, advanced maternal age was also abandoned as a sole criterion to undergo a prenatal diagnostic test in the Netherlands. ${ }^{4}$

Single-gene disorders are caused by a critical error in the genetic information carried by a single gene. ${ }^{1}$ Such error, called a mutation, may be present in only one chromosome of a pair (i.e. in one allele, matched with a normal gene without the error on the homologous allele), or in both chromosomes of a pair (i.e. in both alleles). Single-gene disorders have recessive, dominant and X-linked Mendelian inheritance 
patterns. Couples with single-gene disorders themselves or in their family are offered genetic counseling to discuss the risk of transmitting this disorder to their unborn child. A new gene error (also called "de novo mutation") may be suspected when ultrasound malformations clearly point towards a specific disorder or a group of disorders, e.g. skeletal dysplasia. Furthermore, advanced paternal age ( $>40$ years) is associated with an increased risk of de novo mutations in the unborn child, that were not inherited from the mother or father. ${ }^{5,6}$ The increased risk of advance paternal age is far less wellknown among prospective parents than the increased risk of chromosome disorders in the case of advanced maternal age in pregnancy. It is also not yet included in prenatal counseling guidelines.

\subsection{Traditional prenatal screening for chromosome disorders}

Since the 1980s, multiple biochemical prenatal screening tests have been developed for the identification of three chromosome disorders: Down syndrome (trisomy 21), Edwards syndrome (trisomy 18) and Patau syndrome (trisomy 13). In Europe, the prevalences of trisomy 13, 18 and 21 in pregnancy are 2, 5 and 22 per 10000 births, respectively. ${ }^{7}$ All other nonmosaic autosomal trisomies are incompatible with postnatal survival. Each of these autosomal trisomies is associated with growth retardation, mental retardation, and multiple congenital abnormalities. ${ }^{1}$ Double, triple and quad marker prenatal testing was proposed for women in the second trimester of pregnancy, based on various combinations of serum markers. ${ }^{8}$ In the Netherlands, the second trimester triple test was introduced in 1990. ${ }^{9,10}$ This test measured the serum levels of alpha-fetoprotein (AFP), unconjugated estriol (UE3) and free beta human chorionic gonadotropin (free-ßhCG), and interpreted these levels combined with the maternal age to calculate the woman's individual risk of fetal trisomies 13, 18 and 21.

Later, in 1992, it was shown that the fetal ultrasound marker nuchal translucency was a very good indicator of the risk of Down syndrome in the first trimester of pregnancy. ${ }^{8}$ This led to the implementation of the first trimester combined test (FCT). The FCT includes a nuchal translucency measurement by ultrasound at 12 weeks of gestation and a blood test between 11 and 14 weeks of gestation. In this blood test two serum hormones are quantified, namely pregnancy-associated plasma protein-A (PAPP-A) and free- $\beta$ hCG. The results of these tests are combined with the maternal age and the gestational age to calculate the woman's individual risk for fetal trisomies 13, 18 and 21. A few years after the introduction of the triple test in the Netherlands, the Health Council, an advisory board of the Dutch Ministry of Health, advised the use of the FCT 
instead of the triple test. ${ }^{10}$ In 1999, the integrated test was developed, combining first and second trimester markers. ${ }^{8}$

In Europe, an early prenatal risk assessment with the FCT has classically been preferred..$^{8}$ In 2007, in the Netherlands a national prenatal screening program was introduced aiming to provide all pregnant women the option of prenatal screening with the FCT. ${ }^{11}$ Nowadays, the FCT is still offered to all pregnant women. Traditionally, women with a risk of fetal trisomies 13, 18 or 21 of 1 in 200 or higher after the FCT are offered prenatal diagnosis to further investigate these fetal chromosome disorders.

\subsection{Invasive prenatal diagnosis}

Women may undergo prenatal diagnosis in the case of an a priori increased risk for a genetic disorder, an increased risk of a chromosome disorder following a screening test, or in the case of fetal abnormalities detected on ultrasound. Conventional prenatal diagnosis requires invasive procedures to provide fetal cells, either chorionic villus sampling between 11 and 14 weeks gestation or amniocentesis after 15 weeks of gestation. The procedures are called invasive because they involve a catheter or needle being inserted into the amniotic fluid-filled cavity or into the placenta. The additional risk of miscarriage in women undergoing amniocentesis and chorionic villus sampling is estimated between $0.11-1 \%$ and $0.22-2 \%$, respectively. ${ }^{12-14}$

The invasive procedures provide fetal cells for chromosome analysis as well as for DNA analysis. Karyotyping detects all microscopically visible chromosome aberrations, while submicroscopic chromosomal aberrations below the resolution of a standard karyotype analysis are nowadays routinely investigated by microarray analysis. ${ }^{15}$ Additionally, an imbalance of the chromosomes 13, 18, 21 or the sex chromosomes can be diagnosed within 1-3 days, with one of the so called rapid aneuploidy detection techniques. ${ }^{16}$ These include interphase fluorescence in situ hybridization (FISH), quantitative fluorescent polymerase chain reaction (QF-PCR) and/or multiplex ligation-dependent probe amplification (MLPA). DNA analysis can be performed either by using direct mutation detection by PCR-based methods, or by closely linked microsatellite markers, or by using a combination of these methods. ${ }^{1}$

The invasive approaches to obtain fetal material for genetic chromosome and DNA analysis currently provide the gold standard for prenatal diagnosis. The pregnant couple receives a definite answer to the question whether the genetic disorder is present in the fetus. 


\subsection{Noninvasive prenatal screening and diagnosis}

To avert the risk of miscarriage of the invasive procedures, there has been a longlasting search for a reliable and safe noninvasive prenatal diagnostic test. In 1997, Dennis Lo first showed the presence of fetal cell-free DNA (cfDNA) in the maternal blood circulation by amplifying DYS14, a multicopy marker sequence on the $Y$ chromosome. ${ }^{17}$ Since then, the boundaries of what could be detected in the fetal cfDNA have been enthusiastically expanded, with save noninvasive prenatal tests for the mother and the future child in mind. These tests are referred to as noninvasive, as they only require maternal venous blood sampling. In this thesis, prenatal detection of genetic disorders through analysis of cfDNA in maternal blood is reported, as well as the responsible application of cfDNA-based tests in prenatal screening.

\subsubsection{The origin of cell-free DNA and RNA}

The placenta and umbilical cord form a transport system for substances (nutrients, oxygen, waste materials and carbon dioxide) between the mother and fetus. The placenta is a fetomaternal organ that has two components: a fetal part, derived from the dividing fertilized egg, and a maternal part, derived from the endometrium of the uterus. ${ }^{18}$ Fetal cfDNA originates from degenerating trophoblast cells from the fetal part of the placenta. ${ }^{19,20}$ Trophoblast degeneration occurs in all normal pregnancies, as part of physiological villous remodeling, and may be exaggerated in case of placenta pathology. ${ }^{19}$ In this process the DNA from the degenerating cells is released into the maternal blood circulation passing through the placenta next to the trophoblast cells.

CfDNA of maternal origin, derived from degeneration of hematopoietic cells, is also present in the blood circulation of the mother, and in much higher amounts than fetal cfDNA. ${ }^{21}$ The fetal cfDNA represents on average a fraction of $6-10 \%$ of the total cfDNA in the plasma in first and second trimester pregnancies. This fetal fraction may rise up to $10-20 \%$ in third trimester pregnancies. ${ }^{21,22}$

Maternal as well as fetal cfDNA exist of short, fractionated, DNA sequences. Most cfDNA sequences have a size between 50 and 200 bp. ${ }^{23}$ The most significant difference in the size distribution between the fetal and the maternal cfDNA is that maternal cfDNA is predominantly $166 \mathrm{bp}$ in size, while most fetal cfDNA sequences have size between 122 and 166 bp. ${ }^{23}$ A small portion of the cfDNA, mostly of maternal origin, is larger than $300 \mathrm{bp.}^{24}$ Fetal cfDNA is detectable in maternal serum as well as maternal plasma, but the lysis of maternal nucleated blood cells during the clotting process 
leads to an increased proportion of maternal cfDNA in the serum sample in comparison with plasma. ${ }^{25}$ Fetal cfDNA has also been detected in maternal urine. ${ }^{26,27}$ However, this cfDNA is even more fragmented than in serum and plasma, and is present in low concentrations. ${ }^{27}$ Serum and urine of the pregnant women are therefore less suitable for prenatal tests than plasma. Also cell-free trophoblast RNA (cfRNA) and circulating placental microRNAs (miRNAs) have been detected in the maternal circulation. ${ }^{28-30}$ The cfRNA is mRNA from genes expressed in trophoblast cells. ${ }^{28,29}$ Placental miRNAs regulate placental development and trophoblast cell activities. $^{30}$

Fetal cfDNA can already be detected in the maternal circulation at the fourth week of gestation. ${ }^{31}$ The concentration is very low. Often cited is an expected concentration of 1000 genome equivalents/mL in a human blood sample for the total (maternal and fetal) cfDNA. ${ }^{32,33}$ However, both the concentrations of the total and fetal cfDNA vary between individuals. ${ }^{34-36}$ The amount of maternally derived cfDNA can vary depending on maternal health factors, such as obesity or diabetes. ${ }^{34}$ The amount of fetal cfDNA, i.e. the fetal fraction, is affected by gestational age, maternal weight, and the health of the placenta. ${ }^{34-36}$ Additionally, quantification of cfDNA and of the fetal fraction is influenced by pre-analytical and analytical factors, including storage conditions, delay before plasma separation, blood-processing protocols, DNA extraction method, amplicon size, target gene choice, and the used quantification method. ${ }^{33,34}$ Concentrations in maternal plasma as low as 220 genome equivalents/mL and 20 genome equivalents/mL have been described for total cfDNA and fetal cfDNA, respectively. ${ }^{21,34}$

Fetal cfDNA and cfRNA are rapidly cleared from the maternal plasma after pregnancy. ${ }^{28,37}$ Consequently, the fetal cfDNA in the plasma of a pregnant woman has the same genetic profile as the child she is bearing, and does not resemble the genetic profile from a previous child. This makes fetal cfDNA very useful for prenatal screening and diagnosis. 


\subsubsection{Early developed clinical applications}

Noninvasive prenatal tests using fetal cfDNA are technically very challenging to develop, due to the predominance of maternal cfDNA sequences in the blood sample. Initially, clinical applications of fetal cfDNA mostly focused on fetus-specific sequences that could be distinguished from the maternal sequences.

\section{A. Noninvasive fetal sex determination}

The $Y$ chromosome is unique to the male fetus, and is not present in the genetic blueprint of the mother or a female fetus. This made the development of noninvasive fetal sex determination, where the presence of $Y$ chromosome in the maternal plasma is verified, relatively easy. Sex determination was one of the first clinical applications of fetal cfDNA testing and is routinely used in European countries. ${ }^{38}$ In the Netherlands, it has been offered as a prenatal diagnostic test for clinical purpose since the beginning of 2003. ${ }^{39}$

Early prenatal diagnosis of fetal sex is indicated in case of a fetus at risk of one of the more than 100 known X-linked inherited disorders. ${ }^{40} \mathrm{X}$-linked disorders are caused by a mutation on the $\mathrm{X}$ chromosome, and affect mostly boys, and not or to a lesser degree girls. Their prenatal diagnosis is often performed early in pregnancy by mutation analysis of chorionic villi. Since prenatal diagnosis is only desired in boys for the majority of X-linked disorders, early fetal sex determination by a noninvasive procedure prevents unnecessary chorionic villus sampling in girls. A second indication for fetal sex determination is a fetus at risk of congenital adrenal hyperplasia (CAH) due to 21-hydroxylase deficiency (CYP21 CAH). ${ }^{41,42}$ If female fetuses affected with CAH are exposed to androgens at the critical time of sexual differentiation (between 9 and 15 weeks of gestation) this will result in masculinization of the external genitalia. Starting treatment of the pregnant woman carrying an affected female fetus with dexamethasone before 9 weeks of gestation counters the virilisation. ${ }^{43}$ Prenatal diagnosis of CYP21 CAH requires a chorionic villus sampling or amniocentesis. Early sex determination by a noninvasive procedure prevents an unnecessary invasive procedure and start of dexamethasone treatment in women that are pregnant of a boy. Following the noninvasive identification of a female fetus, dexamethasone is given to the pregnant woman. If the fetus is later determined to be an unaffected female upon DNA analysis, most often after chorionic villus sampling, treatment with dexamethasone can be discontinued. Third, if a fetus presents with ambiguous genitalia on ultrasound examination, noninvasive prenatal determination of the 
genetic sex can be helpful to determine the sex of the fetus and the defect that resulted in genital ambiguity. ${ }^{42,44}$

In the case of amplification of $Y$ chromosome-derived cfDNA sequences in the maternal plasma, the fetus is presumed to be male. However, to conclude whether a negative result is a true-negative result, indicating female gender of the fetus, or a false-negative result, due to a low amount of fetal cfDNA, a marker to confirm the presence of fetal nucleic acids is crucial (a so-called "fetal marker"). The confirmation of the presence of fetal nucleic acids in the maternal plasma requires extra time and expenses by the laboratory. Sometimes the fetal marker fails to confirm the presence of fetal material, and as a result, the assays cannot provide a fetal gender. ${ }^{39,45}$ In Chapter 2 we address these problems and describe the development of a novel singletube noninvasive fetal sex determination assay, in which a gender-independent fetoplacental marker is incorporated in the test, requiring no extra time or expenses by the laboratory.

\section{B. Noninvasive genotyping of fetal blood group antigens}

Another early developed application was the noninvasive determination of the presence of the Rh blood group, $\mathrm{D}$ antigen gene $(R H D)$ in the plasma of alloimunised rhesus $D(R h D)$-negative pregnant women. ${ }^{46,47}$ The presence of $R H D$ in the plasma suggests that the fetus is RhD positive and at risk of hemolytic disease of the fetus and newborn. The maternal immune response against the fetal blood cells can be prevented by prophylactic antenatal and postnatal anti-D immunoglobulin. Next to $\mathrm{RhD}$ incompatibility between the pregnant woman and the fetus, also incompatibility of other red blood cell antigens can cause hemolytic disease of the fetus and the newborn and should therefore be discovered as soon as possible. ${ }^{48}$ Nowadays, noninvasive fetal blood group genotyping has replaced the invasive procedures to prenatally determine the fetal antigen status. In the Netherlands, blood group genotyping for rhesus D is offered since 2003, followed by rhesus $\mathrm{K}$ in 2006 and rhesus C and $\mathrm{E}$ in 2007 in alloimunised women. ${ }^{49}$

\subsubsection{Noninvasive prenatal tests and next-generation sequencing: parallel developments}

While research on fetal cfDNA clinical applications was flourishing, the technical possibilities to investigate the human DNA were also developing fast. Next-generation sequencing (NGS), also called massively parallel sequencing, now allows us to analyze 
and quantify millions of DNA fragments in one single experiment. ${ }^{50}$ All maternal and fetal cfDNA sequences of a plasma sample are sequenced in one experiment with this approach. NGS is increasingly being used in noninvasive prenatal detection of singlegene disorders and chromosome disorders.

\section{A. Developments in noninvasive prenatal diagnosis of single-gene disorders}

A few years after the discovery of fetal cfDNA in the plasma of pregnant women, the first studies aiming at diagnosing single-gene disorders in cfDNA were published.

Early developed tests for fetal single-gene disorders

The development of cfDNA-based tests to diagnose single-gene disorders is challenging from several perspectives: most cfDNA fragments in the maternal blood circulation are of maternal origin, the cfDNA exist of short sequences and the levels of total and fetal cfDNA in the maternal circulation are low. ${ }^{21-23,32}$ Consequently, noninvasive prenatal determination of single-gene disorders depends on subtle changes in the relative proportions of normal and mutated cfDNA in the plasma sample. Moreover, direct mutation detection is not applicable for disorders caused by a mutation longer than the size of the cfDNA fragments, such as repeat expansions and large deletions. Furthermore, the disorders are individually rare. ${ }^{1}$ Collecting a large cohort of pregnant women requesting prenatal diagnosis for an individual singlegene disorder is problematic. As a result, large-scale clinical validation studies are not possible.

Early studies aimed at diagnosing disorders where the mutation is not present in the maternal cfDNA. These are disorders in which the mutation is carried on the paternal allele, disorders caused by a de novo mutation, and autosomal recessive disorders where the parents carry different mutations and diagnosis is based on the detection or exclusion of the paternal mutation. The basic principle of the early studies was the amplification of the mutated allele by PCR, mostly real-time quantitative PCR (qPCR). Early onset primary dystonia and Crouzon syndrome are examples of dominant disorders in which the mutation, carried on the paternal allele, was detected or excluded in fetal cfDNA. ${ }^{51,52}$ Examples of diagnosed autosomal dominant disorders caused by a de novo mutation, suspected following abnormal ultrasound findings, are achondroplasia, thanatophoric dysplasia and Apert syndrome. ${ }^{53-58}$ Repeat expansion disorders that were tested in fetal cfDNA for the detection or exclusion of the paternal inherited allele from an affected father are Huntington disease and myotonic 
dystrophy type $1 .^{59-62}$ Cystic fibrosis, Leber congenital amaurosis, congenital adrenal hyperplasia, and alpha and beta-thalassemia are all autosomal recessive disorders in which the presence of a paternal mutation, different from the maternal mutation, was excluded or confirmed in cfDNA. ${ }^{63-78}$ Later, digital PCR and digital relative mutation dosage were used in the $X$-linked disorders hemophilia $A$ and $B$, to measure the concentration difference between the total amount (maternal-plus fetal-derived) of mutant and wild-type alleles in the plasma of heterozygous pregnant women carrying male fetuses. ${ }^{79}$ In sickle cell anemia, digital qPCR was used to analyze the dosage of the variant encoding hemoglobin $S$ relative to that encoding wild-type hemoglobin $A .{ }^{80}$ Also one case at risk of methylmalonic acidemia was tested in CfDNA using digital PCR to quantify allelic counts. ${ }^{81}$ In these early studies, only a single affected case or a few affected and non-affected cases were tested, due to the low prevalence of single-gene disorders. Only in the case of the inherited autosomal recessive blood disorders, more plasma samples were available to test.

\section{The introduction of NGS for fetal single-gene disorders}

In 2010, genome-wide deep sequencing (up to 65-fold haploid genome coverage) of a plasma sample revealed that both the entire fetal and maternal genome is represented in the fetal and maternal cfDNA, at a constant relative proportion. ${ }^{23}$ In 2012, another group used genome-wide deep sequencing of a maternal plasma sample to a deeper extent (78-fold haploid genome coverage), in combination with haplotype-resolved genome sequencing of the mother and shotgun genome sequencing of the father, to detect both inherited variations and de novo mutations in the fetal cfDNA. ${ }^{82}$ These two studies led to a promising start for a reliable noninvasive detection of all types of single-gene disorders. Using NGS, it is possible to assess the under-representation or over-representation of fetal alleles (by relative mutation dosage). As a result, also cfDNA testing of maternally inherited mutations and recessive disorders is possible.

\section{Noninvasive prenatal diagnosis of fetal single-gene disorders}

NGS has been used to detect single-gene disorders in maternal plasma since 2012 (Table 1.1). ${ }^{83-94}$ Noninvasive assays for single-gene disorders by NGS provide a definite answer to the question whether the disorder is present in the fetus, without the need for a follow-up test to confirm the result. Therefore, these tests are referred to as "noninvasive prenatal diagnosis" (NIPD). 


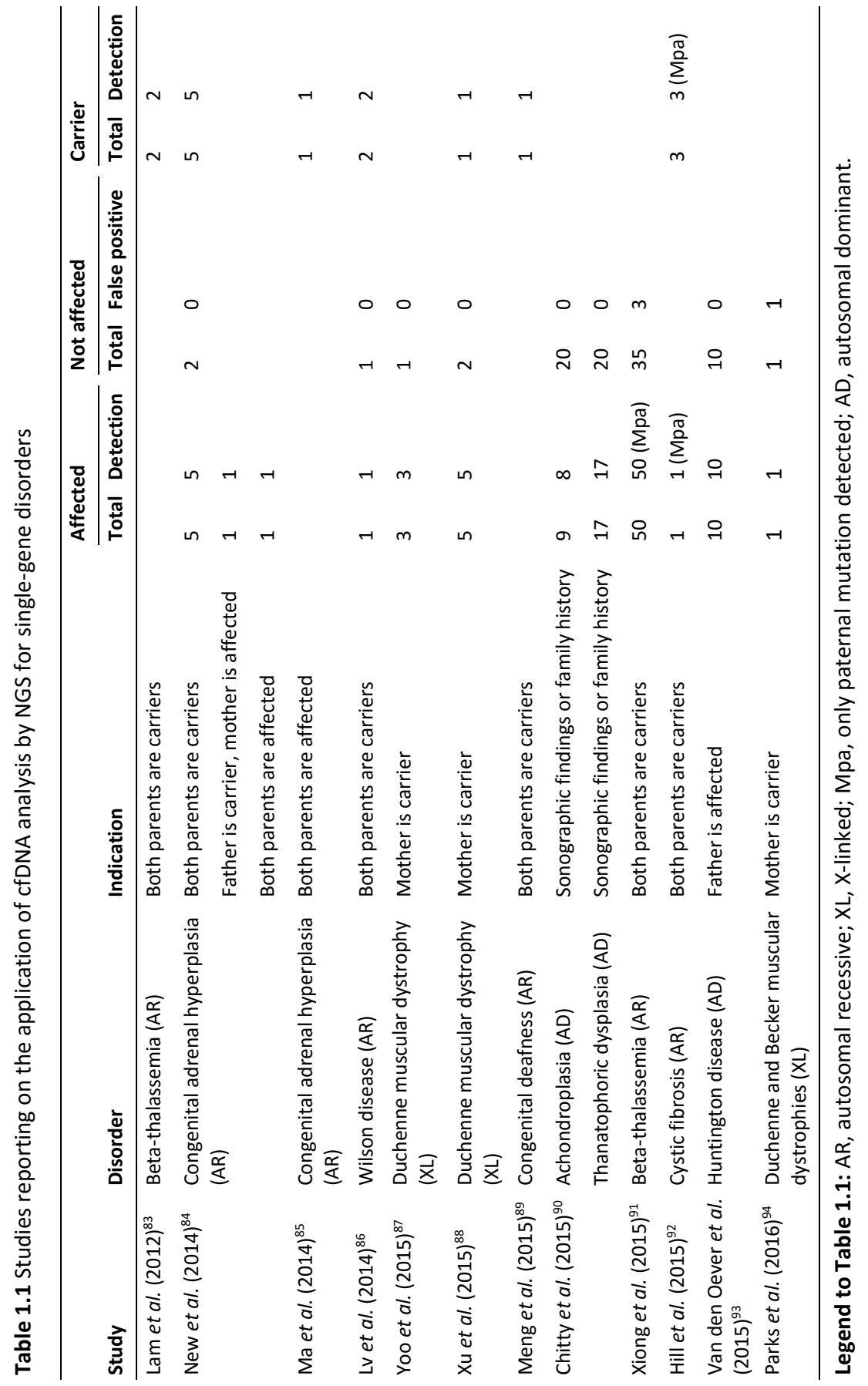


Both direct and indirect methods have been developed. The direct NIPD methods aim to detect or exclude the mutation in the cfDNA. In the case of paternal inheritance or de novo mutations, deep targeted sequencing is used to detect the mutation in a background of wild-type maternal reads. ${ }^{90-92}$ In the case of maternal inheritance, the over-representation of the mutated allele in the plasma sample (i.e. the fetus has inherited the mutation) is determined by relative mutation dosage. The relative mutation dosage relies on the reliable quantification of the fetal fraction. The second method, the indirect NIPD method, uses single nucleotide polymorphisms (SNPs) for genotyping of the parents. Based on SNP genotyping, informative SNPs from the parents are selected to determine the parental haplotypes. After targeted sequencing of the informative SNPs in the cfDNA, the percentages of NGS reads containing the variant or wild-type nucleotide allows to determine whether or not the mutated allele from an affected parent of from both affected parents is present in the maternal plasma. ${ }^{83-86}$ The indirect NIPD method can be used to detect single-gene disorders caused by mutations that are larger than the short cfDNA fragment, such as triple repeat expansions or deletions.

In Chapter 3 we report on the development of a novel NIPD assay to detect the inherited fetal alleles in the cfDNA, using an indirect haplotype-based approach. In our assay, we use single molecule molecular inversions probes (smMIPs) for targeted multiplex NGS of common SNPs. The method enables precise quantification of the variation in the cfDNA. Furthermore, the method has proven to be robust to relatively small amounts and poor quality of source DNA. ${ }^{95}$ As a proof of concept, we applied our smMIP-based NIPD assay to the cfDNA isolated from the plasma of a woman carrying a fetus affected with myotonic dystrophy type 1 (DM1), also known as Steinert's disease. DM1 is an autosomal dominant genetic disorder that affects skeletal and smooth muscle, the eye, heart, endocrine and central nervous systems. ${ }^{96,97}$ It is caused by expansion of a CTG trinucleotide repeat in the dystrophia myotonica protein kinase gene $(D M P K) \cdot{ }^{98,99}$ The disorder is characterized by anticipation: in successive generations, affected family members are at risk for further expansion of the CTG repeat, resulting in decreasing age of onset and increasing severity. ${ }^{96}$ 
Further development and implementation of NIPD of single-gene disorders

A translation into clinical practice of a targeted NGS-based method for some singlegene disorders has already been seen. ${ }^{100}$ At the Great Ormond Street Hospital in London, NIPD for FGFR3-related skeletal dysplasias, FGFR2-related craniosynostosis, Apert syndrome, Crouzon syndrome with acanthosis nigricans and cystic fibrosis is possible and offered to pregnant women. ${ }^{101}$ It is currently not possible for this laboratory to offer NIPD for conditions where the mother is a carrier of the genetic condition in question, or to detect the inheritance of a nucleotide repeat expansion. At the moment, more NIPD assays are being developed. In the near future, it is expected that a noninvasive prenatal diagnostic test for more single-gene disorders will be offered to pregnant women, also in the Netherlands.

\section{B. Developments in noninvasive prenatal detection of chromosome disorders}

The search for a noninvasive prenatal test that could reliably detect fetal trisomies 13, 18 and 21 started very soon after the discovery of fetal cfDNA in maternal plasma. The search for this test was compared in the literature to with the search for the Holy Grail. ${ }^{102}$ The origin of the drive to find this test lays in the fact that these chromosome imbalances have always been important indications for invasive prenatal diagnosis.

\section{Early developed tests for fetal chromosome disorders}

It was for a long time (from the first attempts in 1999 until 2011) impossible to reliably detect fetal chromosome imbalances in the fetal cfDNA in maternal plasma. Several strategies were pursued by both researchers from academic hospitals and commercial companies. Early studies focused on the quantification of fetal and total cfDNA in maternal plasma. ${ }^{103-110}$ In trisomy 21 , as well as in trisomies 13 and 18 , an elevation of fetal cfDNA levels has been reported. However, a large overlap in cfDNA concentrations between non-trisomic and trisomic pregnancies was seen. Later, the amount of cfDNA or cfRNA of specific genes was examined. ${ }^{111-115}$ For instance, an upregulation of hemoglobin beta ( $H B B$ ) cfDNA in trisomy 21 and a down regulation of chorionic gonadotropin, beta polypeptide (CGB) cfRNA in trisomy 18 pregnancies were observed, when compared with non-trisomic pregnancies. In addition, the comparison of maternally and paternally inherited fetal cfDNA and cfRNA sequences was explored. Trisomy 21 could be identified by the relative overrepresentation of maternal chromosome 21 fetal cfDNA or cfRNA sequences to the paternal chromosome 21 fetal cfDNA or cfRNA sequences. ${ }^{116-121}$ Next to these techniques, the dosage of a fetal 
chromosome was determined based on the epigenetic differences between maternal and fetal cfDNA. ${ }^{122-130}$ None of these approaches led to a practical test that could be used routinely in prenatal care.

\section{The introduction of next-generation sequencing for fetal chromosome disorders}

In 2008 the use of NGS was suggested to allow one to detect fetal chromosome disorders through analysis of thousands of millions of cfDNA sequences. ${ }^{131}$ After identifying the chromosomal origin of each sequenced plasma cfDNA molecule, the over- or underrepresentation of any chromosome in maternal plasma could be determined. ${ }^{131,132}$ Different algorithms are now used to calculate the deviation of percentage sequence reads per chromosome reads in a trisomic fetus in comparison with a disomic fetus. Because of the enormous throughput of current NGS systems, an additional advantage of NGS is that the cfDNA sequences from the plasma from many pregnant women can be sequenced at the same time.

Both NGS tests in which all, genome wide, cfDNA sequences in the maternal blood are sequenced (broad), as well as tests in which only specific chromosomes of clinical interest are sequenced (targeted), have been developed. ${ }^{132,133}$ In targeted NGS approaches, the pre-selection of chromosomes leads to less unutilized sequencing data and prevents unsolicited findings in other chromosomes. Furthermore, it was believed that because more rapid NGS devices could be used for targeted NGS, this would reduce the costs and turnaround time, and this would increase the number of pregnant women that could be tested per week. In recent years, these advantages have become less evident, because the broad NGS approaches can now also be performed rapidly and affordably.

\section{Noninvasive prenatal testing of fetal chromosome disorders using NGS}

In 2011 and 2012, the first diagnostic accuracy studies were published using NGS to detect fetal trisomies 13, 18 and 21 in maternal plasma, with or without pre-selection of chromosomes (Table 1.2). ${ }^{134-143}$ In these first studies NGS was mostly validated in women with an increased risk for fetal trisomies 13,18 or 21 . The diagnostic accuracy of the cfDNA-based test was established by comparing its results with karyotyping. In Chapter 4 we provide an overview of all studies evaluating of the diagnostic accuracy of molecular techniques for noninvasive detection of trisomy 21 between 1997 and the beginning of 2012. In this overview we compare these first studies using NGS with the older studies investigating other molecular techniques for trisomy 21 detection. 
We evaluate the quality of the studies (potential bias and applicability) and the diagnostic parameters.

Later studies included cohorts of low-risk pregnant women and mixed risk populations, and compared the performance of the cfDNA-based test with current prenatal screening tests (Table 1.2). ${ }^{144-164}$ It was shown that cfDNA-based tests using NGS can detect fetal trisomy in high-risk and in low-risk pregnant women from 10 weeks of gestation onwards with a sensitivity and specificity of more than $99 \%$. The negative predictive value, the chance that in case of a negative NIPT result the fetus does not have a trisomy, is excellent (almost $100 \%$ ). This means that a negative NIPT result reassures the pregnant couples. However, a variation in the likelihood that a pregnant woman with a positive cfDNA-based test result actually carries a fetus with a trisomy (positive predictive value) was observed. The positive predictive value drops especially when the a priori chance of carrying a fetus with a trisomy declines, and may even fall below $50 \%$ in young, low-risk women. ${ }^{134-165}$ Consequently, an invasive procedure, followed by a rapid aneuploidy detection technique or karyotyping, is recommended by the International Society for Prenatal Diagnosis to confirm suspicion of fetal trisomy following a positive cfDNA-based test result. ${ }^{3,166}$

Soon after the first diagnostic accuracy studies, the term "noninvasive prenatal testing" (NIPT) was formulated and replaced the term "noninvasive prenatal diagnosis" (NIPD) that had been used until then to describe the cfDNA-based trisomy tests. ${ }^{167}$ NIPT refers to cfDNA-based tests that are used as a screening test and require a confirmation by a follow-up diagnostic test, to provide a definite answer on whether the genetic disorder is present in the fetus. Although NGS cfDNA-based tests maybe failed to provide the final answer on whether a trisomy is present in the fetus, they proved to be much better screening tests that the traditional biochemical screening tests used so far. ${ }^{152,159}$ For example, the FCT, combining nuchal translucency measurement and serum markers, is estimated to have a sensitivity of $89.0 \%$ and a specificity of $95.4 \%$ for fetal trisomy 21 detection, if considering women of all age categories and a risk threshold of 1 in $200 .{ }^{168}$ This is considerably lower than the sensitivity and specificity of the NIPT, that both exceed $99 \%$. 


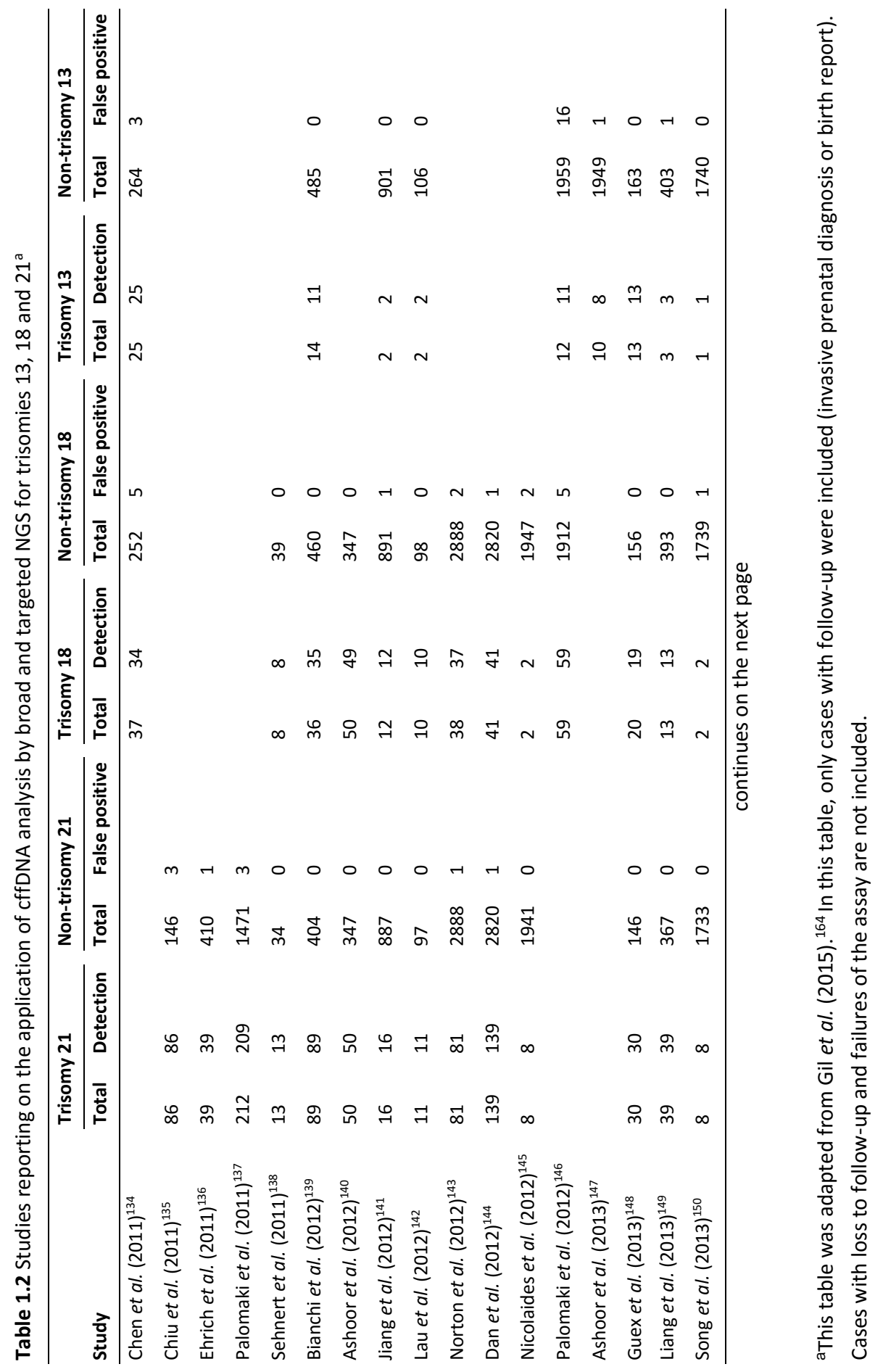




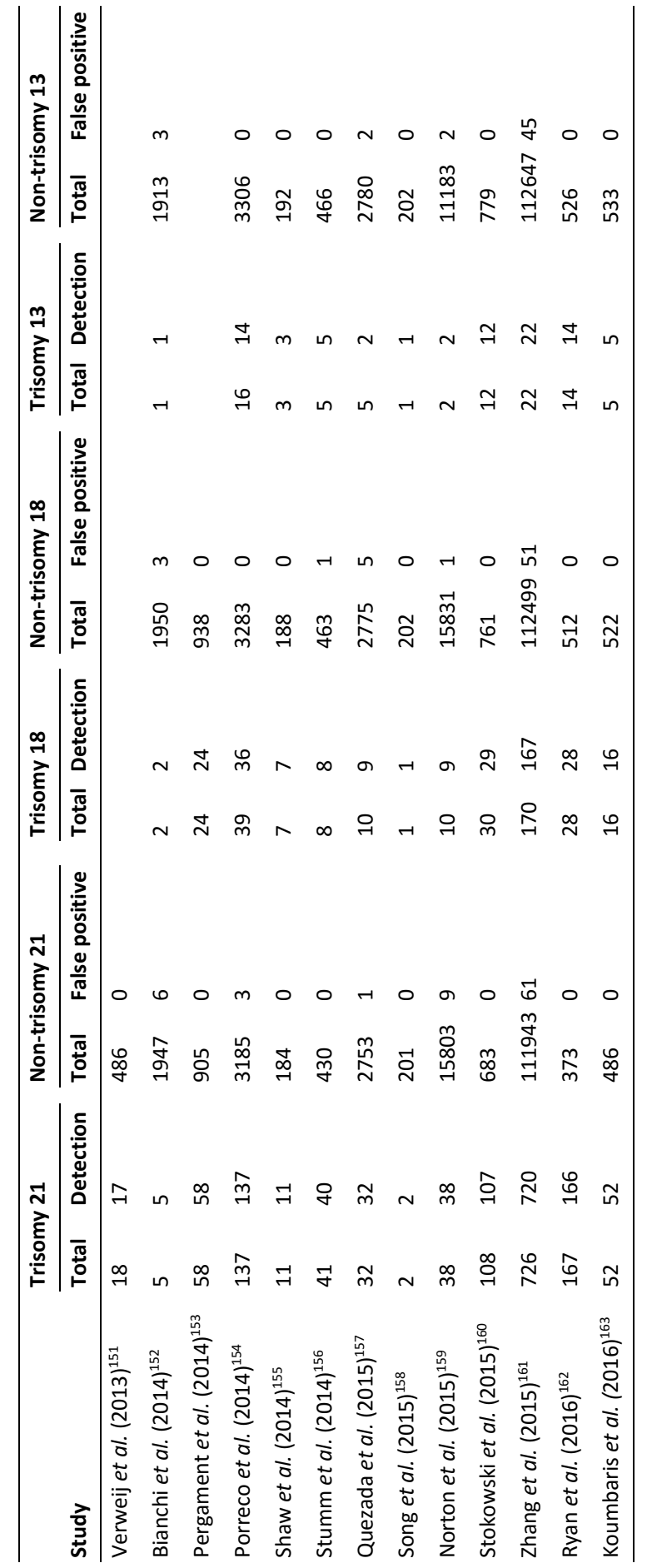


Implementation of NIPT for fetal trisomies 13,18 and 21

Nowadays, commercial NIPT is already offered in over 60 countries throughout six continents. ${ }^{169}$ At present, several countries are organizing the implementation of NIPT in their prenatal trisomy screening program. ${ }^{170-172}$ In the Netherlands, a national implementation study has been organized (the TRIDENT study). ${ }^{173}$ In this study, the genetic laboratories of the country collaborate to investigate the accuracy of NIPT and compare it to the published accuracy. Since April 2014, prenatal screening for trisomies 13,18 and 21 by NIPT is offered as a part of the TRIDENT-1 study to women with an increased risk based on the FCT ( $\geq 1: 200)$, or on the basis of their personal history. As a part of the study, the attitudes and preferences of the Dutch women towards NIPT for the detection of fetal trisomy are investigated. ${ }^{171}$ Recently, the Health Council advised to offer pregnant women the choice for NIPT as the first screening test. ${ }^{174}$ The Minister of Health gave permission to start with the TRIDENT-2 study in April 2017, in which all women in the Netherlands will be able to choose between NIPT and the FCT to screen for fetal aneuploidy from 10 weeks of gestation onward, after being advised about the advantages and disadvantages of both screening tests. ${ }^{173}$

There are a number of ways to implement NIPT into a Down syndrome screening program. NIPT can for example be restricted to preselected high-risk women. Furthermore, its timing in pregnancy can differ. In Chapter 5 we describe a quantitative analysis of different NIPT implementation strategies in order to help health policy decision makers. Decision trees illustrate all plausible alternatives for pregnant women in five theoretical screening programs: classical screening by the FCT, pre-selection of high-risk women prior to NIPT by the FCT, NIPT as the first screening test at 10 weeks and at 13 weeks, and the simultaneous conductance of NIPT and the FCT.

\section{Expansion of disorders included in the NIPT panel}

The detection of other chromosome disorders requires only minor technical alterations to the original NIPT assays. Additionally, no biochemical prenatal screening tests have been available for pregnant women for other chromosome disorders than trisomies 13, 18 and 21. Therefore, broadening the scope of NIPT, by adding screening for other chromosome disorders to the assay, has been explored. 
Since 2013, some NIPT assays can detect submicroscopic chromosomal abnormalities. ${ }^{175-179}$ Clinically significant microdeletion and microduplication syndromes can now be detected by cfDNA whole genome analysis, for instance DiGeorge syndrome (22q11.2 deletion). In the Netherlands, the detection of microdeletions and duplications is possible using the NIPT assay from the TRIDENT study. ${ }^{179}$ However, false negative results, and a remarkable high number of false positive results have been reported. ${ }^{178,180}$ For this group of disorders, confirmation of a positive result by an invasive procedure and microarray analysis is recommended.

Since 2014, commercial laboratories have added detection of sex chromosome imbalances to their NIPT assay. ${ }^{181-184}$ Sometimes the ultrasound shows fetal anomalies that may point towards a sex chromosome imbalance, but more often the sex chromosome imbalances are prenatally diagnosed as an incidental finding of karyotyping aiming to rule out the autosomal chromosome disorders trisomies 13,18 and $21 .{ }^{185}$ These disorders include monosomy $X$ and sex chromosome trisomies (47,XXX; 47, XXY and 47,XYY). The sex chromosome trisomies Klinefelter syndrome $(47, X X Y)$ and Triple $X$ syndrome $(47, X X X)$ are the most common sex chromosome imbalances, occurring in approximately 1 in 600 male births, and in approximately 1 in 1000 female births, respectively. ${ }^{186,187}$ The interpretation of NIPT results and the counseling of pregnant couples can be challenging, because of the mild and variable phenotype, the low positive predictive value (around 50\%), and the possibility of maternal sex chromosome trisomy resulting in false positive results of the NIPT. ${ }^{188-190}$ Similar to the autosomal trisomies, a sex chromosome imbalance suspicion by NIPT should always be confirmed by an invasive procedure and a rapid aneuploidy detection technique or karyotyping. The generally mild phenotype may not justify an invasive procedure for some parents. Little is known about the couples' motives and considerations concerning screening for these conditions, as well as their wishes regarding information provision and support. In Chapter 6 we assess Dutch pregnant couples' opinions about NIPT for sex chromosome trisomy within the broader context of the expansion of disorders included in the NIPT panel. 


\subsection{Outline of the thesis}

The general aim of this thesis is to increase our knowledge about the use of cfDNAbased testing, from bench to clinic. This thesis can be subdivided into two themes:

\section{Part I: Design of noninvasive prenatal diagnostic tests}

In this part the use of cfDNA for prenatal genetic diagnostic testing is explored. The part comprises the design of in-house noninvasive diagnostic tests for fetal sex determination as well as single-gene mutation detection (Chapters 2 and 3 ).

Part II: Noninvasive prenatal screening for fetal chromosome disorders

This part investigates the responsible application of cfDNA-based tests in prenatal screening. It comprises the evaluation of the noninvasive prenatal screening for fetal trisomy 21 (Chapters 4 and 5), and an exploration of the opinion of pregnant women about the expansion of noninvasive prenatal screening to fetal sex trisomy (Chapter $6)$. 


\subsection{References}

1. Nussbaum RL, Mclnnes RR, Willard HF. Thompson and Thompson Genetics in Medicine. 6th rev. ed. Philadelphia: Saunders; 2004.

2. Heffner L. Advanced maternal age--how old is too old? N Engl J Med 2004;351:1927-1929

3. Benn P, Borrell A, Chiu R, Cuckle H, Dugoff L, Faas B, Gross S, Huang T, Johnson J, Maymon R, Norton M, Odibo A, Schielen P, Spencer K, Wright D, Yaron Y. Position Statement from the Chromosome Abnormality Screening Committee on Behalf of the Board of the International Society for Prenatal Diagnosis. Downloaded from http://www.ispdhome.org/, 26 April 2015.

4. http://www.rivm.nl

5. Kong A, Frigge ML, Masson G, Besenbacher S, Sulem P, Magnusson G, Gudjonsson SA, Sigurdsson A, Jonasdottir A, Jonasdottir A, Wong WS, Sigurdsson G, Walters GB, Steinberg S, Helgason H, Thorleifsson G, Gudbjartsson DF, Helgason A, Magnusson OT, Thorsteinsdottir U, Stefansson K. Rate of de novo mutations and the importance of father's age to disease risk. Nature 2012;488:471-475.

6. Veltman JA, Brunner HG. De novo mutations in human genetic disease. Nat Rev Genet 2012;13:565575.

7. Loane M, Morris JK, Addor MC, Arriola L, Budd J, Doray B, Garne E, Gatt M, Haeusler M, Khoshnood B, Klungsøyr Melve K, Latos-Bielenska A, McDonnell B, Mullaney C, O'Mahony M, Queisser-Wahrendorf A, Rankin J, Rissmann A, Rounding C, Salvador J, Tucker D, Wellesley D, Yevtushok L, Dolk H. Twentyyear trends in the prevalence of Down syndrome and other trisomies in Europe: impact of maternal age and prenatal screening. Eur J Hum Genet 2013;21:27-33.

8. Canick J. Prenatal screening for trisomy 21: recent advances and guidelines. Clin Chem Lab Med 2012;50:1003-1008.

9. van Rijn M, Christiaens GC, van der Schouw YT, Hagenaars AM, de Pater JM, Visser GH. Maternal serum screening for Down syndrome and neural tube defects. Ned Tijdschr Geneeskd 1998;142:409-415.

10. Wortelboer EJ, Koster MP, Stoutenbeek P, Loeber JG, Visser GH, Schielen PC. Fifteen years of triple tests in The Netherlands; the life cycle of a screening test. Prenat Diagn 2008;28:950-955.

11. Bakker M, Birnie E, Pajkrt E, Bilardo CM, Snijders RJ. Low uptake of the combined test in The Netherlands--which factors contribute? Prenat Diagn 2012;32:1305-1312.

12. Mujezinovic F, Alfirevic Z. Procedure-related complications of amniocentesis and chorionic villous sampling: a systematic review. Obstet Gynecol 2007;110:687-694.

13. Kozlowski $P$, Knippel A, Stressig R. Individual risk of fetal loss following routine second trimester amniocentesis: a controlled study of 20,460 cases. Ultraschall Med 2008;29:165-172.

14. Akolekar R, Beta J, Picciarelli G, Ogilvie C, D'Antonio F. Procedure-related risk of miscarriage following amniocentesis and chorionic villus sampling: a systematic review and meta-analysis. Ultrasound Obstet Gynecol 2015;45:16-26.

15. Van den Veyver IB, Patel A, Shaw CA, Pursley AN, Kang SH, Simovich MJ, Ward PA, Darilek S, Johnson A, Neill SE, Bi W, White LD, Eng CM, Lupski JR, Cheung SW, Beaudet AL. Clinical use of array comparative genomic hybridization (aCGH) for prenatal diagnosis in 300 cases. Prenat Diagn 2009;29:29-39.

16. Faas BH, Cirigliano V, Bui TH. Rapid methods for targeted prenatal diagnosis of common chromosome aneuploidies. Semin Fetal Neonatal Med 2011;16:81-87.

17. Lo YM, Corbetta N, Chamberlain PF, Rai V, Sargent IL, Redman CW, Wainscoat JS. Presence of fetal DNA in maternal plasma and serum. Lancet 1997;350:485-487.

18. Moore KL, Persaud TV. The developing human: clinically oriented embryology. 7th ed. Philadelphia: Saunders; 2003.

19. Tjoa ML, Cindrova-Davies T, Spasic-Boskovic O, Bianchi DW, Burton GJ. Trophoblastic oxidative stress and the release of cell-free feto-placental DNA. Am J Pathol 2006;169:400-404. 
20. Alberry M, Maddocks D, Jones M, Abdel Hadi M, Abdel-Fattah S, Avent N, Soothill PW. Free fetal DNA in maternal plasma in anembryonic pregnancies: confirmation that the origin is the trophoblast. Prenat Diagn 2007;27:415-418.

21. Lo YM, Tein MS, Lau TK, Haines CJ, Leung TN, Poon PM, Wainscoat JS, Johnson PJ, Chang AM, Hjelm NM. Quantitative analysis of fetal DNA in maternal plasma and serum: implications for noninvasive prenatal diagnosis. Am J Hum Genet 1998;62:768-775.

22. Lun FM, Chiu RW, Chan KC, Leung TY, Lau TK, Lo YM. Microfluidics digital PCR reveals a higher than expected fraction of fetal DNA in maternal plasma. Clin Chem 2008;54:1664-1672.

23. Lo YM, Chan KC, Sun H, Chen EZ, Jiang P, Lun FM, Zheng YW, Leung TY, Lau TK, Cantor CR, Chiu RW. Maternal plasma DNA sequencing reveals the genome-wide genetic and mutational profile of the fetus. Sci Transl Med 2010;2:61ra91.

24. Fan HC, Blumenfeld YJ, Chitkara U, Hudgins L, Quake SR. Analysis of the size distributions of fetal and maternal cell-free DNA by paired-end sequencing. Clin Chem 2010;56:1279-1286.

25. Lee TH, Montalvo L, Chrebtow V, Busch MP. Quantitation of genomic DNA in plasma and serum samples: higher concentrations of genomic DNA found in serum than in plasma. Transfusion 2001;41:276-282.

26. Shekhtman EM, Anne K, Melkonyan HS, Robbins DJ, Warsof SL, Umansky SR. Optimization of transrenal DNA analysis: detection of fetal DNA in maternal urine. Clin Chem 2009;55:723-729.

27. Tsui NB, Jiang P, Chow KC, Su X, Leung TY, Sun H, Chan KC, Chiu RW, Lo YM. High resolution size analysis of fetal DNA in the urine of pregnant women by paired-end massively parallel sequencing. PLoS One 2012;7:e48319.

28. Poon LL, Leung TN, Lau TK, Lo YM. Presence of fetal RNA in maternal plasma. Clin Chem 2000;46:18321834.

29. Ng EK, Tsui NB, Lau TK, Leung TN, Chiu RW, Panesar NS, Lit LC, Chan KW, Lo YM. mRNA of placental origin is readily detectable in maternal plasma. Proc Natl Acad Sci U S A 2003;100:4748-4753.

30. Tsochandaridis M, Nasca L, Toga C, Levy-Mozziconacci A. Circulating microRNAs as clinical biomarkers in the predictions of pregnancy complications. Biomed Res Int 2015;2015:294954.

31. Karakas B, Qubbaj W, Al-Hassan S, Coskun S. Noninvasive Digital Detection of Fetal DNA in Plasma of 4-Week-Pregnant Women following In Vitro Fertilization and Embryo Transfer. PLoS One 2015;10:e0126501.

32. Devonshire AS, Whale AS, Gutteridge A, Jones G, Cowen S, Foy CA, Huggett JF. Towards standardisation of cell-free DNA measurement in plasma: controls for extraction efficiency, fragment size bias and quantification. Anal Bioanal Chem 2014;406:6499-6512.

33. Chiu RW, Poon LL, Lau TK, Leung TN, Wong EM, Lo YM. Effects of blood-processing protocols on fetal and total DNA quantification in maternal plasma. Clin Chem 2001;47:1607-1613.

34. Manokhina I, Singh TK, Peñaherrera MS, Robinson WP. Quantification of cell-free DNA in normal and complicated pregnancies: overcoming biological and technical issues. PLoS One 2014;9:e101500.

35. Ashoor G, Poon L, Syngelaki A, Mosimann B, Nicolaides KH. Fetal fraction in maternal plasma cell-free DNA at 11-13 weeks' gestation: effect of maternal and fetal factors. Fetal Diagn Ther 2012;31:237-243.

36. Ashoor G, Syngelaki A, Poon LC, Rezende JC, Nicolaides KH. Fetal fraction in maternal plasma cell-free DNA at 11-13 weeks' gestation: relation to maternal and fetal characteristics. Ultrasound Obstet Gynecol 2013;41:26-32.

37. Lo YM, Zhang J, Leung TN, Lau TK, Chang AM, Hjelm NM. Rapid clearance of fetal DNA from maternal plasma. Am J Hum Genet 1999;64:218-224.

38. Wright CF, Wei Y, Higgins JP, Sagoo GS. Non-invasive prenatal diagnostic test accuracy for fetal sex using cell-free DNA a review and meta-analysis. BMC Res Notes 2012;5:476.

39. Scheffer PG, van der Schoot CE, Page-Christiaens GC, Bossers B, van Erp F, de Haas M. Reliability of fetal sex determination using maternal plasma. Obstet Gynecol 2010;115:117-126. 
40. Germain DP. General aspects of X-linked diseases. In: Mehta A, Beck M, Sunder-Plassmann G, editors. Fabry Disease: Perspectives from 5 Years of FOS. Oxford: PharmaGenesis; 2006.

41. Rijnders RJ, van der Schoot CE, Bossers B, de Vroede MA, Christiaens GC. Fetal sex determination from maternal plasma in pregnancies at risk for congenital adrenal hyperplasia. Obstet Gynecol 2001;98:374e8.

42. Chitty LS, Chatelain P, Wolffenbuttel KP, Aigrain Y. Prenatal management of disorders of sex development. J Pediatr Urol 2012;8:576-584.

43. Lekarev O, New MI. Adrenal disease in pregnancy. Best Pract Res Clin Endocrinol Metab 2011;25:959973.

44. Iruretagoyena JI, Grady M, Shah D. Discrepancy in fetal sex assignment between cell free fetal DNA and ultrasound. J Perinatol 2015;35:229-230.

45. White HE, Dent CL, Hall VJ, Crolla JA, Chitty LS. Evaluation of a novel assay for detection of the fetal marker RASSF1A: facilitating improved diagnostic reliability of noninvasive prenatal diagnosis. PLoS One 2012;7:e45073.

46. Lo YM, Hjelm NM, Fidler C, Sargent IL, Murphy MF, Chamberlain PF, Poon PM, Redman CW, Wainscoat JS. Prenatal diagnosis of fetal RhD status by molecular analysis of maternal plasma. N Engl J Med 1998;339:1734-1738.

47. Faas BH, Beuling EA, Christiaens GC, von dem Borne AE, van der Schoot CE. Detection of fetal RHDspecific sequences in maternal plasma. Lancet 1998;352:1196.

48. Koelewijn JM, Vrijkotte TG, van der Schoot CE, Bonsel GJ, de Haas M. Effect of screening for red cell antibodies, other than anti-D, to detect hemolytic disease of the fetus and newborn: a population study in the Netherlands. Transfusion 2008;48:941-952.

49. Scheffer PG, van der Schoot CE, Page-Christiaens GC, de Haas M. Noninvasive fetal blood group genotyping of rhesus $D, C, E$ and of $K$ in alloimmunised pregnant women: evaluation of a 7-year clinical experience. BJOG 2011;118:1340-1348.

50. Shendure J, Ji H. Next-generation DNA sequencing. Nat Biotechnol 2008;26:1135-1145.

51. Raymond FL, Whittaker J, Jenkins L, Lench N, Chitty LS. Molecular prenatal diagnosis: the impact of modern technologies. Prenat Diagn 2010;30:674-681.

52. Meaney C, Norbury G. Noninvasive prenatal diagnosis of early onset primary dystonia I in maternal plasma. Prenat Diagn 2009;29:1218-1221.

53. Saito H, Sekizawa A, Morimoto T, Suzuki M, Yanaihara T. Prenatal DNA diagnosis of a single-gene disorder from maternal plasma. Lancet 2000;356:1170.

54. Li Y, Holzgreve W, Page-Christiaens GC, Gille JJ, Hahn S. Improved prenatal detection of a fetal point mutation for achondroplasia by the use of size-fractionated circulatory DNA in maternal plasma-case report. Prenat Diagn 2004;24:896-898.

55. Li Y, Page-Christiaens GC, Gille JJ, Holzgreve W, Hahn S. Non-invasive prenatal detection of achondroplasia in size-fractionated cell-free DNA by MALDI-TOF MS assay. Prenat Diagn 2007;27:1117.

56. Chitty LS, Griffin DR, Meaney C, Barrett A, Khalil A, Pajkrt E, Cole TJ. New aids for the non-invasive prenatal diagnosis of achondroplasia: dysmorphic features, charts of fetal size and molecular confirmation using cell-free fetal DNA in maternal plasma. Ultrasound Obstet Gynecol 2011;37:283289.

57. Lim JH, Kim MJ, Kim SY, Kim HO, Song MJ, Kim MH, Park SY, Yang JH, Ryu HM. Non-invasive prenatal detection of achondroplasia using circulating fetal DNA in maternal plasma. J Assist Reprod Genet 2011;28:167-172.

58. Chitty LS, Khalil A, Barrett AN, Pajkrt E, Griffin DR, Cole TJ. Safe, accurate, prenatal diagnosis of thanatophoric dysplasia using ultrasound and free fetal DNA. Prenat Diagn 2013;33:416-423.

59. González-González MC, Trujillo MJ, Rodríguez de Alba M, García-Hoyos M, Lorda-Sánchez I, DíazRecasens J, Ayuso C, Ramos C. Huntington disease-unaffected fetus diagnosed from maternal plasma using QF-PCR. Prenat Diagn 2003;23:232-234. 
60. Bustamante-Aragones A, Trujillo-Tiebas MJ, Gallego-Merlo J, Rodriguez de Alba M, Gonzalez-Gonzalez C, Cantalapiedra D, Ayuso C, Ramos C. Prenatal diagnosis of Huntington disease in maternal plasma: direct and indirect study. Eur J Neurol 2008;15:1338-1344.

61. van den Oever JM, Bijlsma EK, Feenstra I, Muntjewerff N, Mathijssen IB, Bakker E, van Belzen MJ, Boon EM. Noninvasive prenatal diagnosis of Huntington disease: detection of the paternally inherited expanded CAG repeat in maternal plasma. Prenat Diagn 2015;35:945-949.

62. Amicucci P, Gennarelli M, Novelli G, Dallapiccola B. Prenatal diagnosis of myotonic dystrophy using fetal DNA obtained from maternal plasma. Clin Chem 2000;46:301-302.

63. González-González MC, García-Hoyos M, Trujillo MJ, Rodríguez de Alba M, Lorda-Sánchez I, DíazRecasens J, Gallardo E, Ayuso C, Ramos C. Prenatal detection of a cystic fibrosis mutation in fetal DNA from maternal plasma. Prenat Diagn 2002;22:946-948.

64. Bustamante-Aragones A, Gallego-Merlo J, Trujillo-Tiebas MJ, de Alba MR, Gonzalez-Gonzalez C, Glover G, Diego-Alvarez D, Ayuso C, Ramos C. New strategy for the prenatal detection/exclusion of paternal cystic fibrosis mutations in maternal plasma. J Cyst Fibros 2008;7:505-510.

65. Bustamante-Aragones A, Vallespin E, Rodriguez de Alba M, Trujillo-Tiebas MJ, Gonzalez-Gonzalez C, Diego-Alvarez D, Riveiro-Alvarez R, Lorda-Sanchez I, Ayuso C, Ramos C. Early noninvasive prenatal detection of a fetal CRB1 mutation causing Leber congenital amaurosis. Mol Vis 2008;14:1388-1394.

66. Chiu RW, Lau TK, Cheung PT, Gong ZQ, Leung TN, Lo YM. Noninvasive prenatal exclusion of congenital adrenal hyperplasia by maternal plasma analysis: a feasibility study. Clin Chem 2002;48:778-780.

67. Tungwiwat W, Fucharoen S, Fucharoen G, Ratanasiri T, Sanchaisuriya K. Development and application of a real-time quantitative PCR for prenatal detection of fetal alpha(0)-thalassemia from maternal plasma. Ann N Y Acad Sci 2006;1075:103-107.

68. Ho SS, Chong SS, Koay ES, Ponnusamy S, Chiu L, Chan YH, Rauff M, Baig S, Chan J, Su LL, Biswas A, Hahn $\mathrm{S}$, Choolani M. Noninvasive prenatal exclusion of haemoglobin Bart's using foetal DNA from maternal plasma. Prenat Diagn 2010;30:65-73.

69. Yan TZ, Mo QH, Cai R, Chen X, Zhang CM, Liu YH, Chen YJ, Zhou WJ, Xiong F, Xu XM. Reliable detection of paternal SNPs within deletion breakpoints for non-invasive prenatal exclusion of homozygous $\alpha$ thalassemia in maternal plasma. PLoS One 2011;6:e24779.

70. Sirichotiyakul S, Charoenkwan P, Sanguansermsri T. Prenatal diagnosis of homozygous alphathalassemia-1 by cell-free fetal DNA in maternal plasma. Prenat Diagn 2012;32:45-49.

71. Chiu RW, Lau TK, Leung TN, Chow KC, Chui DH, Lo YM. Prenatal exclusion of beta thalassaemia major by examination of maternal plasma. Lancet 2002;360:998-1000.

72. Papasavva T, Kalakoutis G, Kalikas I, Neokli E, Papacharalambous S, Kyrri A, Kleanthous M. Noninvasive prenatal diagnostic assay for the detection of beta-thalassemia. Ann N Y Acad Sci 2006;1075:148-153.

73. Tungwiwat W, Fucharoen G, Fucharoen S, Ratanasiri T, Sanchaisuriya K, Sae-Ung N. Application of maternal plasma DNA analysis for noninvasive prenatal diagnosis of $\mathrm{Hb}$ E-beta-thalassemia. Transl Res 2007;150:319-325.

74. Papasavva T, Kalikas I, Kyrri A, Kleanthous M. Arrayed primer extension for the noninvasive prenatal diagnosis of beta-thalassemia based on detection of single nucleotide polymorphisms. Ann N Y Acad Sci 2008;1137:302-308.

75. Li Y, Di Naro E, Vitucci A, Grill S, Zhong XY, Holzgreve W, Hahn S. Size fractionation of cell-free DNA in maternal plasma improves the detection of a paternally inherited beta-thalassemia point mutation by MALDI-TOF mass spectrometry. Fetal Diagn Ther 2009;25:246-249.

76. Chan K, Yam I, Leung KY, Tang M, Chan TK, Chan V. Detection of paternal alleles in maternal plasma for non-invasive prenatal diagnosis of beta-thalassemia: a feasibility study in southern Chinese. Eur J Obstet Gynecol Reprod Biol 2010;150:28-33.

77. Yi P, Chen Z, Yu L, Zheng Y, Xie H, Zheng X, Liu Q, Han J, Li L. Prenatal detection of beta-thalassemia CD17 (A->T) mutation by polymerase chain reaction/ligase detection reaction/capillary electrophoresis for fetal DNA in maternal plasma-a case report. Fetal Diagn Ther 2010;27:25-31. 
78. Phylipsen M, Yamsri S, Treffers EE, Jansen DT, Kanhai WA, Boon EM, Giordano PC, Fucharoen S, Bakker E, Harteveld CL. Non-invasive prenatal diagnosis of beta-thalassemia and sickle-cell disease using pyrophosphorolysis-activated polymerization and melting curve analysis. Prenat Diagn 2012;32:578587.

79. Tsui NB, Kadir RA, Chan KC, Chi C, Mellars G, Tuddenham EG, Leung TY, Lau TK, Chiu RW, Lo YM. Noninvasive prenatal diagnosis of hemophilia by microfluidics digital PCR analysis of maternal plasma DNA. Blood 2011;117:3684-3691.

80. Barrett AN, McDonnell TC, Chan KC, Chitty LS. Digital PCR analysis of maternal plasma for noninvasive detection of sickle cell anemia. Clin Chem 2012;58:1026-1032.

81. Gu W, Koh W, Blumenfeld YJ, El-Sayed YY, Hudgins L, Hintz SR, Quake SR. Noninvasive prenatal diagnosis in a fetus at risk for methylmalonic acidemia. Genet Med 2014;16:564-567.

82. Kitzman JO, Snyder MW, Ventura M, Lewis AP, Qiu R, Simmons LE, Gammill HS, Rubens CE, Santillan DA, Murray JC, Tabor HK, Bamshad MJ, Eichler EE, Shendure J.Noninvasive whole-genome sequencing of a human fetus. Sci Transl Med 2012;4:137ra76.

83. Lam KW, Jiang P, Liao GJ, Chan KC, Leung TY, Chiu RW, Lo YM. Noninvasive prenatal diagnosis of monogenic diseases by targeted massively parallel sequencing of maternal plasma: application to $\beta$ thalassemia. Clin Chem 2012;58:1467-1475.

84. New MI, Tong YK, Yuen T, Jiang P, Pina C, Chan KC, Khattab A, Liao GJ, Yau M, Kim SM, Chiu RW, Sun L, Zaidi M, Lo YM. Noninvasive prenatal diagnosis of congenital adrenal hyperplasia using cell-free fetal DNA in maternal plasma. J Clin Endocrinol Metab 2014;99:e1022-1030.

85. Ma D, Ge H, Li X, Jiang T, Chen F, Zhang Y, Hu P, Chen S, Zhang J, Ji X, Xu X, Jiang H, Chen M, Wang W, $\mathrm{Xu}$ Z. Haplotype-based approach for noninvasive prenatal diagnosis of congenital adrenal hyperplasia by maternal plasma DNA sequencing. Gene 2014;544:252-258.

86. Lv W, Wei X, Guo R, Liu Q, Zheng Y, Chang J, Bai T, Li H, Zhang J, Song Z, Cram DS, Liang D, Wu L. Noninvasive prenatal testing for Wilson disease by use of circulating single-molecule amplification and resequencing technology (cSMART). Clin Chem 2015;61:172-181.

87. Yoo SK, Lim BC, Byeun J, Hwang H, Kim KJ, Hwang YS, Lee J, Park JS, Lee YS, Namkung J, Park J, Lee S, Shin JY, Seo JS, Kim JI, Chae JH. Noninvasive prenatal diagnosis of duchenne muscular dystrophy: comprehensive genetic diagnosis in carrier, proband, and fetus. Clin Chem 2015;61:829-837.

88. Xu Y, Li X, Ge HJ, Xiao B, Zhang YY, Ying XM, Pan XY, Wang L, Xie WW, Ni L, Chen SP, Jiang WT, Liu P, Ye H, Cao Y, Zhang JM, Liu Y, Yang ZJ, Chen YW, Chen F,Jiang H, Ji X. Haplotype-based approach for noninvasive prenatal tests of Duchenne muscular dystrophy using cell-free fetal DNA in maternal plasma. Genet Med 2015;17:889-896.

89. Meng M, Li X, Ge H, Chen F, Han M, Zhang Y, Kang D, Xie W, Gao Z, Pan X, Dai P, Chi F, Chen S, Liu P, Zhang C, Cao J, Jiang H, Xu X, Wang W, Duan T. Noninvasive prenatal testing for autosomal recessive conditions by maternal plasma sequencing in a case of congenital deafness. Genet Med 2014;16:972976.

90. Chitty LS, Mason S, Barrett AN, McKay F, Lench N, Daley R, Jenkins LA. Non-invasive prenatal diagnosis of achondroplasia and thanatophoric dysplasia: next-generation sequencing allows for a safer, more accurate, and comprehensive approach. Prenat Diagn 2015;35:656-662.

91. Xiong L, Barrett AN, Hua R, Tan TZ, Ho SSY, Chan JKY, Zhong M, Choolani M. Non-invasive prenatal testing for $\beta$-thalassaemia using cell-free DNA and next generation sequencing. Prenat Diagn 2015;35:258-265.

92. Hill M, Twiss $P$, Verhoef TI, Drury S, McKay F, Mason S, Jenkins L, Morris S, Chitty LS. Non-invasive prenatal diagnosis for cystic fibrosis: detection of paternal mutations, exploration of patient preferences and cost analysis. Prenat Diagn 2015;35:950-958.

93. van den Oever JM, Bijlsma EK, Feenstra I, Muntjewerff N, Mathijssen IB, Bakker E, van Belzen MJ, Boon EM. Noninvasive prenatal diagnosis of Huntington disease: detection of the paternally inherited expanded CAG repeat in maternal plasma. Prenat Diagn 2015;35:945-949. 
94. Parks M, Court S, Cleary S, Clokie S, Hewitt J, Williams D, Cole T, MacDonald F, Griffiths M, Allen S. Noninvasive prenatal diagnosis of Duchenne and Becker muscular dystrophies by relative haplotype dosage. Prenat Diagn 2016;36:312-320.

95. Hiatt JB, Pritchard CC, Salipante SJ, O'Roak BJ, Shendure J. Single molecule molecular inversion probes for targeted, high-accuracy detection of low-frequency variation. Genome Res 2013;23:843-854.

96. Ho G, Cardamone M, Farrar M. Congenital and childhood myotonic dystrophy: Current aspects of disease and future directions. World J Clin Pediatr 2015;4:66-80.

97. Udd B, Krahe R. The myotonic dystrophies: molecular, clinical, and therapeutic challenges. Lancet Neurol 2012;11:891.

98. Brook JD, McCurrach ME, Harley HG, Buckler AJ, Church D, Aburatani H, Hunter K, Stanton VP, Thirion JP, Hudson T, et al. Molecular basis of myotonic dystrophy: expansion of a trinucleotide (CTG) repeat at the 3 ' end of a transcript encoding a protein kinase family member. Cell 1992;69:385.

99. Mahadevan M, Tsilfidis C, Sabourin L, Shutler G, Amemiya C, Jansen G, Neville C, Narang M, Barceló J, O'Hoy K, et al. Myotonic dystrophy mutation: an unstable CTG repeat in the 3' untranslated region of the gene. Science 1992;255:1253-1255.

100. Lench N, Barrett A, Fielding S, McKay F, Hill M, Jenkins L, White H, Chitty LS. The clinical implementation of non-invasive prenatal diagnosis for single-gene disorders: challenges and progress made. Prenat Diagn 2013;33:555-562.

101. http://www.rapid.nhs.uk/guides-to-nipd-nipt/nipd-for-single-gene-disorders/

102. Bianchi DW, Maron JL, Johnson KL. Insights into fetal and neonatal development through analysis of cell-free RNA in body fluids. Early Hum Dev 2010;86:747-752.

103. Lo YM, Lau TK, Zhang J, Leung TN, Chang AM, Hjelm NM, Elmes RS, Bianchi DW. Increased fetal DNA concentrations in the plasma of pregnant women carrying fetuses with trisomy 21 . Clin Chem 1999;45:1747-1751.

104. Zhong XY, Burk MR, Troeger C, Jackson LR, Holzgreve W, Hahn S. Fetal DNA in maternal plasma is elevated in pregnancies with aneuploid fetuses. Prenat Diagn 2000;20:795-798.

105. Lee T, LeShane ES, Messerlian GM, Canick JA, Farina A, Heber WW, Bianchi DW. Down syndrome and cell-free fetal DNA in archived maternal serum. Am J Obstet Gynecol 2002;187:1217-1221.

106. Ohashi Y, Miharu N, Honda H, Samura O, Ohama K. Quantitation of fetal DNA in maternal serum in normal and aneuploid prenancies. Hum Genet 2001;108:123-127.

107. Spencer K, de Kok JB, Swinkels DW. Increased total cell-free DNA in the serum of pregnant women carrying a fetus affected by trisomy 21. Prenat Diagn 2003;23:580-583.

108. Hromadnikova I, Houbova B, Hridelova D, Voslarova S, Calda P, Nekolarova K, Kofer J, Stejskal D, Doucha J, Cinek O, Vavrirec J. Quantitative analysis of DNA levels in maternal plasma in normal and Down syndrome pregnancies. BMC Pregnancy Childbirth 2002;2:4.

109. Gerovassili A, Garner C, Nicolaides KH, Thein SL, Rees DC. Free fetal DNA in maternal circulation: a potential prognostic marker for chromosomal abnormalities? Prenat Diagn 2007;27:104-110.

110. Wataganara T, LeShane ES, Farina A, Messerlian GM, Lee T, Canick JA, Bianchi DW. Maternal serum cell-free fetal DNA levels are increased in cases of trisomy 13 but not trisomy 18 . Hum Genet 2003;112:204-208.

111. Jorgez CJ, Dang DD, Wapner R, Farina A, Simpson JL, Bischoff FZ. Elevated levels of total (maternal and fetal) beta-globin DNA in maternal blood from first trimester pregnancies with trisomy 21. Hum Reprod 2007;22:2267-2272.

112. Bischoff FZ, Dang DX, Marquez-Do D, Martinez D, Horne C, Lewis DE, Simpson JL. Detecting fetal DNA from dried maternal blood spots: another step towards broad scale non-invasive prenatal genetic screening and feasible testing. Reprod Biomed Online 2003;6:349-351.

113. Jorgez CJ, Simpson JL, Bischoff FZ. Recovery and amplification of placental RNA from dried maternal blood spots: utility for non-invasive prenatal diagnosis. Reprod Biomed Online 2006;13:558-561. 
114. Go AT, Visser A, Mulders MA, Twisk JW, Blankenstein MA, van Vugt JM, Oudejans CB. C210RF105, A chromosome 21-encoded $m R N A$, is not a discriminative marker gene for prediction of Down syndrome in maternal plasma. Prenat Diagn 2007;27:146-149.

115. Ng EK, El-Sheikhah A, Chiu RW, Chan KC, Hogg M, Bindra R, Leung TN, Lau TK, Nicolaides KH, Lo YM. Evaluation of human chorionic gonadotropin beta-subunit mRNA concentrations in maternal serum in aneuploid pregnancies: a feasibility study. Clin Chem 2004;50:1055-1057.

116. Lo YM, Tsui NB, Chiu RW, Lau TK, Leung TN, Heung MM, Gerovassili A, Jin Y, Nicolaides KH, Cantor CR, Ding C. Plasma placental RNA allelic ratio permits noninvasive prenatal chromosomal aneuploidy detection. Nat Med 2007;13:218-223.

117. Tsui NB, Wong BC, Leung TY, Lau TK, Chiu RW, Lo YM. Non-invasive prenatal detection of fetal trisomy 18 by RNA-SNP allelic ratio analysis using maternal plasma SERPINB2 mRNA: a feasibility study. Prenat Diagn 2009;29:1031-1037.

118. Tsui NB, Akolekar R, Chiu RW, Chow KC, Leung TY, Lau TK, Nicolaides KH, Lo YM. Synergy of total PLAC4 RNA concentration and measurement of the RNA single-nucleotide polymorphism allelic ratio for the noninvasive prenatal detection of trisomy 21. Clin Chem 2010;56:73-81.

119. Deng YH, Yin AH, He Q, Chen JC, He YS, Wang HQ, Li M, Chen HY. Non-invasive prenatal diagnosis of trisomy 21 by reverse transcriptase multiplex ligation-dependent probe amplification. Clin Chem Lab Med 2011;49:641-646.

120. Dhallan R, Guo X, Emche S, Damewood M, Bayliss P, Cronin M, Barry J, Betz J, Franz K, Gold K, Vallecillo $B$, Varney J. A non-invasive test for prenatal diagnosis based on fetal DNA present in maternal blood: a preliminary study. Lancet 2007;369:474-481.

121. Ghanta S, Mitchell ME, Ames M, Hidestrand M, Simpson P, Goetsch M, Thilly WG, Struble CA, TomitaMitchell A. Non-invasive prenatal detection of trisomy 21 using tandem single nucleotide polymorphisms. PLoS One 2010;5:e13184

122. Chim SS, Tong YK, Chiu RW, Lau TK, Leung TN, Chan LY, Oudejans CB, Ding C, Lo YM. Detection of the placental epigenetic signature of the maspin gene in maternal plasma. Proc Natl Acad Sci USA 2005;102:14753-14758.

123. Tong YK, Lo YM. Diagnostic developments involving cell-free (circulating) nucleic acids. Clin Chim Acta 2006;363:187-196.

124. Papageorgiou EA, Fiegler H, Rakyan V, Beck S, Hulten M, Lamnissou K, Carter NP, Patsalis PC. Sites of differential DNA methylation between placenta and peripheral blood: molecular markers for noninvasive prenatal diagnosis of aneuploidies. Am J Pathol 2009;174:1609-1618.

125. Tong YK, Jin S, Chiu RW, Ding C, Chan KC, Leung TY, Yu L, Lau TK, Lo YM. Noninvasive prenatal detection of trisomy 21 by an epigenetic-genetic chromosome-dosage approach. Clin Chem 2010;56:90-98.

126. Tong YK, Chiu RW, Akolekar R, Leung TY, Lau TK, Nicolaides KH, Lo YM. Epigenetic-genetic chromosome dosage approach for fetal trisomy 21 detection using an autosomal genetic reference marker. PLoS One 2010;5:e15244.

127. Papageorgiou EA, Karagrigoriou A, Tsaliki E, Velissariou V, Carter NP, Patsalis PC. Fetal-specific DNA methylation ratio permits noninvasive prenatal diagnosis of trisomy 21. Nat Med 2011;17:510-513.

128. Lim JH, Kim SY, Park SY, Lee SY, Kim MJ, Han YJ, Lee SW, Chung JH, Kim MY, Yang JH, Ryu HM. Noninvasive epigenetic detection of fetal trisomy 21 in first trimester maternal plasma. PLoS One 2011;6:e27709.

129. Zhang M, Li T, Chen J, Li L, Zhou C, Wang Y, Liu W, Zhang Y. Non-invasive prenatal diagnosis of trisomy 21 by dosage ratio of fetal chromosome-specific epigenetic markers in maternal plasma. J Huazhong Univ Sci Technolog Med Sci 2011;31:687-692.

130. Tsaliki E, Papageorgiou EA, Spyrou C, Koumbaris G, Kypri E, Kyriakou S, Sotiriou C, Touvana E, Keravnou A, Karagrigoriou A, Lamnissou K, Velissariou V, Patsalis PC. MeDIP real-time qPCR of maternal peripheral blood reliably identifies trisomy 21. Prenat Diagn 2012;32:996-1001.

131. Fan HC, Blumenfeld YJ, Chitkara U, Hudgins L, Quake SR. Noninvasive diagnosis of fetal aneuploidy by shotgun sequencing DNA from maternal blood. Proc Natl Acad Sci U S A 2008;105:16266-16271. 
132. Chiu RW, Sun H, Akolekar R, Clouser C, Lee C, McKernan K, Zhou D, Nicolaides KH, Lo YM. Maternal plasma DNA analysis with massively parallel sequencing by ligation for noninvasive prenatal diagnosis of trisomy 21. Clin Chem 2010;56:459-463.

133. Sparks AB, Struble CA, Wang ET, Song K, Oliphant A. Noninvasive prenatal detection and selective analysis of cell-free DNA obtained from maternal blood: evaluation for trisomy 21 and trisomy 18. Am J Obstet Gynecol 2012;206:319.e1-9.

134. Chen EZ, Chiu RW, Sun H, Akolekar R, Chan KC, Leung TY, Jiang P, Zheng YW, Lun FM, Chan LY, Jin Y, Go AT, Lau ET, To WW, Leung WC, Tang RY, Au-Yeung SK, Lam H, Kung YY, Zhang X, van Vugt JM, Minekawa R, Tang MH, Wang J, Oudejans CB, Lau TK, Nicolaides KH, Lo YM. Noninvasive prenatal diagnosis of fetal trisomy 18 and trisomy 13 by maternal plasma DNA sequencing. PLoS One 2011;6:e21791.

135. Chiu RW, Akolekar R, Zheng YW, Leung TY, Sun H, Chan KC, Lun FM, Go AT, Lau ET, To WW, Leung WC, Tang RY, Au-Yeung SK, Lam H, Kung YY, Zhang X, van Vugt JM, Minekawa R, Tang MH, Wang J, Oudejans CB, Lau TK, Nicolaides KH, Lo YM. Non-invasive prenatal assessment of trisomy 21 by multiplexed maternal plasma DNA sequencing: large scale validity study. BMJ 2011;342:c7401.

136. Ehrich M, Deciu C, Zwiefelhofer T, Tynan JA, Cagasan L, Tim R, Lu V, McCullough R, McCarthy E, Nygren AO, Dean J, Tang L, Hutchison D, Lu T, Wang H, Angkachatchai V, Oeth P, Cantor CR, Bombard A, van den Boom D. Noninvasive detection of fetal trisomy 21 by sequencing of DNA in maternal blood: a study in a clinical setting. Am J Obstet Gynecol 2011;204:205e1-11.

137. Palomaki GE, Kloza EM, Lambert-Messerlian GM, Haddow JE, Neveux LM, Ehrich M, van den Boom D, Bombard AT, Deciu C, Grody WW, Nelson SF, Canick JA. DNA sequencing of maternal plasma to detect Down syndrome: An international clinical validation study. Genet Med 2011;13:913-920.

138. Sehnert AJ, Rhees B, Comstock D, de Feo E, Heilek G, Burke J, Rava RP. Optimal detection of fetal chromosomal abnormalities by massively parallel DNA sequencing of cell-free fetal DNA from maternal blood. Clin Chem 2011;57:1042-1049.

139. Bianchi DW, Platt LD, Goldberg JD, Abuhamad AZ, Sehnert AJ, Rava RP. Genome-wide fetal aneuploidy detection by maternal plasma DNA sequencing. Obstet Gynecol 2012;119:890-901.

140. Ashoor G, Syngelaki A, Wagner M, Birdir C, Nicolaides KH. Chromosome-selective sequencing of maternal plasma cell-free DNA for first-trimester detection of trisomy 21 and trisomy 18. Am J Obstet Gynecol 2012;206:322.e1-5.

141. Jiang F, Ren J, Chen F, Zhou Y, Xie J, Dan S, Su Y, Xie J, Yin B, Su W, Zhang H, Wang W, Chai X, Lin L, Guo H, Li Q, Li P, Yuan Y, Pan X, Li Y, Liu L, Chen H, Xuan Z, Chen S, Zhang C, Zhang H, Tian Z, Zhang Z, Jiang H, Zhao L, Zheng W, Li S, Li Y, Wang J, Wang J, Zhang X. Noninvasive Fetal Trisomy (NIFTY) test: an advanced noninvasive prenatal diagnosis methodology for fetal autosomal and sex chromosomal aneuploidies. BMC Med Genomics 2012;5:57.

142. Lau TK, Chen F, Pan X, Pooh RK, Jiang F, Li Y, Jiang H, Li X, Chen S, Zhang X. Noninvasive prenatal diagnosis of common fetal chromosomal aneuploidies by maternal plasma DNA sequencing. J Matern Fetal Neonatal Med 2012;25:1370-1374.

143. Norton ME, Brar H, Weiss J, Karimi A, Laurent LC, Caughey AB, Rodriguez MH, Williams J 3rd, Mitchell ME, Adair CD, Lee H, Jacobsson B, Tomlinson MW, Oepkes D, Hollemon D, Sparks AB, Oliphant A, Song K. Non-invasive chromosomal evaluation (NICE) study: results of a multicenter prospective cohort study for detection of fetal trisomy 21 and trisomy 18. Am J Obstet Gynecol 2012;207:137.e1-8.

144. Dan S, Wang W, Ren J, Li Y, Hu H, Xu Z, Lau TK, Xie J, Zhao W, Huang H, Xie J, Sun L, Zhang X, Wang W, Liao S, Qiang R, Cao J, Zhang Q, Zhou Y, Zhu H, Zhong M, Guo Y, Lin L, Gao Z, Yao H, Zhang H, Zhao L, Jiang F, Chen F, Jiang H, Li S, Li Y, Wang J, Wang J, Duan T, Su Y, Zhang X. Clinical application of massively parallel sequencing-based prenatal noninvasive fetal trisomy test for trisomies 21 and 18 in 11,105 pregnancies with mixed risk factors. Prenat Diagn 2012;32:1225-1232.

145. Nicolaides KH, Syngelaki A, Ashoor G, Birdir C, Touzet G. Noninvasive prenatal testing for fetal trisomies in a routinely screened first-trimester population. Am J Obstet Gynecol 2012;207:374.e1-6. 
146. Palomaki GE, Deciu C, Kloza EM, Lambert-Messerlian GM, Haddow JE,Neveux LM, Ehrich M, van den Boom D, Bombard AT, Grody WW, Nelson SF, Canick JA. DNA sequencing of maternal plasma reliably identifies trisomy 18 and trisomy 13 as well as Down syndrome: an international collaborative study. Genet Med 2012;14:296-305.

147. Ashoor G, Syngelaki A, Wang E, Struble C, Oliphant A, Song K, Nicolaides KH. Trisomy 13 detection in the first trimester of pregnancy using a chromosome-selective cell-free DNA analysis. Ultrasound Obstet Gynecol 2013; 41:21-25.

148. Guex N, Iseli C, Syngelaki A, Pescia G, Nicolaides KH, Xenarios I, Conrad B. A robust second-generation genome-wide test for fetal aneuploidy based on shotgun sequencing cell-free DNA in maternal blood. Prenat Diagn 2013;33:707-710.

149. Liang D, Lv W, Wang H, Xu L, Liu J, Li H, Hu L, Peng Y, Wu L. Non-invasive prenatal testing of fetal whole chromosome aneuploidy by massively parallel sequencing. Prenat Diagn 2013;33:409-415.

150. Song Y, Liu C, Qi H, Zhang Y, Bian X, Liu J. Noninvasive prenatal testing of fetal aneuploidies by massively parallel sequencing in a prospective Chinese population. Prenat Diagn 2013;33:700-706.

151. Verweij EJ, Jacobsson B, van Scheltema PA, de Boer MA, Hoffer MJ, Hollemon D, Westgren M, Song K, Oepkes D. European Non-Invasive Trisomy Evaluation (EU-NITE) study: a multicenter prospective cohort study for non-invasive fetal trisomy 21 testing. Prenat Diagn 2013;22:1-6.

152. Bianchi DW, Parker RL, Wentworth J, Madankumar R, Saffer C, Das AF, Craig JA, Chudova DI, Devers PL, Jones KW, Oliver K, Rava RP, Sehnert AJ; CARE Study Group. DNA sequencing versus standard prenatal aneuploidy screening. N Engl J Med 2014;370:799-808.

153. Pergament $E$, Cuckle $H$, Zimmermann B, Banjevic M, Sigurjonsson S, Ryan A, Hall MP, Dodd M, Lacroute P, Stosic M, Chopra N, Hunkapiller N, Prosen DE, McAdoo S, Demko Z, Siddiqui A, Hill M, RabinowitzM. Single-nucleotide polymorphism-based noninvasive prenatal screening in a high-risk and low-risk cohort. Obstet Gynecol 2014;124:210-218.

154. Porreco RP, Garite TJ, Maurel K, Marusiak B; Obstetrix Collaborative Research Network, Ehrich M, van den Boom D, Deciu C, Bombard A. Noninvasive prenatal screening for fetal trisomies 21, 18, 13 and the common sex chromosome aneuploidies from maternal blood using massively parallel genomic sequencing of DNA. Am J Obstet Gynecol 2014;211:365.e1-12.

155. Shaw SW, Hsiao CH, Chen CY, Ren Y, Tian F, Tsai C, Chen M, Cheng PJ. Noninvasive prenatal testing for whole fetal chromosomal aneuploidies: a multicenter prospective cohort trial in Taiwan. Fetal Diagn Ther 2014;35:13-17.

156. Stumm M, Entezami M, Haug K, Blank C, Wüstemann M, Schulze B, Raabe-Meyer G, Hempel M, Schelling M, Ostermayer E, Langer-Freitag S, Burkhardt T, Zimmermann R, Schleicher T, Weil B, Schöck U, Smerdka P, Grömminger S, Kumar Y, Hofmann W. Diagnostic accuracy of random massively parallel sequencing for non-invasive prenatal detection of common autosomal aneuploidies: a collaborative study in Europe. Prenat Diagn 2014;34:185-191.

157. Quezada MS, Gil MM, Francisco C, Oròsz G, Nicolaides KH. Screening for trisomies 21, 18 and 13 by cell-free DNA analysis of maternal blood at 10-11 weeks' gestation and the combined test at 11-13 weeks. Ultrasound Obstet Gynecol 2015;45:36-41.

158. Song Y, Huang S, Zhou X, Jiang Y, Qi Q, Bian X, Zhang J, Yan Y, Cram DS, Liu J. Non-invasive prenatal testing for fetal aneuploidies in the first trimester of pregnancy. Ultrasound Obstet Gynecol 2015;45:55-60.

159. Norton ME, Jacobsson B, Swamy GK, Laurent LC, Ranzini AC, Brar H, Tomlinson MW, Pereira L, Spitz JL, Hollemon D, Cuckle H, Musci TJ, Wapner RJ. Cell-free DNA analysis for noninvasive examination of trisomy. N Engl J Med 2015;372:1589-1597.

160. Stokowski R, Wang E, White K, Batey A, Jacobsson B, Brar H, Balanarasimha M, Hollemon D, Sparks A, Nicolaides K, Musci TJ. Clinical performance of non-invasive prenatal testing (NIPT) using targeted cellfree DNA analysis in maternal plasma with microarrays or next generation sequencing (NGS) is consistent across multiple controlled clinical studies. Prenat Diagn 2015;35:1243-1246. 
161. Zhang H, Gao Y, Jiang F, Fu M, Yuan Y, Guo Y, Zhu Z, Lin M, Liu Q, Tian Z, Zhang H, Chen F, Lau TK, Zhao $L, Y i X$, Yin $Y$, Wang W. Non-invasive prenatal testing for trisomies 21, 18 and 13: clinical experience from 146,958 pregnancies. Ultrasound Obstet Gynecol 2015;45:530-538.

162. Ryan A, Hunkapiller N, Banjevic M, Vankayalapati N, Fong N, Jinnett KN, Demko Z, Zimmermann B, Sigurjonsson S, Gross SJ, Hill M. Validation of an Enhanced Version of a Single-Nucleotide Polymorphism-Based Noninvasive Prenatal Test for Detection of Fetal Aneuploidies. Fetal Diagn Ther. 2016 Mar 31. [Epub ahead of print]

163. Koumbaris G, Kypri E, Tsangaras K, Achilleos A, Mina P, Neofytou M, Velissariou V, Christopoulou G, Kallikas I, González-Liñán A, Benusiene E, Latos-Bielenska A, Marek P, Santana A, Nagy N, Széll M, Laudanski P, Papageorgiou EA, loannides M, Patsalis PC. Cell-Free DNA Analysis of Targeted Genomic Regions in Maternal Plasma for Non-Invasive Prenatal Testing of Trisomy 21, Trisomy 18, Trisomy 13, and Fetal Sex. Clin Chem 2016;62:848-855.

164. Table addapted from Gil MM, Quezada MS, Revello R, Akolekar R, Nicolaides KH. Analysis of cell-free DNA in maternal blood in screening for fetal aneuploidies: updated meta-analysis. Ultrasound Obstet Gynecol 2015;45:249-266.

165. Morain S, Greene MF, Mello MM: A new era in noninvasive prenatal testing. N Engl J Med 2013;369:499-501.

166. Bianchi DW, Wilkins-Haug L. Integration of noninvasive DNA testing for aneuploidy into prenatal care: what has happened since the rubber met the road? Clin Chem 2014;60:78-87.

167. Benn P, Cuckle H, Pergament E. Non-invasive prenatal diagnosis for Down syndrome: the paradigm will shift, but slowly. Ultrasound Obstet Gynecol 2012;39:127-130.

168. Kagan KO, Wright D, Baker A, Sahota D, Nicolaides KH. Screening for trisomy 21 by maternal age, fetal nuchal translucency thickness, free beta-human chorionic gonadotropin and pregnancy-associated plasma protein-A. Ultrasound Obstet Gynecol 2008;31:618-624.

169. Allyse M, Minear MA, Berson E, Sridhar S, Rote M, Hung A, Chandrasekharan S. Non-invasive prenatal testing: a review of international implementation and challenges. Int J Womens Health 2015;7:113126.

170. Hui L, Hyett J. Noninvasive prenatal testing for trisomy 21: challenges for implementation in Australia. Aust N Z J Obstet Gynaecol 2013;53:416-424.

171. van Schendel RV, Kleinveld JH, Dondorp WJ, Pajkrt E, Timmermans DR, Holtkamp KC, Karsten M, Vlietstra AL, Lachmeijer AM, Henneman L. Attitudes of pregnant women and male partners towards non-invasive prenatal testing and widening the scope of prenatal screening. Eur J Hum Genet 2014;22:1345-1350.

172. Hill M, Wright D, Daley R, Lewis C, McKay F, Mason S, Lench N, Howarth A, Boustred C, Lo K, Plagnol V, Spencer K, Fisher J, Kroese M, Morris S, Chitty LS. Evaluation of non-invasive prenatal testing (NIPT) for aneuploidy in an NHS setting: a reliable accurate prenatal non-invasive diagnosis (RAPID) protocol. BMC Pregnancy Childbirth 2014;14:229.

173. http://www.meerovernipt.nl/

174. Gezondheidsraad. Wet op het bevolkingsonderzoek: NIPT als eerste test voor de syndromen van Down, Patau en Edwards. Den Haag: Gezondheidsraad, 2016; publicatienr. 2016/10.

175. Zhao C, Tynan J, Ehrich M, Hannum G, McCullough R, Saldivar JS, Oeth P, van den Boom D, Deciu C. Detection of fetal subchromosomal abnormalities by sequencing circulating cell-free DNA from maternal plasma. Clin Chem 2015;61:608-616.

176. Bayindir B, Dehaspe L, Brison N, Brady P, Ardui S, Kammoun M, Van der Veken L, Lichtenbelt K, Van den Bogaert K, Van Houdt J, Peeters H, Van Esch H, de Ravel T, Legius E, Devriendt K, Vermeesch JR. Noninvasive prenatal testing using a novel analysis pipeline to screen for all autosomal fetal aneuploidies improves pregnancy management. Eur J Hum Genet 2015;23:1286-1293.

177. Snyder MW, Simmons LE, Kitzman JO, Coe BP, Henson JM, Daza RM, Eichler EE, Shendure J, Gammill HS. Copy-number variation and false positive prenatal aneuploidy screening results. N Engl J Med 2015;372:1639-1645. 
178. Helgeson J, Wardrop J, Boomer T, Almasri E, Paxton WB, Saldivar JS, Dharajiya N, Monroe TJ, Farkas DH, Grosu DS, McCullough RM. Clinical outcome of subchromosomal events detected by wholegenome noninvasive prenatal testing. Prenat Diagn 2015;35:999-1004.

179. Straver R, Sistermans EA, Holstege H, Visser A, Oudejans CB, Reinders MJ. WISECONDOR: detection of fetal aberrations from shallow sequencing maternal plasma based on a within-sample comparison scheme. Nucleic Acids Res 2014;42:e31.

180. Valderramos SG, Rao RR, Scibetta EW, Silverman NS, Han CS, Platt LD. Cell-free DNA Screening in Clinical Practice: Abnormal Autosomal Aneuploidy and Microdeletion Results. Am J Obstet Gynecol. 2016 Jun 28. [Epub ahead of print]

181. Hooks J, Wolfberg AJ, Wang ET, Struble CA, Zahn J, Juneau K, Mohseni M, Huang S, Bogard P, Song K, Oliphant A, Musci TJ. Non-invasive risk assessment of fetal sex chromosome aneuploidy through directed analysis and incorporation of fetal fraction. Prenat Diagn 2014;34:496-499.

182. Nicolaides KH, Musci TJ, Struble CA, Syngelaki A, Gil MM. Assessment of fetal sex chromosome aneuploidy using directed cell-free DNA analysis. Fetal Diagn Ther 2014;35:1-6.

183. Yao H, Jiang F, Hu H, Gao Y, Zhu Z, Zhang H, Wang Y, Guo Y, Liu L, Yuan Y, Zhou L, Wang J, Du B, Qu N, Zhang R, Dong $\mathrm{Y}, \mathrm{Xu} \mathrm{H}$, Chen F, Jiang H, Liu Y, Zhang L, Tian Z, Liu Q, Zhang C, Pan X, Yang S, Zhao L, Wang W, Liang Z. Detection of fetal sex chromosome aneuploidy by massively parallel sequencing of maternal plasma DNA: initial experience in a Chinese hospital. Ultrasound Obstet Gynecol 2014;44:17 24.

184. Bianchi DW, Parsa S, Bhatt S, Halks-Miller M, Kurtzman K, Sehnert AJ, Swanson A. Fetal sex chromosome testing by maternal plasma DNA sequencing: clinical laboratory experience and biology. Obstet Gynecol 2015;125:375-382.

185. Pieters JJ, Verhaak CM, Braat DD, van Leeuwen E, Smits AP. Experts' opinions on the benefit of an incidental prenatal diagnosis of sex chromosomal aneuploidy: a qualitative interview survey. Prenat Diagn 2012;32:1151-1157.

186. Morris JK, Alberman E, Scott C, Jacobs P. Is the prevalence of Klinefelter syndrome increasing? Eur J Hum Genet 2008;16:163-170.

187. Tartaglia NR, Howell S, Sutherland A, Wilson R, Wilson L. A review of trisomy X $(47, X X X)$. Orphanet J Rare Dis 2010;5:8.

188. Kalafat E, Seval MM, Turgay B, Koç A. Non-invasive prenatal testing for sex chromosome abnormalities: a source of confusion. BMJ Case Rep 2015 Jan 28;2015.

189. McNamara CJ, Limone LA, Westover T, Miller RC. Maternal source of false-positive fetal sex chromosome aneuploidy in noninvasive prenatal testing. Obstet Gynecol 2015;125:390-392.

190. Wang Y, Chen Y, Tian F, Zhang J, Song Z, Wu Y, Han X, Hu W, Ma D, Cram D, Cheng W. Maternal mosaicism is a significant contributor to discordant sex chromosomal aneuploidies associated with noninvasive prenatal testing. Clin Chem 2014;60:251-259. 


\section{Part I}

\section{Design of noninvasive prenatal diagnostic tests}





\section{Chapter 2}

\section{Cell-free RNA is a reliable fetoplacental marker in noninvasive fetal sex determination}

Elke Mersy, Brigitte H.W. Faas, Sabine Spierts, Leonie M.H. Houben, Merryn V.E. Macville, Suzanna G.M. Frints, Aimee D.C. Paulussen, and Joris A. Veltman

Clin Chem 2015;61:1515-1523. 


\subsection{Abstract}

Background: Noninvasive genetic tests that use cell-free fetal DNA (cffDNA) are used increasingly in prenatal care. A low amount of cffDNA can have detrimental effects on the reliability of these tests. A marker to confirm the presence of fetal nucleic acids is therefore required that is universally applicable and easy to incorporate.

Methods: We developed a novel multiplex, single-tube, noninvasive fetal sex determination assay by combining amplification of AMELY cffDNA with one-step reverse transcription (RT)-PCR of trophoblast-derived cell-free RNA (cfRNA), which functions as a sex-independent fetoplacental marker. We tested plasma samples from 75 pregnant women in duplicate in a blinded fashion. The fetus was considered to be male in the case of a positive result for AMELY and cfRNA amplification in both RTPCRs. The fetus was considered to be female in the case of negative AMELY and positive cfRNA result in both RT-PCRs. In other cases, the test was repeated. We compared the results with invasive prenatal testing and pregnancy outcomes.

Results: The AMELY cffDNA amplification and cfRNA result was unambiguous and identical in duplicate in 71 of 75 plasma samples (95\%). Four samples (5\%) required an extra replicate because of an absent fetoplacental marker. Thereafter, fetal sex was correctly determined in all 75 plasma samples.

Conclusions: Amplification of trophoblast-derived cfRNA is a reliable marker for the confirmation of the presence of fetoplacentally derived nucleic acids in noninvasive fetal sex determination. 


\subsection{Introduction}

Cell-free fetal DNA (cffDNA) in maternal plasma is analyzed for noninvasive prenatal diagnosis (NIPD), e.g., to determine the fetal sex. It is well known that the fetal fraction, i.e., the cffDNA subfraction from the total maternal and fetal cfDNA in the plasma, correlates with test success and interpretation reliability. ${ }^{1}$ The cffDNA represents on average $6-10 \%$ of the total cfDNA in first- and second-trimester pregnancies, and increases to $10-20 \%$ in third-trimester pregnancies. ${ }^{2,3}$ However, the fetal fraction can remain $<4 \%$ in the first trimester. ${ }^{4,5}$ To conclude whether a negative result of an NIPD assay is a true or false negative, a marker to confirm the presence of fetal nucleic acids (a fetal marker) is crucial. The ideal fetal marker can be used as an internal control in the same test to detect any technical failure of the assay. As such, the fetal marker should be (a) part of the NIPD assay, (b) specific for fetoplacentally derived nucleic acids, and (c) sex-independent.

Trophoblastic cells from the fetal part of the placenta are the source of cffDNA. ${ }^{6}$ CfRNA derived from genes that are expressed only by the trophoblastic cells may be used as a sex-independent marker to prove the presence of fetoplacentally derived nucleic acids in the plasma sample. Trophoblast-derived messenger RNA (mRNA) of the pregnancy-specific hormones placental lactogen $(\mathrm{PL})$ and human chorionic gonadotropin (hCG) is constantly released into maternal plasma during pregnancy. ${ }^{7,8}$ The amount of cfRNA in maternal plasma corresponds with known expression patterns of the genes in the villous layer during placental development and with concentrations of released hormone in maternal serum. ${ }^{7,9,10}$ Therefore, the amount of hCG cfRNA is highest in the first trimester of pregnancy, whereas the amount of PL cfRNA is highest in the third trimester. ${ }^{7,8}$ This cfRNA is stable and rapidly cleared after delivery. ${ }^{7}$ cfRNA has been used as a marker to detect placental disease, fetal hypoxia, or ectopic pregnancy, but not as a fetal marker in noninvasive genetic tests. ${ }^{11-14}$

This study examines the use of trophoblast-derived cfRNA as a fetoplacental marker in noninvasive fetal sex determination. Noninvasive fetal sex determination is often requested in case of a fetus at risk for 1 of the $>100$ known X-linked inherited disorders or for autosomal recessive congenital adrenal hyperplasia. ${ }^{15,16}$ Furthermore, if a fetus presents with ambiguous genitalia on ultrasound examination, prenatal determination of the genetic sex can be part of the structured approach to detect the underlying condition. In the case of amplification of $Y$ chromosome-derived cffDNA sequences in maternal plasma by real-time quantitative PCR ( $q P C R$ ) or standard PCR, the fetus is presumed to be male. If no $\mathrm{Y}$ chromosome-derived cffDNA sequences are amplified, 
the fetus is most likely female, but this could also be the result of an insufficient amount of cffDNA. To date, in general, 2 methods are used to confirm that cffDNA is present in the sample. The first is the detection of paternally inherited alleles ${ }^{17}$, and the second is the amplification of hypermethylated placental genes, such as RASSF1A [Ras association (RalGDS/AF-6) domain family member 1 , isoform A], after removing maternal unmethylated gene sequences by a methylation-sensitive endonuclease. ${ }^{18}$ Both approaches have drawbacks. They require extra time and expense by the laboratory, and they sometimes fail to confirm the presence of fetal nucleic acids. ${ }^{17,18}$ In addition, the first method requires paternal DNA. As a consequence, the ideal fetal marker for noninvasive sex determination, which is incorporated in the test and requires no extra time or expense, is not yet available. In this study, we developed a novel single-tube NIPD assay for fetal sex determination by combining amplification of AMELY (amelogenin, Y-linked) cffDNA with one-step reverse transcription (RT)-PCR of trophoblast-derived cfRNA, which functions as a sex-independent fetoplacental marker. We present a proof-of-principle study in 75 pregnant women with known pregnancy outcomes.

\subsection{Materials and Methods}

\subsubsection{Blood sample collection}

We collected EDTA-anticoagulated blood samples of 75 pregnant women at $9+4$ to $34+1$ weeks (+ days) of gestation at the Department of Clinical Genetics of the Maastricht University Medical Center, the Netherlands. These pregnant women were scheduled to undergo invasive chorionic villous sampling or amniocentesis for prenatal microarray analysis because of structural abnormalities seen on prenatal ultrasound scan. Parental blood samples were collected for interpretation studies should an abnormality be detected in the prenatal sample upon array analysis. Additionally, we used EDTA-anticoagulated blood samples from 20 randomly selected male partners as positive $\mathrm{Y}$ chromosome control samples and from 20 nonpregnant women of reproductive age (nulli-, primi-, and multipara women) as negative nonpregnant non$Y$ chromosome control samples.

Blood was stored at $4{ }^{\circ} \mathrm{C}$ before processing. All participants agreed to the use of their coded body material for improvement of diagnostic tests, according to the Code of Conduct for Responsible Use of Human Tissue and Medical Research in the Netherlands. The sample characteristics are listed in Table 2.1. 
Table 2.1 Sample characteristics

\begin{tabular}{|c|c|}
\hline & $\mathbf{n}$ \\
\hline \multicolumn{2}{|l|}{ Gestational age, weeks + days } \\
\hline $9+4$ to $11+6$ & 9 \\
\hline $12+0$ to $14+6$ & 12 \\
\hline $15+0$ to $17+6$ & 12 \\
\hline $18+0$ to $20+6$ & 27 \\
\hline $21+0$ to $23+6$ & 12 \\
\hline $24+0$ to $34+1$ & 3 \\
\hline \multicolumn{2}{|l|}{ Venipuncture before/after any invasive procedure } \\
\hline Before & 71 \\
\hline 7-8 days after & 3 \\
\hline 2 months after & 1 \\
\hline \multicolumn{2}{|l|}{ Fetal sex } \\
\hline Boy & 42 \\
\hline Girl & 33 \\
\hline \multicolumn{2}{|l|}{ Source fetal sex } \\
\hline Prenatal karyotyping/microarray analysis & 72 \\
\hline Postnatal microarray analysis & 2 \\
\hline Birth report only & 1 \\
\hline \multicolumn{2}{|l|}{ BMI at first prenatal visit, $\mathrm{kg} / \mathrm{m}^{2}$} \\
\hline$<20$ & 12 \\
\hline $20-25$ & 40 \\
\hline $25-30$ & 12 \\
\hline$>30$ & 5 \\
\hline Unknown & 6 \\
\hline \multicolumn{2}{|l|}{ Parity in female-bearing pregnancies } \\
\hline Primipara & 15 \\
\hline Multipara & 17 \\
\hline Unknown & 1 \\
\hline \multicolumn{2}{|l|}{ Offspring in multipara female-bearing women } \\
\hline Male (n) & $8(1-2)$ \\
\hline Female only & 7 \\
\hline Unknown & 1 \\
\hline
\end{tabular}

\begin{tabular}{lr}
\hline Storage & \\
EDTA-anticoagulated blood samples $\left(\mathbf{4}^{\circ} \mathrm{C}\right), \mathbf{h}$ & 62 \\
$<24$ & 11 \\
$24-48$ & 1 \\
$48-72$ & 1 \\
Unknown & \\
Plasma $\left(-80^{\circ} \mathrm{C}\right)$, months & 6 \\
$<1$ & 65 \\
$1-6$ & 0 \\
$7-12$ & 3 \\
$12-13$ & 1 \\
Unknown & \\
cfDNA/RNA (-80 $\left.{ }^{\circ} \mathrm{C}\right)$ & 10 \\
$1-6$ days & 31 \\
$1-4$ weeks & 28 \\
1-6 months & 6 \\
6-11 months & 6 \\
\hline
\end{tabular}


Further laboratory tests were conducted blinded to the clinical characteristics of the samples, except for the gestational age of the women at the time of blood sample collection. The blood samples of the controls were anonymized. Only the parity and number of male offspring were registered from the nonpregnant females. The women had 0-2 male pregnancies in the past.

\subsubsection{Sample processing and cfDNA/RNA extraction}

Figure 2.1 illustrates the test procedure and suggested time schedule. Blood samples were centrifuged at $1600 \times \mathrm{g}$ for $10 \mathrm{~min}$ at $4{ }^{\circ} \mathrm{C}$. The plasma portion was transferred into plain polypropylene tubes and centrifuged at $7470 \times \mathrm{g}$ for $10 \mathrm{~min}$ at $4{ }^{\circ} \mathrm{C}$. Cryogenic vials containing the supernatant were stored at $-80^{\circ} \mathrm{C}$ until cfDNA/RNA extraction. We performed simultaneous extraction of total cfDNA and cfRNA in duplicate from $2 \times 2$ $\mathrm{mL}$ plasma from the pregnant women with the QIAamp Circulating Nucleic Acid Kit (Qiagen), following a slightly adjusted protocol (see Supplemental data). The cfDNA/RNA (elution volume $50 \mu \mathrm{L}$ ) was subsequently stored at $-80{ }^{\circ} \mathrm{C}$ for optimal conservation of the cell-free nucleic acids. Additionally, we performed 1 cfDNA/RNA extraction with $1 \mathrm{~mL}$ plasma from the nonpregnant females and male controls (elution volume $25 \mu \mathrm{L}$ ).

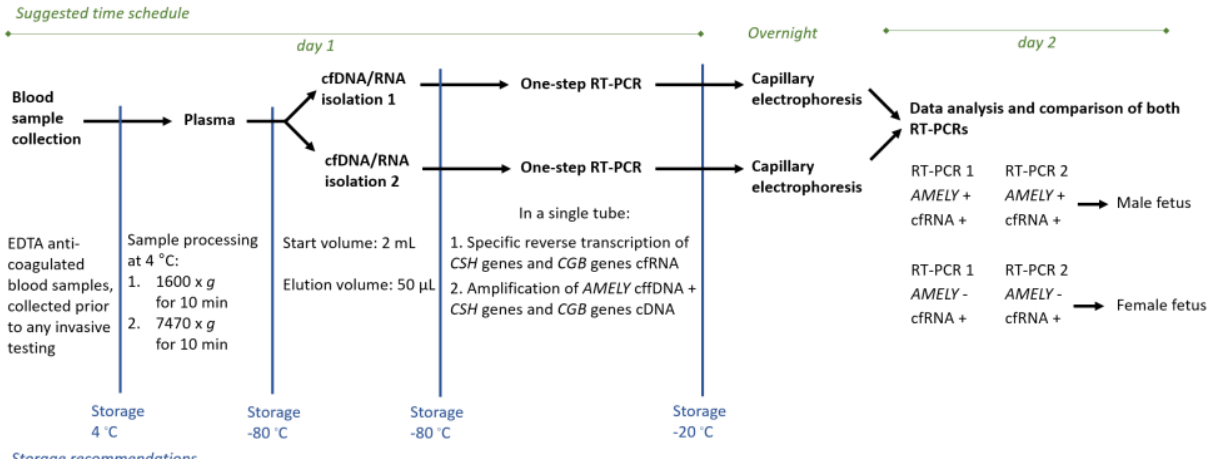

Figure 2.1 Test procedure and suggested time schedule.

\subsubsection{Primer design}

To investigate the presence of trophoblast-derived cfRNA in the maternal plasma, we designed oligonucleotide primer pairs for specific RT and amplification of trophoblastexpressed genes encoding the hormones PL and hCG. For PL, these are the highly similar genes $\mathrm{CSH} 1$ and $\mathrm{CSH} 2$ [respectively, chorionic somatomammotropin hormone 1 (placental lactogen) and chorionic somatomammotropin hormone 2], and for hCG, 
4 highly homologous genes: CGB (chorionic gonadotropin, $\beta$ polypeptide), CGB5, CGB7, and CGB8 [chorionic gonadotropin, $\beta$ polypeptides 5,7 , and 8 , respectively]. ${ }^{10,19}$ The primers were developed with the free web program Primer3 (http://bioinfo.ut.ee/primer3-0.4.0/ primer3). Criteria for primer design were primer size (20-30 nucleotides), GC content (40-60\%), melting temperature of the primers (65 ${ }^{\circ} \mathrm{C}-70{ }^{\circ} \mathrm{C}$, optimal $68^{\circ} \mathrm{C}$ ), primers preferably ending $3^{\prime}$ with a guanine or cytosine, and RNA PCR product lengths between 60 and $150 \mathrm{bp}$. The primers anneal to sequences in exons on both sides of an intron. As a result, a larger product amplified from cfDNA (both maternal and fetoplacental) and a smaller product amplified from the intronless cfRNA (fetoplacental) is predicted. The cfDNA product will provide an internal control in cases in which no amplification of cfRNA is expected, e.g., in plasma samples from males and nonpregnant females. All forward primers were fluorophore-labelled, allowing visualization of the PCR products after separation by a capillary sequencer. The sequences of the primers, their fluorescent labels, and the theoretic cfDNA and cfRNA product sizes are listed in Table 2.2. Because of the $>85-90 \%$ sequence identity among the genes in the human growth hormone/CSH gene cluster (17q22-24) and the LHB (luteinizing hormone $\beta$ polypeptide)/CGB gene cluster (19q13.3), our primers will most likely also initiate RT and amplification of cfRNA from other trophoblastexpressed genes. These are CSHL1 (chorionic somatomammotropin hormone-like 1), a paralog gene of $C S H 1$ and $C S H 2$, and $C G B 1$ and $C G B 2$ (chorionic gonadotropin, $\beta$ polypeptides 1 and 2, respectively). The function of these genes is currently unclear, but their expression is trophoblast specific. ${ }^{9,10,20}$ We expect amplification products of the same size in all genes and transcript variants of the genes (see Supplemental Figure 2.5). As such, the combined amplification of the cDNA of all genes can be used to investigate the presence of trophoblast-derived cfDNA. We refer to the amplified genes in the human growth hormone/CSH gene cluster as "CSH genes" and those in the $L H B / C G B$ gene cluster as "CGB genes" throughout this article.

To detect $Y$ chromosome-specific cffDNA in the maternal plasma, we designed oligonucleotide primer pairs for the amplification of AMELY (Yp11.2). To facilitate combination of all primer pairs in a multiplex test, the primers were developed with Primer3 and the same criteria for primer design as for the cfRNA targets. The primers were designed to overlap with mismatches compared with the homologous gene on the $\mathrm{X}$ chromosome: AMELX (amelogenin, X-linked) (Xp22.31-p22.1). As a result, amplification of maternal cfDNA derived from the $X$ chromosome was avoided (see Supplemental Figure 2.6). 
Table 2.2 Primer sequences and product sizes

\begin{tabular}{|c|c|c|c|}
\hline \multirow[t]{2}{*}{ Chromosome and gene } & \multirow[t]{2}{*}{ Sequence 5'- 3' with fluorescent dye* } & \multicolumn{2}{|c|}{ Product size, bp } \\
\hline & & cfDNA & cfRNA \\
\hline \multicolumn{4}{|l|}{ 17, $\mathrm{CSH}$ genes } \\
\hline Forward & VIC-CCAACATGGAGGAAACGCAACAG & 163 & 70 \\
\hline Reverse & GACTCGATGAGCAGCAGGGAGA & & \\
\hline \multicolumn{4}{|l|}{ 19, CGB genes } \\
\hline Forward & VIC-TGTGCATCACCGTCAACACCAC & 364 & 129 \\
\hline Reverse & GGATGGACTCGAAGCGCACA & & \\
\hline \multicolumn{4}{|l|}{$\mathrm{Y}, A M E L Y$} \\
\hline Forward & NED-AGCCACCTCTGCCTCCAATGTTC & 81 & \\
\hline Reverse & TTGCTGGCCAAGCTTCCAGATG & & \\
\hline
\end{tabular}

Legend to Table 2.2: *VIC and NED emit fluorescent signals at $554 \mathrm{~nm}$ and $575 \mathrm{~nm}$ of wavelengths, respectively.

\subsubsection{One-step RT-PCR}

For each isolation, single-tube one-step RT-PCR was carried out with the Qiagen OneStep RT-PCR Kit (Qiagen), according to the manufacturer's instructions. RT-PCRs were set up in a total volume of $25 \mu \mathrm{L}$, with $4 \mu \mathrm{L}$ cfDNA/RNA, $1 \mu \mathrm{L}$ OneStep RT-PCR Enzyme Mix (containing Omniscript and Sensiscript Reverse Transcriptases and HotStarTaq DNA polymerase), $5 \mu \mathrm{L} 5$ x OneStep RT-PCR Buffer, $1 \mu \mathrm{L}$ dNTP mix (containing $10 \mathrm{mmol} / \mathrm{L}$ of each dNTP), and 2.5 or $2.1 \mu \mathrm{L}$ PCR primer mix (containing 10 pmol CGB forward and reverse primer, 7 pmol CSH forward and reverse primer, and 8 or 4 pmol AMELY forward and reverse primer, for gestational ages $<15$ weeks and > 15 weeks, respectively). RT-PCR was performed on the GeneAmp ${ }^{\circledR}$ PCR System 9700 (Applied Biosystems). The reaction was initiated at $50{ }^{\circ} \mathrm{C}$ for $30 \mathrm{~min}$, allowing specific RT of $C S H$ and $C G B$ genes cfRNA. This was followed by $95^{\circ} \mathrm{C}$ for 15 min for inactivation of the reverse transcriptases, denaturation of the cDNA and cffDNA template, and activation of the HotStarTaq DNA polymerase. Simultaneous amplification of AMELY cffDNA and CSH and CGB genes cDNA was conducted by 10 cycles of $94^{\circ} \mathrm{C}$ for $10 \mathrm{~s}, 66$ ${ }^{\circ} \mathrm{C}$ for $1 \mathrm{~min}$, and $72{ }^{\circ} \mathrm{C}$ for $1 \mathrm{~min}$, followed by 35 cycles of $94{ }^{\circ} \mathrm{C}$ for $10 \mathrm{~s}, 66^{\circ} \mathrm{C}$ for $30 \mathrm{~s}$, and $72{ }^{\circ} \mathrm{C}$ for $30 \mathrm{~s}$. The reaction was ended by a final incubation at $72{ }^{\circ} \mathrm{C}$ for $10 \mathrm{~min}$. The RT-PCR products were either immediately separated and analyzed or stored at $-20^{\circ} \mathrm{C}$. 


\subsubsection{Separation of RT-PCR products and data analysis}

The fluorescently labeled RT-PCR products were diluted 1:100 (1 part RT-PCR product and 99 parts $\mathrm{H}_{2} \mathrm{O}$ ) before separation and separated by capillary electrophoresis on the ABI 3730 DNA Analyzer (Applied Biosystems by Life Technologies). The sizes, peak heights, and areas under the amplification peaks of the RT-PCR products were analyzed with data analysis software (GeneMarker v2.4.0, Soft Genetics).

\section{$2.4 \quad$ Results}

\subsubsection{Analysis of the electropherograms}

The nonspecific background for each of the cfRNA and cfDNA amplification products was determined by use of the 40 plasma samples from the nonpregnant female and male controls. For all subsequent analyses, we used the criterion that if the area under the amplification peak was above the nonspecific background, a peak was considered present.

Figure 2.2 shows the primer binding sites in the exons, the theoretic sizes of the CfDNA and cfRNA products, and examples of the amplified fluorescent RT-PCR products in different sample types. The electropherogram of all sample types (pregnant and nonpregnant controls) showed 2 amplified VIC fluorescent dye-labeled products of 160 and $361 \mathrm{bp}$, representing CSH and CGB genes cfDNA, respectively. In case of a pregnancy, 2 smaller VIC-labeled products were seen (64 and $125 \mathrm{bp}$ ), representing CSH and CGB genes cfRNA, respectively. In case of the presence of a $Y$ chromosome (male fetus or adult male), the electropherograms showed an amplified NED dyelabeled product of 76 bp representing AMELY cffDNA or cfDNA. No trophoblastderived cfRNA peaks were found in the 40 control plasma samples in which no fetoplacental nucleic acids were expected ( 20 males and 20 nonpregnant females). 
A $C S H$ genes cfDNA

\begin{tabular}{|c|c|c|}
\hline 29 bp from EXON 3 & intron (93 bp) & 41 bp from EXON 4 \\
\hline CCAACATGGAGGAAACGCAACAGAAATCO & gtgagtggat ...tcccctgcag & AATCTAGAGCTGCTCCGCATCTCCCTGCTGCTCATCGAGTC \\
\hline
\end{tabular}

CGB genes cfDNA

\begin{tabular}{|c|c|}
\hline 50 bp from EXON 2 & intron (235 bp) \\
\hline TGTGCATCACCGTCAACACCACCATCTGTGCCGGCTACTGCCCCACCATG & gtgagctgcc... \\
\hline FORWARD-VIC & KON 3 \\
\hline
\end{tabular}

AMELY cfDNA

81 bp from EXON 5

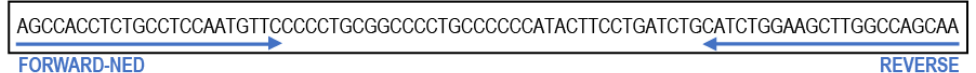

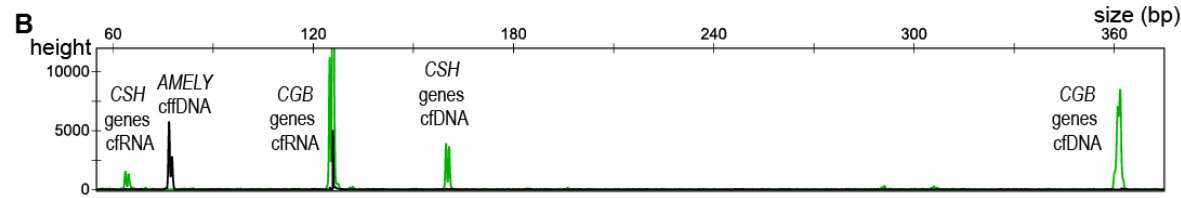

C

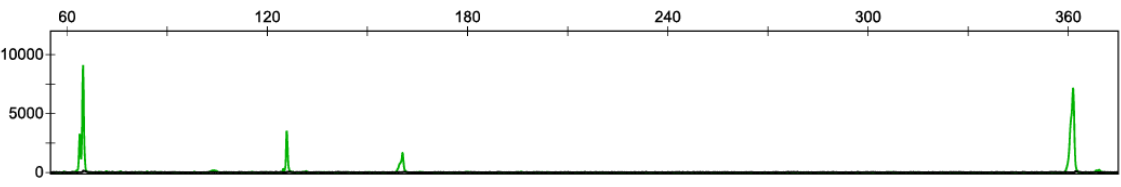

D

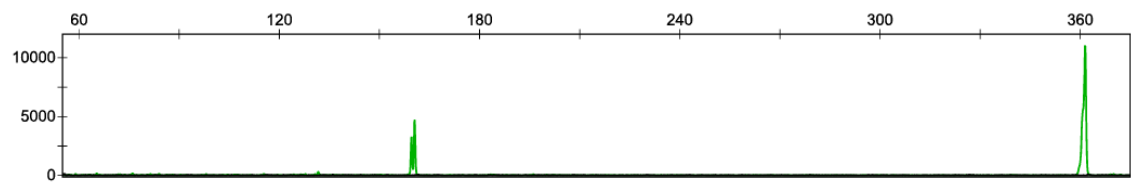

E

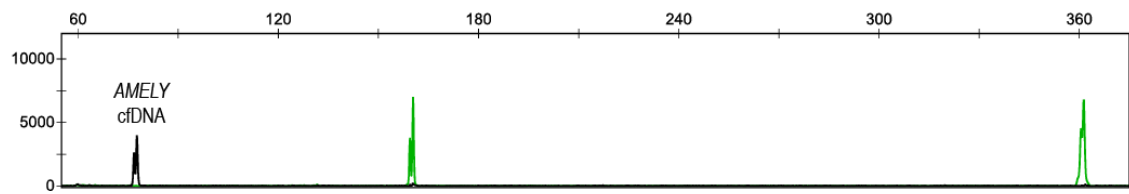

Figure 2.2 Multiplex one-step RT-PCR. (A), Primer binding sites in the exons. (B-E), GeneMapper electropherograms showing the amplified fluorescent products in a plasma sample of a woman carrying a male fetus ( $9+4$ weeks of gestation) (B); a woman carrying a female fetus (19+4 weeks of gestation) (C); an adult nonpregnant woman (D); and an adult male (E). In all samples, 2 VIC-labeled products of 160 and 361 bp, representing CSH and CGB genes cfDNA, respectively, were detected (A-E). In case of a pregnancy, 2 smaller VIC-labeled products were seen (64 and $125 \mathrm{bp})$, representing $C S H$ and $C G B$ genes cfRNA, respectively $(A-C)$. In case of a male fetus or adult male, an amplified NED-labeled product of $76 \mathrm{bp}$ representing AMELY cffDNA or cfDNA was detected $(A, B, E)$. 


\subsubsection{Fetoplacental markers throughout pregnancy}

The fetoplacental marker was considered present if the trophoblast-derived cfRNA peaks were detected according to gestational age, i.e., according to the expression patterns during placental development. In the first trimester of pregnancy, we expected the area under the CGB genes cfRNA amplification peak to be higher than that of the CSH genes cfRNA amplification peak. In the second and third trimesters of pregnancy, we expected the area under the CGB genes cfRNA amplification peak to be below the area of the CSH genes cfRNA amplification peak. To confirm this, we evaluated the cfRNA peaks in the 75 plasma samples from the pregnant women. The ratio of both areas (CSH to CGB peak ratio) was calculated for each sample. The distribution of the $C S H$ to $C G B$ peak ratio throughout pregnancy is shown in Figure 2.3. Indeed, from this graph it can be seen that all first-trimester samples had a higher area under the CGB genes cfRNA amplification peak than under the CSH genes cfRNA amplification peak, and that with increasing gestational age the $C S H$ to CGB peak ratio increases. Electropherograms early and later in the pregnancy illustrate this trend in Supplemental Figure 2.7.

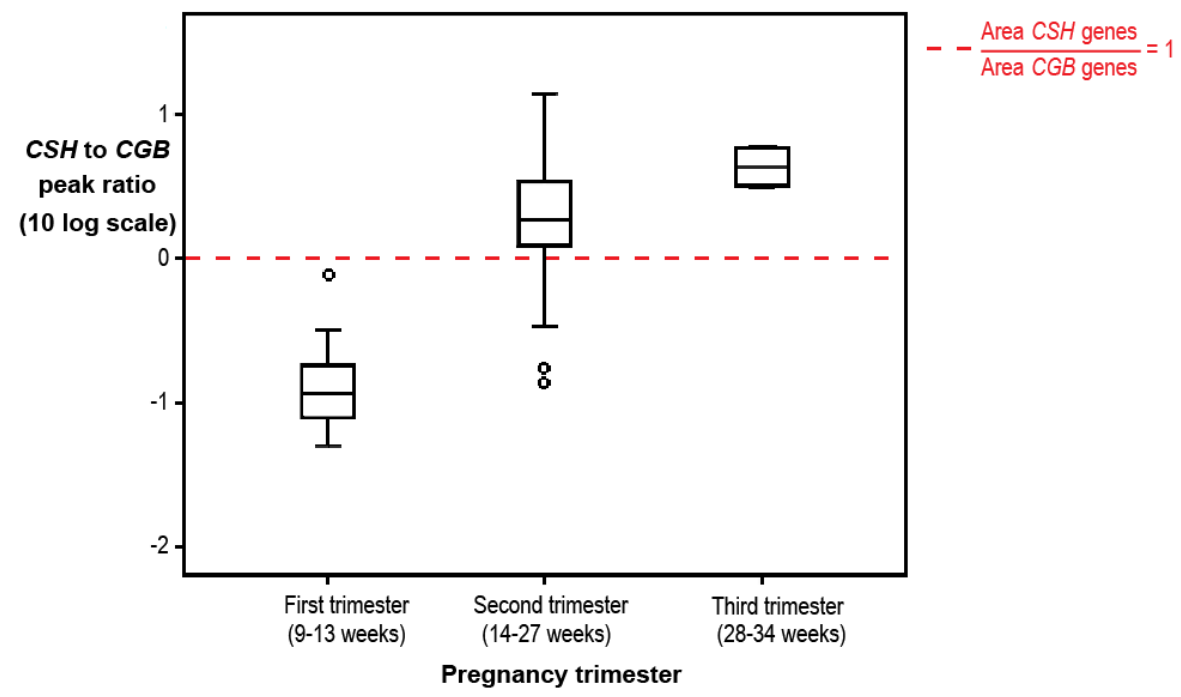

Figure 2.3 Fetoplacental markers throughout pregnancy. Box plots represent the distribution of $\mathrm{CSH}$ to $C G B$ peak ratio in the first, second, and third trimesters in the sample set of 75 pregnant women. 


\subsubsection{Determination of fetal sex}

The sample was considered to be derived from a woman carrying a male fetus in the case of a positive result for AMELY cffDNA and trophoblast-derived cfRNA amplification in both RT-PCRs. The fetus was considered to be female in the case of a negative $A M E L Y$ cffDNA amplification result and a positive trophoblast-derived cfRNA amplification result in both RT-PCRs.

The AMELY and cfRNA amplification result was unambiguous and identical after conducting the duplicate one-step RT-PCR once in 71 of 75 plasma samples (Figure 2.4). In 41, a distinct positive result for the AMELY cffDNA and cfRNA amplification was seen in both RT-PCRs, whereas the remaining 30 samples showed no AMELY cffDNA amplification in combination with a positive cfRNA result in both RT-PCRs. We classified the first 41 samples as male fetuses and the latter 30 samples as female fetuses.

Three samples required a third replicate of RT-PCR (NY-19, 15 + 1 weeks; NY-41, 14 + 1 weeks; NY-49, $21+1$ weeks). They were classified as "probably female" fetuses after the second test, because the presence of fetoplacentally derived nucleic acids was evident in only 1 of the 2 RT-PCRs. We repeated the dubious RT-PCR run in all 3 samples with the same starting materials and conditions. Thereafter, a $100 \%$ concordance rate between the clear RT-PCR and the repeated RT-PCR was reached for all samples. Samples NY-19, NY-41, and NY-49 were thus all classified as femalebearing pregnancies. A last sample required a rerun of the duplicate RT-PCR. No sex could be determined for the sample (NY-36, $19+6$ weeks), because no AMELY cffDNA amplification and no positive cfRNA result was found in either RT-PCR. The same starting materials and conditions were used during the rerun. In both cfDNA/RNA isolations, the fetoplacental marker was present, as well as an AMELY cffDNA peak. Apparently, both RT-PCRs had initially failed, although they were performed at separate times. This sample was now classified as being derived from a woman carrying a male fetus.

Comparison of the result of our noninvasive fetal sex determination test with the result of invasive prenatal testing and pregnancy outcomes revealed that the fetal sex was correctly determined in all of these 75 samples (100\%). 
Blinded noninvasive fetal sex determination in duplicate

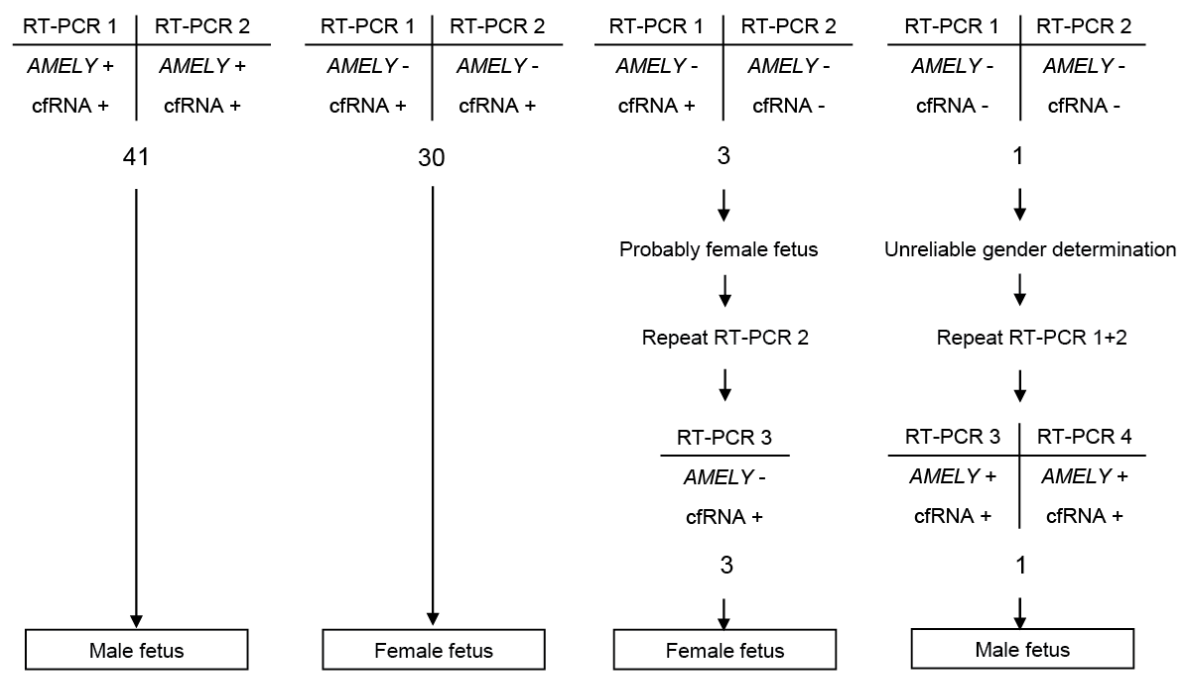

Comparison with invasive prenatal testing and/or pregnancy outcome

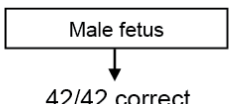

$42 / 42$ correct

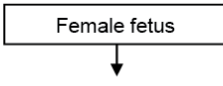

$33 / 33$ correct

Figure 2.4 Determination of fetal sex. The fetal sex could be determined unequivocally after conducting the RT-PCR once in 2 separate cfDNA/RNA isolations in 71 of 75 plasma samples. Three samples required a third repeat, and 1 sample required a rerun of the duplicate RT-PCR for a definitive conclusion, because of an absent fetoplacental marker. Thereafter, fetal sex was correctly determined in all 75 plasma samples.

\subsection{Discussion}

This study examined the use of cfRNA as a fetoplacental marker incorporated in a noninvasive fetal sex determination assay. In our proof-of-principle study, 75 blinded plasma samples from pregnant women were tested to find out whether the fetal sex could be determined and whether cfRNA was a reliable fetoplacental marker in this process.

The fetal sex could be determined unequivocally after conducting RT-PCR once in 2 separate cfDNA/RNA isolations in the majority of the plasma samples (95\%). Absence of the fetoplacental marker in 1 of both RT-PCRs in $5 \%$ of the cases required a repeat RT-PCR to have an unambiguous result for fetal sex determination. After these replicates, the fetoplacental markers turned out to be present in all samples. More 
importantly, the fetal sex was correctly determined in all cases $(100 \%)$.

Because of low template DNA, a noninvasive fetal sex determination assay sometimes requires multiple replicates to provide an unambiguous indication of fetal sex. ${ }^{17,18}$ In clinical practice, it is advisable to test each cfDNA/RNA extraction at least twice. If the fetoplacental marker is not detected after repeated testing in $A M E L Y$-negative samples, it is recommended to redraw blood from the pregnant women.

Our proof-of-principle study results indicate that the presence of the fetoplacental cfRNA marker in this single-tube assay is tightly correlated with an adequate amount of cffDNA in the plasma for noninvasive sex determination. We conclude this on the basis that in all pregnancies with male fetuses, both AMELY cffDNA and trophoblastspecific cfRNA were reliably detected, and in none was $A M E L Y$ cffDNA detected without the trophoblast-specific cfRNA peaks. Also, in none of these samples were the trophoblast-specific cfRNA peaks present while the AMELY cffDNA peak was absent. Moreover, we would have determined 1 sample from a male fetus as being derived from a female-bearing pregnancy without the use of the fetoplacental marker. In addition, no AMELY cffDNA was detected above background in any of the nullipara or multipara nonpregnant women or women carrying a female fetus. In case of a negative result of the cfRNA marker, however, it was also clear there was an insufficient amount of fetal nucleic acids present (if not due to a technical failure) and the test needed to be repeated, on the same or a new blood sample.

Clearly, this proof-of-principle study needs further replication before entering the diagnostic arena. One of the limitations of our study is that we did not test samples from pregnant women at 7-8 weeks of gestation and only 1 at 9 weeks of gestation (male fetus). However, our data do not show a decreased detection rate for 8 pregnancies at 11 weeks of gestation. After conducting the duplicate one-step RT-PCR once, the fetal sex was unambiguous and correct in all 8 samples ( 2 male fetuses, 6 female fetuses). Although these numbers are small, they suggest that the assay can be reliably applied early in pregnancy. A follow-up study, including samples from women between 7 and 10 weeks of pregnancy, is now recommended.

RT of cfRNA to cDNA could be added to other noninvasive prenatal tests investigating fetal alleles, e.g., for monogenic traits. cfDNA and cfRNA are extracted simultaneously from the plasma sample in most extraction kits, and therefore no additional procedure is necessary to obtain cfRNA. The cfRNA peaks did not appear to be strongly influenced by high BMI or longer storage of blood, plasma, or cfDNA/RNA. As an example, the 
cfDNA/RNA of NY-92 was stored for 11 months at $-80^{\circ} \mathrm{C}$ before analysis. This was a plasma sample collected at $13+2$ weeks of gestation from a woman with a BMI of 30.9. The cfRNA peak areas obtained for this sample are in the expected range for gestational age. This was also found in the other samples stored for a long time and in all women with high BMI.

Our test is based on $A M E L Y$ only for fetal sex determination. Sex determination on the basis of $A M E L Y$ is widely accepted in genetic diagnosis for sex determination, e.g., in the forensic field, prenatal diagnosis, and preimplantation genetic diagnosis. However, a few cases with $A M E L Y$ deletion resulting in allelic dropout have been reported in different populations. ${ }^{21}$ The frequency of $A M E L Y$ negatives is low, and ethnic differences seem to exist $10.018 \%$ in Europe, $0.02 \%$ in Australia, $1.85-2.36 \%$ in India). ${ }^{21,22}$ In a pilot study, we have attempted to incorporate other $Y$ chromosome genes, SRY (sex-determining region $Y$ ) and UTY (ubiquitously transcribed tetratricopeptide repeat containing, $Y$-linked), but found too many primer interactions in the multiplex RT-PCR (data not shown).

Finally, massively parallel sequencing approaches also can be used to determine the sex of the fetus, but at the moment this is still rather expensive. ${ }^{23,24}$ Our noninvasive fetal sex determination assay is a useful addition to the next-generation sequencing flow, as it is cheap, fast, and easy to use and provides a result within 1 or 2 days. Furthermore, it can be conducted in laboratories that do not have access to nextgeneration sequencing facilities.

In conclusion, in this proof-of-principle study, we have shown that amplification of placenta-expressed genes is an elegant way to confirm the presence of fetal nucleic acids in the maternal plasma and can be combined in a single tube with a sexdetermination assay. 


\subsection{References}

1. Palomaki GE, Kloza EM, Lambert-Messerlian GM, van den Boom D, Ehrich M, Deciu C, Bombard AT, Haddow JE. Circulating cell free DNA testing: are some test failures informative? Prenat Diagn 2015;35:289-293.

2. Lo YM, Chan KC, Sun H, Chen EZ, Jiang P, Lun FM, Zheng YW, Leung TY, Lau TK, Cantor CR, Chiu RW. Maternal plasma DNA sequencing reveals the genome-wide genetic and mutational profile of the fetus. Sci Transl Med 2010;2:61ra91.

3. Lun FM, Chiu RW, Chan KC, Leung TY, Lau TK, Lo YM. Microfluidics digital PCR reveals a higher than expected fraction of fetal DNA in maternal plasma. Clin Chem 2008;54:1664-1672.

4. Ashoor G, Syngelaki A, Poon LC, Rezende JC, Nicolaides KH. Fetal fraction in maternal plasma cell-free DNA at 11-13 weeks' gestation: relation to maternal and fetal characteristics. Ultrasound Obstet Gynecol 2013;41:26-32.

5. Ashoor G, Poon L, Syngelaki A, Mosimann B, Nicolaides KH. Fetal fraction in maternal plasma cell-free DNA at 11-13 weeks' gestation: effect of maternal and fetal factors. Fetal Diagn Ther 2012;31:237-243.

6. Alberry M, Maddocks D, Jones M, Abdel Hadi M, Abdel-Fattah S, Avent N, Soothill PW. Free fetal DNA in maternal plasma in anembryonic pregnancies: confirmation that the origin is the trophoblast. Prenat Diagn 2007;27:415-418.

7. Ng EK, Tsui NB, Lau TK, Leung TN, Chiu RW, Panesar NS, Lit LC, Chan KW, Lo YM. mRNA of placental origin is readily detectable in maternal plasma. Proc Natl Acad Sci U S A 2003;100:4748-4753.

8. Costa JM, Benachi A, Olivi M, Dumez Y, Vidaud M, Gautier E. Fetal expressed gene analysis in maternal blood: a new tool for noninvasive study of the fetus. Clin Chem 2003;49:981-983.

9. Farina A, Chan CW, Chiu RW, Tsui NB, Carinci P, Concu M, Banzola I, Rizzo N, Lo YM. Circulating corticotropin-releasing hormone mRNA in maternal plasma: relationship with gestational age and severity of preeclampsia. Clin Chem 2004;50:1851-1854.

10. Masuzaki H, Miura K, Yoshiura K, Yamasaki K, Miura S, Yoshimura S, Nakayama D, Mapendano CK, Niikawa N, Ishimaru T. Placental mRNA in maternal plasma and its clinical application to the evaluation of placental status in a pregnant woman with placenta previa-percreta. Clin Chem 2005;51:923-925.

11. Takacs P, Jaramillo S, Datar R, Williams A, Olczyk J, Barnhart K. Placental mRNA in maternal plasma as a predictor of ectopic pregnancy. Int J Gynaecol Obstet 2012;117:131-133.

12. Whitehead C, Teh WT, Walker SP, Leung C, Mendis S, Larmour L, Tong S. Quantifying circulating hypoxia-induced RNA transcripts in maternal blood to determine in utero fetal hypoxic status. BMC Med 2013;11:256.

13. MacLeod JN, Lee AK, Liebhaber SA, Cooke NE. Developmental control and alternative splicing of the placentally expressed transcripts from the human growth hormone gene cluster. J Biol Chem 1992;267:14219-14226.

14. Rull K, Laan M. Expression of beta-subunit of HCG genes during normal and failed pregnancy. Hum Reprod 2005;20:3360-3368.

15. Devaney SA, Palomaki GE, Scott JA, Bianchi DW. Noninvasive fetal sex determination using cell-free fetal DNA: a systematic review and meta-analysis. JAMA 2011;306:627-636.

16. Wright CF, Wei Y, Higgins JP, Sagoo GS. Non-invasive prenatal diagnostic test accuracy for fetal sex using cell-free DNA a review and meta-analysis. BMC Res Notes 2012;5:476.

17. Scheffer PG, van der Schoot CE, Page-Christiaens GC, Bossers B, van Erp F, de Haas M. Reliability of fetal sex determination using maternal plasma. Obstet Gynecol 2010;115:117-126.

18. White HE, Dent CL, Hall VJ, Crolla JA, Chitty LS. Evaluation of a novel assay for detection of the fetal marker RASSF1A: facilitating improved diagnostic reliability of noninvasive prenatal diagnosis. PLoS One 2012;7:e45073.

19. Männik J, Vaas P, Rull K, Teesalu P, Laan M. Differential placental expression profile of human growth hormone/chorionic somatomammotropin genes in pregnancies with pre-eclampsia and gestational diabetes mellitus. Mol Cell Endocrinol 2012;355:180-187. 
20. Männik J, Vaas P, Rull K, Teesalu P, Rebane T, Laan M. Differential expression profile of growth hormone/chorionic somatomammotropin genes in placenta of small- and large-for-gestational-age newborns. J Clin Endocrinol Metab 2010;95:2433-2442.

21. Lattanzi W, Di Giacomo MC, Lenato GM, Chimienti G, Voglino G, Resta N, Pepe G, Guanti G. A large interstitial deletion encompassing the amelogenin gene on the short arm of the $Y$ chromosome. Hum Genet 2005;116:395-401.

22. Mitchell RJ, Kreskas M, Baxter E, Buffalino L, Van Oorschot RA. An investigation of sequence deletions of amelogenin (AMELY), a Y-chromosome locus commonly used for gender determination. Ann Hum Biol 2006;33:227-240.

23. Bianchi DW, Parsa S, Bhatt S, Halks-Miller M, Kurtzman K, Sehnert AJ, Swanson A. Fetal sex chromosome testing by maternal plasma DNA sequencing: clinical laboratory experience and biology. Obstet Gynecol 2015;125:375-382.

24. Porreco RP, Garite TJ, Maurel K, Marusiak B; Obstetrix Collaborative Research Network, Ehrich M, van den Boom D, Deciu C, Bombard A. Noninvasive prenatal screening for fetal trisomies 21, 18, 13 and the common sex chromosome aneuploidies from maternal blood using massively parallel genomic sequencing of DNA. Am J Obstet Gynecol 2014;211:365.e1-12. 

Supplemental data Chapter 2 


\section{Isolation of cell-free DNA and cell-free RNA using the QIAamp ${ }^{\circledR}$ Circulating Nucleic Acid Kit and a slightly adjusted protocol}

\section{Procedure}

1. Pipet $200 \mu \mathrm{L}$ QIAGEN Proteinase $\mathrm{K}$ into a $15 \mathrm{~mL}$ centrifuge tube.

2. Add $2 \mathrm{~mL}$ of plasma to the $15 \mathrm{~mL}$ tube. Add PBS if less than $2 \mathrm{~mL}$ plasma.

3. Add $1.6 \mathrm{~mL}$ Buffer ACL. Close the cap and mix thoroughly by pulse vortexing for $30 \mathrm{~s}$.

4. Incubate at $60^{\circ} \mathrm{C}$ for $30 \mathrm{~min}$ in water bath.

5. Place the tube back on the lab bench and unscrew the cap.

6. Add $3.6 \mathrm{~mL}$ Buffer ACB to the lysate in the tube. Close the cap and mix thoroughly by pulsevortexing for $15-30 \mathrm{~s}$.

7. Incubate the lysate-Buffer ACB mixture in the tube for $5 \mathrm{~min}$ on ice.

8. Carefully apply $750 \mu \mathrm{L}$ of the lysate from step 7 onto the QIAamp Mini column, without wetting the rim. Close the cap and centrifuge at $6000 \times g(8000 \mathrm{rpm})$ for $1 \mathrm{~min}$. Place the QIAamp Mini column in a clean $2 \mathrm{~mL}$ collection tube, and discard the collection tube containing the filtrate. Repeat this step 9 times.

9. Carefully open the QIAamp Mini column, and add $600 \mu \mathrm{L}$ Buffer ACW1 without wetting the rim. Close the cap and centrifuge at $6000 \times g(8000 \mathrm{rpm})$ for $1 \mathrm{~min}$. Place the QIAamp Mini column in a clean $2 \mathrm{~mL}$ collection tube, and discard the collection tube containing the filtrate.

10. Carefully open the QIAamp Mini column, and add $750 \mu \mathrm{L}$ Buffer ACW2 without wetting the rim. Close the cap and centrifuge at $6000 \times g(8000 \mathrm{rpm})$ for $1 \mathrm{~min}$. Place the QIAamp Mini column in a clean $2 \mathrm{~mL}$ collection tube, and discard the collection tube containing the filtrate.

11. Carefully open the QIAamp Mini column, and add $750 \mu \mathrm{L}$ ethanol (96-100\%) without wetting the rim. Close the cap and centrifuge at $6000 \times g(8000 \mathrm{rpm})$ for $1 \mathrm{~min}$. Discard the collection tube containing the filtrate.

12. Close the lid of the QIAamp Mini column. Place the QIAamp Mini column in a clean $2 \mathrm{~mL}$ collection tube. Close the cap and centrifuge at full speed (20000 x g; $14000 \mathrm{rpm})$ for 3 $\min$.

13. Place the QIAamp Mini column into a new $2 \mathrm{~mL}$ collection tube. Open the lid, and incubate the assembly at $56^{\circ} \mathrm{C}$ for $10 \mathrm{~min}$ to dry the membrane completely.

14. Place the QIAamp Mini column in a clean $1.5 \mathrm{~mL}$ elution tube and discard the $2 \mathrm{~mL}$ collection tube from step 13. Carefully apply $55 \mu \mathrm{L}$ of Buffer AVE to the center of the QIAamp Mini membrane. Close the lid and incubate at room temperature for $30 \mathrm{~min}$ before proceeding to the next step (improves yield).

15. Centrifuge in a microcentrifuge at full speed (20000 x g; $14000 \mathrm{rpm})$ for $1 \mathrm{~min}$ to elute the nucleic acids.

16. Storage of the vials: use immediately or store at $-80^{\circ} \mathrm{C}$. 

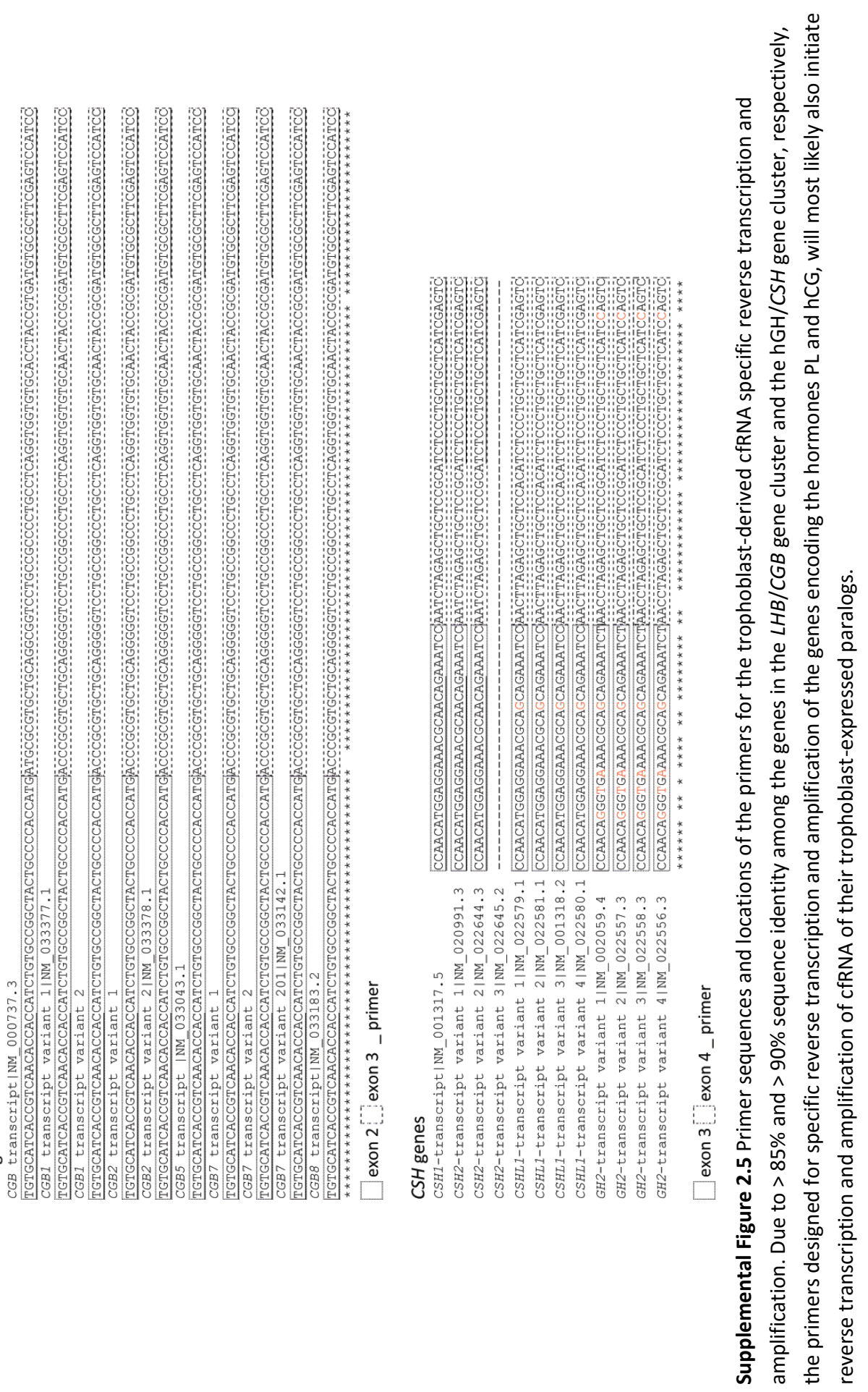
AMELY AGCCACCTCTGCCTCCAATGTTCCCCCTGCGGCCCCTGCCCCCCATACTTCCTGATCTGCATCTGGAAGCTTGGCCAGCAA

AMELX AGCCACCTCTGCCTCCGATGTTCCCCATGCAGCCCCTGCCTCCCATGCTTCCTGATCTGACTCTGGAAGCTTGGCCATCAA

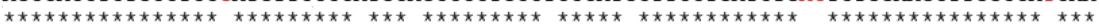

Supplemental Figure 2.6 Primer sequences and locations of the primers for AMELY cffDNA amplification. The primers were designed to overlap with mismatches compared with the homologous gene on the X-chromosome: AMELX. The forward and reverse primer are underlined.

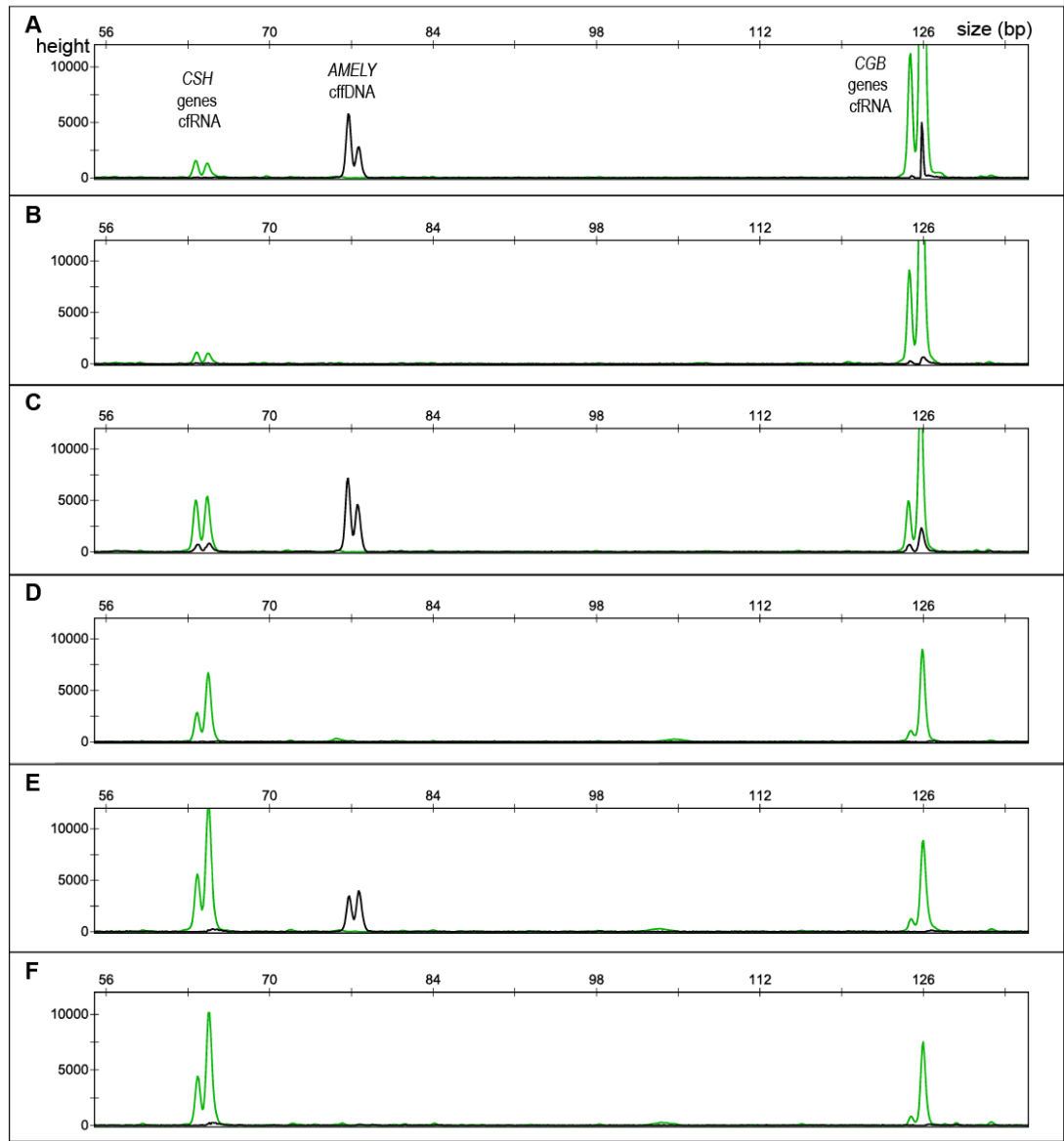

Supplemental Figure 2.7 Electropherograms showing the fetoplacental marker throughout pregnancy. GeneMapper electropherograms showing the amplified fluorescent-labelled (NED or VIC) products of the multiplex one-step RT-PCR in plasma samples of a pregnant woman carrying A) a male fetus at $9+4$ weeks of gestation; B) a female fetus at $11+0$ weeks of gestation; C) a male fetus at $15+2$ weeks of gestation; D) a female fetus at $16+3$ weeks of gestation; E) a male fetus at $20+5$ weeks of gestation; F) a female fetus at $21+0$ weeks of gestation. 


\section{Chapter 3}

\section{Noninvasive prenatal diagnosis of myotonic dystrophy type 1}

Elke Mersy, Aimee D.C. Paulussen, Nienke Muntjewerff, Leonie M.H. Houben, Sabine Spierts, Michael Kwint, Maartje van de Vorst, Brigitte H.W. Faas, Joris A. Veltman, Christine E.M. de Die-Smulders, and Alexander Hoischen

In preparation 


\subsection{Abstract}

Background: Myotonic dystrophy 1 (DM1) is an autosomal dominant disorder, caused by an unstable CTG trinucleotide repeat, ranging from 50 to $>1000$ repeats. In patients with DM1 skeletal and smooth muscle are affected, as well as the eye, heart, endocrine and central nervous systems. DM1 is a frequent indication for prenatal diagnosis. Noninvasive prenatal diagnosis (NIPD) aims to detect the disorder in the fetal cell-free DNA (cfDNA) in maternal plasma, thereby avoiding the miscarriage risk associated with an invasive procedure. We present proof of concept of an haplotype-based NIPD assay to detect DM1 in the fetus.

Methods: Single molecule molecular inversion probes (smMIPs) were designed and optimized for targeted next-generation sequencing of common SNP markers flanking the causative DMPK CTG repeat expansion. Plasma from a pregnant woman with a DM1 affected partner was collected. After sequencing the SNP markers from the parents and a previous child with DM1 (= reference), informative SNPs for the mutated allele of the father and reference were selected. Subsequently, the plasma cfDNA was sequenced to determine the fetal inheritance, calculated from the percentage of the informative SNPs in the cfDNA reads.

Results: Twelve SNPs were informative. The paternal-specific allele was identified in on average $4 \%$ of the cfDNA reads (range 1.5-9.9\%), corresponding to a fetal fraction of $8 \%$. Ten SNPs unequivocally reported presence of the mutated paternal allele in het cfDNA. Furthermore there was no single marker reporting presence of the wild-type paternal allele. Fetal gDNA analysis from the invasive procedure (chorionic villus sampling) confirmed all findings.

Conclusion: This assay has the potential to deliver a fast and reliable assay for NIPD of single-gene disorders caused by trinucleotide repeat expansion mutations through haplotyping of fetal alleles in fractionated, low input cfDNA. 


\subsection{Introduction}

Myotonic dystrophy 1 (DM1), also known as Steinert's disease, is an autosomal dominant genetic disorder that affects skeletal and smooth muscle, the eye, heart, endocrine and central nervous systems. ${ }^{1,2}$ It is caused by expansion of a CTG trinucleotide repeat in the non-coding intron 1 of the dystrophia myotonica protein kinase gene $(D M P K){ }^{3,4}$ There is a broad spectrum of clinical severity, ranging from mild to severe. Five clinical phenotypes of DM1 were described that generally correlate with CTG repeat size, including premutation (38-49 CTG repeats), mild adult DM1 (50100 CTG repeats), classical adult DM1 (50-1000 CTG repeats), childhood-onset DM1 (> 800 CTG repeats) and congenital DM1 (> 1000 CTG repeats). ${ }^{1}$ The classical adult DM1 is characterized by progressive muscle weakness and wasting, myotonia, and cataract, and often cardiac conduction abnormalities. ${ }^{5}$ In congenital DM1 hypotonia and severe generalized weakness at birth is seen, often with respiratory insufficiency and early death. ${ }^{5}$ DM1 is characterized by anticipation: in successive generations, affected family members are at risk for further expansion of the CTG repeat, resulting in decreasing age of onset and increasing severity. ${ }^{1}$

Prenatal diagnosis of DM1 is offered for pregnancies at increased risk, when the diagnosis of DM1 has been confirmed by molecular genetic testing in an affected family member. ${ }^{5}$ Traditionally, an invasive procedure is performed to provide fetal cells for genetic testing, either chorionic villus sampling (CVS) between 11 and 14 weeks of gestation or amniocentesis after 15 weeks of gestation. The additional risk of miscarriage in women undergoing amniocentesis or CVS is estimated between 0.11$1.00 \%$ and $0.22-2.00 \%$, respectively.$^{6-8}$ To avert the additional miscarriage risk of the invasive procedures, safe noninvasive prenatal tests using fetal cell-free DNA (cfDNA) in maternal plasma are now offered to pregnant women. Highly reliable and already implemented in clinical practice are noninvasive fetal sex determination, genotyping of fetal blood group antigens and fetal aneuploidy detection. ${ }^{9-12}$ Recently, the first efforts have been made to expand non-invasive prenatal cfDNA testing to single-gene disorders. ${ }^{13}$

Noninvasive prenatal diagnosis (NIPD) of DM1 in fetal cfDNA is challenging from several perspectives. A first challenge is the CTG repeat size. The affected parent can easily have a CTG expansion of more than $500 \mathrm{bp}$, and the fetus can have an even higher repeat size due to the instability of the repeat. Cell-free DNA exists of short, fractionated, DNA sequences that vary in size, but are mostly shorter than 200 bp. ${ }^{14,15}$ A second challenge is that most of cfDNA fragments in the maternal blood circulation 
are of maternal origin. The fetal cfDNA represents on average a fraction of $6-10 \%$ of the total cfDNA in first and second trimester pregnancies. ${ }^{16,17}$ This so-called fetal fraction rises up to $10-20 \%$ in third trimester pregnancies. ${ }^{16,17}$ Evidently, the maternally inherited fetal $D M P K$ allele, represented in the fetal cfDNA, is identical to half of the $D M P K$ alleles in the abundantly present maternal cfDNA fragments. The paternally inherited fetal DMPK allele is only present in half of the fetal fraction of the cfDNA. A third challenge is the low level of cfDNA in maternal plasma. Often cited is an expected amount of total (maternal and fetal) cfDNA of 1000 genome equivalents $/ \mathrm{mL}$ in a human blood sample. ${ }^{18,19}$ However, the level of the total cfDNA and the fraction of fetal cfDNA vary between individuals, depending on maternal health factors, such as obesity or diabetes, the condition of the placenta and the gestational age. ${ }^{20,21}$ Additionally, quantification of the total cfDNA and of the fetal fraction is influenced by pre-analytical and analytical factors, including storage conditions, delay before plasma separation, blood-processing protocols, DNA extraction method, amplicon size, target gene choice, and used method. ${ }^{19,20}$ Concentrations in maternal plasma as low as 220 genome equivalents $/ \mathrm{mL}$ and 20 genome equivalents $/ \mathrm{mL}$ have been described for total (maternal and fetal) cfDNA and fetal cfDNA, respectively. ${ }^{16,20}$ Due to an already known predisposition, prenatal diagnosis of DM1 is mostly requested early in pregnancy, when the fetal fraction is at its lowest.

For NIPD of DM1, we have developed a method to detect the inherited DMPK alleles in the cfDNA, using an haplotype-based approach. Fetal haplotype inference using single nucleotide polymorphisms (SNPS) for NIPD of single-gene disorders has been suggested by others. ${ }^{22,23}$ In our assay, we use single molecule molecular inversions probes (smMIPs) for targeted multiplex next-generation sequencing of CTG repeat flanking common SNPs. ${ }^{24}$ MIPs can easily be adapted to target genomic regions of interest, and allow parallel capture across many targets. Adding single molecule tagging to the MIPs allows to mark sequence reads derived from a common progenitor molecule (that is, the same genomic equivalent in source DNA), resulting in counting of unique captured molecules, and tag-based consensus calling to minimize errors from PCR or sequencing. This enables precise quantification of the variation in the cfDNA. Furthermore, the method has proven to be robust to relatively small amounts and poor quality of source DNA. ${ }^{24}$ As a result, smMIPs are not only suitable to detect heterozygous and homozygous variation at the SNP loci in the gDNA from the parents, but are in theory also highly sensitive for the detection of low frequency variation in the fetal cfDNA. As a proof of concept, we applied our smMIP NIPD assay to the cfDNA 
isolated from the plasma of a woman carrying a fetus affected with DM1. We demonstrate that we can detect the mutated DMPK allele, inherited from the father, in the fetal cfDNA.

\subsection{Materials and methods}

\subsubsection{Patient recruitment}

The study was approved by the Ethics Committee of the Maastricht University Medical Center (MUMC+). A pregnant woman (I:2) undergoing CVS for prenatal diagnosis of DM1 was asked to participate, together with her partner. The pedigree of the family is illustrated in Figure 3.1. The father of the fetus $(I: 1)$ is affected and has a CTG repeat size between 77-86 repeats. The couple has an older son that was postnatally diagnosed with DM1 and has a CTG repeat size of approximately 350 repeats (II:1), and two healthy children (II:2 and II:3). The pregnant woman donated $6 \times 6 \mathrm{~mL}$ EDTA blood at 10 weeks +1 day of gestation, before the CVS, for cfDNA and gDNA isolation. Her partner donated $2 \times 6 \mathrm{~mL}$ EDTA blood for gDNA isolation. Furthermore, gDNA was collected from the previous son with DM1 (II:1), to use as a reference during SNP genotyping. Analysis of the fetal cells from the chorionic villi revealed that the fetus (II:4) was affected and carried a CTG repeat that had an very high size.

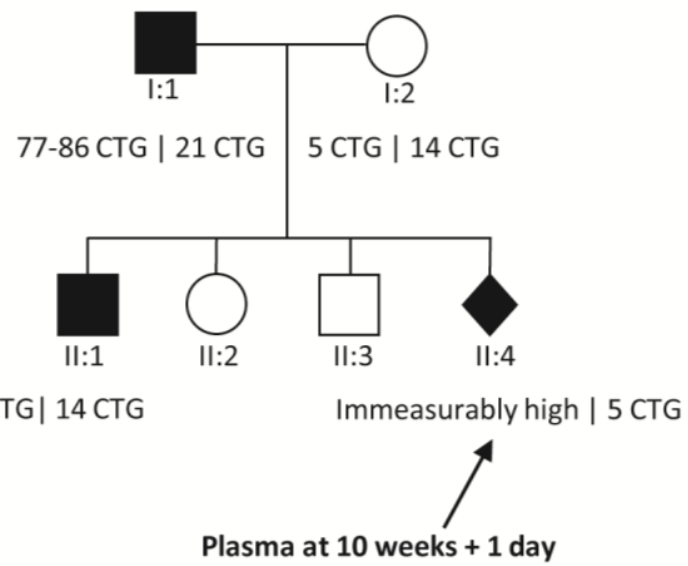

Figure 3.1 Pedigree of the included subjects. Plasma was collected at 10 weeks +1 day of gestation of a pregnant woman (I:2) carrying a fetus affected with myotonic dystrophy type 1 (DM1), as diagnosed by invasive prenatal testing (II:4). SNP genotyping was conducted in a trio of the pregnant woman, her partner with DM1 (I:1) and a previous affected son (II:1). 


\subsubsection{Sample processing and DNA extraction}

Processing of the blood samples for cfDNA isolation occurred within $1 \mathrm{~h}$ after blood drawing. The blood samples were centrifuged at $1600 \times \mathrm{g}$ for $10 \mathrm{~min}$ at $4{ }^{\circ} \mathrm{C}$. The plasma was transferred into plain polypropylene tubes, and re-centrifuged at $7470 \times \mathrm{g}$ for 10 $\min$ at $4{ }^{\circ} \mathrm{C}$. Cryo vials containing the supernatant were stored at $-80{ }^{\circ} \mathrm{C}$ until cfDNA extraction.

Extraction of cfDNA was performed out of $6 \mathrm{~mL}$ plasma from the pregnant woman, using the QIAamp Circulating Nucleic Acid Kit (Qiagen). Elution was performed in $25 \mu \mathrm{L}$ of $\mathrm{AE}$ buffer, included in the kit (consisting of $10 \mathrm{mM}$ Tris-Cl and $0.5 \mathrm{mM}$ EDTA). The cell-free nucleic acids were stored at $-80^{\circ} \mathrm{C}$ before use. Extraction of gDNA from the parents, the affected child and invasive prenatal procedure was performed from whole blood and chorionic villous sample cells, following standard procedures.

\subsubsection{Design of smMIPs and rebalancing}

SmMIPs are single stranded oligonucleotides consisting of a common linker sequence flanked by annealing arms which complement genomic sequences next to the target sequence. SmMIPs bind to one strand of the target DNA (sense or antisense strand). ${ }^{24}$ Ninety-eight smMIPs were designed to contain common CTG repeat flanking SNPS markers (minor allele frequency 5-49\%) in the targeted sequence. The principle is shown in Figure 3.2. All smMIPs were designed with the open-source software MIPGEN (Version 0.9.1), as previously described. ${ }^{25,26}$ In total, sixty SNPs were targeted, thirty up to $500 \mathrm{kbp}$ upstream of the CTG repeat, and thirty up to $500 \mathrm{kbp}$ downstream of the CTG repeat. For forty-eight SNP loci two independent smMIPs were designed, one for each DNA strand. One SNP was targeted by three smMIPs, one binding to the sense strand, and two binding to the antisense strand. The remaining eleven SNP loci were single tiled, either by a smMIP for the sense strand or a smMIP for the antisense strand. To be eligible for cfDNA, the predicted gap fill between the annealing arms was set to a fixed length of $80 \mathrm{nt}$, and the sum of the annealing arms was set to $40 \mathrm{nt}$. Theoretically, the smMIPs could bind to sequences of $120 \mathrm{nt}$ and larger, and analysis of the majority of the cfDNA reads present in the maternal plasma was predicted. Two times five degenerate bases at either end of the common linker sequence were used as unique tag, marking sequence reads derived from a common smMIP capture. This enables duplicate removal and consensus calling. Two times five $\mathrm{N}$ allows for a maximum theoretical non-duplicate coverage of $4^{10}$ (= 1048576$)$. 
In an initial experiment all individual smMIP probes were pooled at identical concentrations ( $1 \times$ pool), phosphorylated and used to capture and sequence four control gDNAs. ${ }^{27}$ After coverage calculations of the control gDNAs, the following rebalancing of the probe ratios was performed: the lowest performing probes $(n=7)$ were rebalanced with a $10 x$ excess, other poor performing probes $(n=31)$ were rebalanced with a $5 x$ excess. The final MIP pool was phosphorylated. In addition over performing smMIPs $(n=3)$ were counter-acted by adding native, unphosphorylated probes. The rebalanced smMIP assay was applied to the included family.

Targeted sequencing using single molecule molecular inversion probes (smMIPs)

1. 98 smMIPs with random tag $2 \times 5 \mathrm{Ns}=4^{10}$ molecular counts per smMIPs, designed to target 60 DMPK repeat flanking SNPs

2. Hybridization to a single strand of gDNA + gap fill + ligation

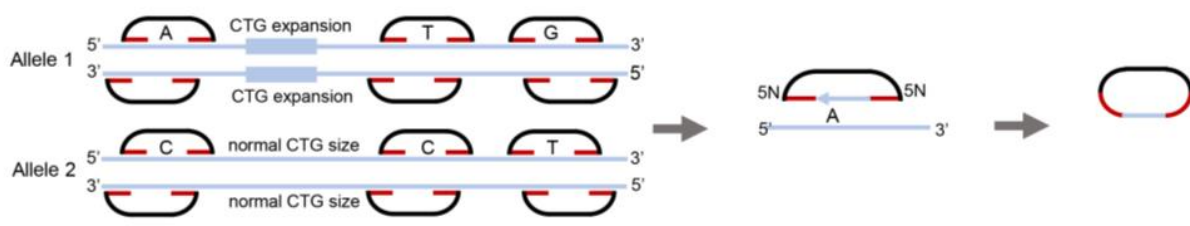

3. Amplification + adding of adaptors and barcode per patient

4. Sequencing and allele counting: consensus read per barcode and per random tag DMPK

$\begin{array}{lllll}- & \text { A } & & & - \\ - & \text { A } & \text { T } & & - \\ - & \text { A } & & \text { C } & - \\ - & \text { A } & & & - \\ - & \text { A } & & & - \\ - & \text { A } & & & -\end{array}$

Figure 3.2 Single molecule molecular inversion probes (smMIPs) for multiplex targeted nextgeneration sequencing of CTG repeat flanking SNPs.

\subsubsection{Multiplex capture and amplification of targeted sequences}

SmMIP-based target enrichment of the gDNA derived from the parents, the previous child with DM1 and the chorionic villi of the fetus, was performed as described previously. ${ }^{24,27-29}$ The probes were added to $100 \mathrm{ng}$ of gDNA in a ratio of 800 copies of each smMIP to each haploid genome copy. Hybridization of smMIPs to gDNA or cfDNA, gap filling and ligation were performed in a $25 \mu \mathrm{L}$ reaction, containing of 10x Ampligase buffer (Illumina), 0.25 mM dNTPs (Life technologies), 3 units of Hemo KlenTaq (NEB), 1 unit of Ampligase DNA ligase (Westburg), and the calculated number of smMIPs. Reactions were incubated at $95{ }^{\circ} \mathrm{C}$ for $10 \mathrm{~min}$, followed by capture at $60{ }^{\circ} \mathrm{C}$ for $24 \mathrm{~h}$. Remaining linear gDNA, and unhybridized probes were removed by adding $2 \mu \mathrm{L}$ of 
exonuclease mix (containing 10 units of exonuclease I (NEB) and 50 units of exonuclease III (NEB) in $10 \times$ Ampligase buffer), and incubation of the reaction at $37^{\circ} \mathrm{C}$ for $45 \mathrm{~min}$ and then at $95{ }^{\circ} \mathrm{C}$ for $2 \mathrm{~min}$. Amplification of the exonuclease-treated circularized probes was done by standard polymerase chain reaction (PCR) in a $25 \mu \mathrm{L}$ reaction, containing 2 x iProof HF Master Mix (Bio-Rad), $100 \mu \mathrm{M}$ of common forward primer (Illumina), $10 \mu \mathrm{M}$ of barcode-containing reverse primer (Illumina) and $5 \mu \mathrm{L}$ of exotreated product. The reaction was initiated at $98^{\circ} \mathrm{C}$ for $30 \mathrm{~s}$, followed by 22 cycles of $98{ }^{\circ} \mathrm{C}$ for $10 \mathrm{~s}, 60{ }^{\circ} \mathrm{C}$ for $30 \mathrm{~s}$, and $72{ }^{\circ} \mathrm{C}$ for $30 \mathrm{~s}$, and ended at $72{ }^{\circ} \mathrm{C}$ for $2 \mathrm{~min}$. The optimal amount of PCR cycles was previously determined by real-time quantitative PCR (qPCR). PCR products were pooled and the desired products were purified from self-ligated SmMIP probes and residual PCR primers or primer dimers with 0.7-1 $\mathrm{x}$ AMPure XP beads (Beckman Coulter) according to the manufacturer's protocol. Pools were quantified using the Qubit dsDNA HS Assay. Illumina NextSeq sequencing was performed according to manufacturer's instructions, with additional spike in of MIP custom primers (MIP_fwd, MIP_rev and MIP_index) into Illumina primer wells, as described previously. ${ }^{27-29}$

Subsequently, the smMIPs were applied to the cfDNA from the plasma sample, with minor modifications to the protocol. The same amount of probes were added to the cfDNA sample; ensuring high capture rates of sparse cfDNA molecules. We used all cfDNA extracted from $6 \mathrm{~mL}$ of plasma. The concentration after cfDNA isolation (1.97 $n g / \mu L$ ) was measured by Qubit dsDNA HS Assay (Life Technologies). However, measurements of cfDNA on Qubit are not always trustworthy. Additionally, no difference between maternal and fetal cfDNA can be made. We estimate that we extracted at least 160 fetal genome equivalents from $6 \mathrm{~mL}$ plasma. ${ }^{16,20}$ We divided the entire volume of the exonuclease-treated SmMIP-captured product over two PCR tubes ( $2 \times 25 \mu \mathrm{L}$ reactions). PCR-amplification was done by qPCR in two separate reactions using two independent barcodes, in order to increase the amount of unique molecules to count after sequencing and to limit PCR-based artifacts. The same PCR program was used as for gDNA samples, but the qPCR was stopped in the linear phase of amplification ( 24 cycles). The cfDNA-derived NGS-library was prepared separately and sequenced in an independent sequencing run to avoid contamination or barcode bleed-through of high coverage gDNA samples. 


\subsection{5 smMIP sequencing analysis}

The SNP loci were analyzed using the MIP-based VARiant calling tool MIPVAR, a fully automated MIP Analysis Tool for large-scale MIP experiments. ${ }^{30}$ MIPVAR provides variant calling combined with detailed coverage information per MIP. It excludes reads of low quality. Additionally, when the adding of molecular barcodes to the MIPS (smMIPs) is specified in the pipeline configuration, reads for the same sample, aligning to the same position and with the same molecular barcode are removed. In this way all resulting reads will be guaranteed to originate from unique DNA fragments allowing for a more reliable identification of variants. All variants were called using the human reference genome hg19. The informative SNPs were selected according to the procedure explained in 3.3.6.

All low frequency variant calling results in the cfDNA by MIPVAR were confirmed using the Integrative Genomics Viewer (IGV) software and the SeqNext software package (version 4.2.2; JSI medical systems $\mathrm{GmbH}$ ), using the optional smMIP analysis module. ${ }^{31,32}$ In IGV, the same fastq-files are analyzed as in the MIPVAR tool. In SeqNext, reads with undefined nucleotides in their barcodes or of low quality are ignored. To generate consensus reads, all bases should be covered at least once in the consensus reads, at least two tagged reads are required to create a consensus read. Consequently, this is the most rigorous method. All informative SNP positions were manually inspected in these two software package, and the amount of unique molecules covering each key-SNP position were counted for each nucleotide. The error rate for every type of substitution at all SNP loci from the three gDNA samples was used as "noise" for the interpretation of the cfDNA substitutions. In case of informative SNPs, only the mother, who is homozygous for those loci, could be used for the error rate.

\subsubsection{Parental SNP genotyping and deducing of the fetal inheritance}

The procedure for SNP genotyping of the parents and the child with DM1, and subsequently the deduction of the fetal inheritance is illustrated in Figure 3.3. 

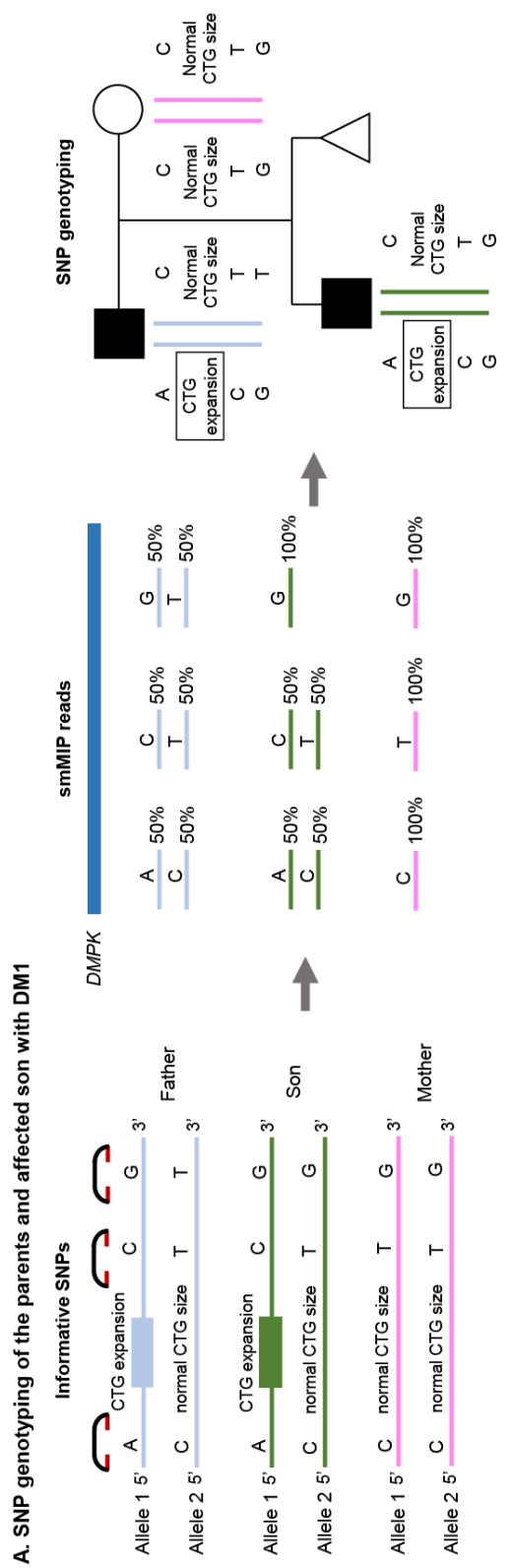

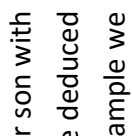

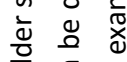

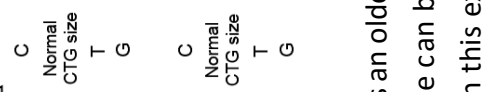

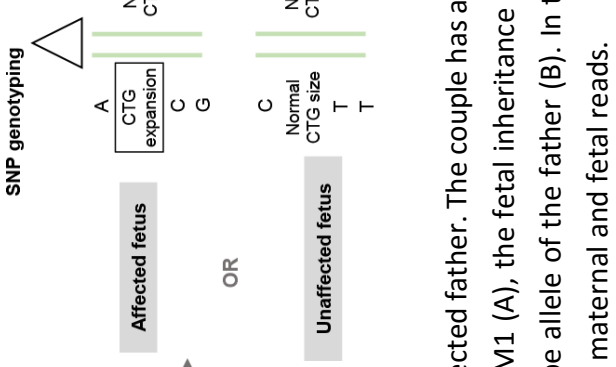

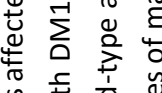

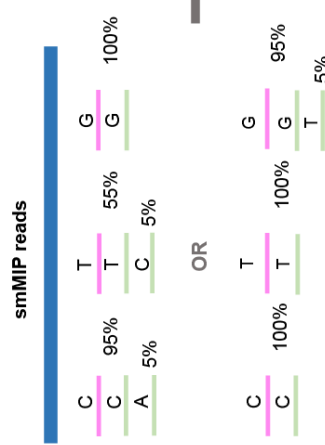
$\sum_{\substack{1 \\ 0}}^{\frac{1}{2}}$
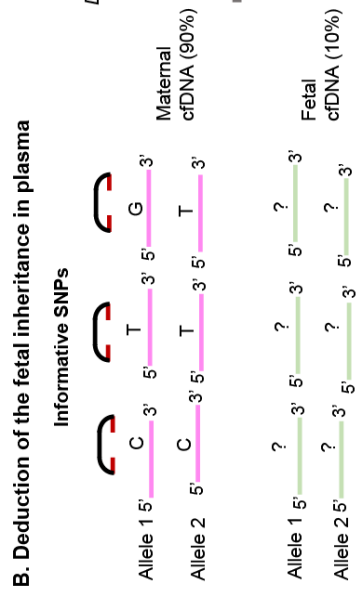

$\stackrel{0}{\stackrel{0}{n}}$

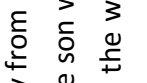
ते 竞 范 ํ.

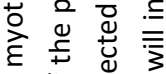
D. : 兵

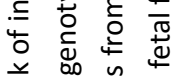
紊然 눠 는

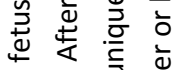
인 ते d

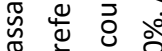
व 0 엄 尖 잉 응 으

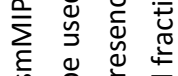
ติ ป ญ 点

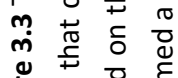
咅 
First, the SNP loci that can be used for the calculation of the fetal fraction are selected. These are the SNP loci where one parent is homozygous for the wild-type allele, and the other parent is homozygous for the allele with the substitution. The fetal fraction is two times the percentage of substitution in the cfDNA sequencing reads if the mother is homozygous for the wild-type allele, and two times the percentage of the wild-type nucleotide if the mother is homozygous for the allele with the substitution. These SNPs are not informative for the disease status of the parents or the fetus, and can only be used to determine the fetal fraction. Furthermore, the SNP loci where the mother is homozygous for the wild-type allele or homozygous for the allele with the substitution, and where the father is heterozygous, can be used for the calculation of the fetal fraction, if the fetus inherited the other type of allele (wild-type or with substitution) from the father than the allele for which the mother is homozygous (Figure 3.4). Some of these SNPs may also be useful for the disease status of the fetus.

\begin{tabular}{|c|c|c|c|}
\hline & Father heterozygous A/B & Father homozygous B/B & Father homozygous A/A \\
\hline \multirow{2}{*}{ Mother homozygous B/B } & $\begin{array}{l}\text { Plasma cfDNA A/B } \\
\text { Fetal fraction: A reads } \times 2\end{array}$ & \multirow{2}{*}{$\begin{array}{l}\text { Plasma cfDNA B/B } \\
\text { Fetal fraction: cannot be } \\
\text { determined }\end{array}$} & \multirow{2}{*}{$\begin{array}{l}\text { Plasma cfDNA A/B } \\
\text { Fetal fraction: A reads } \times 2\end{array}$} \\
\hline & $\begin{array}{l}\text { Plasma cfDNA B/B } \\
\text { Fetal fraction: cannot be } \\
\text { determined }\end{array}$ & & \\
\hline \multirow{2}{*}{ Mother homozygous A/A } & $\begin{array}{l}\text { Plasma cfDNA A/B } \\
\text { Fetal fraction: B reads } \times 2\end{array}$ & \multirow{2}{*}{$\begin{array}{l}\text { Plasma cfDNA A/B } \\
\text { Fetal fraction: B reads } \times 2\end{array}$} & \multirow{2}{*}{$\begin{array}{l}\text { Plasma cfDNA A/A } \\
\text { Fetal fraction: cannot be } \\
\text { determined }\end{array}$} \\
\hline & $\begin{array}{l}\text { Plasma cfDNA A/A } \\
\text { Fetal fraction: cannot be } \\
\text { determined }\end{array}$ & & \\
\hline
\end{tabular}

Figure 3.4 Deduction of the fetal fraction

Second, informative SNPs defining the mutated DMPK allele from the affected parent are identified. Only SNP loci where the father is heterozygous and where the mother is homozygous for the wild-type allele or for the allele with the substitution, are informative for the disease status of the affected father. The affected child can be heterozygous, homozygous for the wild-type allele or homozygous for the allele with the substitution. The deduction of the fetal inheritance is illustrated in Figures 3.3B and 3.5. For all informative SNPs, the genetic status of the fetus is determined by calculating the percentage of the substitution in the cfDNA sequencing reads. This percentage is than combined with the known genotype of the mother and the affected child to deduct the fetal inheritance. 


\begin{tabular}{|l|l|l|l|l|l|l|}
\hline \multicolumn{3}{|l}{ Plasma } & & & Interpretation \\
\hline Father heterozygous A/B & $\begin{array}{l}\% \text { fetal B } \\
\text { in plasma }\end{array}$ & $\begin{array}{l}\% \text { maternal B } \\
\text { in plasma }\end{array}$ & $\begin{array}{l}\text { Total \% B } \\
\text { in plasma }\end{array}$ & Fetal SNP genotype & Reference: B/B & Reference: A/B \\
\hline Mother homozygous B/B & $10 \%$ & $90 \%$ & $100 \%$ & Fetus homozygous B/B & Fetus affected & Fetus not affected \\
\hline Mother homozygous A/A & $5 \%$ & $90 \%$ & $95 \%$ & Fetus heterozygous A/B & Fetus not affected & Fetus affected \\
\hline & $0 \%$ & $0 \%$ & $5 \%$ & Fetus heterozygous A/B & Fetus affected & Fetus not affected \\
\hline
\end{tabular}

Figure 3.5 Inferring of the fetal inheritance in case of a father affected with DM1, assuming $10 \%$ fetal fraction.

\subsection{Results}

We applied our smMIP NIPD assay to the cfDNA isolated from the plasma of a pregnant woman with a DM1 affected partner. After sequencing the SNP markers from the parents and a previous child with DM1 (= reference), informative SNPs for the mutated $D M P K$ allele of the father and reference were selected. Subsequently, the plasma cfDNA was sequenced to determine the fetal inherited haplotypes, calculated from the percentages of the informative SNPs in the cfDNA sequencing reads. The determined haplotypes indicated that the fetus was affected with DM1. This result was confirmed with diagnostic DM1 testing of gDNA from the invasively obtained fetal cells (chorionic villi). Finally, the smMIP NIPD assay was also applied to the fetal DNA from the chorionic villi, to validate the SNP genotyping results from cfDNA.

\subsubsection{Coverage}

In the gDNA samples from the parents, the affected son, and the chorionic villi an adequate unique read coverage was obtained for 59 out of 60 SNP loci (98\%). In one SNP locus, the sum of the unique reads of the sense-binding and antisense-binding smMIP was below $30 \mathrm{x}$. This SNP was excluded from SNP genotyping. In the cfDNA sample from the pregnant woman the coverage was on average 5-20 times higher for each smMIP locus in comparison to the gDNA samples (Table 3.1). This was because less samples were pooled, in order to obtain a maximum number of unique reads per SNP locus. 
Table 3.1 Coverage of the SNPs in all samples

\begin{tabular}{llllll}
\hline & $\begin{array}{l}\text { Affected child } \\
\text { gDNA }\end{array}$ & $\begin{array}{l}\text { Father } \\
\text { gDNA }\end{array}$ & $\begin{array}{l}\text { Pregnant woman } \\
\text { gDNA }\end{array}$ & $\begin{array}{l}\text { Plasma } \\
\text { cfDNA }\end{array}$ & $\begin{array}{l}\text { CVS } \\
\text { gDNA }\end{array}$ \\
\hline Minimum & 29 & 28 & 59 & 499 & 18 \\
Maximum & 2723 & 2213 & 3290 & 20994 & 2675 \\
Mean & 458 & 382 & 625 & 5672 & 440 \\
Median & 174 & 264 & 463 & 4782 & 250 \\
\hline
\end{tabular}

\subsubsection{SNP genotyping of the parents and the affected previous child}

For the 59 adequately covered SNPs the percentages of variant was determined in the gDNA reads from the parents and the previous child with DM1 by the MIPVAR tool through counting of the number of unique reads for each individual tag. Noise variants in the raw reads from one tag, occurring from PCR mistakes or sequencing mistakes were filtered out, and only variants occurring in all raw reads from one tag were saved in the unique tag. The MIPVAR tool reported a homozygous or heterozygous substitution at 34 out of 59 SNP loci (58\%) in at least one of the subjects. In 24 SNP loci out of the remaining 25 targeted loci (41\%) both parents, and evidently their child, carried the wild-type nucleotide in both alleles. One SNP could not be evaluated because the genomic region containing the SNP was deleted in the three subjects. Out of the 34 SNPs present in the subjects, six SNP loci, all targeted by the one smMIP pair, were excluded from further analysis. High background noise of all four nucleotides in all patients suggested low quality of data at these loci. Consequently, 28 SNPs were available for SNP genotyping of the parents (Table 3.2). Five SNPs upstream of the CTG repeat and seven SNPs downstream of the repeat were informative for the disease status of the father, and the reference (affected child), i.e. SNP loci where the father is heterozygous and where the mother is homozygous for the wild-type allele or homozygous for the allele with the substitution.

\subsubsection{Targeted sequencing of the cfDNA}

For the twelve informative SNPs the percentage of substitution in cfDNA reads was determined by the MIPVAR tool. Figure 3.6 illustrates the detection of a paternally inherited SNP in four percent of the cfDNA reads. The remaining 96 percent of the reads represents the maternal wild-type allele. The percentage of substitution in the cfDNA reads, as determined by the MIPVAR tool, are illustrated and compared with the results from SeqNext in Table 3.3. 


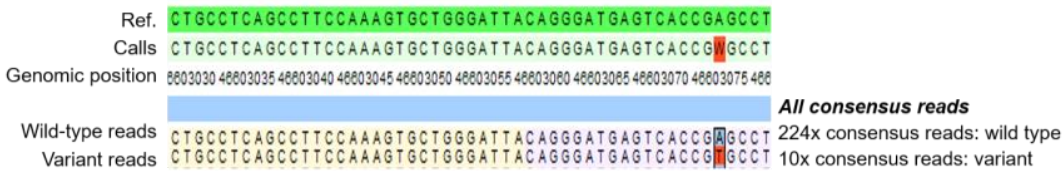

All raw reads for consensus tag 1

All raw reads for consensus tag 2

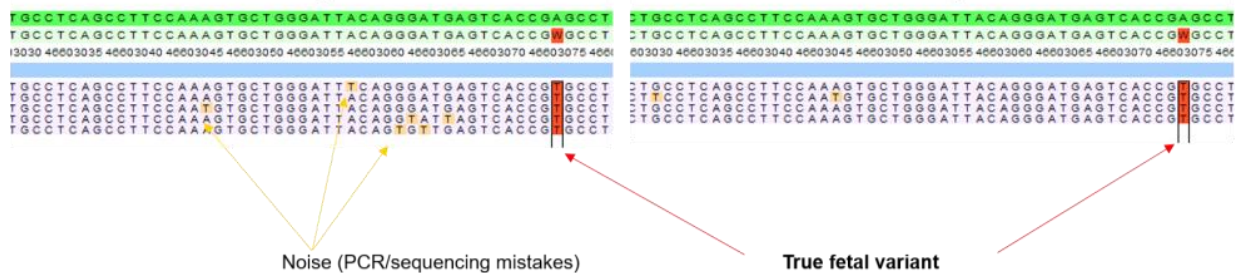

Figure 3.6 Plasma cfDNA smMIP reads for the informative SNP rs12104327 (g.46603075A>T). Two examples of raw reads for a consensus tag are illustrated. For all 234 consensus reads at this position the noise by PCR mistakes and sequencing mistakes was eliminated in the consensus read. For this SNP 224 (96\%) of the consensus reads showed the wild-type nucleotide, while $10(4 \%)$ of the consensus reads showed the variant.

The fetal fraction was determined based on the average of the unique inherited paternal variants. In these loci, the mother was homozygous for the wild-type allele, and the father heterozygous (Table 3.3). The percentage of the substitution in the cfDNA in the background of the maternal wild-type reads was assumed to be half of the fetal fraction (the paternally inherited part of the fetal cfDNA). Depending of the analysis tool (Fastq in IGV or NextSeq), the variants were present in on average $4-4.7 \%$ of the cfDNA reads. The deducted fetal fraction was $8-9.4 \%$. There were no SNP loci that could contribute to the determination of the fetal fraction where one parent was homozygous for the wild-type allele, and the other parent was homozygous for the allele with the substitution. The presence of the mutated paternal DMPK allele in the fetal cfDNA was predicted, based on the percentages of substitution or wild-type nucleotide in the twelve informative SNPs (Figure 3.7). Five of them unequivocally proved the presence of the paternal mutated allele in the plasma, while five showed that the paternal wild-type allele was excluded in the plasma. In the remaining two informative SNPs the percentage of paternal substitution was only seen in $1.5 \%$ (both in IGV and SeqNext), and 1.7/1.2\% (IGV/SeqNext), as illustrated in Table 3.2 and Figure 3.7A), which is only slightly above the expected noise of $0-1 \%$ for that substitution at that SNP locus. Subsequently, the variants in the gDNA from chorionic villus sampling was used to confirm findings in the cfDNA reads. In the chorionic villi, the presence of the affected paternal DMPK allele was inferred in all informative SNP loci (Figure 3.7B). 
Table 3.2 SNP genotyping and selection of the informative SNPs

\begin{tabular}{|c|c|c|c|c|c|c|c|}
\hline & $\begin{array}{l}\text { Info targeted SN } \\
\text { SNP (hg19) }\end{array}$ & rs & MAF & $\begin{array}{l}\text { Genotype } \\
\text { affected } \\
\text { child }\end{array}$ & $\begin{array}{l}\text { Genotype } \\
\text { affected } \\
\text { father }\end{array}$ & $\begin{array}{l}\text { Genotype } \\
\text { pregnant } \\
\text { woman }\end{array}$ & $\begin{array}{l}\text { Informative } \\
\text { for disease } \\
\text { status }\end{array}$ \\
\hline 1 & g.45769749G $>A$ & rs345421 & $A=0.27$ & GA & GA & GG & informative \\
\hline 2 & g. $45809208 \mathrm{~T}>\mathrm{C}$ & rs8111989 & $C=0.34$ & TC & TC & $\mathrm{CC}$ & informative \\
\hline 3 & g. $45887622 T>A$ & rs375938885 & Unknown & TA & TA & TA & \\
\hline 4 & g. $45887624 C>A$ & rs367683031 & Unknown & $\mathrm{CA}$ & $\mathrm{CA}$ & $\mathrm{CA}$ & \\
\hline 5 & g. $45887653 C>A$ & rs73044586 & $C=0.36$ & AA & AA & $\mathrm{AA}$ & \\
\hline 6 & g.45938905G $>\mathrm{T}$ & rs10408989 & $G=0.44$ & GT & GT & GT & \\
\hline 7 & g.45986890A>G & rs7250901 & $A=0.35$ & GG & GG & GG & \\
\hline 8 & g.46059364T>G & rs11673516 & $G=0.32$ & GG & GT & GG & informative \\
\hline 9 & g. $46076381 C>A$ & rs6509224 & $C=0.32$ & CC & CA & CC & informative \\
\hline 10 & g. $46105198 A>G$ & rs10411518 & $A=0.25$ & GG & GG & GG & \\
\hline 11 & g. $46108455 A>G$ & rs35070164 & $G=0.33$ & GG & AG & GG & informative \\
\hline 12 & g.46219145G>C & rs35302007 & $C=0.29$ & GG & GG & $\mathrm{GC}$ & \\
\hline 13 & g.46267534C>T & rs10775546 & $C=0.10$ & CC & CC & CT & \\
\hline 14 & g.46268902C>T & rs2341097 & $\mathrm{T}=0.30$ & CC & CC & CT & \\
\hline 15 & g.46269313G>C & rs2014377 & $G=0.10$ & GG & GG & $\mathrm{GC}$ & \\
\hline \multicolumn{8}{|c|}{ CTG repeat region } \\
\hline 16 & g. $46282890 A>T$ & rs2070737 & $\mathrm{T}=0.29$ & AA & AA & AT & \\
\hline 17 & g. $46363689 \mathrm{G}>\mathrm{C}$ & rs113480080 & $C=0.23$ & CC & CC & CG & \\
\hline 18 & g.46363754G>C & rs79839858 & $C=0.14$ & GG & CG & GG & informative \\
\hline 19 & g.46363756G >T & rs 200360080 & $\mathrm{~T}=0.14$ & GG & GT & GG & informative \\
\hline 20 & g.46459965T>C & rs11083790 & $\mathrm{T}=0.29$ & CC & CC & CC & \\
\hline 21 & g. $46574845 C>G$ & rs10425314 & $C=0.32$ & GG & GG & GG & \\
\hline 22 & g.46590131G>A & rs4802288 & $G=0.43$ & AA & AA & AA & \\
\hline 23 & g.46603075A>T & rs12104327 & $\mathrm{T}=0.22$ & AT & AT & $\mathrm{AA}$ & informative \\
\hline 24 & g.46603081T>G & rs12104199 & $G=0.22$ & TG & TG & TT & informative \\
\hline 25 & g. $46603082 \mathrm{G}>\mathrm{C}$ & rs12104333 & $C=0.22$ & GC & GC & GG & informative \\
\hline 26 & g. $46614077 A>T$ & rs73046152 & $\mathrm{T}=0.21$ & AT & AT & AA & informative \\
\hline 27 & g.46628395G >C & rs4803898 & $G=0.27$ & CC & CC & CC & \\
\hline 28 & g.46730614A>G & rs1008591 & $G=0.43$ & AG & AG & GG & informative \\
\hline
\end{tabular}

Legend to Table 3.2: MAF, minor allele frequency. Twenty-eight SNPs were available for SNP genotyping of the parents. Twelve SNPs were informative for the disease status of the father, and the reference (affected child), i.e. where the father is heterozygous and where the mother is homozygous for the wild-type allele or homozygous for the allele with the substitution. 


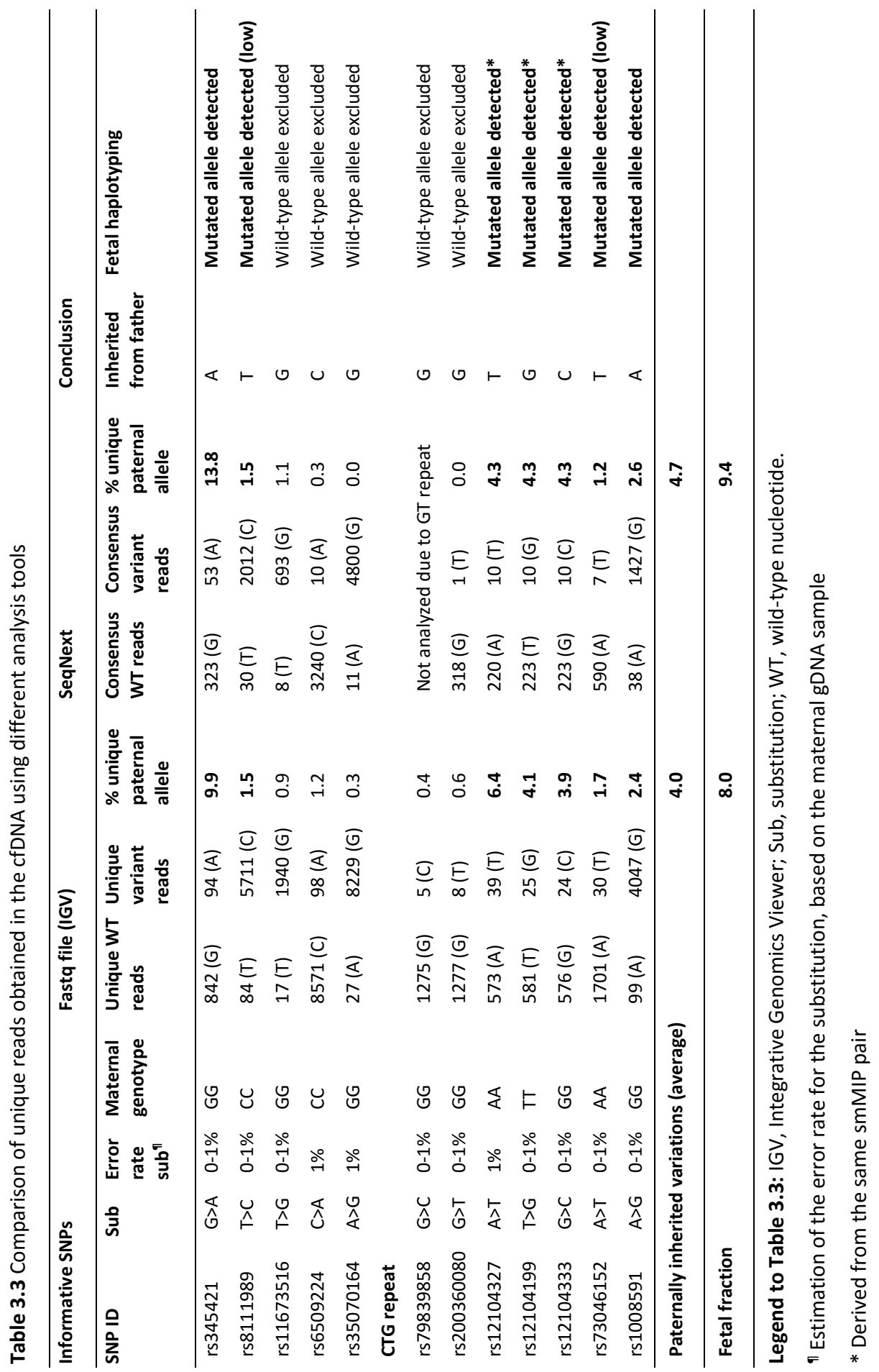




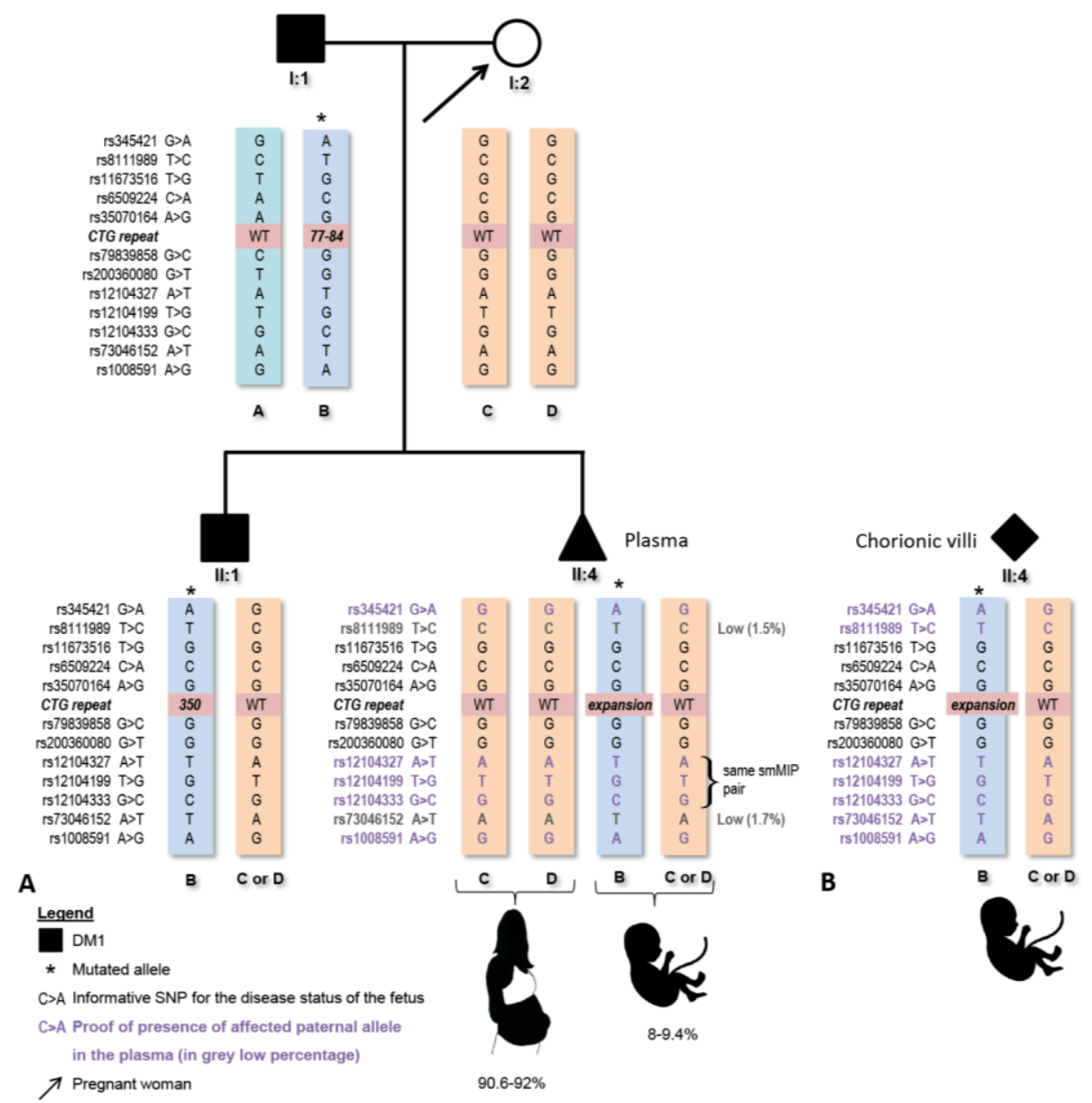

Figure 3.7 A. Pedigree with parental SNP genotypes and deduction of fetal inheritance. Purple bold SNP loci are proof of the presence of the mutated paternal allele in the plasma. Grey bold SNP loci showed the presence of the mutated paternal allele in only a low percentage of the cfDNA reads. The remaining five SNPs show that the paternal wild type allele is not present in the plasma. B. Confirmation of the fetal inheritance in the gDNA from chorionic villi. (Pregnant woman created by Petal Wijnen, fetus created by Anthony Bossard from Noun Project). 


\subsection{Discussion}

In this proof of concept study, we present a novel assay for NIPD of single-gene disorders, demonstrated in a pregnant woman carrying a fetus that inherited DM1 from its affected father. Maternal plasma was obtained before chorionic villus sampling, at 10 weeks of gestation. Our assay is a haplotype-based approach, using smMIPs for targeted next-generation sequencing of common CTG repeat flanking SNPs. Following parental SNP genotyping, and identification of informative SNP loci, the fetal haplotypes are inferred based on the percentages of the substitution and wild-type nucleotide in the cfDNA reads. Our smMIP-based assay was successfully applied to identify the presence of the paternal mutated DMPK allele with the trinucleotide repeat expansion in twelve flanking SNPs in the maternal plasma. We are the first to use smMIPs for NIPD. Molecular inversion probes represent an attractive platform for targeted capture because of their very low per-sample cost, workflow simplicity, target-set modularity and low sample input requirement. ${ }^{24}$ Adding single molecule tagging to the MIPs allows for counting of unique captured molecules, and tag-based consensus calling to minimize error rates, thereby facilitating both highly sensitive variant calling and precise quantitation of mutation frequency. The smMIPs assay is also robust to relatively small amounts and poor quality of source DNA. ${ }^{24}$ As a result, smMIPs are not only suitable to detect heterozygous and homozygous variation at the SNP loci in the gDNA from the parents, but are also highly sensitive for SNPs that are present at a low relative abundance in a cfDNA sample. Furthermore, the assay is compatible with a desktop sequencing instrument for potential rapid return of results in a clinical setting.

The assay was conducted with cfDNA obtained from $6 \mathrm{~mL}$ plasma at 10 weeks of gestation. We estimate that we extracted at least 160 fetal genome equivalents from $6 \mathrm{~mL}$ plasma. ${ }^{16,20} \mathrm{~A}$ maximal amount of plasma for cfDNA extraction is $10 \mathrm{~mL}$. Probably, the assay may benefit from increasing the amount of plasma for cfDNA extraction, which may lead to a higher cfDNA input for the assay. Because of the variable absolute concentration of fetal cfDNA and the fetal fraction in pregnant women, as a result of pre-analytic, analytic and biological factors, cfDNA extraction from $10 \mathrm{~mL}$ is recommended. ${ }^{18-20}$ In the cfDNA from this pregnant woman, the fetal fraction was approximately $8 \%$, which is expected from a sample obtained at 10 weeks of gestation. We have to establish the minimal input cfDNA and minimal fetal fraction for a reliable assay. Targeting of 60 SNPs allowed for deduction of the fetal fraction based on seven SNPs and of the fetal inheritance based on twelve informative flanking SNPs. Of these 
SNPs, three were targeted by the same smMIP pair. Reliability of variant calling depends highly on the coverage of unique molecules. After testing more samples with the assay, a minimal coverage of unique reads can be determined per SNP locus. Now, in this proof of principle study we have excluded one SNP locus, that was not adequately covered in the gDNA samples as well as in the cfDNA sample $<30$ unique reads). In the future, the assay can easily be adapted to obtain information from more SNP loci. SmMIPs offer the advantage to have a modular nature, i.e. additional SNP markers can be added to a subsequent design with relative ease. Also a more uniform performance of individual smMIPs can be reached by additional rebalancing. In two informative SNPs the percentage of paternal substitution from the mutated DMPK allele was only seen in 1.5\% (both in IGV and SeqNext), and 1.7/1.2\% (IGV/SeqNext). In one informative SNP the percentage of the paternal substitution from the wild-type DMPK allele, was present in 1.2/0.3\% (IGV/SeqNext). The error rate for every type of substitution at all SNP loci from the parents and the previous child were used as "noise" for the interpretation of the cfDNA substitutions, because at the moment no other cfDNA samples were available for background noise analysis. In case of informative SNPs, only the mother, who is homozygous for those loci, could be used for the error rate. For further use of the assay, the error for every type of substitution at all SNP loci should be documented for a large sample of cfDNA samples, in order to reliably call a variant in het cfDNA.

Also direct analysis of the mutations will benefit from additional haplotyping. It could be ideal to design smMIPs to target the coding regions as well as common SNPs outside these regions, in order to provide a reliable combined direct and indirect NIPD assay. As a result, this NIPD assay can be used for all autosomal dominant disorders, and paternal as well as maternal mutations may be detected. For the maternal mutations, replication of our assay is required to investigate if the quantification is accurate enough to determine the difference between a mutation that is only present in the maternal cfDNA, and a mutation that is present in the fetal cfDNA as well. In autosomal dominant disorders the reference can be an affected grandparent or previous child. The smMIP NIPD assay can also be used for autosomal recessive disorders, although a previous affected child should always be available to be used as a reference. In that case SNPs that are heterozygous in both parents and homozygous in the affected child, are informative for the deduction of the fetal inheritance, and as a result for the fetal disease status. 


\subsection{Conclusion}

In this proof of concept study, we presented a novel assay for NIPD of single-gene disorders, demonstrated in a pregnant woman carrying a fetus that inherited DM1 from its affected father. Our haplotype-based assay uses smMIPs for targeted nextgeneration re-sequencing of common repeat flanking SNPs. This assay can deliver a fast and reliable assay for noninvasive prenatal diagnosis of single-gene disorders caused by a trinucleotide repeat expansion mutation and by other mutation types. 


\subsection{References}

1. Ho G, Cardamone M, Farrar M. Congenital and childhood myotonic dystrophy: Current aspects of disease and future directions. World J Clin Pediatr 2015;4:66-80.

2. Udd B, Krahe R. The myotonic dystrophies: molecular, clinical, and therapeutic challenges. Lancet Neurol 2012;11:891.

3. Brook JD, McCurrach ME, Harley HG, Buckler AJ, Church D, Aburatani H, Hunter K, Stanton VP, Thirion JP, Hudson T, et al. Molecular basis of myotonic dystrophy: expansion of a trinucleotide (CTG) repeat at the $3^{\prime}$ end of a transcript encoding a protein kinase family member. Cell 1992;69:385.

4. Mahadevan M, Tsilfidis C, Sabourin L, Shutler G, Amemiya C, Jansen G, Neville C, Narang M, Barceló J, O'Hoy K, et al. Myotonic dystrophy mutation: an unstable CTG repeat in the 3' untranslated region of the gene. Science. 1992;255:1253-1255.

5. Bird TD. Myotonic Dystrophy Type 1. 1999 Sep 17 [Updated 2015 Oct 22]. In: Pagon RA, Adam MP, Ardinger HH, et al., editors. GeneReviews ${ }^{\circledR}$ [Internet]. Seattle (WA): University of Washington, Seattle; 1993-2016. Available from: http://www.ncbi.nlm.nih.gov/books/NBK1165/

6. Mujezinovic F, Alfirevic Z. Procedure-related complications of amniocentesis and chorionic villous sampling: a systematic review. Obstet Gynecol 2007;110:687-694.

7. Kozlowski $P$, Knippel A, Stressig R. Individual risk of fetal loss following routine second trimester amniocentesis: a controlled study of 20,460 cases. Ultraschall Med 2008;29:165-172.

8. Akolekar R, Beta J, Picciarelli G, Ogilvie C, D'Antonio F. Procedure-related risk of miscarriage following amniocentesis and chorionic villus sampling: a systematic review and meta-analysis. Ultrasound Obstet Gynecol 2015;45:16-26.

9. Wright CF, Wei Y, Higgins JP, Sagoo GS. Non-invasive prenatal diagnostic test accuracy for fetal sex using cell-free DNA a review and meta-analysis. BMC Res Notes 2012;5:476.

10. Lo YM, Hjelm NM, Fidler C, Sargent IL, Murphy MF, Chamberlain PF, Poon PM, Redman CW, Wainscoat JS. Prenatal diagnosis of fetal RhD status by molecular analysis of maternal plasma. $\mathrm{N}$ Engl J Med 1998;339:1734-1738.

11. Scheffer PG, van der Schoot CE, Page-Christiaens GC, de Haas M. Noninvasive fetal blood group genotyping of rhesus $\mathrm{D}, \mathrm{C}, \mathrm{E}$ and of $\mathrm{K}$ in alloimmunised pregnant women: evaluation of a 7-year clinical experience. BJOG 2011;118:1340-1348.

12. Gil MM, Quezada MS, Revello R, Akolekar R, Nicolaides KH. Analysis of cell-free DNA in maternal blood in screening for fetal aneuploidies: updated meta-analysis. Ultrasound Obstet Gynecol 2015;45:249266.

13. Lench N, Barrett A, Fielding S, McKay F, Hill M, Jenkins L, White H, Chitty LS. The clinical implementation of non-invasive prenatal diagnosis for single-gene disorders: challenges and progress made. Prenat Diagn 2013;33:555-562.

14. Lo YM, Chan KC, Sun H, Chen EZ, Jiang P, Lun FM, Zheng YW, Leung TY, Lau TK, Cantor CR, Chiu RW. Maternal plasma DNA sequencing reveals the genome-wide genetic and mutational profile of the fetus. Sci Transl Med 2010;2:61ra91.

15. Fan HC, Blumenfeld YJ, Chitkara U, Hudgins L, Quake SR. Analysis of the size distributions of fetal and maternal cell-free DNA by paired-end sequencing. Clin Chem 2010;56:1279-1286.

16. Lo YM, Tein MS, Lau TK, Haines CJ, Leung TN, Poon PM, Wainscoat JS, Johnson PJ, Chang AM, Hjelm NM. Quantitative analysis of fetal DNA in maternal plasma and serum: implications for noninvasive prenatal diagnosis. Am J Hum Genet 1998;62:768e75.

17. Lun FM, Chiu RW, Chan KC, Leung TY, Lau TK, Lo YM. Microfluidics digital PCR reveals a higher than expected fraction of fetal DNA in maternal plasma. Clin Chem 2008;54:1664-1672.

18. Devonshire AS, Whale AS, Gutteridge A, Jones G, Cowen S, Foy CA, Huggett JF. Towards standardisation of cell-free DNA measurement in plasma: controls for extraction efficiency, fragment size bias and quantification. Anal Bioanal Chem 2014;406:6499-6512. 
19. Chiu RW, Poon LL, Lau TK, Leung TN, Wong EM, Lo YM. Effects of blood-processing protocols on fetal and total DNA quantification in maternal plasma. Clin Chem 2001;47:1607-1613.

20. Manokhina I, Singh TK, Peñaherrera MS, Robinson WP. Quantification of cell-free DNA in normal and complicated pregnancies: overcoming biological and technical issues. PLoS One 2014;9:e101500.

21. Ashoor G, Syngelaki A, Poon LC, Rezende JC, Nicolaides KH. Fetal fraction in maternal plasma cell-free DNA at 11-13 weeks' gestation: relation to maternal and fetal characteristics. Ultrasound Obstet Gynecol 2013;41:26-32.

22. Ma D, Ge H, Li X, Jiang T, Chen F, Zhang Y, Hu P, Chen S, Zhang J, Ji X, Xu X, Jiang H, Chen M, Wang W, $\mathrm{Xu} Z$ Z. Haplotype-based approach for noninvasive prenatal diagnosis of congenital adrenal hyperplasia by maternal plasma DNA sequencing. Gene 2014;544:252-258.

23. Lv W, Wei X, Guo R, Liu Q, Zheng Y, Chang J, Bai T, Li H, Zhang J, Song Z, Cram DS, Liang D, Wu L. Noninvasive prenatal testing for Wilson disease by use of circulating single-molecule amplification and resequencing technology (cSMART). Clin Chem 2015;61:172-181.

24. Hiatt JB, Pritchard CC, Salipante SJ, O'Roak BJ, Shendure J. Single molecule molecular inversion probes for targeted, high-accuracy detection of low-frequency variation. Genome Res 2013;23:843-854.

25. Boyle EA, O'Roak BJ, Martin BK, Kumar A, Shendure J. MIPgen: optimized modeling and design of molecular inversion probes for targeted resequencing. Bioinformatics 2014;30:2670-2672.

26. https://github.com/shendurelab/MIPGEN

27. O'Roak BJ, Vives L, Fu W, Egertson JD, Stanaway IB, Phelps IG, Carvill G, Kumar A, Lee C, Ankenman K, Munson J, Hiatt JB, Turner EH, Levy R, O'Day DR, Krumm N, Coe BP, Martin BK, Borenstein E, Nickerson DA, Mefford HC, Doherty D, Akey JM, Bernier R, Eichler EE, Shendure J. Multiplex targeted sequencing identifies recurrently mutated genes in autism spectrum disorders. Science 2012;338:1619-1622.

28. de Voer RM, Hahn MM, Mensenkamp AR, Hoischen A, Gilissen C, Henkes A, Spruijt L, van Zelst-Stams WA, Kets CM, Verwiel ET, Nagtegaal ID, Schackert HK, van Kessel AG, Hoogerbrugge N, Ligtenberg MJ, Kuiper RP. Deleterious Germline BLM Mutations and the Risk for Early-onset Colorectal Cancer. Sci Rep 2015;5:14060.

29. Ockeloen CW, Khandelwal KD, Dreesen K, Ludwig KU, Sullivan R, van Rooij IA, Thonissen M, Swinnen S, Phan M, Conte F, Ishorst N, Gilissen C, Roa Fuentes L, van de Vorst M, Henkes A, Steehouwer M, van Beusekom E, Bloemen M, Vankeirsbilck B, Bergé S, Hens G, Schoenaers J, Vander Poorten V, Roosenboom J, Verdonck A, Devriendt K, Roeleveldt N, Jhangiani SN, Vissers LE, Lupski JR, de Ligt J, Von den Hoff JW, Pfundt R, Brunner HG, Zhou H, Dixon J, Mangold E, van Bokhoven H, Dixon MJ, Kleefstra T, Hoischen A, Carels CE. Novel mutations in LRP6 highlight the role of WNT signaling in tooth agenesis. Genet Med 2016 Mar 10. Epub ahead of print

30. van de Vorst M, de Koning B, Castelein S, Zafeiropoulou D, Nelen M, Hoischen A, Gilissen C. MIPVAR: MIP-based VARiant calling tool. Submitted.

31. Robinson JT, Thorvaldsdóttir H, Winckler W, Guttman M, Lander ES, Getz G, Mesirov JP. Integrative genomics viewer. Nat Biotechnol 2011;29:24-26.

32. Thorvaldsdóttir H, Robinson JT, Mesirov JP. Integrative Genomics Viewer (IGV): high-performance genomics data visualization and exploration. Brief Bioinform 2013;14:178-192. 


\section{Part II}

Noninvasive prenatal screening

for fetal chromosome disorders 



\section{Chapter 4}

Noninvasive detection of fetal trisomy 21:

Systematic review and report of quality and

outcomes of diagnostic accuracy studies performed between 1997 and 2012

Elke Mersy, Luc J.M. Smits, Larissa A.A.P. van Winden, Christine E.M. de Die-Smulders, South-East Netherlands NIPT Consortium*, Aimee D.C. Paulussen, Merryn V.E. Macville, Audrey B.C. Coumans, and Suzanna G.M. Frints

Hum Reprod Update 2013;19:318-329.

*The complete member list is supplied in the Supplemental data. 


\subsection{Abstract}

Background: Research on noninvasive prenatal testing (NIPT) of fetal trisomy 21 is developing fast. Commercial tests have become available. To provide an up-to-date overview of NIPT of trisomy 21, an evaluation of the methodological quality and outcomes of diagnostic accuracy studies was made.

Methods: We undertook a systematic review of the literature published between 1997 and 2012 after searching PubMed, using MeSH terms 'RNA', 'DNA' and 'Down Syndrome' in combination with 'cell-free fetal (cff) RNA', 'cffDNA', 'trisomy 21' and 'noninvasive prenatal diagnosis' and searching reference lists of reported literature. From 79 abstracts, 16 studies were included as they evaluated the diagnostic accuracy of a molecular technique for NIPT of trisomy 21 , and the test sensitivity and specificity were reported. Meta-analysis could not be performed due to the use of six different molecular techniques and different cutoff points. Diagnostic parameters were derived or calculated, and possible bias and applicability were evaluated utilizing the revised tool for Quality Assessment of Diagnostic Accuracy (QUADAS-2).

Results: Seven of the included studies were recently published in large cohort studies that examined massively parallel sequencing (MPS), with or without pre-selection of chromosomes, and reported sensitivities between $98.58 \%$ [95\% confidence interval (Cl) $95.9-99.5 \%$ ] and $100 \%$ (95\% Cl 96-100\%) and specificities between $97.95 \%(95 \% \mathrm{Cl}$ 94.1-99.3\%) and $100 \%$ (95\% Cl 99.1-100\%). None of these seven large studies had an overall low risk of bias and low concerns regarding applicability. MPS with or without pre-selection of chromosomes exhibits an excellent negative predictive value (100\%) in conditions with disease odds from 1:1500 to 1:200. However, positive predictive values were lower, even in high-risk pregnancies (19.7-100\%). The other nine cohort studies were too small to give precise estimates (number of trisomy 21 cases: $\leq 25$ ) and were not included in the discussion.

Conclusions: NIPT of trisomy 21 by MPS with or without pre-selection of chromosomes is promising and likely to replace the prenatal serum screening test that is currently combined with nuchal translucency measurement in the first trimester of pregnancy. Before NIPT can be introduced as a screening test in a social insurance health-care system, more evidence is needed from large prospective diagnostic accuracy studies in first trimester pregnancies. Moreover, we believe further assessment, of whether NIPT can be provided in a cost effective, timely and equitable manner for every pregnant woman, is required. 


\subsection{Introduction}

In developed countries, the two-step prenatal care system includes a noninvasive risk assessment for the most common aneuploidies, before invasive prenatal procedures are offered. In this prenatal risk assessment, along with nuchal translucency measurement by ultrasound, different maternal serum biochemical screening tests are offered in the first or second trimester. At the moment, the most used noninvasive screening test for individual trisomy 21 (Down syndrome) risk calculation worldwide is the combined test. The combined test includes a serum screening test containing two blood markers, namely pregnancy-associated plasma protein-A and free beta human chorionic gonadotrophin, combined with nuchal translucency measurement (Figure 4.1). In the case of an a priori high-risk or a positive individual risk assessment of trisomy 21 (Down syndrome), 18 (Edwards syndrome) or 13 (Patau syndrome), invasive prenatal diagnosis by fetal karyotyping or rapid aneuploidy detection is performed after preservation of fetal cells by amniocentesis or chorionic villus sampling. ${ }^{1,2}$ These invasive procedures carry a risk of miscarriage ranging from $0.6 \%$, within 14 days of the procedure, to $2 \%$ for total pregnancy loss. ${ }^{3}$ To avert this risk of miscarriage, there is an increasing demand for a reliable and safe noninvasive prenatal test that is applicable as early in pregnancy as possible. Since the discovery of the presence of cell-free fetal (cff) DNA and cff placental-specific mRNA (cffRNA) in maternal plasma, the possibility of using this as the target for noninvasive prenatal testing (NIPT) of fetal genetic conditions is being explored widely. ${ }^{4-7}$ Maternal and fetal cell-free (cf) DNA consist of nuclease-fractionated histone-bound DNA sequences, with the most abundant sequence length (predominantly maternal) being between 133 and 166 base pairs. ${ }^{8}$ The cffDNA represents a subfraction of $6-10 \%$ of the total cfDNA in first and second trimester pregnancies and rises up to $10-20 \%$ in third trimester pregnancies. ${ }^{8,9}$

The small-sized fragments and the subfraction of cffDNA/RNA next to abundantly present maternal disomic genome are bottlenecks in developing NIPT techniques for aneuploidy detection. Nevertheless, several molecular techniques have been proposed for the detection of trisomy 21, 18 and 13. Early studies concerning NIPT of aneuploidy focused on the quantification of male cffDNA sequences in maternal plasma samples by real-time PCR (qPCR). ${ }^{10-17}$ Later, qPCR was used to examine a possible elevation of specific genes, e.g. 'hemoglobin beta $(H B B)$ ' and 'chromosome 21 open reading frame 105 (C21orf105)'. ${ }^{18-21}$ Another approach for noninvasive detection of trisomy 21 is determining the dosage of chromosome 21 cffRNA single 
nucleotide polymorphism (SNP) alleles of genes that are not expressed in maternal blood cells, but only in placental tissue such as 'placenta-specific 4 (PLAC4)' or 'serpin peptidase inhibitor, clade B (ovalbumin), member 2 (SERPINB2)' ${ }^{22-25}$ The ratio of SNP alleles using cffDNA instead of cffRNA is also examined for NIPT of trisomy $21 .{ }^{26,27} \mathrm{~A}$ limitation of the SNP-dependent approaches is that they are only applicable for fetuses that are heterozygous for the studied SNP. ${ }^{28}$ Furthermore, additional conditions are sometimes required, e.g. a heterozygous or a homozygous mother. To overcome this, several researchers focus on single molecule counting techniques, including digital PCR, that has not been applied in real plasma samples yet. ${ }^{29-31}$ Recently, massively parallel sequencing (MPS) of maternal plasma DNA has been introduced. ${ }^{32-42}$ MPS can identify the chromosomal origin of each sequenced plasma DNA molecule and can detect the over- or underrepresentation of any chromosome in maternal plasma.

Recently, two MPS techniques, in which only the chromosomes of clinical interest are sequenced, have been described. In these targeted MPS techniques, pre-selection of chromosomes leads to less unutilized sequencing data. Moreover, rapid nextgeneration sequencing devices can be used, altering the costs, turnaround time and the number of patients who can be tested per week. One of these techniques is digital analysis of selected regions (DANSR), in which selected nonpolymorphic loci on chromosomes of clinical interest are simultaneously quantified. ${ }^{43-47}$ The other technique is parental support, in which the observed allele distribution after sequencing of polymorphic loci on the chromosomes of clinical interest is compared with the expected allele distribution based on parental genotypes. ${ }^{48}$ Next to these techniques, fetal chromosome dosage determination has been studied based on the well-known epigenetic differences between maternal and fetal DNA, an approach that also can be used for all fetuses. ${ }^{49-57}$

At the moment, commercial NIPT of trisomy 21 by MPS has become available for highrisk pregnant women and includes the MaterniT21 ${ }^{\mathrm{TM}}$ PLUS test from Sequenom (http://www.sequenom.com), the Praena-Test ${ }^{\circledR}$ from their European partner LifeCodexx (http://www.lifecodexx.com), the verifi ${ }^{\circledR}$ test from Verinata (http://www.verinata.com) and the Harmony ${ }^{\mathrm{TM}}$ prenatal test from Ariosa (http://www.ariosadx.com). The International Society of Prenatal Diagnosis (ISPD) formulated, on 24 October 2011 in a rapid response statement, its considerations and recommendations for the clinical use of the commercial MPS tests in women at high risk and at lower risk. ${ }^{58} \mathrm{~A}$ final position statement on screening for fetal aneuploidy of ISPD is in the process of being updated and will soon be released. Nowadays, the 
option of NIPT of aneuploidy has reached pregnant women through the Internet, social media and gynecologists. Interest in large-scale validation studies grows. Molecular NIPT of trisomy 21 will play an important role in prenatal diagnosis and possibly in prenatal screening in the coming years (Figure 4.1).

Invasive prenatal diagnosis $(\diamond)$ of trisomy 21

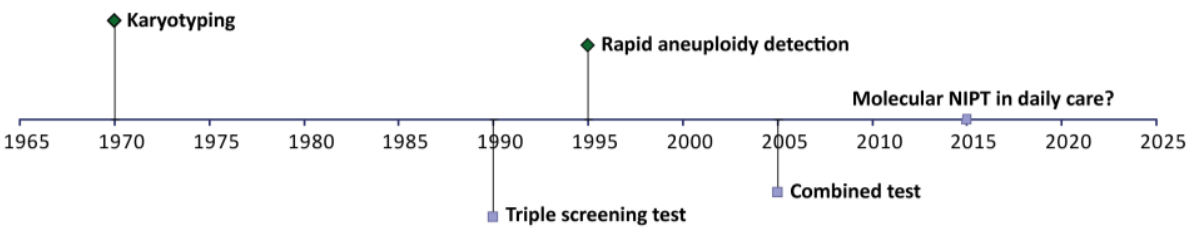

Noninvasive ( ${ }^{-}$) prenatal risk calculation tests for trisomy 21

Figure 4.1 Schematic representation of the implementation of invasive and noninvasive prenatal testing for trisomy 21 in Europe.

Invasive prenatal diagnosis of trisomy 21: Karyotyping detects all microscopically visible chromosome aberrations and is performed on fetal cells obtained by amniocentesis or chorionic villus sampling. Rapid aneuploidy detection (RAD) techniques currently used include: (1) interphase fluorescence in situ hybridization (FISH), (2) quantitative fluorescent PCR (QF-PCR) or (3) multiplex ligation-dependent probe amplification (MLPA). These tests are also performed on fetal cells obtained by amniocentesis or chorionic villus sampling and generate reliable results within 3 days that is much faster than karyotyping and are used to diagnose only trisomies 21,18 and 13 , although probes often also include the sex chromosomes.

Noninvasive prenatal risk calculation tests for trisomy 21: The triple screening test (a second trimester screening test) is performed between the 15th and 20th week of pregnancy and measures high and low levels of alpha-fetoprotein (AFP) and abnormal levels of human chorionic gonadotrophin and estriol in maternal blood. The results are combined with the mother's age, weight, ethnicity and gestation of pregnancy to assess probabilities of aneuploidy. The combined test (a first trimester screening test) is performed between the 11th and 13th weeks of pregnancy and combines the results from the nuchal translucency measurement and the levels of human chorionic gonadotrophin and placental-associated plasma protein $A$ in maternal blood, with maternal age risk factors to assess probabilities of aneuploidy (www.americanpregnancy.org).

In this article, we provide an up-to-date overview of all studies that have evaluated the diagnostic accuracy of one or more molecular techniques for NIPT of trisomy 21 in a clinical setting and that have reported test sensitivity and specificity. Firstly, we compared the characteristics of the different studies, including the molecular genetic 
technique used for NIPT, the size, the inclusion criteria, the reference standard test and the timing of testing in pregnancy. Secondly, we derived or calculated diagnostic parameters and evaluated potential bias and applicability of the evidence using the revised tool for Quality Assessment of Diagnostic Accuracy (QUADAS-2)..$^{59}$

\subsection{Methods}

\subsubsection{Search strategy and selection criteria}

We undertook a systematic review of the literature and selected relevant studies published between 1 January 1997 and 15 December 2012 in the online database PubMed. The search strategy used was ('RNA'[Mesh]) or ('DNA'[Mesh]) or (cff RNA) or (cffDNA) and (trisomy 21) or ('Down Syndrome'[Mesh]) and (noninvasive prenatal diagnosis). The last search was performed on 15 December 2012. No limits were used. In addition, reference lists were checked for further published studies, and studies suggested by colleagues and reviewers were also assessed for eligibility. Studies were included, if they evaluated the diagnostic accuracy of one or more molecular techniques for NIPT of trisomy 21 and mentioned test sensitivity and specificity. We excluded studies that examined NIPT of other disorders, reviews, bioethical or other comments, studies that did not use cffDNA/RNA for the detection of trisomy 21 and proof of concept studies.

\subsubsection{Comparison of the included studies and calculation of predictive values}

We compared the characteristics of the different studies, including the molecular genetic technique used for NIPT, the size, the inclusion criteria, the reference standard test and the timing of testing in pregnancy. If a study mentioned more than one sensitivity and specificity, e.g. because the authors tested different ways of multiplexing, we included the best result in the comparison. If we believed that sensitivity and/or specificity should have been calculated differently than done by the authors, we recalculated and explained our motives in the comments of the table generated. In addition, we calculated the positive and negative predictive values (PPVS and NPVs, respectively) of the tests for different prevalence conditions because they are dependent on the prevalence. Firstly, we calculated them for a prevalence of trisomy 21 of 1:200 (which is equal to the a priori risk of a 38-year-old pregnant woman and which is the cutoff value for a high-risk pregnancy in the Netherlands), secondly, for a prevalence of 1:380 (the a priori risk of a 35-year-old pregnant woman and an 
estimated trisomy 21 risk based on the European population) and thirdly, for a prevalence of 1:1500 (the a priori risk of a 20-year-old pregnant woman).

\subsubsection{Quality assessment using the QUADAS-2 tool}

The quality of the diagnostic studies was evaluated by three independent reviewers (E.M., L.A.A.P.v.W. and L.J.M.S.) using the QUADAS-2 tool. ${ }^{59}$ In this redesigned tool, studies are scored as 'high risk of bias', 'low risk of bias' or 'unclear risk of bias' and 'high concerns regarding applicability', 'low concerns regarding applicability' or 'unclear concerns regarding applicability' for four key domains: patient selection (domain 1), index test (domain 2), reference standard test (domain 3) and flow and timing (domain 4). The 'unclear' category is used when insufficient data are reported to permit judgment. We set up a list of characteristics of the most ideal study on NIPT of trisomy 21 (Table 4.1). To tailor the QUADAS-2 tool to studies about NIPT of trisomy 21 , we adjusted the original signaling questions of the tool according to this list and formulated extra signaling questions to check applicability (Supplemental Table 4.5). 
Table 4.1 The "ideal study" on NIPT of trisomy 21.

\section{Low risk of bias}

- A consecutive or random sample of pregnant women is enrolled.

- A case-control design is avoided.

- Inappropriate exclusions based on the reference standard test results are avoided (e.g. another aneuploidy). ${ }^{\text {a }}$

- NIPT results are interpreted without knowledge of the reference standard test results.

- Reference standard test results are interpreted without knowledge of the NIPT results.

- Cutoff values or the threshold are explained before data-analysis.

- The used reference standard test is karyotyping after amniocentesis or chorionic villus sampling, or postnatal karyotyping, and all patients receive this reference standard test.

- All patients are included in the analysis.

\section{High applicability}

- Pregnant women are considered as having high risk of trisomy 21 offspring, if the goal of the study is to compare the accuracy of NIPT with karyotyping after amniocentesis or chorionic villus sampling during pregnancy. ${ }^{b}$

- NIPT is performed before invasive testing. ${ }^{c}$

- One threshold is used, or in case the results can fall in between two thresholds (and is inconclusive), this is the case in maximum $5 \%$ of tested women.

- Fetal trisomy 21 is detected early in the pregnancy by the used reference standard test.

- The manuscripts includes samples until 20 weeks of gestation. ${ }^{d}$

- The window of gestational age is narrow enough $(<4$ weeks).e

Legend to Table 4.1: $a$. The test has to be able to exclude all non-trisomy 21 samples, including samples with other genetic abnormalities. b. A woman can be at high risk of trisomy 21 offspring when there is a positive family or obstetric history, when they are aged above 35 years, or when other diagnostic and screening procedures without cffDNA/RNA, such as ultrasound abnormalities, indicate a high risk of aneuploidy. c. The performance of an invasive procedure before the NIPT can increase the concentration of cell-free fetal DNA/RNA in maternal plasma samples, which can lead to an easier detection of the target condition by the index test.60 d. Concerns rise when NIPT has been performed late in the second trimester or even in the third trimester. To permit a consequence to the result of NIPT in countries, where by law a limit of gestational age for termination is set, the result of NIPT should be known before 22 weeks of gestation.61 Taking into account the run time of NIPT itself, the studies should only include samples until 20 weeks of gestation (domain 4A). e. There are concerns about the derivation of a preferable time point in pregnancy for NIPT when a too broad window of gestational age is examined ( $>4$ weeks). 


\subsection{Results}

\subsubsection{Inclusion and exclusion strategy}

Figure 4.2 shows the process of study selection. We identified 79 studies, of which 45 described 1 or more molecular NIPT technique(s) of trisomy 21 detection during pregnancy. From these, 29 studies were further excluded, mainly because they were proof of concept studies. Only 16 of these 45 studies evaluated the diagnostic accuracy of 1 or more molecular NIPT technique(s) and mentioned test sensitivity and specificity and could, therefore, be included in the review.

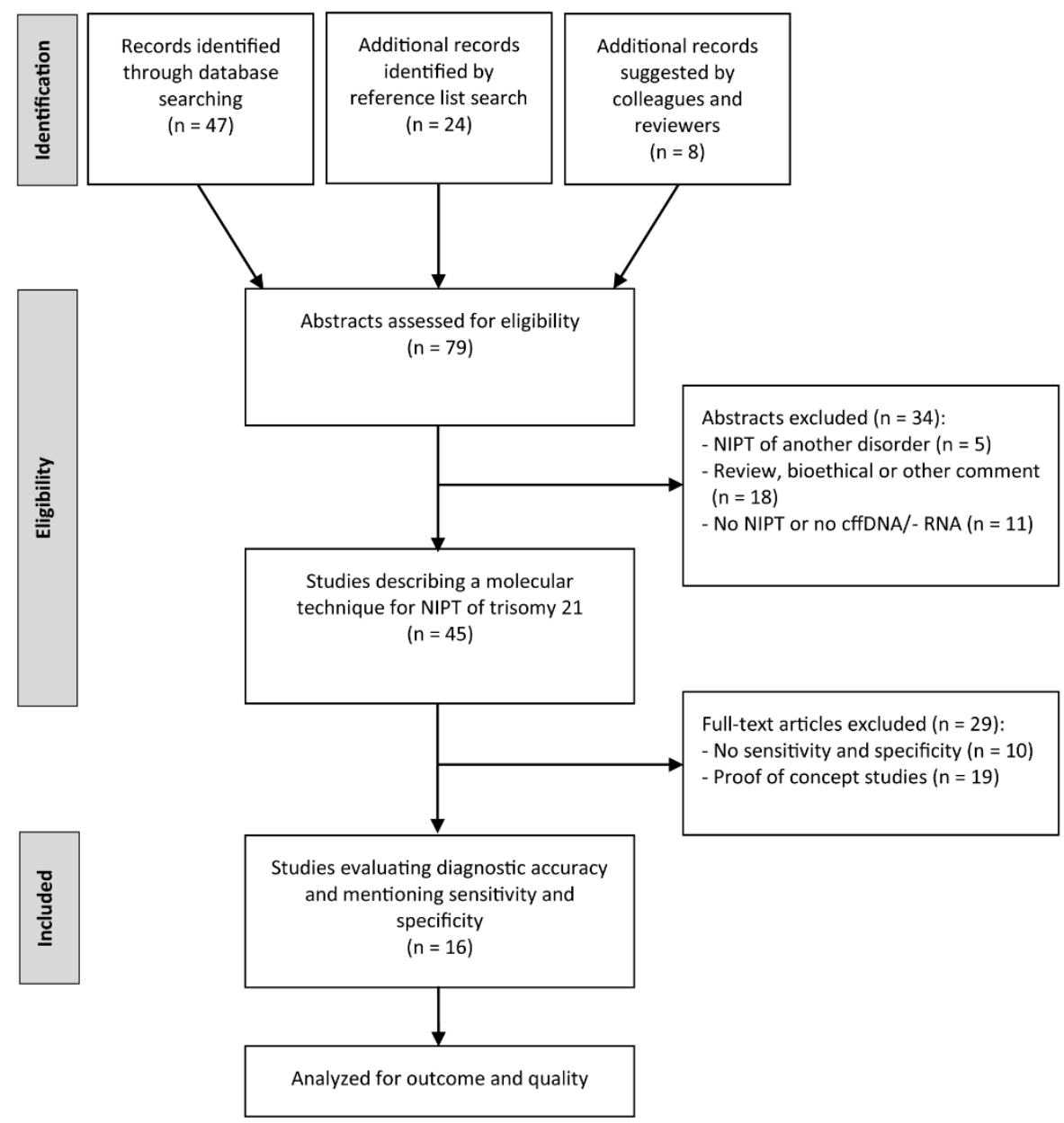

Figure 4.2 Process of study selection for the analysis of quality and outcome. 


\subsubsection{Characteristics of the included studies}

The 16 included studies, dating from 2007 to 2012, applied 6 different molecular genetic techniques for NIPT of trisomy 21 in a high-risk population (Table 4.2). Five studies investigated the diagnostic accuracy of NIPT of trisomy 21 by MPS without preselection of chromosomes, and three studies examined one of the MPS methods with pre-selection of chromosomes, the DANSR method. ${ }^{38-42,45-47}$ Two of the 16 studies examined fetal chromosome 21 dosage by analysis of different epigenetic regions between maternal and fetal cfDNA by 2 different molecular techniques: the unmethylation index of the phosphodiesterases gene 9A (PDE9A) and methylated DNA immunoprecipitation and $q P C R .{ }^{54,55}$ Three of the included studies calculated the ratio of cffRNA SNP alleles of PLAC4, a gene that is not expressed in maternal blood cells, but only in placental tissue. ${ }^{22,24,25}$ Two studies calculated the ratio of chromosome 21 cffDNA SNP alleles. ${ }^{26,27}$ Finally, one study examined the amplification of the HBB gene by qPCR in fetal trisomy 21 cases. ${ }^{20}$ The majority of the studies ( 9 out of 16 ) evaluated diagnostic accuracy in remarkably small cohorts ( $\leq 25$ trisomy 21 cases). Four studies included less than ten trisomy 21 cases, and the lowest number of controls included was 20. 24,26,27,47 Seven recently published larger studies (7 out of 16) evaluated the diagnostic accuracy of NIPT of trisomy 21 by MPS with or without pre-selection of chromosomes in larger cohorts (Table 4.2, studies 2-5, 7, 8 and 11). ${ }^{38-42,45,46}$ In the majority of the studies, high-risk pregnancies were included, although the inclusion criteria were often not clearly described, and different definitions of 'high risk of trisomy 21 ' were applied. Blood sampling took place throughout pregnancy, including sampling in the third trimester. The diagnostic accuracy of NIPT was compared with karyotyping, although in some studies in combination with another reference standard test.

\subsubsection{Diagnostic performance}

NIPT of trisomy 21 shows variable levels of sensitivity (58.82-100\%) with, in general, higher levels of specificity (83.33-100\%) (Table 4.3). Pooling of results could not be performed due to the use of different molecular techniques and different cutoff points. The larger studies on NIPT by MPS or DANSR (Table 4.3, studies 2-5, 7, 8 and 11 ) showed higher sensitivities (98.58-100\%) and specificities (97.95-100\%), combined with narrower $95 \%$-confidence intervals (Cls). ${ }^{38-42,45,46}$ Three smaller studies $(1,9$ and 12) report a sensitivity and specificity of $100 \%$, with, however, broad $95 \% \mathrm{Cls}^{27,47,54}$ Study 1 included 1949 subjects to examine sensitivity and specificity in a low-risk 
population. In this group, only a small number of subjects will have a child with trisomy 21 , leading to a poor estimation of the sensitivity in particular. ${ }^{47}$ In the larger studies, due to the low likelihood of trisomy 21 on the one hand, and good sensitivity of NIPT on the other hand, NPVs were excellent (100\%). However, PPVs showed large variation, ranging from $19.3 \%$ to $100 \%$ for the group with a high risk of trisomy 21 offspring (1:200), from $11.2 \%$ to $100 \%$ for a risk of $1: 380$ and from $3.1 \%$ to $100 \%$ for a risk of $1: 1500 .^{38-42,45,46}$

\subsubsection{Analysis of quality by the QUADAS-2 assessment}

The QUADAS-2 assessment (Table 4.4) demonstrates that none of the 16 included studies had a low risk of bias or low concerns regarding applicability in all 4 domains evaluated by the reviewers. In general, most studies had a high risk of bias in domain 1 of patient selection and had high concerns regarding applicability, in domains $4 \mathrm{~A}$ and $4 \mathrm{~B}$, the domains concerning the timing of NIPT in pregnancy. This was also the case for the seven larger studies (Table 4.4, studies 2-5, 7, 8, and 11) examining NIPT of trisomy 21 by MPS with or without pre-selection of chromosomes. ${ }^{38-42,45,46}$ Five out of seven studies $(4,5,7,8$ and 11$)$ had a risk of bias in patient selection. ${ }^{38-41,45}$ and five out of seven $(2,3,5,7$ and 8$)$ had high concerns regarding applicability in domains $4 \mathrm{~A}$ and/or $4 \mathrm{~B}$ because a too broad window of gestational age was included or blood sampling took place too late in pregnancy. ${ }^{39-42,46}$ Moreover, studies 3-5 and 8 had also high risk of bias in domain 4, flow and timing because not all samples were included in the analysis. . $^{39,41,45,46}$ 


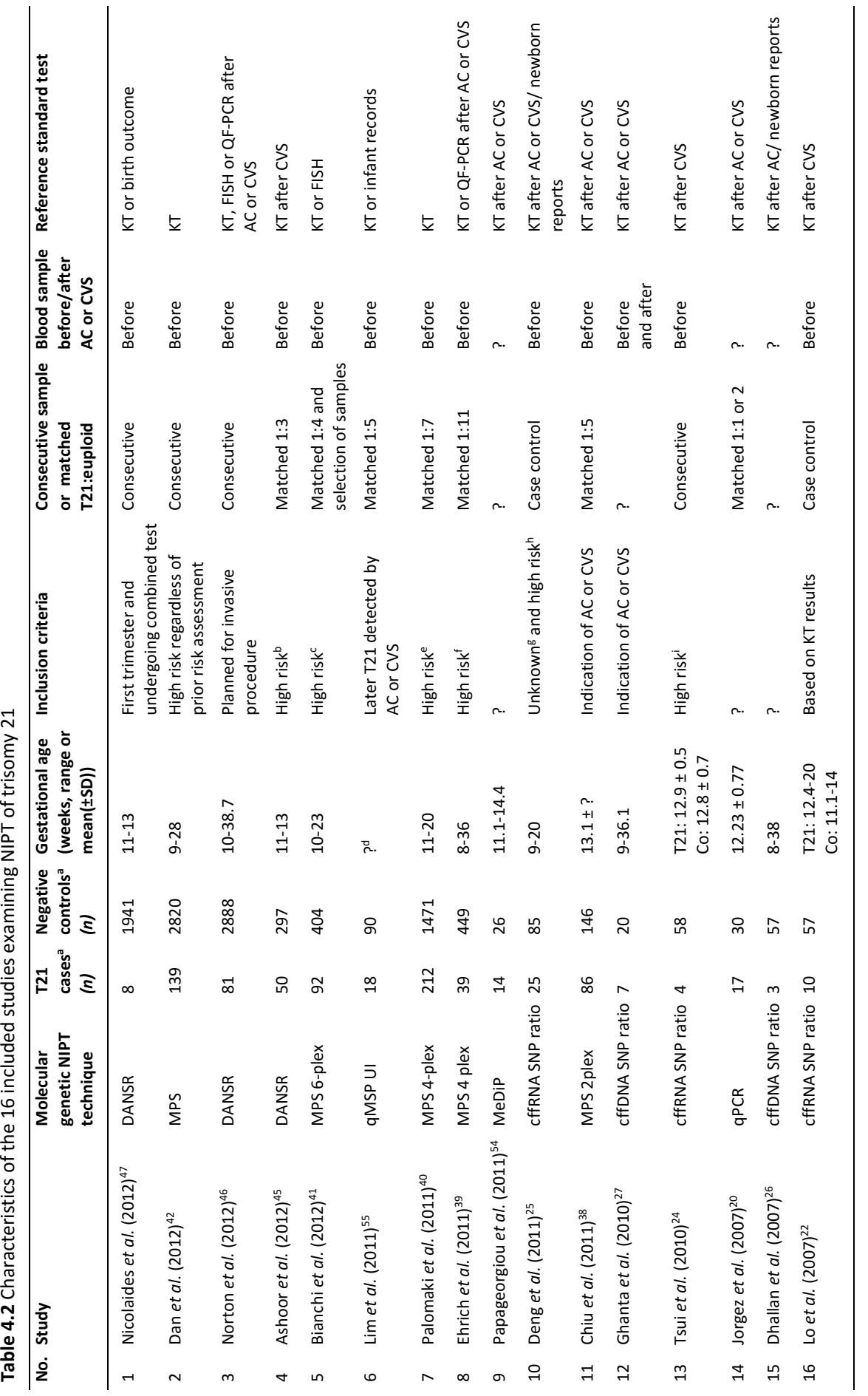




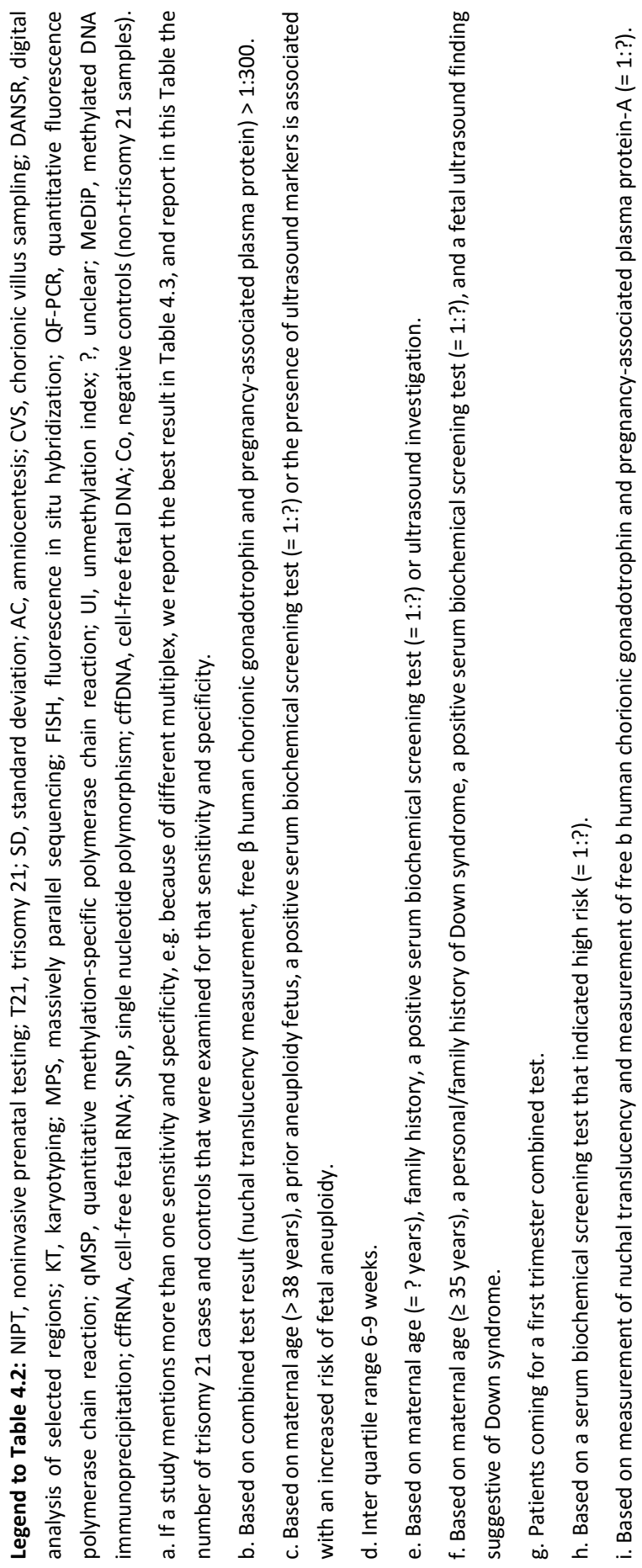




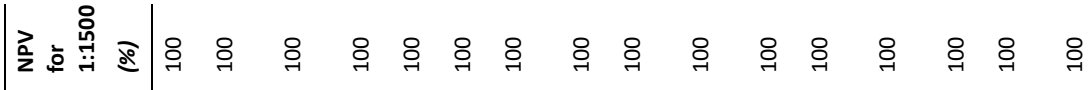

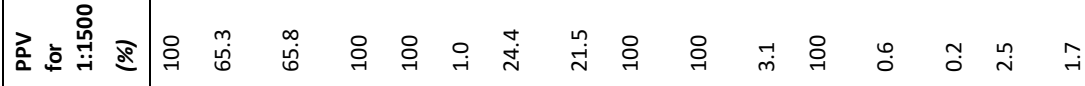

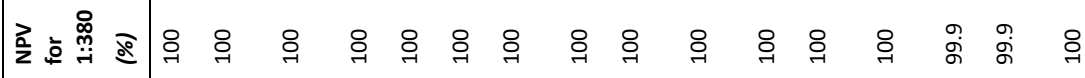

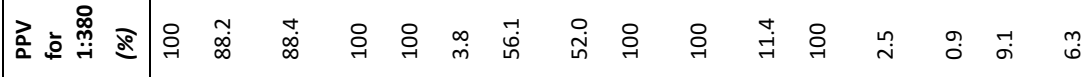

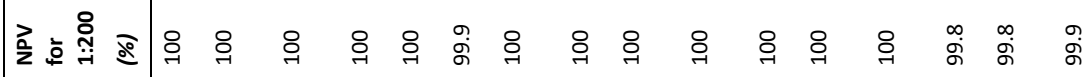

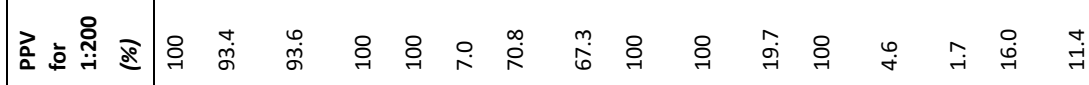

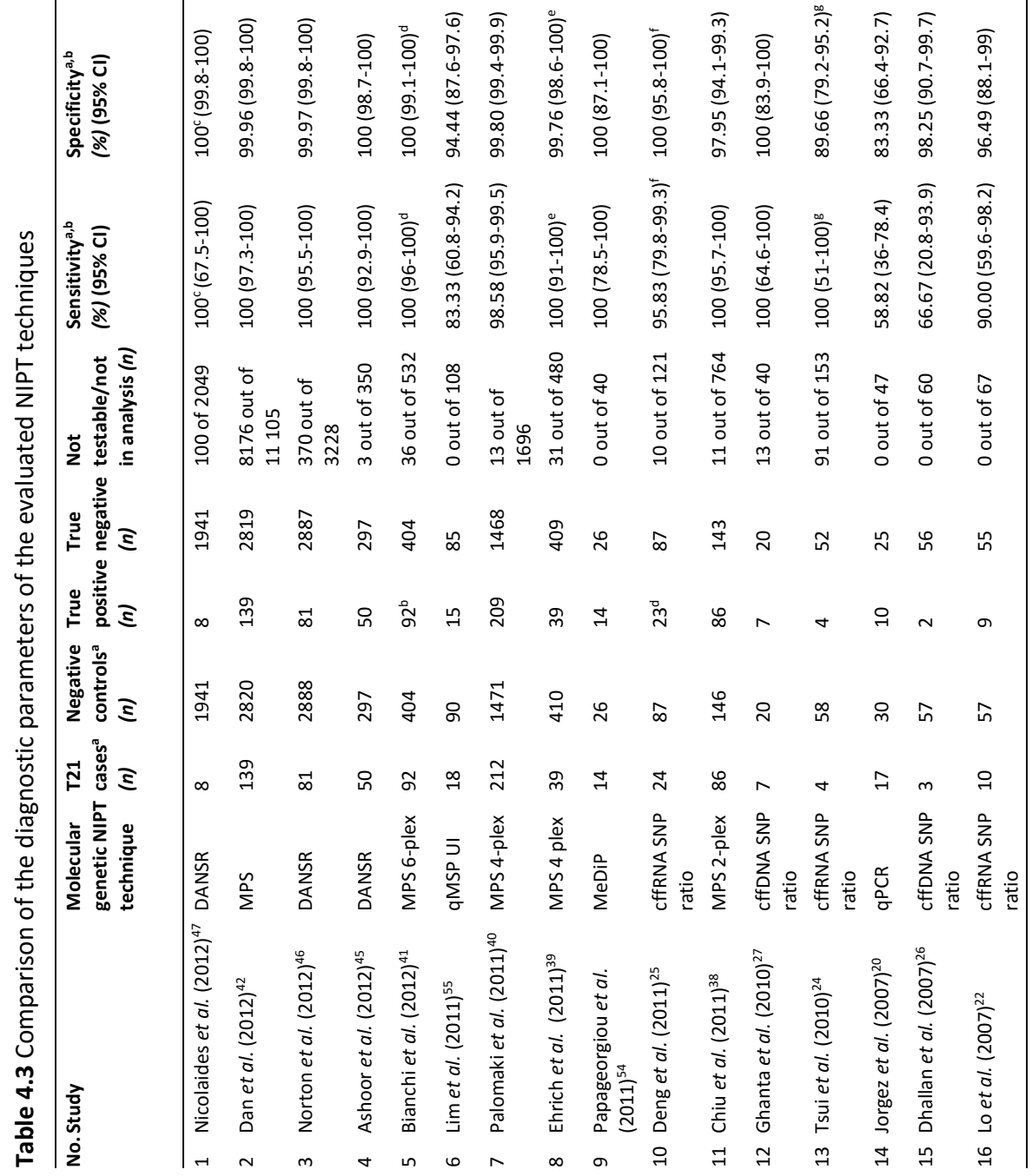




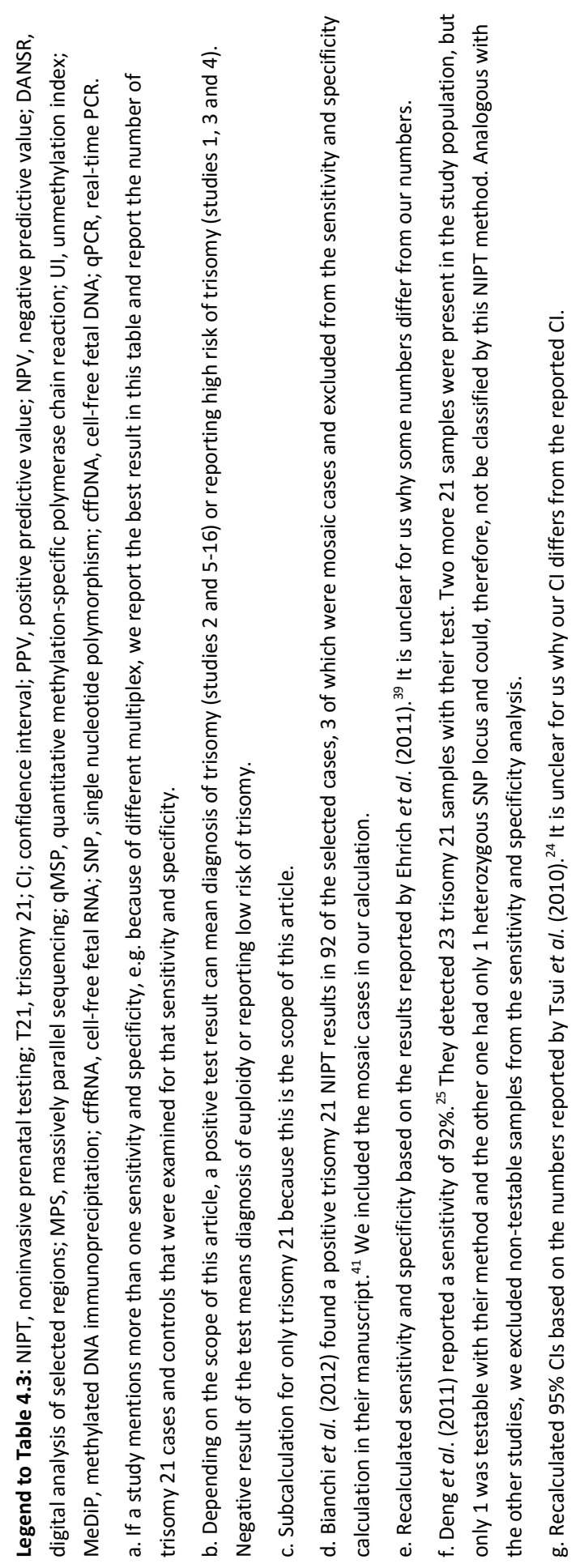




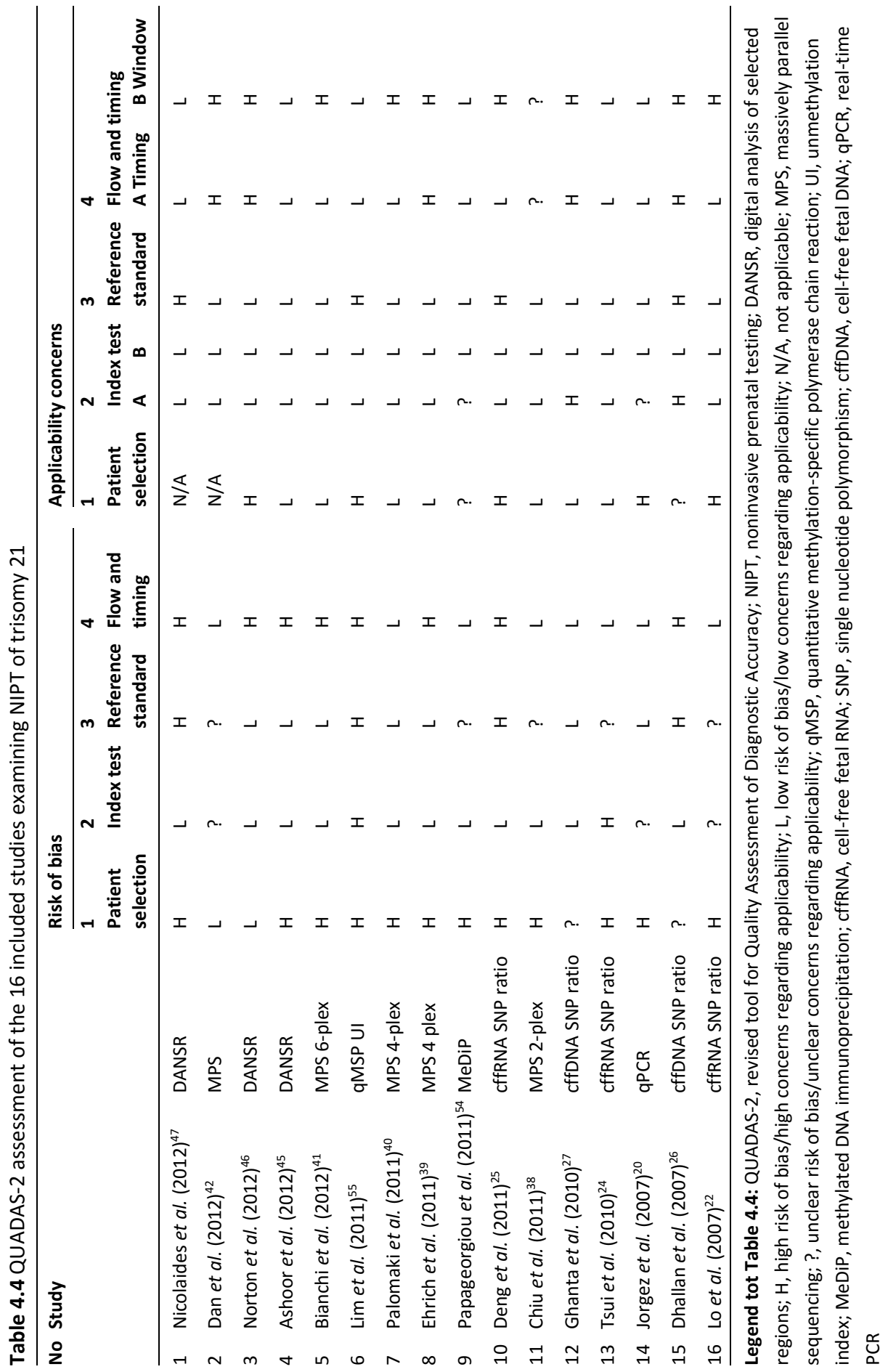




\subsection{Discussion}

\subsubsection{Implementation of NIPT of trisomy 21 in high-risk pregnancies}

The diagnostic accuracy of NIPT was compared with karyotyping in high-risk pregnant women, in 14 out of 79 studies assessed for eligibility in this systematic review (Table 4.2, studies 3-16). Our study demonstrates that only a small number of studies were conducted on the topic and that the ideal study on NIPT has not been performed yet in high-risk pregnancies. In general, strikingly, small cohorts of pregnant women were examined. Eight cohort studies were too small to give precise estimates (number of trisomy 21 cases: $\leq 25)$. Therefore, conclusions were drawn from six large cohort studies that are currently all the studies evaluating the diagnostic accuracy of NIPT of trisomy 21 by MPS with or without pre-selection of chromosomes (Table 4.2, studies 3-5, 7, 8 and 11).

The outcome analysis illustrates variable levels of sensitivity (58.82-100\%) with, in general, higher levels of specificity (83.33-100\%) throughout the 14 articles. The large cohort studies on NIPT by MPS with and without pre-selection of chromosomes have a higher sensitivity, ranging from $98.58 \%$ to $100 \%$, as well a high specificity, ranging from $97.95 \%$ to $100 \%$. These NIPT techniques exhibit an excellent NPV in natural conditions with disease odds up to 1:200. However, PPVs were often very low, even in high-risk pregnancies. A PPV of $19.7 \%$ as can be calculated from the study of Chiu et al. in 2011 (Table 4.2, study 11) indicates that, even in a high-risk population (odds $1: 200)$, a positive test result is false in $>80 \%$ of the cases. ${ }^{38}$

None of these six large cohort studies had an optimal quality. The QUADAS-2 results depict high concerns of sampling time in pregnancy in most of these studies, which was often too late in pregnancy or in a too broad window of gestational age. Only the DANSR technique was evaluated in a small window of gestational age in the first trimester (Table 4.2, study 4). ${ }^{45}$ At the moment, this technique can be performed more rapidly than MPS without pre-selection of chromosomes. Although the perfect study has not been performed yet, three studies, studies 4, 5 and 7, were of better quality. ${ }^{40,41,45}$ In the future, NIPT by MPS with and without pre-selection of chromosomes should be further explored, focusing on the inclusion of a consecutive sample early in the first trimester of pregnancy and the incorporation of all samples in the analysis. Large prospective studies will give more certainty about the predictive values in the high-risk group. 


\subsubsection{NIPT of trisomy 21 as a screening test in low-risk pregnancies}

The sensitivity and specificity of NIPT were examined in a population of low-risk pregnant women and in a mixed population in 2 out of 16 studies included in the QUADAS-2 assessment (Table 4.2, studies 1 and 2). ${ }^{42,47}$ Furthermore, we calculated the PPVs and NPVs in an average-risk population (1:380) and a low-risk population (1:1500) for these 2 studies and for the remaining 14 studies. In this systematic review, we demonstrate that the diagnostic parameters of NIPT are better than those of the current first trimester prenatal screening risk assessment for fetal trisomy 21.

Therefore, NIPT is likely to replace the prenatal serum screening test that is currently combined with nuchal translucency measurement in the first trimester of pregnancy. The replacement of the current two-step triage testing procedure by NIPT of trisomy 21 would maximize the benefits of NIPT at an early stage of pregnancy: the drawbacks of false-positive and false-negative results generated by the current risk assessment and the miscarriage risk attached to current invasive diagnostic methods would, thereby, be reduced. ${ }^{7}$ In that case, less invasive procedures would be needed, only to verify a positive NIPT result and to confirm non-inheritable or inheritable forms of Down syndrome, using the gold standard that is still karyotyping. Most likely, more women will opt for NIPT in pregnancy because of its proven diagnostic accuracy.

However, there is still more evidence needed before NIPT of trisomy 21 can be introduced in routine prenatal care, e.g. as routine screening NIPT in the first trimester of pregnancy. Preferably, large prospective diagnostic accuracy studies, including lowrisk pregnant women recruited in a clinical setting early in pregnancy, will have to be performed before this will become a reality in the public, social insurance health-care systems in Europe. One study included in this systematic review examined diagnostic accuracy in low-risk pregnant women (Table 4.2, study 1). ${ }^{47}$ However, a 5-10 times larger sample size than the 1949 samples analyzed in this study is needed for a reliable estimation of the sensitivity in a priori low-risk first trimester pregnancies. Additional accuracy studies are currently designed and ongoing. Moreover, we believe that NIPT should be provided in a cost-effective, timely and equitable manner.

Finally, further ethical exploration and evaluation of the current opinion of pregnant women and the formulation of proper informed consent information are needed. ${ }^{7}$ We estimate that it will take a few years until NIPT of trisomy 21 can be integrated as a part of routine prenatal care for every pregnant woman in the public, social insurance health-care system (Figure 4.1) We speculate that NIPT by MPS will replace the current 
serum screening test after legal licenses are arranged and informed consent information is drawn.

\subsection{Conclusion}

The 16 NIPT studies included in the QUADAS-2 assessment illustrate that the results are promising. Nevertheless, considering the limited size and quality of the studies, additional large prospective studies will allow more precise estimates about sensitivity, specificity and predictive values in high-risk and low-risk pregnancies. We demonstrate that the diagnostic parameters of NIPT of trisomy 21 are better than those of the current first trimester risk assessment. Therefore, NIPT is likely to be implemented in this risk assessment, as a replacement for the current serum screening test. Due to the reduction in false-positive and false-negative results, fewer trisomy cases would be missed at the first screening step and fewer invasive procedures would be needed, only to verify a positive NIPT result and to confirm non-inheritable or inheritable forms of Down syndrome, using the gold standard karyotyping. Before NIPT of trisomy 21 can be introduced as a replacement for the current serum screening test in a public, social insurance health-care system, still more evidence is needed from large prospective diagnostic accuracy studies, including low-risk pregnant women early in pregnancy. Moreover, we believe that NIPT should be provided in a costeffective, timely and equitable manner. Finally, further ethical exploration and evaluation of the current opinion of pregnant women and the formulation of proper informed consent information are needed. 


\subsection{References}

1. de Jong A, Dondorp WJ, Frints SG, de Die-Smulders CE, de Wert GM. Advances in prenatal screening: the ethical dimension. Nat Rev Genet 2011;12:657-663.

2. Faas BH, Cirigliano V, Bui TH. Rapid methods for targeted prenatal diagnosis of common chromosome aneuploidies. Semin Fetal Neonatal Med 2011;16:81-87.

3. Mujezinovic F, Alfirevic Z. Procedure-related complications of amniocentesis and chorionic villous sampling: a systematic review. Obstet Gynecol 2007;110:687-694.

4. Lo YM, Corbetta N, Chamberlain PF, Rai V, Sargent IL, Redman CW, Wainscoat JS. Presence of fetal DNA in maternal plasma and serum. Lancet 1997;350:485-487.

5. Poon LL, Leung TN, Lau TK, Lo YM. Presence of fetal RNA in maternal plasma. Clin Chem 2000;46:18321834.

6. Chiu RW, Lo YM. Non-invasive prenatal diagnosis by fetal nucleic acid analysis in maternal plasma: the coming of age. Semin Fetal Neonatal Med 2011;16:88-93.

7. de Jong A, Dondorp WJ, Frints SG, de Die-Smulders CE, de Wert GM. Non-invasive prenatal diagnosis for aneuploidy: toward an integral ethical assessment. Hum Reprod 2011;26:2915-2917.

8. Lo YM, Chan KC, Sun H, Chen EZ, Jiang P, Lun FM, Zheng YW, Leung TY, Lau TK, Cantor CR, Chiu RW. Maternal plasma DNA sequencing reveals the genome-wide genetic and mutational profile of the fetus. Sci Transl Med 2010;2:61ra91

9. Lun FM, Chiu RW, Chan KC, Leung TY, Lau TK, Lo YM. Microfluidics digital PCR reveals a higher than expected fraction of fetal DNA in maternal plasma. Clin Chem 2008;54:1664-1672.

10. Lo YM, Zhang J, Leung TN, Lau TK, Chang AM, Hjelm NM. Rapid clearance of fetal DNA from maternal plasma. Am J Hum Genet 1999;64:218-224.

11. Zhong $X Y$, Bürk MR, Troeger C, Jackson LR, Holzgreve W, Hahn S. Fetal DNA in maternal plasma is elevated in pregnancies with aneuploid fetuses. Prenat Diagn 2000;20:795-798.

12. Ohashi Y, Miharu N, Honda H, Samura O, Ohama K. Quantitation of fetal DNA in maternal serum in normal and aneuploid pregnancies. Hum Genet 2001;108:123-127.

13. Lee T, LeShane ES, Messerlian GM, Canick JA, Farina A, Heber WW, Bianchi DW. Down syndrome and cell-free fetal DNA in archived maternal serum. Am J Obstet Gynecol 2002;187:1217-1221.

14. Hromadnikova I, Houbova B, Hridelova D, Voslarova S, Kofer J, Komrska V, Habart D. Replicate realtime PCR testing of DNA in maternal plasma increases the sensitivity of non-invasive fetal sex determination. Prenat Diagn 2003;23:235-238.

15. Spencer K, de Kok JB, Swinkels DW. Increased total cell-free DNA in the serum of pregnant women carrying a fetus affected by trisomy 21. Prenat Diagn 2003;23:580-583.

16. Wataganara T, LeShane ES, Farina A, Messerlian GM, Lee T, Canick JA, Bianchi DW. Maternal serum cell-free fetal DNA levels are increased in cases of trisomy 13 but not trisomy 18 . Hum Genet 2003;112:204-208.

17. Gerovassili A, Garner C, Nicolaides KH, Thein SL, Rees DC. Free fetal DNA in maternal circulation: a potential prognostic marker for chromosomal abnormalities? Prenat Diagn 2007;27:104-110.

18. Ng EK, El-Sheikhah A, Chiu RW, Chan KC, Hogg M, Bindra R, Leung TN, Lau TK, Nicolaides KH, Lo YM. Evaluation of human chorionic gonadotropin beta-subunit mRNA concentrations in maternal serum in aneuploid pregnancies: a feasibility study. Clin Chem 2004;50:1055-1057.

19. Jorgez CJ, Simpson JL, Bischoff FZ. Recovery and amplification of placental RNA from dried maternal blood spots: utility for non-invasive prenatal diagnosis. Reprod Biomed Online 2006;13:558-561.

20. Jorgez CJ, Dang DD, Wapner R, Farina A, Simpson JL, Bischoff FZ. Elevated levels of total (maternal and fetal) beta-globin DNA in maternal blood from first trimester pregnancies with trisomy 21 . Hum Reprod 2007;22:2267-2272. 
21. Go AT, Visser A, Mulders MA, Twisk JW, Blankenstein MA, van Vugt JM, Oudejans CB. C21ORF105, A chromosome 21-encoded $\mathrm{mRNA}$, is not a discriminative marker gene for prediction of Down syndrome in maternal plasma. Prenat Diagn 2007;27:146-149.

22. Lo YM, Tsui NB, Chiu RW, Lau TK, Leung TN, Heung MM, Gerovassili A, Jin Y, Nicolaides KH, Cantor CR, Ding C. Plasma placental RNA allelic ratio permits noninvasive prenatal chromosomal aneuploidy detection. Nat Med 2007;13:218-223.

23. Tsui NB, Wong BC, Leung TY, Lau TK, Chiu RW, Lo YM. Non-invasive prenatal detection of fetal trisomy 18 by RNA-SNP allelic ratio analysis using maternal plasma SERPINB2 mRNA: a feasibility study. Prenat Diagn 2009;29:1031-1037.

24. Tsui NB, Akolekar R, Chiu RW, Chow KC, Leung TY, Lau TK, Nicolaides KH, Lo YM. Synergy of total PLAC4 RNA concentration and measurement of the RNA single-nucleotide polymorphism allelic ratio for the noninvasive prenatal detection of trisomy 21. Clin Chem 2010;56:73-81.

25. Deng YH, Yin AH, He Q, Chen JC, He YS, Wang HQ, Li M, Chen HY. Non-invasive prenatal diagnosis of trisomy 21 by reverse transcriptase multiplex ligation-dependent probe amplification. Clin Chem Lab Med 2011;49:641-646.

26. Dhallan R, Guo X, Emche S, Damewood M, Bayliss P, Cronin M, Barry J, Betz J, Franz K, Gold K, Vallecillo $B$, Varney J. A non-invasive test for prenatal diagnosis based on fetal DNA present in maternal blood: a preliminary study. Lancet 2007;369:474-481.

27. Ghanta S, Mitchell ME, Ames M, Hidestrand M, Simpson P, Goetsch M, Thilly WG, Struble CA, TomitaMitchell A. Non-invasive prenatal detection of trisomy 21 using tandem single nucleotide polymorphisms. PLoS One 2010;5:e13184.

28. Lo YM, Chiu RW. Genomic analysis of fetal nucleic acids in maternal blood. Annu Rev Genomics Hum Genet 2012;13:285-306.

29. Fan HC, Quake SR. Detection of aneuploidy with digital polymerase chain reaction. Anal Chem 2007;79:7576-7579.

30. Lo YM, Lun FM, Chan KC, Tsui NB, Chong KC, Lau TK, Leung TY, Zee BC, Cantor CR, Chiu RW. Digital PCR for the molecular detection of fetal chromosomal aneuploidy. Proc Natl Acad Sci USA 2007;104:1311613121.

31. Chiu RW, Cantor CR, Lo YM. Non-invasive prenatal diagnosis by single molecule counting technologies. Trends Genet 2009;25:324-331.

32. Chiu RW, Chan KC, Gao Y, Lau VY, Zheng W, Leung TY, Foo CH, Xie B, Tsui NB, Lun FM, Zee BC, Lau TK, Cantor CR, Lo YM. Noninvasive prenatal diagnosis of fetal chromosomal aneuploidy by massively parallel genomic sequencing of DNA in maternal plasma. Proc Natl Acad Sci U S A 2008;105:2045820463.

33. Fan HC, Blumenfeld YJ, Chitkara U, Hudgins L, Quake SR. Noninvasive diagnosis of fetal aneuploidy by shotgun sequencing DNA from maternal blood. Proc Natl Acad Sci USA 2008;105:16266-16271.

34. Chu T, Bunce K, Hogge WA, Peters DG. Statistical model for whole genome sequencing and its application to minimally invasive diagnosis of fetal genetic disease. Bioinformatics 2009;25:1244-1250.

35. Chiu RW, Sun H, Akolekar R, Clouser C, Lee C, McKernan K, Zhou D, Nicolaides KH, Lo YM. Maternal plasma DNA analysis with massively parallel sequencing by ligation for noninvasive prenatal diagnosis of trisomy 21. Clin Chem 2010;56:459-463.

36. Lau TK, Chen F, Pan X, Pooh RK, Jiang F, Li Y, Jiang H, Li X, Chen S, Zhang X. Noninvasive prenatal diagnosis of common fetal chromosomal aneuploidies by maternal plasma DNA sequencing. J Matern Fetal Neonatal Med 2011;25:1370-1374.

37. Sehnert AJ, Rhees B, Comstock D, de Feo E, Heilek G, Burke J, Rava RP. Optimal detection of fetal chromosomal abnormalities by massively parallel DNA sequencing of cell-free fetal DNA from maternal blood. Clin Chem 2011;57:1042-1049. 
38. Chiu RW, Akolekar R, Zheng YW, Leung TY, Sun H, Chan KC, Lun FM, Go AT, Lau ET, To WW, Leung WC, Tang RY, Au-Yeung SK, Lam H, Kung YY, Zhang X, van Vugt JM, Minekawa R, Tang MH, Wang J, Oudejans CB, Lau TK, Nicolaides KH, Lo YM. Non-invasive prenatal assessment of trisomy 21 by multiplexed maternal plasma DNA sequencing: large scale validity study. BMJ 2011;342:c7401.

39. Ehrich M, Deciu C, Zwiefelhofer T, Tynan JA, Cagasan L, Tim R, Lu V, McCullough R, McCarthy E, Nygren AO, Dean J, Tang L, Hutchison D, Lu T, Wang H, Angkachatchai V, Oeth P, Cantor CR, Bombard A, van den Boom D. Noninvasive detection of fetal trisomy 21 by sequencing of DNA in maternal blood: a study in a clinical setting. Am J Obstet Gynecol 2011;204:205e1-11.

40. Palomaki GE, Kloza EM, Lambert-Messerlian GM, Haddow JE, Neveux LM, Ehrich M, van den Boom D, Bombard AT, Deciu C, Grody WW, Nelson SF, Canick JA. DNA sequencing of maternal plasma to detect Down syndrome: an international clinical validation study. Genet Med 2011;13:913-920.

41. Bianchi DW, Platt LD, Goldberg JD, Abuhamad AZ, Sehnert AJ, Rava RP. Genome-wide fetal aneuploidy detection by maternal plasma DNA sequencing. Obstet Gynecol 2012;119:890-901.

42. Dan S, Wang W, Ren J, Li Y, Hu H, Xu Z, Lau TK, Xie J, Zhao W, Huang H, Xie J, Sun L, Zhang X, Wang W, Liao S, Qiang R, Cao J, Zhang Q, Zhou Y, Zhu H, Zhong M, Guo Y, Lin L, Gao Z, Yao H, Zhang H, Zhao L, Jiang F, Chen F, Jiang H, Li S, Li Y, Wang J, Wang J, Duan T, Su Y, Zhang X. Clinical application of massively parallel sequencing-based prenatal noninvasive fetal trisomy test for trisomies 21 and 18 in 11,105 pregnancies with mixed risk factors. Prenat Diagn 2012;32:1225-1232.

43. Sparks AB, Wang ET, Struble CA, Barrett W, Stokowski R, McBride C, Zahn J, Lee K, Shen N, Doshi J, Sun M, Garrison J, Sandler J, Hollemon D, Pattee P, Tomita-Mitchell A, Mitchell M, Stuelpnagel J, Song K, Oliphant A. Selective analysis of cell-free DNA in maternal blood for evaluation of fetal trisomy. Prenat Diagn 2012;32:3-9.

44. Sparks AB, Struble CA, Wang ET, Song K, Oliphant A. Noninvasive prenatal detection and selective analysis of cell-free DNA obtained from maternal blood: evaluation for trisomy 21 and trisomy 18. Am J Obstet Gynecol 2012; 206:319.e1-9.

45. Ashoor G, Syngelaki A, Wagner M, Birdir C, Nicolaides KH. Chromosome-selective sequencing of maternal plasma cell-free DNA for first-trimester detection of trisomy 21 and trisomy 18. Am J Obstet Gynecol 2012;206:322.e321-e325.

46. Norton ME, Brar H, Weiss J, Karimi A, Laurent LC, Caughey AB, Rodriguez MH, Williams J 3rd, Mitchell ME, Adair CD, Lee H, Jacobsson B, Tomlinson MW, Oepkes D, Hollemon D, Sparks AB, Oliphant A, Song K. Non-Invasive Chromosomal Evaluation (NICE) Study: results of a multicenter prospective cohort study for detection of fetal trisomy 21 and trisomy 18. Am J Obstet Gynecol 2012;207:137.e1-8.

47. Nicolaides KH, Syngelaki A, Ashoor G, Birdir C, Touzet G. Noninvasive prenatal testing for fetal trisomies in a routinely screened first-trimester population. Am J Obstet Gynecol 2012;374:e1-e6.

48. Zimmermann B, Hill M, Gemelos G, Demko Z, Banjevic M, Baner J, Ryan A, Sigurjonsson S, Chopra N, Dodd M, Levy B, Rabinowitz M. Noninvasive prenatal aneuploidy testing of chromosomes $13,18,21$, $X$, and $Y$, using targeted sequencing of polymorphic loci. Prenat Diagn 2012;32:1233-1241.

49. Chim SS, Tong YK, Chiu RW, Lau TK, Leung TN, Chan LY, Oudejans CB, Ding C, Lo YM. Detection of the placental epigenetic signature of the maspin gene in maternal plasma. Proc Natl Acad Sci USA 2005;102:14753-14758.

50. Tong YK, Lo YM. Diagnostic developments involving cell-free (circulating) nucleic acids. Clin Chim Acta 2006;363:187-196.

51. Papageorgiou EA, Fiegler H, Rakyan V, Beck S, Hulten M, Lamnissou K, Carter NP, Patsalis PC. Sites of differential DNA methylation between placenta and peripheral blood: molecular markers for noninvasive prenatal diagnosis of aneuploidies. Am J Pathol 2009;174:1609-1618.

52. Tong YK, Jin S, Chiu RW, Ding C, Chan KC, Leung TY, Yu L, Lau TK, Lo YM. Noninvasive prenatal detection of trisomy 21 by an epigenetic-genetic chromosome-dosage approach. Clin Chem 2010;56:90-98.

53. Tong YK, Chiu RW, Akolekar R, Leung TY, Lau TK, Nicolaides KH, Lo YM. Epigenetic-genetic chromosome dosage approach for fetal trisomy 21 detection using an autosomal genetic reference marker. PLoS One 2010;5:e15244. 
54. Papageorgiou EA, Karagrigoriou A, Tsaliki E, Velissariou V, Carter NP, Patsalis PC. Fetal-specific DNA methylation ratio permits noninvasive prenatal diagnosis of trisomy 21. Nat Med 2011;17:510-513.

55. Lim JH, Kim SY, Park SY, Lee SY, Kim MJ, Han YJ, Lee SW, Chung JH, Kim MY, Yang JH, Ryu HM. Noninvasive epigenetic detection of fetal trisomy 21 in first trimester maternal plasma. PLoS One 2011;6:e27709.

56. Zhang M, Li T, Chen J, Li L, Zhou C, Wang Y, Liu W, Zhang Y. Non-invasive prenatal diagnosis of trisomy 21 by dosage ratio of fetal chromosome-specific epigenetic markers in maternal plasma. J Huazhong Univ Sci Technolog Med Sci 2011;31:687-692.

57. Tsaliki E, Papageorgiou EA, Spyrou C, Koumbaris G, Kypri E, Kyriakou S, Sotiriou C, Touvana E, Keravnou A, Karagrigoriou A, Lamnissou K, Velissariou V, Patsalis PC. MeDIP real-time qPCR of maternal peripheral blood reliably identifies trisomy 21. Prenat Diagn 2012;32:996-1001.

58. Benn P, Borrell A, Cuckle H, Dugoff L, Gross S, Johnson JA, Maymon R, Odibo A, Schielen P, Spencer K, Wright D, Yaron Y. Prenatal Detection of Down Syndrome using Massively Parallel Sequencing (MPS): a rapid response statement from a committee on behalf of the Board of the International Society for Prenatal Diagnosis, 24 October 2011. Prenat Diagn 2012;32:1-2.

59. Whiting PF, Rutjes AW, Westwood ME, Mallett S, Deeks JJ, Reitsma JB, Leeflang MM, Sterne JA, Bossuyt PM. QUADAS-2: a revised tool for the quality assessment of diagnostic accuracy studies. Ann Intern Med 2011;155:529-536.

60. Bussani C, Di Tommaso M, Cioni R, Pasquini L, Quitadamo L, Scarselli G. Quantitative variation analysis of fetal DNA in maternal plasma samples collected before and after amniocentesis. J Obstet Gynaecol Res 2011;37:571-574.

61. United Nations Population Division. Abortion policies: a global review. 2002.

62. Heckerling PS, Verp MS. Amniocentesis or chorionic villus sampling for prenatal genetic testing: a decision analysis. J Clin Epidemiol 1991;44:657-670. 

Supplemental data Chapter 4 


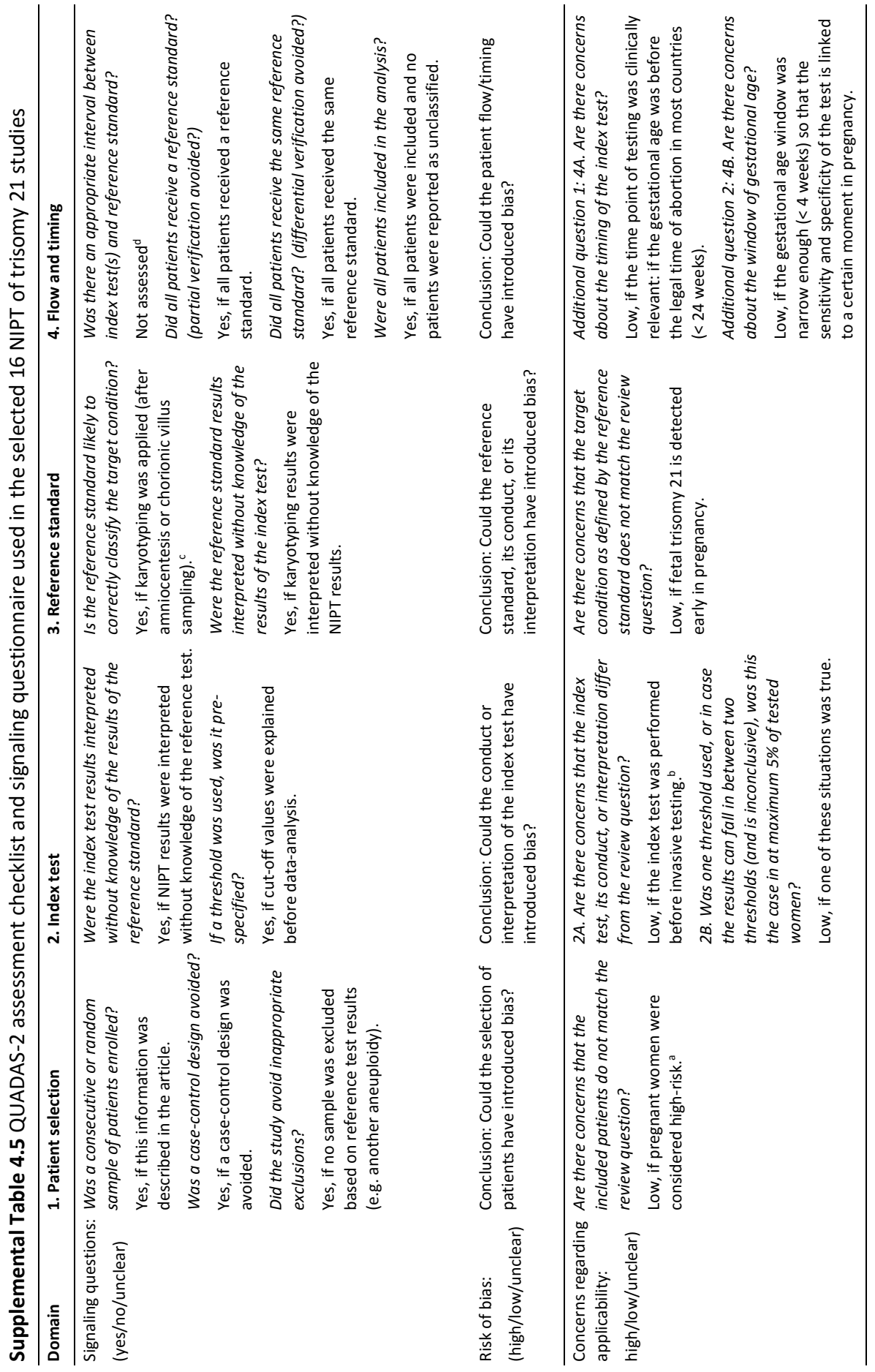




\section{Legend to Supplemental Table 4.5:}

a. A woman can be at high risk of trisomy 21 offspring when there is a positive family or obstetric history, when she is aged above 35 years or when other diagnostic and screening procedures without cffDNA/RNA, such as ultrasound abnormalities, indicate a high risk of aneuploidy. We believe that the final result of this research should be the development of a test that is suitable for all pregnant women. However, most research focuses at the moment on the high-risk pregnant women. The current state of the art is to first develop a test for high-risk pregnant women.

b. The performance of an invasive procedure before NIPT, can increase the concentration of cell-free fetal DNA/RNA in maternal plasma samples, which can lead to an easier detection of the target condition by the index test.

c. The gold standard of invasive prenatal testing for aneuploidy is still karyotyping. Karyotyping after amniocentesis has a sensitivity of $99.6 \%$ and a specificity of $99.93 \%$ for aneuploidy detection. Also after chorionic villus detection, the sensitivity and specificity of karyotyping for aneuploidy detection is high (99.6\% and $99.9 \%$ respectively). ${ }^{62}$

d. Non-issue since the target condition does not vary over time.

e. Follow-up and loss to follow-up are no issues for the target conditions.

\section{Members of the South-East Netherlands NIPT-Consortium}

S. Al-Nasiry, gynecologist Maastricht University Medical Center+ (MUMC+), Y. Arens, clinical geneticist, MUMC+; D. de Boer, clinical chemist, MUMC+; L. Claes, clinical genomics laboratory assistant, Maastricht University (UM); A. Coumans, gynecologist, MUMC+; C. de Die-Smulders, clinical geneticist, MUMC+; A. van Dobben, M.D. sonographer, Diagnostic Center Eindhoven (DVU); W. Dondorp, health ethicist, UM; J. Engelen, clinical cytogeneticist, MUMC+; M. Eijck-Vievermans, research nurse, MUMC+, S. Evers, Health Services Research/ Health Technology Assessment expert, UM; S. Frints, clinical geneticist, MUMC+, J. Geraedts, biologist, MUMC+; A. de Jong, ethicist and lawyer, UM; N. Kisters, research technician, UM; M. Macville, clinical cytogeneticist, MUMC+; P. Menheere, clinical chemist, MUMC+; E. Mersy, M.D., UM; L. Mulders, gynecologist, Maxima Medical Center Veldhoven (MMC-V); N. Muntjewerff, M.D. in PND and PGD, MUMC+, J. Nijhuis, gynecologist, MUMC+; J. Offermans, gynecologist, Atrium Medical Center Heerlen; A. Paulussen, molecular biologist, MUMC+; M. Porath, gynecologist MMC-V; L. Smits, epidemiologist, UM; S. Stevens, clinical cytogeneticist, MUMC+; D. Veersema, gynecologist, MUMC+ DVU; I. Witters, gynecologist MUMC+; G. De Wert, biomedical and health ethicist, UM; C. Willekes, gynecologist MUMC 



\section{Chapter 5}

\section{Advantages and disadvantages of different implementation strategies of noninvasive prenatal testing in Down syndrome screening programs}

Elke Mersy, Christine E.M. de Die-Smulders, Audrey B.C. Coumans, Luc J.M. Smits, Guido M.W.R. de Wert, Suzanna G.M. Frints, and Joris A. Veltman

Public Health Genomics 2015;18:260-271. 


\subsection{Abstract}

Background: Implementation of non-invasive prenatal testing (NIPT) in Down syndrome screening programs requires health policy decisions about its combination with other tests and its timing in pregnancy.

Aim: Our aim was to aid health policy decision makers by conducting a quantitative analysis of different NIPT implementation strategies.

Methods: Decision trees were created to illustrate all plausible alternatives in a theoretical cohort of 100000 pregnant women in five screening programs: classical screening by the first-trimester combined test (FCT), pre-selection of high-risk women prior to NIPT by the FCT, NIPT as the first screening test at 10 weeks and at 13 weeks, and the simultaneous conductance of NIPT and the FCT.

Results: Pre-selection by FCT prior to NIPT reduces the number of amniocenteses to a minimum because of a reduction of false-positive NIPT results. If NIPT is the first screening test, it detects almost all fetal Down syndrome cases. NIPT at 10 weeks reassures women early in pregnancy, while NIPT at 13 weeks prevents unnecessary tests due to spontaneous miscarriages and allows for immediate confirmation by amniocentesis.

Conclusion: Every implementation strategy has its advantages and disadvantages. The most favorable implementation strategy may be NIPT as the first screening test at 13 weeks, offering the most accurate screening test for Down syndrome, when the risk for spontaneous miscarriage has declined remarkably and timely confirmation by amniocentesis can be performed. 


\subsection{Introduction}

For the past few years, professionals involved in prenatal diagnostic testing have seen the rapid development of non-invasive prenatal testing (NIPT) of Down syndrome by massively parallel sequencing of cell-free DNA in maternal plasma. ${ }^{1-4}$ In several large clinical validation studies, it was established that NIPT can detect fetal Down syndrome accurately from 10 weeks of gestation onwards in high-risk and low-risk pregnancies with a sensitivity and specificity of $>99 \%$ and a negative predictive value of almost $100 \% .^{1,2,5-8}$ However, the positive predictive value of NIPT for Down syndrome varies between 62 and 93\% in a high-risk population (risk of 1 in 200), drops to $50-80 \%$ in a more general population and may even fall below $50 \%$ in young, low-risk women. ${ }^{1,2,5-}$ ${ }^{8}$ As a result, the International Society for Prenatal Diagnosis recently stated that NIPT is a screening test that is not fully diagnostic and can be offered as the primary screening test or as a secondary screening test subsequent to conventional screening. After suspicion of fetal Down syndrome following a positive NIPT result, invasive diagnostic testing is recommended to confirm the diagnosis. ${ }^{9}$

NIPT has been available through commercial laboratories since 2011, mostly for highrisk pregnant women, at 10 weeks of gestation or later in pregnancy. ${ }^{6-8,10-13}$ Ideally, NIPT should be incorporated into a well-designed screening program based on informed decision-making and equity of access. ${ }^{13}$ The aim of a prenatal screening program for Down syndrome is to provide pregnant women with an autonomous reproductive choice about continuing or terminating the pregnancy on the basis of the prenatal diagnosis of fetal Down syndrome. At present, several countries are organizing the implementation of NIPT in their Down syndrome screening program. ${ }^{14-}$ 16 There are a number of ways to implement NIPT into a Down syndrome screening program. Health policy decisions are now required about the possible restriction of NIPT to preselected high-risk women, its timing in pregnancy and its combination with other tests. For health policy choices, a thorough understanding is needed of the consequences, the potential harms and benefits, of different implementation strategies of NIPT in Down syndrome screening programs. The clinical utility, costeffectiveness and ethical consequences of plausible NIPT implementation strategies have been evaluated in previous studies. ${ }^{17-23}$ In addition, the attitudes of pregnant women and obstetricians and gynecologists towards NIPT have been investigated through questionnaires and interviews. ${ }^{15,24-27}$ In this study, we aim to aid health policy decision makers by conducting a comprehensive analysis of the advantages and disadvantages of different implementation strategies through a decision-analytic 
model. ${ }^{28}$ After a quantitative estimation of pre-defined clinical outcome measures and a reflection upon the results in the light of practical and psychological considerations, we formulate an advice about what may be the most favorable NIPT implementation strategy.

\subsection{Methods}

\subsubsection{The Down syndrome screening programs}

Four hypothetical Down syndrome screening programs in which NIPT was implemented (programs P1-P4) and the classical screening program (program C) were compared in a decision-analytic model (Figure 5.1).

\section{$\begin{array}{llllllllll}10 & 11 & 12 & 13 & 14 & 15 & 16 & 17 & 18 & \text { wks }\end{array}$}

Program 1 (P1):

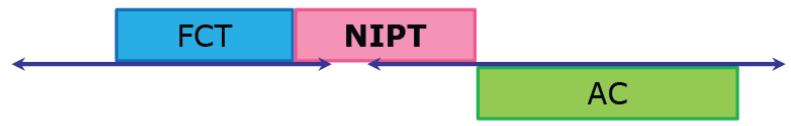

Program 2 (P2):

\section{NIPT}

$A C$

Program 3 (P3):

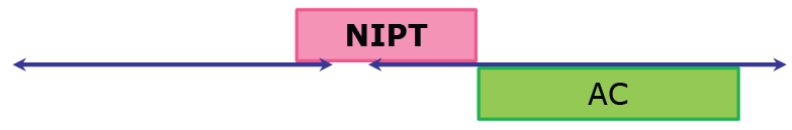

Program 4 (P4):

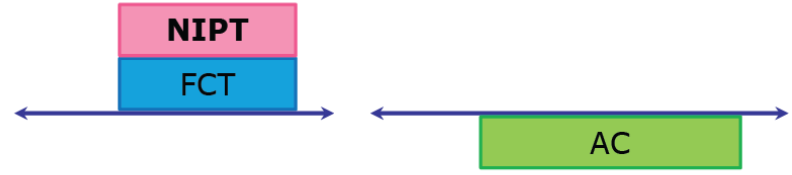

Classical (C):

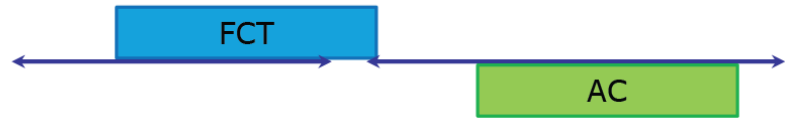

Figure 5.1 The timing of the offered screening tests (FCT and/or NIPT) in the four hypothetical Down syndrome screening programs in which NIPT is implemented (P1-P4) and the classical screening program (C). Following suspicion of fetal Down syndrome, pregnant women are offered an amniocentesis (AC) to confirm the diagnosis in all programs. 
In the classical screening program, pregnant women first underwent the first-trimester combined test (FCT) between $11+0$ and $13+6$ weeks of gestation, the classical noninvasive risk assessment in most Western countries. Following a risk of fetal Down syndrome of 1 in 200 or higher, the risk threshold used in the Netherlands, the women were offered an amniocentesis to confirm the diagnosis of fetal Down syndrome.

In the hypothetical screening programs, NIPT was offered at 10 weeks or at 13 weeks of gestation. NIPT should not be offered too late in pregnancy because it is not preferable that implementation of NIPT leads to a delay in the timing of the invasive test compared with the classical screening program. The accuracy of NIPT was confirmed in clinical validation studies as early as 10 weeks of gestation. ${ }^{1,2,5-8}$

In program P1, all pregnant women first underwent the FCT before 13 weeks of gestation, followed by NIPT at 13 weeks of gestation if women had a risk of fetal Down syndrome of 1 in 200 or higher. If fetal Down syndrome was still suspected following NIPT, women were offered an amniocentesis. In program P2, NIPT was offered to all pregnant women as an early screening test at 10 weeks of gestation (10-week NIPT), and in program P3, NIPT was available for all pregnant women at 13 weeks of gestation (13-week NIPT). Following suspicion of Down syndrome by NIPT, an amniocentesis was offered. In the last program P4, NIPT and the FCT were offered to all pregnant women. NIPT was performed at 10 weeks of gestation, and FCT was conducted between 11 and 13 weeks of gestation. Assuming that the result of the NIPT would be dominant for decision-making in case of discordant results of the FCT and the NIPT, because of the better accuracy of NIPT, an amniocentesis was offered to all women with a positive NIPT result. Arguments to keep the FCT despite the better accuracy of NIPT are listed in the Discussion section of this paper.

In our screening programs, we preferred amniocentesis over chorionic villus sampling (CVS) to confirm the NIPT result. Although CVS can be performed earlier in pregnancy, the potential of confined placental mosaicism should be considered. Analysis of amniotic fluid cells is considered to be a more reliable test for the true fetal karyotype. ${ }^{9}$ Following amniocentesis, women will receive a definitive confirmation of the presence of fetal Down syndrome as fast as 3 days later through rapid aneuploidy detection. ${ }^{29}$ 


\subsubsection{Decision trees}

For each Down syndrome screening program, a decision tree was created in Microsoft Excel using the open source Excel Add-in Simple Decision Tree. ${ }^{30}$ We assumed that of the total pregnant population, a theoretical cohort of 100000 pregnant women of all age categories would opt for prenatal screening. The decision trees illustrate all plausible alternatives and outcomes for these women within a hypothetical screening program between 10 and 18 weeks of gestation. A decision tree starts with a 'decision node', indicating the hypothetical top-down health policy choice for the screening program. It consists further of 'chance nodes' from which two or more branches start to illustrate possible alternative scenarios. The probability variables were obtained through a systematic analysis of the literature and are listed in Table 5.1. The estimated uptake of the offered prenatal tests, the probability of a true or false result of these tests, and the estimated fetal losses due to amniocentesis complications were incorporated in the decision trees. Furthermore, we incorporated the chances of spontaneous miscarriage in the time windows in which NIPT was hypothetically offered, i.e. between 10 and 13 weeks of gestation and between 13 and 15 weeks of gestation. 
Table 5.1 Variables and probabilities used in the decision-analytic model

\begin{tabular}{|c|c|c|c|}
\hline Probability variable & $\begin{array}{l}\text { Proba- } \\
\text { bility, \% }\end{array}$ & $\begin{array}{l}\text { Plausible } \\
\text { range, \% }\end{array}$ & $\begin{array}{l}\text { Source of probabilities and } \\
\text { plausible ranges }\end{array}$ \\
\hline $\begin{array}{l}\text { Prevalence of fetal Down syndrome in women } \\
\text { of all age categories at } 10 \text { weeks of gestation }\end{array}$ & 0.2 & $0.17-0.23$ & $\begin{array}{l}\text { Weighted mean of European and } \\
\text { American population }{ }^{39,40} ; 95 \% \mathrm{Cl} \\
\text { used for plausible range. }\end{array}$ \\
\hline $\begin{array}{l}\text { Spontaneous loss rates for fetuses with Down } \\
\text { syndrome }\end{array}$ & & & \multirow{4}{*}{$\begin{array}{l}\text { Calculated using published } \\
\text { estimates for spontaneous loss } \\
\text { rates for fetuses with trisomy } 21 \\
\text { between various gestations and } \\
\text { delivery at } 40 \text { weeks by Snijders } \\
\text { et al. (1999). }{ }^{41}\end{array}$} \\
\hline Between 10 weeks and 13 weeks of gestation & 12.0 & & \\
\hline Between 13 weeks and 15 weeks of gestation & 5.7 & & \\
\hline $\begin{array}{l}\text { Between } 15 \text { weeks of gestation and delivery } \\
\text { at term }\end{array}$ & 22.9 & & \\
\hline $\begin{array}{l}\text { Spontaneous loss rates for fetuses without } \\
\text { chromosomal abnormalities }\end{array}$ & & & \multirow{3}{*}{$\begin{array}{l}\text { Weighted mean of the three } \\
\text { largest studies from the } \\
\text { systematic review by Avalos et al. } \\
(2012){ }^{31}\end{array}$} \\
\hline Between 10 weeks and 13 weeks of gestation & 3.9 & & \\
\hline Between 13 weeks and 15 weeks of gestation & 1.2 & & \\
\hline $\begin{array}{l}\text { Sensitivity of the FCT for fetal Down syndrome } \\
\text { in women of all age categories for a risk } \\
\text { threshold of } 1 \text { in } 200\end{array}$ & 89.0 & $83.9-92.7$ & $\begin{array}{l}\text { Kagan et al. }(2008)^{42} ; 95 \% \mathrm{Cl} \text { used } \\
\text { for plausible range. }\end{array}$ \\
\hline $\begin{array}{l}\text { Specificity of the FCT for fetal Down syndrome } \\
\text { in women of all age categories for a risk } \\
\text { threshold of } 1 \text { in } 200\end{array}$ & 95.4 & $95.3-95.5$ & $\begin{array}{l}\text { Kagan et al. }(2008)^{42} ; 95 \% \mathrm{Cl} \text { used } \\
\text { for plausible range. }\end{array}$ \\
\hline $\begin{array}{l}\text { Proportion of women opting for NIPT following } \\
\text { Down syndrome suspicion by the FCT }\end{array}$ & 100 & $39.4-100$ & $\begin{array}{l}\text { Our model assumes that all } \\
\text { women are in favor of NIPT; } \\
\text { lower border of plausible range } \\
\text { based on publication by Chetty et } \\
\text { al. (2013). } .^{43}\end{array}$ \\
\hline $\begin{array}{l}\text { Sensitivity of NIPT for fetal Down syndrome for } \\
\text { high-risk and low-risk pregnancies }\end{array}$ & 99.6 & & $\begin{array}{l}\text { Weighted mean of the larger } \\
\text { clinical validation studies in high- } \\
\text { risk pregnancies. }{ }^{1}\end{array}$ \\
\hline $\begin{array}{l}\text { Specificity of NIPT for fetal Down syndrome for } \\
\text { high-risk and low-risk pregnancies }\end{array}$ & 99.9 & & $\begin{array}{l}\text { Weighted mean of the larger } \\
\text { clinical validation studies in high- } \\
\text { risk pregnancies. }{ }^{1}\end{array}$ \\
\hline $\begin{array}{l}\text { Proportion of women opting for amniocentesis } \\
\text { following Down syndrome suspicion by the } \\
\text { screening test (FCT or NIPT) }\end{array}$ & 90.0 & $50.0-90.0$ & $\begin{array}{l}\text { Own estimation based on the } \\
\text { intention of the program ( } 100 \% \\
\text { confirmation by invasive PND). }\end{array}$ \\
\hline $\begin{array}{l}\text { Risk of fetal loss following amniocentesis } \\
\text { complications }\end{array}$ & 0.60 & $0.11-0.60$ & $\begin{array}{l}\text { Mujezinovic and Alfirevic } \\
(2007)^{44} \text {; lower border of } \\
\text { plausible range based on meta- } \\
\text { analysis by Akolekar et al. } \\
(2015) .45\end{array}$ \\
\hline $\begin{array}{l}\text { Sensitivity of the rapid aneuploidy detection } \\
\text { for fetal Down syndrome }\end{array}$ & 100 & & Own estimation \\
\hline
\end{tabular}

Legend to Table 5.1: 95\% Cl, 95\% confidence interval; FCT, first trimester combined test; NIPT, non-invasive prenatal testing; PND, prenatal diagnosis 


\subsubsection{Quantitative analysis of clinical outcome measures and order of preference}

The clinical outcome measures that were quantitatively analyzed are listed in Table 5.2. Based on the results of this analysis, the screening programs were ordered from most favorable to least favorable.

Table 5.2 Pre-defined clinical outcome measures that were quantitatively evaluated

- $\quad$ Fetal Down syndrome cases detected by screening and confirmed by amniocentesis

- Fetal Down syndrome cases detected by screening without confirmation by amniocentesis

- $\quad$ Fetal Down syndrome cases not detected by first-trimester screening

- Number of women reassured about the absence of fetal Down syndrome by first-trimester screening

- Total number of amniocenteses performed

- Number of women that undergo amniocentesis and do not carry a fetus with Down syndrome

- Fetal losses because of amniocentesis complications

- $\quad$ Cases of spontaneous miscarriage while waiting for the first-trimester screening result

- Cases of spontaneous miscarriage while waiting for the amniocentesis

\subsubsection{One-way sensitivity analyses}

As the used probabilities may be associated with some degree of uncertainty, reasonable probability changes must be specified. ${ }^{28}$ For probabilities that were uncertain, we defined a plausible range (Table 5.1). Where possible, 95\% confidence intervals were used; otherwise, we made up a range in mutual consultation. To test the model's robustness to variations in the probabilities employed, one-way sensitivity analyses were performed. In these analyses, we assessed for each probability variable whether or not variation across the plausible range led to a change in the order of preference. 


\subsection{Results}

Four hypothetical Down syndrome screening programs in which NIPT was implemented (programs P1-P4) and the classical screening program (program C) were compared in a decision-analytic model. In Figures 5.2-5.5, the decision trees of the programs are visualized. In Table 5.3, the screening programs are ordered from most favorable to least favorable for each of the pre-defined clinical outcome measures of the quantitative analysis. For all clinical outcome measures, variation across the plausible ranges revealed no change of preferred program.

\subsubsection{Comparison of implementation of NIPT with the classical screening program}

Irrespective of the implementation strategy, incorporating NIPT in Down syndrome screening programs resulted in important advantages for pregnant women compared with the classical Down syndrome screening programs. As can be seen from our decision-analytic model, implementation of NIPT reduced the number of missed Down syndrome cases by $94 \%$ in most programs, except for P1. Furthermore, our model showed a $98-100 \%$ reduction of false-positive first-trimester screening results by NIPT compared with classical screening by the FCT. As a consequence, a 94-97\% reduction of the amniocenteses and of fetal losses due to amniocentesis complications was calculated (Figures 5.2-5.5; Table 5.3).

Below, we compare the different NIPT implementation strategies while considering detection of Down syndrome, the number of women reassured correctly about the absence of Down syndrome, the number of false-positive results and conducted amniocenteses, the number of unnecessary tests, and the time until confirmatory testing (Figures 5.3-5.5; Table 5.3).

\subsubsection{Detection of fetal Down Syndrome}

Considering Down syndrome detection, the preferred screening programs were the programs in which NIPT was offered as the first screening test at 10 weeks (P2 and P4) or at 13 weeks of gestation (P3). In these programs, the largest proportion of the 200 fetal Down syndrome cases was detected by NIPT: 175 cases in P2 and P4, and 165 cases in P3. Missed cases were explained by a false-negative NIPT result in 1 case $(1 / 200 ; 0.5 \%)$ and by a spontaneous loss of the pregnancy before a screening result could be obtained in the remaining cases (24/200; $12 \%$ in P3 and P4; 34/200; $17 \%$ in P3). When NIPT was offered to high-risk women, pre-selected by the FCT (P1), only 
147 cases of fetal Down syndrome were detected by NIPT due to 19 false-negative results of the FCT (19/200; 9.5\%), 1 false-negative result of NIPT $(1 / 200 ; 0.5 \%)$ and spontaneous miscarriages occurring between the conductance of FCT and the result of the NIPT (33/200; $16.5 \%)$. Five of the missed cases due to a false-negative result of one of the screening tests in P1 were predicted to result in fetal loss after NIPT conductance, while the remaining 15 cases were predicted to result in continuing pregnancies.

\subsubsection{Reassurance about the absence of fetal Down syndrome}

Considering reassurance about the absence of fetal Down syndrome, the programs in which NIPT was offered at 10 weeks of gestation were preferred (P2 and P4): 95812 women were reassured by a negative 10 -week NIPT result (96\%). When NIPT was offered to high-risk women, pre-selected by the FCT (P1), 91496 women were correctly reassured by the FCT about the absence of fetal Down syndrome (92\%). Later, in 4354 additional cases in which the FCT had provided a false high risk of fetal Down syndrome, women were reassured by a true-negative result of the 13-week NIPT (4\%). If NIPT was offered as the first screening test at 13 weeks of gestation (P3), the 13-week NIPT was true-negative in 94662 cases (95\%). These women waited 2-3 weeks longer for this result than the women of P2 and P4.

\subsubsection{Number of false-positive results and performed amniocenteses}

Considering the number of false-positive results and performed amniocenteses, the preferred program was P1 in which NIPT was offered to high-risk women, preselected by the FCT. In the case of pre-selection by the FCT prior to NIPT, a $95 \%$ reduction in the number of false-positive NIPT results was predicted, in comparison with P2-P4. In $P 1$, the number of false-positive screening results was reduced from 4412 following FCT to only 4 following NIPT (4\%). In total, 136 amniocenteses were conducted to identify 132 out of 200 fetal Down syndrome cases. Only one loss of a fetus with Down syndrome because of amniocentesis complications was predicted. In programs P2-P4, the NIPT was false-positive in 95-96 cases (0.1\%). Comparing P2, P3 and P4, there was no difference in the number of performed amniocenteses (234), number of Down syndrome cases confirmed by amniocenteses (148/200) and number of spontaneous miscarriages due to amniocentesis complications ( 1 fetus with Down syndrome and 1 fetus without Down syndrome). In all programs, we predicted that some fetal Down syndrome cases detected by first-trimester screening would not be confirmed by an 
amniocentesis (15 in P1 and 17 in P2-P4). A detection of fetal Down syndrome by screening could be not confirmed because the pregnant woman chose not to undergo amniocentesis, a spontaneous miscarriage occurred before amniocentesis was possible or a fetal loss occurred following amniocentesis complications.

\subsubsection{Unnecessary tests and time until the confirmatory amniocentesis}

Considering unnecessary tests and the time until the confirmatory testing, the program in which NIPT was offered at 13 weeks of gestation was preferred (P3). A decline by more than $50 \%$ of the number of spontaneous miscarriages that occurred between the NIPT conductance and the result of the NIPT, assuming a 2-week turnaround time (from 3916 to 1161), in comparison to programs P2 and P4, was calculated. This meant a decline of more than $50 \%$ of unnecessary NIPTs in P3. Additionally, following a positive 13-week NIPT (P1, P3 and P4), a timely confirmatory amniocentesis was possible, and a miscarriage occurring before amniocentesis was unlikely. 

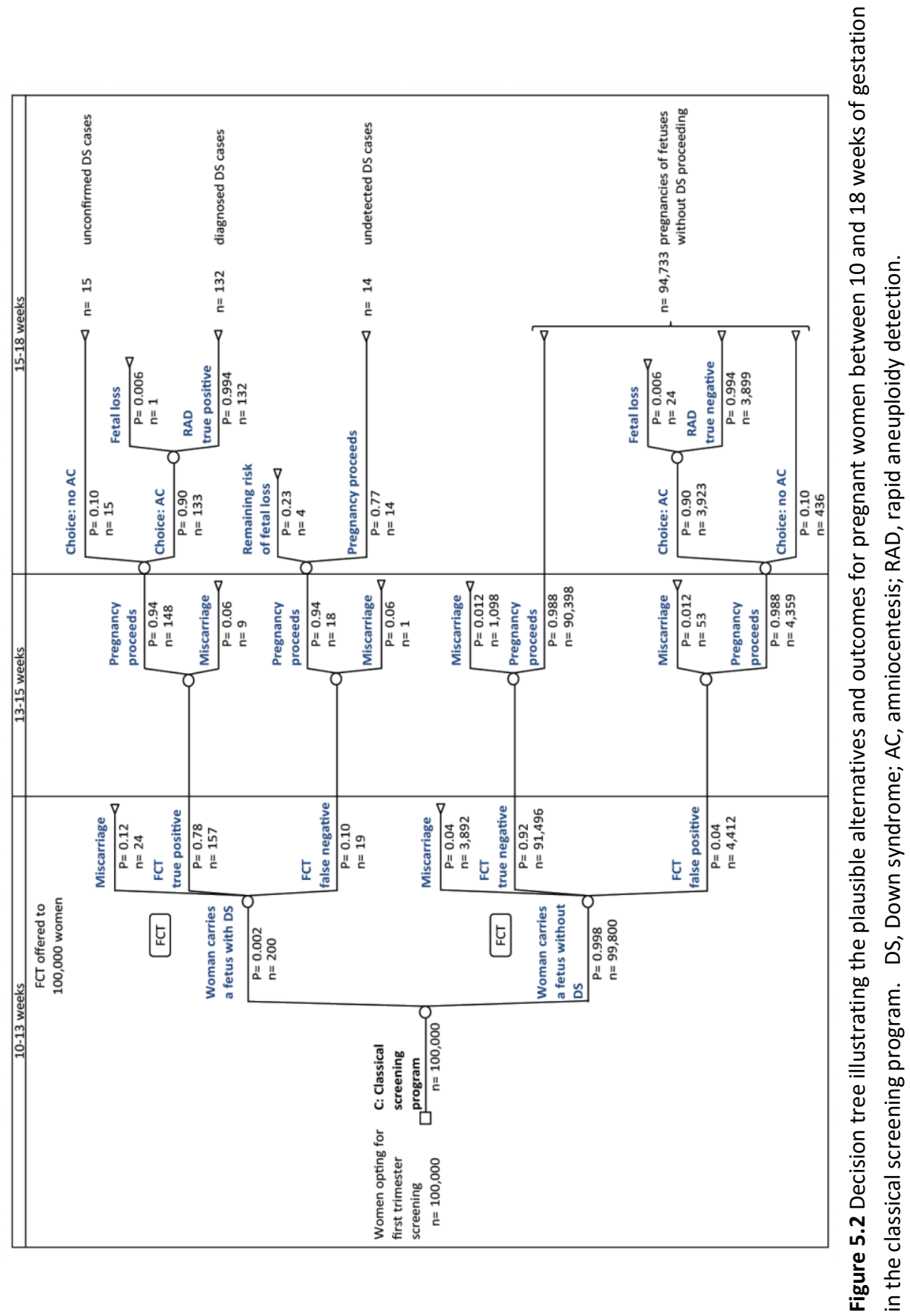


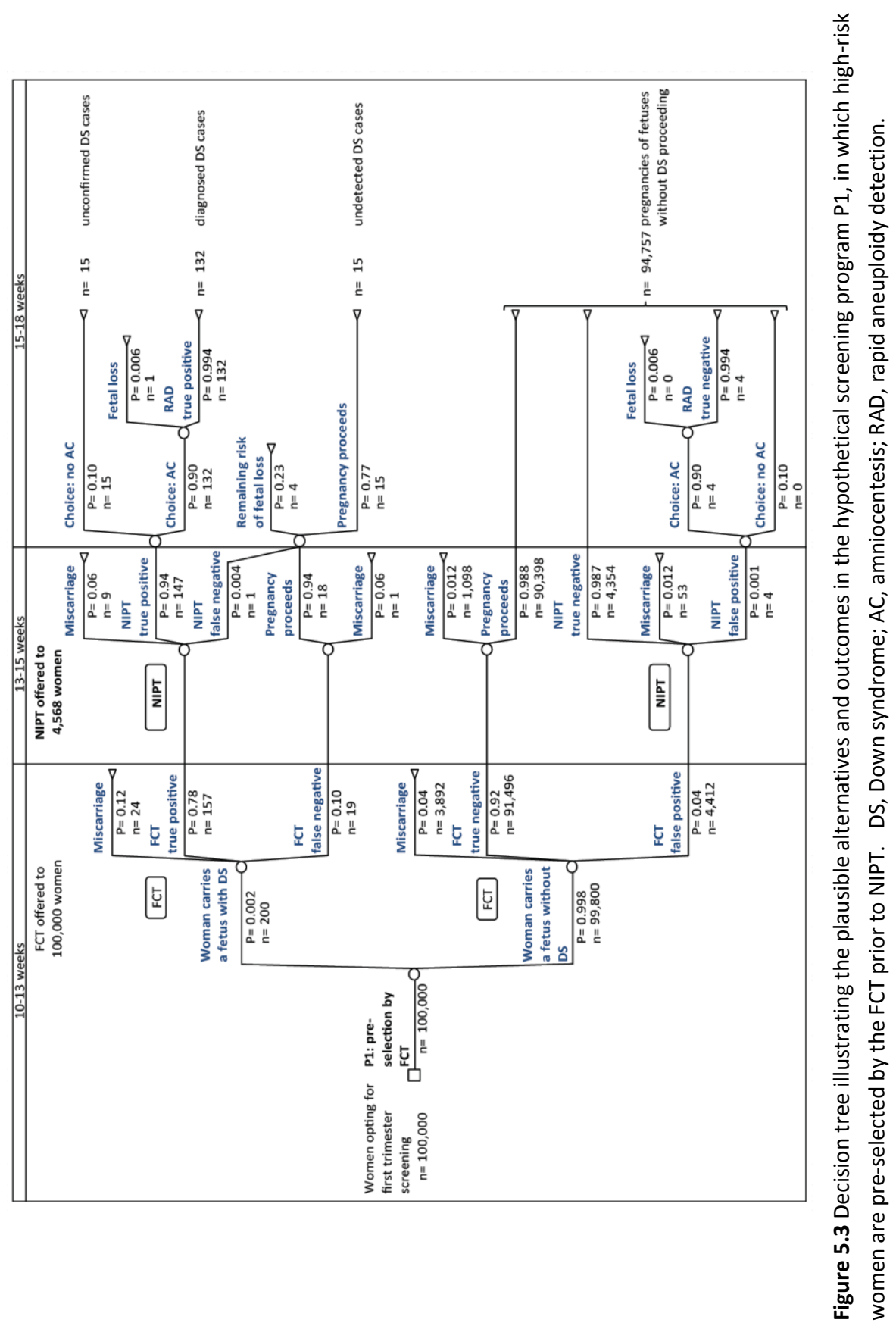



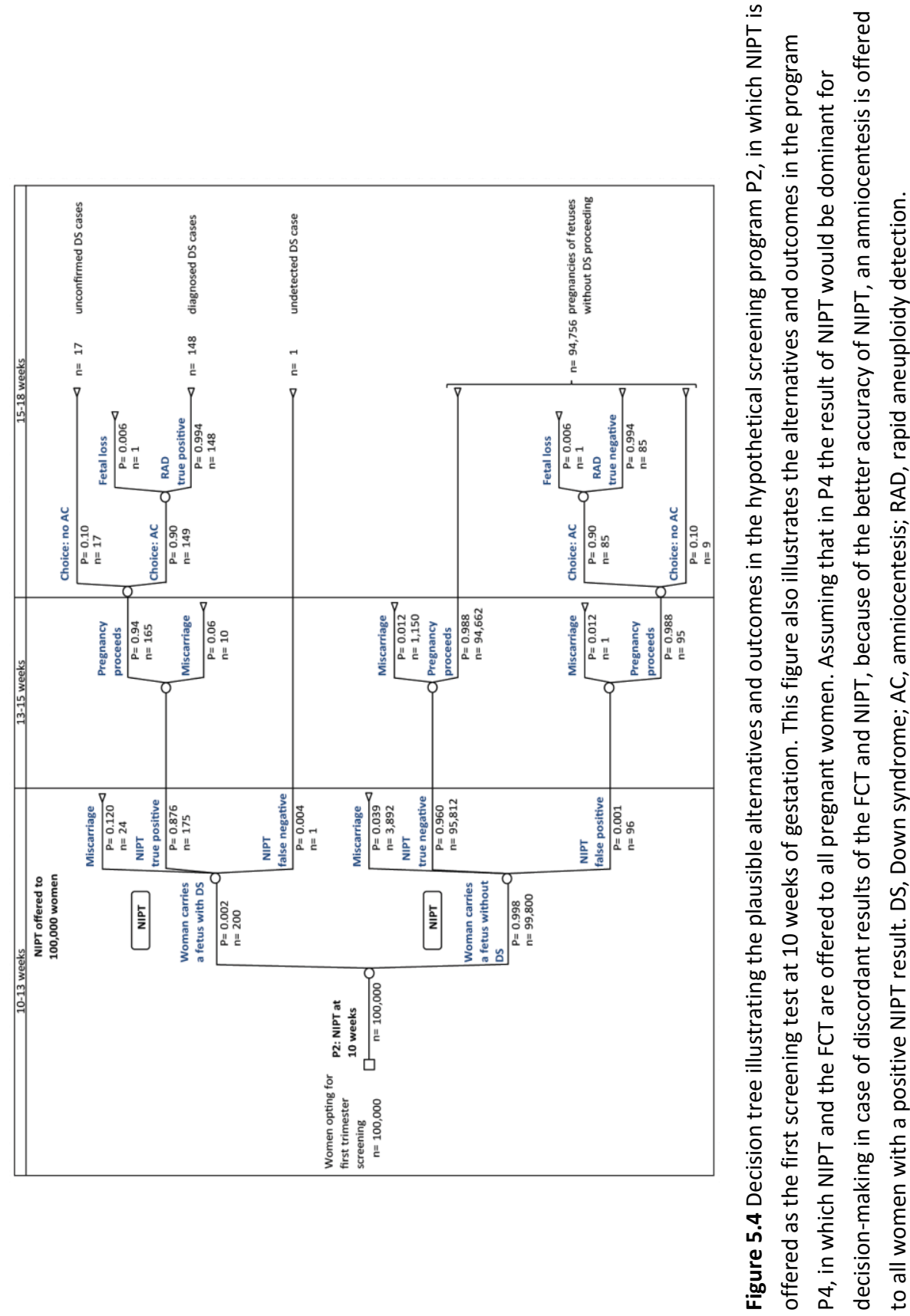


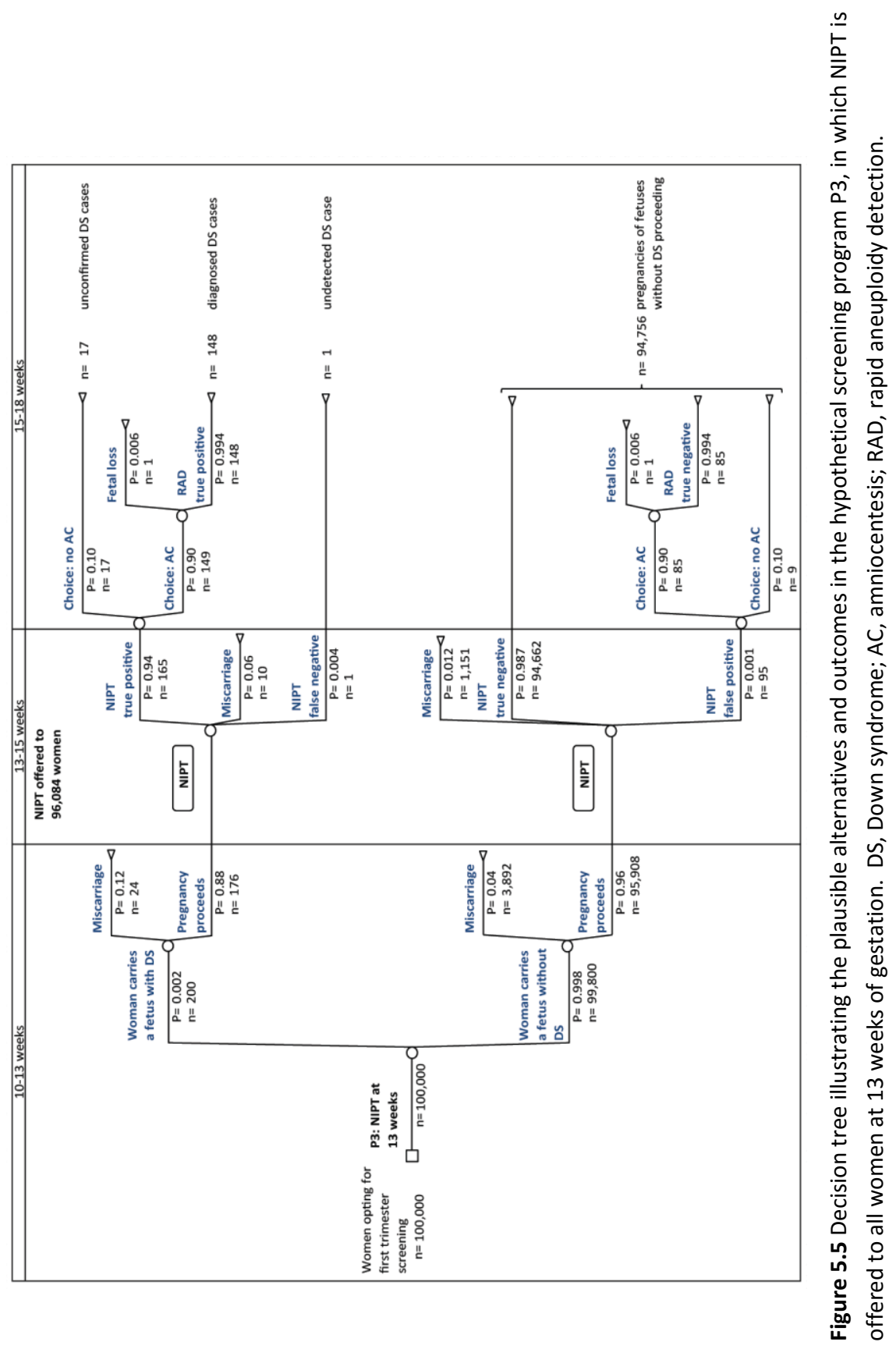




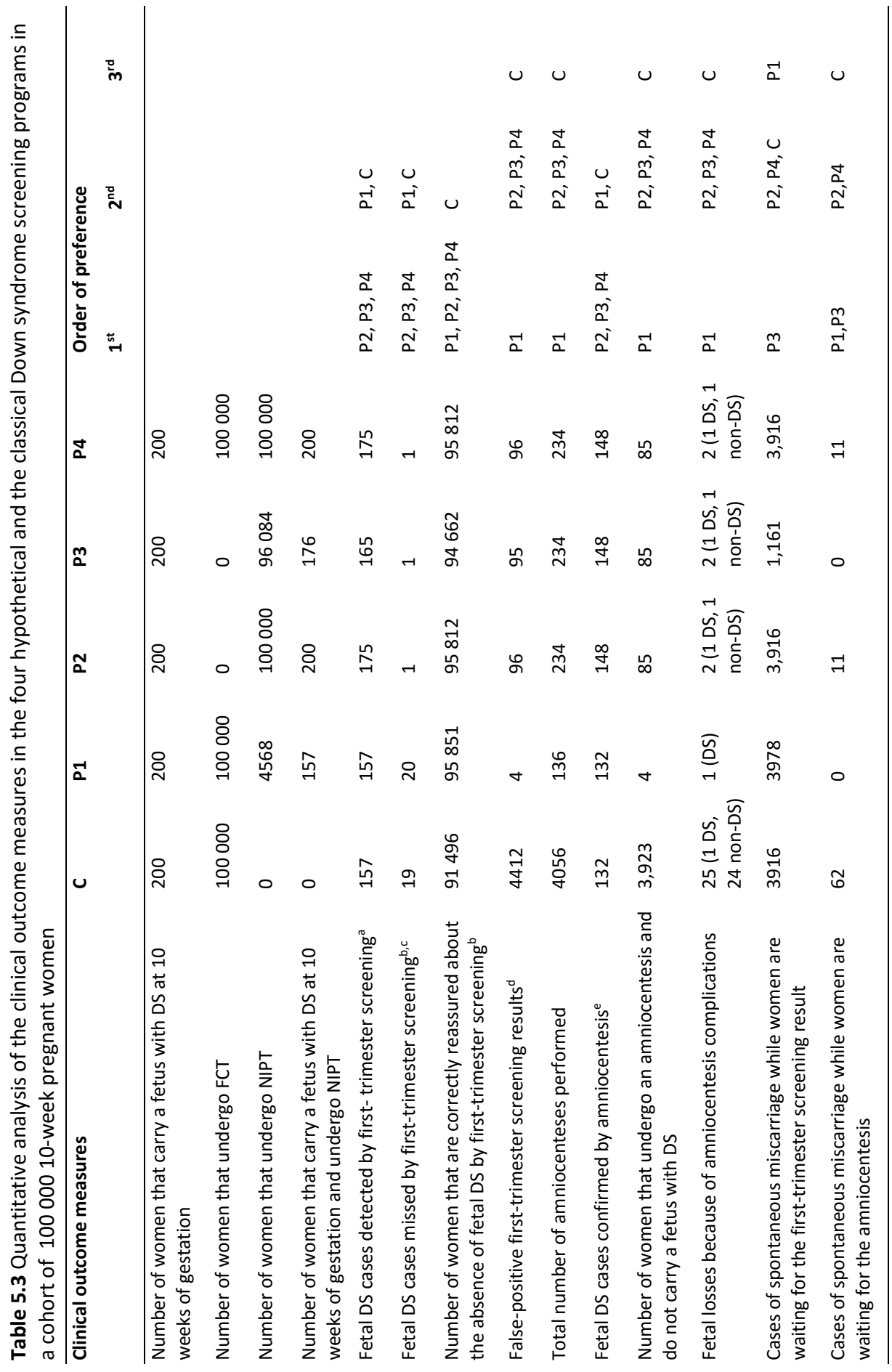




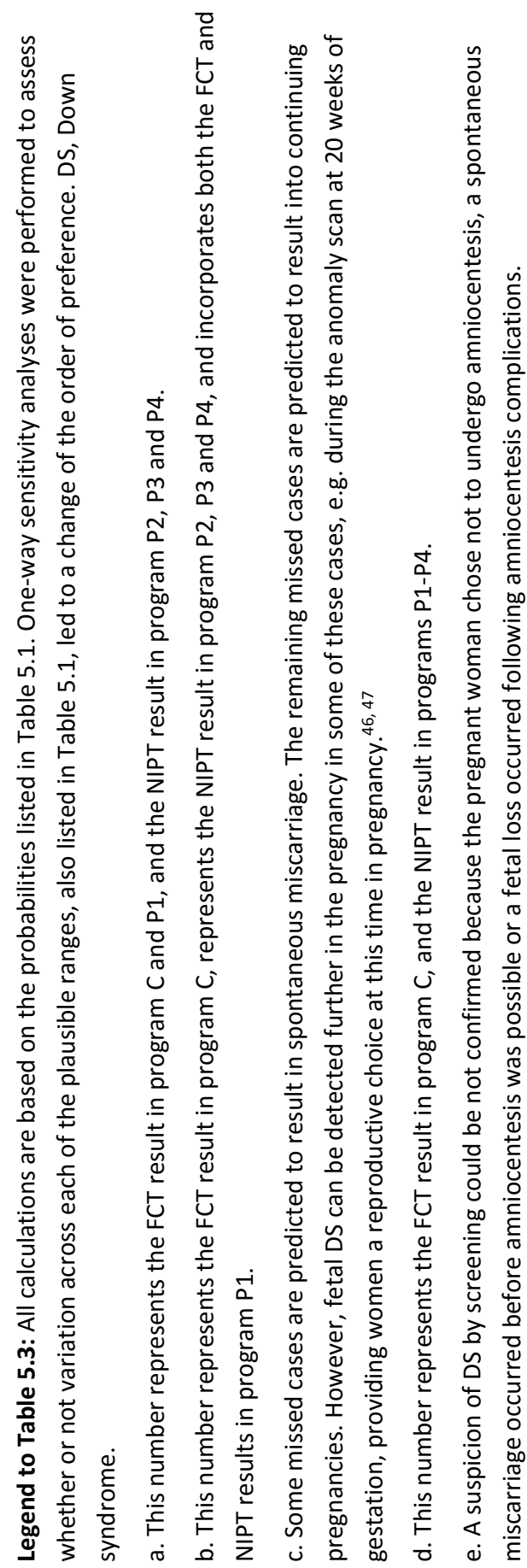




\subsection{Discussion}

In this study, we used a decision-analytic model to compare four hypothetical Down syndrome screening programs, in which NIPT was offered as a single first-trimester screening test or in combination with the FCT. We compared these programs with the classical Down syndrome screening program. As can be seen from our decisionanalytic model, and according to the literature, every program has its advantages and disadvantages. ${ }^{17-23}$

\subsubsection{A suggestion for the most favorable program - P3: NIPT as the first screening test for Down syndrome at 13 weeks of gestation}

We reflected upon the results of the quantitative analysis in the light of psychological and practical considerations, e.g. the chance that women are correctly reassured by a negative screening result, the chance of a correct positive screening result, the time until the result of the screening test, the time from the result of the screening test until the confirmation of a positive result by amniocentesis, the number of decision-making moments for women, etc.

We concluded that the most favorable Down syndrome screening program may be P3, in which NIPT is offered to all women at 13 weeks of gestation as the first screening test. Our conclusion is based on the following arguments: (1) The most sensitive programs, in which a minimal number of fetal Down syndrome cases is missed by the first-trimester screening, are the programs in which NIPT is offered to all women. The decline in detection of fetal Down syndrome at 13 weeks of gestation compared with 10 weeks of gestation is only explained by the occurring miscarriages. (2) Additionally, women only have to make a decision about whether or not they want to undergo an invasive test based on the result of one screening test, which is the least confusing scenario for the women. (3) At 13 weeks of gestation, NIPT is offered when the risk for spontaneous miscarriage has declined remarkably. Possibly, the number of spontaneous miscarriages was overestimated in the reference that we used, because early dating ultrasound was not routine practice in that time. ${ }^{31}$ However, we wanted to calculate the miscarriage risk in the specific time windows in which NIPT was offered, and we could not obtain this information from more recent studies. ${ }^{32,33}$ No change in the order of preference was seen if the miscarriage risks in fetuses without Down syndrome were much lower, i.e. half of the current estimated risk. The most preferable program was still P3. (4) Furthermore, following a positive 13-week NIPT, timely confirmatory amniocentesis is possible. After amniocentesis, a definitive 
diagnosis of fetal Down syndrome can be made by rapid aneuploidy detection. As a result, a total turnaround time from blood drawing for NIPT to a definitive diagnosis would be on average 3 weeks for all women, and a spontaneous miscarriage between a positive NIPT and the result of the amniocentesis is very unlikely to occur. (5) A last benefit of NIPT at 13 weeks of gestation is that women are offered some more time for adequate counseling and for reflection before they decide to undergo NIPT. At 10 weeks of gestation, women may speak to their midwife or obstetrician for the first time.

\subsubsection{What would be the arguments to keep the FCT?}

An advantage of preservation of the FCT may be that in the case of a NIPT failure, which has been reported in 1.3-5\%, women can base their decision of follow-up testing on the result of the FCT. ${ }^{10-13}$ It has been suggested that the prevalence of aneuploidy is higher in the NIPT failure group than in the overall population, so this group of women would benefit from an additional test. ${ }^{7}$

In the case of pre-selection by the FCT prior to NIPT, almost no false-positive results of NIPT are predicted; as a consequence, almost no unnecessary amniocenteses would be performed (4/100 000 in our cohort). This is a 1000-fold decline in comparison to the classical screening program. It is interesting to note that pre-selection by the FCT prior to NIPT would imply a similar Down syndrome detection rate (157/200 in our cohort), as in the classical screening program, and even a small increase in falsenegative results of the screening (2/200 instead of $1 / 200$ in our cohort). Therefore, we still believe that P3 (NIPT as a single test at 13 weeks) is the preferable program, leading to the detection of almost all cases of fetal Down syndrome by the screening while 85 out of 100000 screened women undergo an unnecessary amniocentesis. A possible way to overcome the decline of Down syndrome detection in the case of preselection by the FCT prior to NIPT is to lower the risk threshold from $\geq 1: 200$ to $\geq$ 1:1000 or $\geq 1: 2500$ to be eligible for NIPT and to offer women with a risk above a very high risk threshold ( $\geq 1: 100$ or $\geq 1: 150$ ) the choice between a direct invasive test and NIPT. ${ }^{16,20}$ This approach is called contingent screening and is investigated in two separate clinical studies in the state healthcare-funded system in the UK. It is also considered an appropriate screening option by the International Society for Prenatal Diagnosis. ${ }^{9}$ Unfortunately, contingent screening could not be included in our model because no information is available about the percentage of high-risk women that would choose amniocentesis or NIPT. Of course, the number of unnecessary 
amniocenteses increases if the risk threshold of the FCT is lower.

Finally, the Down syndrome screening program could still include the FCT to provide pregnant women information about their risk for other conditions, such as chromosomal abnormalities other than trisomies 21,18 and 13 , or structural anomalies and developmental disorders. ${ }^{34,35}$ However, some of the current NIPT assays already provide risk assessments for sex chromosomal aneuploidies, polyploidy and some microdeletions and duplications. ${ }^{3,36,37}$ If the FCT would be offered next to NIPT to target other conditions, this must be in line with the requirement of proportionality. ${ }^{17}$ In other words, the advantages should clearly outweigh the possible disadvantages. If this is proportional, and classical incidental findings are turned into a screening target, an accordingly adapted informed consent is required. Furthermore, there is no reason to believe that the early structural ultrasound at 12 weeks to screen for severe structural abnormalities, such as anencephaly, would disappear. An increased nuchal translucency seen during the early structural survey will as all other ultrasound abnormalities lead to follow-up investigations, including follow-up ultrasound or karyotyping.

\subsubsection{What would be the arguments to offer NIPT at 10 weeks of gestation?}

An advantage of NIPT at 10 weeks of gestation is that women are reassured earlier if the NIPT result is normal. If the result is abnormal, they either have some more time to plan and prepare for raising a child with Down syndrome or to make a decision about terminating the pregnancy. ${ }^{17,18}$ Furthermore, in the case of a NIPT failure, there is still time to repeat the NIPT or to perform an FCT next to the repeated NIPT to increase the chance to provide the couple with a prenatal screening result.

\subsubsection{What did we not include in our model?}

We are aware that health policy choices about followed strategies are among others based on the financial capacity and organizational capabilities of the healthcare system. In our decision-analytic model, we did not take into account the costs of the tests and assumed that all hypothetical strategies could be organized by the healthcare system. Furthermore, some scenarios were left out of the analysis for practical reasons. To have comparable results of the quantitative analysis, it was necessary to assume the same undefined uptake in all screening programs, leading to 100000 women undergoing prenatal screening (FCT and NIPT) for Down syndrome. Still, the 
uptake could be very different if other tests are available. Additionally, women who opt to go straight for invasive testing following a high risk of the FCT rather than undergo NIPT were not included in the model. They could make this decision either because they do not want to wait 2 weeks for the NIPT result or because of the increased accuracy of amniocentesis. Occasionally, if both screening tests are performed, it can happen that the risk provided by NIPT is low, while the FCT provides a very high risk. In that case, women can choose to undergo an invasive procedure despite the low risk of the NIPT, also because this very high risk may indicate another chromosome abnormality that is not detected by NIPT. ${ }^{35}$ Failure of NIPT was also not included in the model. Women undergo significant delay and potential stress from a failed test. If, after repeating the NIPT, still no result can be reported, women may opt for another prenatal test if they meet the conditions, or may choose to withdraw from prenatal screening for Down syndrome.

\subsubsection{Top-down decision or individualized choice?}

In view of the primary aim of prenatal screening, i.e. the provision of autonomous reproductive choice, it can be argued that women should, as far as is reasonably possible, be given the opportunity to decide for themselves what test strategy best fits their personal values and preferences. This strategy is termed individualized choice. ${ }^{38}$ Women could be offered the choice between 10-week NIPT and 13-week NIPT or above what risk threshold of the FCT they wish to undergo NIPT. Obviously, such individualized choice requires adequate professional support during pre-test counseling. The results of this study could be used to explain to women how their choice influences their risk to undergo an unnecessary amniocentesis and consequently their risk for fetal loss because of amniocentesis complications. Empirical research into feasibility, barriers and facilitators of individualized choice is crucially important. 


\subsection{Conclusion}

We conducted a quantitative analysis of the clinical outcome measures of four hypothetical programs and the classical Down syndrome screening program in order to aid health policy decision makers. Irrespective of the implementation strategies, offering NIPT results in important advantages for pregnant women compared with the classical Down syndrome screening program. However, every NIPT implementation strategy has its advantages and disadvantages. After a reflection upon the results of our analysis in the light of psychological and practical implications, we concluded that offering NIPT to all women at 13 weeks of gestation may be the most favorable program if detection of Down syndrome is the primary goal. In this program, women undergo one highly accurate screening test for Down syndrome when their risk for spontaneous miscarriage has declined remarkably. If fetal Down syndrome is suspected, a confirmatory amniocentesis can be scheduled shortly afterwards, leading to a total turnaround time from blood drawing to the result of the rapid aneuploidy detection of on average 3 weeks. 


\subsection{References}

1. Mersy E, Smits LJ, van Winden LA, de Die-Smulders CE; South-East Netherlands NIPT Consortium, Paulussen AD, Macville MV, Coumans AB, Frints SG. Noninvasive detection of fetal trisomy 21: systematic review and report of quality and outcomes of diagnostic accuracy studies performed between 1997 and 2012. Hum Reprod Update 2013;19:318-329.

2. Morain S, Greene MF, Mello MM. A new era in noninvasive prenatal testing. N Engl J Med 2013;369:499-501.

3. Bianchi DW, Wilkins-Haug L. Integration of noninvasive DNA testing for aneuploidy into prenatal care: what has happened since the rubber met the road? Clin Chem 2014;60:78-87.

4. Hui L. Non-invasive prenatal testing for fetal aneuploidy: charting the course from clinical validity to clinical utility. Ultrasound Obstet Gynecol 2013;41:2-6.

5. Gil MM, Quezada MS, Revello R, Akolekar R, Nicolaides KH. Analysis of cell-free DNA in maternal blood in screening for fetal aneuploidies: updated meta-analysis. Ultrasound Obstet Gynecol 2015;45:249266.

6. Bianchi DW, Parker RL, Wentworth J, Madankumar R, Saffer C, Das AF, Craig JA, Chudova DI, Devers $\mathrm{PL}$, Jones KW, Oliver K, Rava RP, Sehnert AJ; CARE Study Group. DNA sequencing versus standard prenatal aneuploidy screening. N Engl J Med 2014;370:799-808.

7. Norton ME, Jacobsson B, Swamy GK, Laurent LC, Ranzini AC, Brar H, Tomlinson MW, Pereira L, Spitz JL, Hollemon D, Cuckle H, Musci TJ, Wapner RJ. Cell-free DNA analysis for noninvasive examination of trisomy. N Engl J Med 2015;372:1589-1597.

8. Zhang H, Gao Y, Jiang F, Fu M, Yuan Y, Guo Y, Zhu Z, Lin M, Liu Q, Tian Z, Zhang H, Chen F, Lau TK, Zhao L, Yi X, Yin Y, Wang W: Non-invasive prenatal testing for trisomies 21, 18 and 13: clinical experience from 146958 pregnancies. Ultrasound Obstet Gynecol 2015;45:530-538.

9. Benn P, Borrell A, Chiu R, Cuckle H, Dugoff L, Faas B, Gross S, Huang T, Johnson J, Maymon R, Norton M, Odibo A, Schielen P, Spencer K, Wright D, Yaron Y. Position Statement from the Chromosome Abnormality Screening Committee on behalf of the Board of the International Society for Prenatal Diagnosis. http://www.ispdhome.org/ (accessed April 26, 2015).

10. Futch T, Spinosa J, Bhatt S, de Feo E, Rava RP, Sehnert AJ. Initial clinical laboratory experience in noninvasive prenatal testing for fetal aneuploidy from maternal plasma DNA samples. Prenat Diagn 2013;33:569-574.

11. Taylor JB, Chock VY, Hudgins L. NIPT in a clinical setting: an analysis of uptake in the first months of clinical availability. J Genet Couns 2014;23:72-78.

12. Gil MM, Quezada MS, Bregant B, Ferraro M, Nicolaides KH. Implementation of maternal blood cell-free DNA testing in early screening for aneuploidies. Ultrasound Obstet Gynecol 2013;42:34-40.

13. Song Y, Liu C, Qi H, Zhang Y, Bian X, Liu J. Noninvasive prenatal testing of fetal aneuploidies by massively parallel sequencing in a prospective Chinese population. Prenat Diagn 2013;33:700-706.

14. Hui L, Hyett J. Noninvasive prenatal testing for trisomy 21: challenges for implementation in Australia. Aust NZ J Obstet Gynaecol 2013;53:416-424.

15. van Schendel RV, Kleinveld JH, Dondorp WJ, Pajkrt E, Timmermans DR, Holtkamp KC, Karsten M, Vlietstra AL, Lachmeijer AM, Henneman L. Attitudes of pregnant women and male partners towards non-invasive prenatal testing and widening the scope of prenatal screening. Eur J Hum Genet 2014;22:1345-1350.

16. Hill M, Wright D, Daley R, Lewis C, McKay F, Mason S, Lench N, Howarth A, Boustred C, Lo K, Plagnol V, Spencer K, Fisher J, Kroese M, Morris S, Chitty LS. Evaluation of non-invasive prenatal testing (NIPT) for aneuploidy in an NHS setting: a reliable accurate prenatal non-invasive diagnosis (RAPID) protocol. BMC Pregnancy Childbirth 2014;14:229.

17. de Jong A, Dondorp WJ, Frints SG, de Die-Smulders CE, de Wert GM. Non-invasive prenatal diagnosis for aneuploidy: toward an integral ethical assessment. Hum Reprod 2011;26:2915-2917. 
18. Deans Z, Newson AJ. Ethical considerations for choosing between possible models for using NIPD for aneuploidy detection. J Med Ethics 2012;38:614-618.

19. Song K, Musci TJ, Caughey AB. Clinical utility and costs of non-invasive prenatal testing with cfDNA analysis in high-risk women based on a US population. J Matern Fetal Neonatal Med 2013;26:11801185.

20. Nicolaides $\mathrm{KH}$, Wright D, Poon LC, Syngelaki A, Gil MM. First-trimester contingent screening for trisomy 21 by biomarkers and maternal blood cell-free DNA testing. Ultrasound Obstet Gynecol 2013;42:4150 .

21. Cuckle H, Benn P, Pergament E. Maternal cfDNA screening for Down syndrome - a cost sensitivity analysis. Prenat Diagn 2013;33:636-642.

22. Beulen L, Grutters JP, Faas BH, Feenstra I, van Vugt JM, Bekker MN. The consequences of implementing non-invasive prenatal testing in Dutch national health care: a cost-effectiveness analysis. Eur J Obstet Gynecol Reprod Biol 2014;182:53-61.

23. Twiss $P$, Hill M, Daley R, Chitty LS. Non-invasive prenatal testing for Down syndrome. Semin Fetal Neonatal Med 2014;19:9-14.

24. Hill M, Fisher J, Chitty LS, Morris S. Women's and health professionals' preferences for prenatal tests for Down syndrome: a discrete choice experiment to contrast noninvasive prenatal diagnosis with current invasive tests. Genet Med 2012;14:905-913.

25. Lewis C, Silcock C, Chitty LS. Non-invasive prenatal testing for Down's syndrome: pregnant women's views and likely uptake. Public Health Genomics 2013;16:223-232.

26. Verweij EJ, Oepkes D, de Vries M, van den Akker ME, van den Akker ES, de Boer MA. Non-invasive prenatal screening for trisomy 21: what women want and are willing to pay. Patient Educ Couns 2013;93:641-645.

27. Benn P, Chapman AR, Erickson K, Defrancesco MS, Wilkins-Haug L, Egan JF, Schulkin J. Obstetricians and gynecologists' practice and opinions of expanded carrier testing and noninvasive prenatal testing. Prenat Diagn 2014;34:145-152.

28. Aleem IS, Schemitsch EH, Hanson BP. What is a clinical decision analysis study? Indian J Orthop 2008;42:137-139.

29. Hahnemann JM, Vejerslev LO. Accuracy of cytogenetic findings on chorionic villus sampling (CVS) diagnostic consequences of CVS mosaicism and non-mosaic discrepancy in centres contributing to EUCROMIC 1986-1992. Prenat Diagn 1997;17:801-820.

30. Seyller T: Simple decision tree. 2009. https://sites.google.com/site/simpledecisiontree/.

31. Avalos LA, Galindo C, Li DK. A systematic review to calculate background miscarriage rates using life table analysis. Birth Defects Res A Clin Mol Teratol 2012;94:417-423.

32. Makrydimas G, Sebire NJ, Lolis D, Vlassis N, Nicolaides KH. Fetal loss following ultrasound diagnosis of a live fetus at 6-10 weeks of gestation. Ultrasound Obstet Gynecol 2003;22:368-372.

33. Tong S, Kaur A, Walker SP, Bryant V, Onwude JL, Permezel M. Miscarriage risk for asymptomatic women after a normal first-trimester prenatal visit. Obstet Gynecol 2008;111:710-714.

34. Bilardo CM, Timmerman E, Pajkrt E, van Maarle M. Increased nuchal translucency in euploid fetuses what should we be telling the parents? Prenat Diagn 2010;30:93-102.

35. Petersen OB, Vogel I, Ekelund C, Hyett J, Tabor A; Danish Fetal Medicine Study Group; Danish Clinical Genetics Study Group. Potential diagnostic consequences of applying non-invasive prenatal testing: populationbased study from a country with existing firsttrimester screening. Ultrasound Obstet Gynecol 2014;43:265-271.

36. Daley R, Hill M, Chitty LS. Non-invasive prenatal diagnosis: progress and potential. Arch Dis Child Fetal Neonatal Ed 2014;99:F426-F430.

37. Srinivasan A, Bianchi DW, Huang H, Sehnert AJ, Rava RP. Noninvasive detection of fetal subchromosome abnormalities via deep sequencing of maternal plasma. Am J Hum Genet 2013;92:167-176. 
38. Bunnik EM, de Jong A, Nijsingh N, de Wert GM. The new genetics and informed consent: differentiating choice to preserve autonomy. Bioethics 2013;27:348-355.

39. Loane M, Morris JK, Addor MC, Arriola L, Budd J, Doray B, Garne E, Gatt M, Haeusler M, Khoshnood B, Klungsøyr Melve K, Latos- Bielenska A, McDonnell B, Mullaney C, O'- Mahony M, Queisser-Wahrendorf A, Rankin J, Rissmann A, Rounding C, Salvador J, Tucker D, Wellesley D, Yevtushok L, Dolk H. Twentyyear trends in the prevalence of Down syndrome and other trisomies in Europe: impact of maternal age and prenatal screening. Eur J Hum Genet 2013;21:27-33.

40. Resta RG. Changing demographics of advanced maternal age (AMA) and the impact on the predicted incidence of Down syndrome in the United States: implications for prenatal screening and genetic counseling. Am J Med Genet A 2005;133A:31-36.

41. Snijders RJ, Sundberg K, Holzgreve W, Henry G, Nicolaides KH. Maternal age- and gestation- specific risk for trisomy 21. Ultrasound Obstet Gynecol 1999;13:167-170.

42. Kagan KO, Wright D, Baker A, Sahota D, Nicolaides KH. Screening for trisomy 21 by maternal age, fetal nuchal translucency thickness, free beta-human chorionic gonadotropin and pregnancy-associated plasma protein-A. Ultrasound Obstet Gynecol 2008;31:618-624.

43. Chetty S, Garabedian MJ, Norton ME. Uptake of noninvasive prenatal testing (NIPT) in women following positive aneuploidy screening. Prenat Diagn 2013;33:542-546.

44. Mujezinovic F, Alfirevic Z. Procedure-related complications of amniocentesis and chorionic villous sampling: a systematic review. Obstet Gynecol 2007;110:687-694.

45. Akolekar R, Beta J, Picciarelli G, Ogilvie C, D’Antonio F. Procedure-related risk of miscarriage following amniocentesis and chorionic villus sampling: a systematic review and meta-analysis. Ultrasound Obstet Gynecol 2015;45:16-26.

46. Molander E, Alehagen S, Berterö CM. Routine ultrasound examination during pregnancy: a world of possibilities. Midwifery 2010;26:18-26.

47. Odibo AO, Ghidini A. Role of the second-trimester 'genetic sonogram' for Down syndrome screen in the era of first-trimester screening and noninvasive prenatal testing. Prenat Diagn 2014;34:511-517. 



\section{Chapter 6}

Noninvasive prenatal testing for sex chromosome trisomy: exploring opinions of pregnant women

Elke Mersy, Christine E.M. de Die-Smulders, Kelly Reumkens, Audrey B.C. Coumans, and Liesbeth A.D.M. van Osch 


\subsection{Abstract}

Objective: It is expected that in the coming years it will be possible to screen for a broad range of fetal conditions by noninvasive prenatal screening (NIPT). For women that only have access to NIPT through a national public health setting, this expansion is not available yet. The aim of this study was to explore the opinion of pregnant women about expanding the NIPT to sex chromosome trisomies (SCTs) in a national screening program. From a broader perspective, the expansion of disorders included in the NIPT panel was discussed.

Methods: We conducted qualitative semi-structured interviews with eight pregnant women about a hypothetical broader NIPT, with emphasis on sex chromosome trisomies.

Results: The interviewees expressed a variety of opinions concerning NIPT for SCTs. Four of them agreed with adding SCTs to the NIPT panel. The overall opinion is that women want to choose for themselves which disorders in the NIPT panel they wish to screen for, and which conditions they want to confirm by invasive testing.

Conclusion: While opinions about screening for SCTs were very diverse among the interviewees, all requested adequate information about every condition included in the NIPT panel, and the possibility to choose for themselves which screening strategy best fits their personal values and preferences. 


\subsection{Introduction}

For the past few years, pregnant women have been offered noninvasive prenatal testing (NIPT) for fetal autosomal aneuploidy (trisomies 13, 18 and 21) from 10 weeks of gestation onwards. ${ }^{1}$ The safe NIPT assays, based on next-generation sequencing of fetal cell-free DNA in maternal blood, proved to be much more reliable screening tests than the traditional biochemical screening tests, with significantly higher detection rates and lower false positive rates. ${ }^{2-4}$ Recently, some commercial laboratories added detection of sex chromosome aneuploidy (SCA) to their NIPT assay, since it requires only minor technical alterations to the original NIPT assays, and no biochemical screening tests have been available for these disorders. ${ }^{5-9}$ These assays are mostly available to pregnant women through individual practitioners or practices, such as in the USA. SCAs result from numerical abnormalities of the $X$ and $Y$ chromosomes with diverse clinical manifestations and dissimilar prevalences. ${ }^{10}$ Sometimes the fetal anomaly ultrasound scan shows fetal anomalies that may point towards a SCA, but more often fetal SCAs are prenatally diagnosed as an incidental finding of karyotyping aiming to rule out autosomal aneuploidy. ${ }^{11} \mathrm{~A}$ different NIPT accuracy was reported for each of them..$^{5-9}$

The two most common SCAs are the sex chromosome trisomies (SCTs) involving the $X$ chromosome: Klinefelter syndrome $(47, X X Y)$, occurring in approximately 1 in 600 male births, and Triple $X$ syndrome or Trisomy X (47,XXX), occurring in 1 in 1000 females births. ${ }^{12,13}$ Children born with SCTs have typically a normal lifespan and few, if any dysmorphic features. ${ }^{14}$ The conditions are estimated to remain undiagnosed in $64 \%$ of males with Klinefelter syndrome, and in up to $90 \%$ of women with Triple $X$ syndrome. ${ }^{13,15}$ Incidental prenatal diagnoses of SCTs are reported to lead to milder phenotypes than found in individuals diagnosed on clinical grounds, but the prognosis of any child prenatally diagnosed with an SCT cannot be predicted. ${ }^{11,16,17}$ Klinefelter is associated with a variable level of testosterone deficiency, leading to small testes and infertility, which can be treated by timely testosterone replacement therapy. ${ }^{15-18}$ Furthermore, boys with 47,XXY are at increased risk for mild developmental delay, speech-language disorders, learning disabilities, attention deficit hyperactivity disorder (ADHD), and other psychological conditions. ${ }^{15-18}$ Girls with Triple $X$ are at increased risk of motor and speech delays, cognitive deficits, learning disabilities, attention deficits and mood disorders (anxiety and depression). ${ }^{13}$

The interpretation of NIPT results and the counseling of pregnant couples can be challenging. While NIPT is excellent at excluding fetal SCTs, its positive predictive value 
is only around $50 \%$ (33.3-42.9\% for Klinefelter syndrome, and $57.1-70.0 \%$ for Triple $X$ syndrome).$^{7,8,19}$ This means that a positive result of the NIPT is discordant with the true fetal karyotype in approximately half of the cases. A second challenge is that Triple $X$ of the mother can be detected while screening the cell-free DNA in maternal blood for a fetal SCT. ${ }^{20,21}$ For these reasons, an invasive diagnostic procedure is recommended to confirm the diagnosis after suspicion of a fetal SCT following a positive NIPT result. ${ }^{19}$ Here, a third challenge arises. The generally mild and very variable phenotype may not justify an invasive procedure for some parents.

In some countries, where women only have access to NIPT through a national public health setting, NIPT for SCA is not available yet. The aim of this study was to explore the opinion of pregnant women about expanding the NIPT to SCTs in a national screening program. We investigated the motives and considerations of pregnant women concerning screening for these conditions, as well as their wishes regarding information provision and support. From a broader perspective, the expansion of disorders included in the NIPT panel was discussed.

\subsection{Methods}

\subsubsection{Participants}

The study was approved by the Medical Ethics Committee of the Academic Hospital Maastricht and Maastricht University. Pregnant women (> 18 years) who underwent prenatal screening for fetal trisomies 13,18 and 21 by the first trimester combined screening test or NIPT received oral and written information about the study. The women were invited to participate in an interview with the investigator (E.M.). Women were asked to return a filled out consent form in a freepost envelope or contact the investigator when interested in participating in the study.

\subsubsection{Semi-structured interviews}

Individual interviews were conducted in the hospital. Before the start of the interview, participants filled out two brief questionnaires: one on demographic and socioeconomic characteristics and one on reproductive and genetic history. Subsequently, some written and oral information was provided about SCTs and the possibilities and limitations of NIPT for SCTs (see Supplemental data). After ascertaining that the information about SCTs and NIPT for SCTs was clear for the participants, their ideas 
regarding NIPT for SCTs and the expansion of the spectrum of detectable disorders by NIPT were explored using open questions in a semi-structured interview schedule (see Supplemental data). All interviews were audiotaped and collected data was coded to guarantee the privacy of the respondents.

\subsubsection{Analysis}

True verbatim transcription of all audiotaped interviews was conducted and transcriptions were manually coded by two researchers (E.M. and K.R.). Open coding was followed by axial coding to retrieve the most important themes. In the axial coding the interviews were re-read to confirm that the themes arising from the open coding accurately represented the interview responses. Any discrepancies were discussed until consensus was reached.

\section{$6.4 \quad$ Results}

\subsubsection{Sample characteristics}

Of the twenty-five pregnant women that were invited to participate between July and October 2015, eight responded and agreed to take part (32\%, Table 6.1). Lack of knowledge about SCTs and preferring not to think about any genetic disorder in their fetus after being reassured by the screening for autosomal aneuploidy, were the main arguments for not participating. Seven participants had undergone screening for trisomies 13,18 and 21 by the first trimester combined test or NIPT. One pregnant woman was a young woman ( 23 years) and had not undergone prenatal screening but expressed interest in prenatal screening at older age. For every participant, screening for SCTs was hypothetical. Theoretical saturation was reached in interview 7 (i.e. no additional information was obtained in interview 8 ) and recruitment was ended. 
Table 6.1 Characteristics of the pregnant women (F)

\begin{tabular}{|c|c|c|c|}
\hline $\begin{array}{l}\text { Demographic and socio- } \\
\text { economic characteristics }\end{array}$ & $n(F)$ & Reproductive and genetic history & $n(F)$ \\
\hline \multirow[t]{2}{*}{ Mean age (years) (range) } & $32(23-42)$ & Number of pregnancy & \\
\hline & & 1st & $1(\mathrm{~F} 4)$ \\
\hline Nationality & & 2nd & $4(F 1, F 3, F 5, F 7)$ \\
\hline \multirow[t]{2}{*}{ Dutch } & 8 & 4th & $2(F 2, F 6)$ \\
\hline & & 7th & 1 (F8) \\
\hline Education & & Trimester of pregnancy & \\
\hline High & 5 (F1-F5) & Second & $3(F 2, F 7, F 8)$ \\
\hline Medium & 3 (F6-F8) & Third & $5(F 1, F 3-F 6)$ \\
\hline \multirow[t]{2}{*}{ Low } & 0 & Screening in this pregnancy & \\
\hline & & NIPT & $1(\mathrm{~F} 1)$ \\
\hline Religion & & First trimester combined test & 7 (F1-F7) \\
\hline Roman Catholic & $2(F 1, F 7)$ & No screening yet & 1 (F8) \\
\hline \multirow[t]{9}{*}{ None } & $6(\mathrm{~F} 2-\mathrm{F} 6, \mathrm{~F} 8)$ & Obstetric history & \\
\hline & & IVF, this pregnancy & $2(\mathrm{~F} 1, \mathrm{~F} 6)$ \\
\hline & & $\begin{array}{l}\text { Fetal trisomy 21, previous } \\
\text { pregnancy }\end{array}$ & $1(\mathrm{~F} 1)$ \\
\hline & & TOP, previous pregnancy & $2(F 1, F 7)$ \\
\hline & & Spontaneous miscarriage(s) & $2(\mathrm{~F} 2, \mathrm{~F} 8)$ \\
\hline & & Familial history & \\
\hline & & Son with autism & 1 (F7) \\
\hline & & Niece with Turner syndrome & $1(\mathrm{~F} 2)$ \\
\hline & & Aunt with mental retardation & $1(\mathrm{~F} 8)$ \\
\hline
\end{tabular}

Legend to Table 6.1: IVF, in vitro fertilization; TOP, termination of pregnancy

\subsubsection{Themes}

Six broad themes emerged from the analysis (Table 6.2). The first five themes were proposed by the investigator and discussed by open questions from the interview schedule. A sixth theme (individualized choice) was derived from the answers of the participants. Themes 1 and 2 were divided into subthemes. Most subthemes were part of the original interview schedule, only the first subtheme from theme 2 (safety and timing of NIPT) was derived from the answers of the interviewers. 
Table 6.2 Main themes and subthemes

\begin{tabular}{ll}
\hline Main themes & Subthemes \\
\hline 1. Prenatal screening for SCTs & $\begin{array}{l}\text { Severity of SCTs } \\
\text { Advantages and disadvantages of prenatal } \\
\text { screening for the future parents } \\
\text { Advantages and disadvantages of prenatal } \\
\text { screening for the fetus }\end{array}$ \\
& $\begin{array}{l}\text { Fetal sex is known } \\
\text { 2. Specific aspects of cell-free DNA testing }\end{array}$ \\
$\begin{array}{ll}\text { Safety and timing of NIPT } \\
\text { 3. Postnatal screening for SCTs }\end{array}$ & $\begin{array}{l}\text { The limited positive predictive value } \\
\text { Detection of maternal Tripe X syndrome }\end{array}$ \\
5. Pre-test and post-test informed decision-making & \\
6. Individualized choice & \\
\hline
\end{tabular}

Legend to table 6.2: SCTs, Sex chromosome trisomies

\subsubsection{Theme 1: Prenatal screening for SCTs}

Four of the respondents indicated that SCTs should be added to the spectrum of detectable genetic conditions by NIPT (F1, F3, F6, F7). The other four stated that they saw no additional value for themselves to screen for SCTs during pregnancy (F2, F4, F5, F8). To clarify their opinion, the pregnant women were asked to elaborate on these topics: the severity of SCTs, possible advantages and disadvantages of screening for SCTs, and how they felt about knowing the fetal sex early in pregnancy.

\section{Severity of SCTS}

The vast majority of the pregnant women (7/8) perceived SCTs as less severe than the autosomal trisomies. Arguments were the normal lifespan and a lower burden and impact on the quality of life of the parents. Two illustrative citations are: "IQ a little less, some troubles at school, this is not comparable with trisomy 13, which is simply not compatible with life" (F1), "In case of Down syndrome, I would terminate the pregnancy. But for these disorders, I would absolutely not terminate the pregnancy" (F7). Only one pregnant woman valued the SCTs as equally severe as the other trisomies if her own child would be affected (F6).

\section{Advantages and disadvantages of prenatal screening for the pregnant couple}

All eight women would appreciate to receive additional information about their fetus, 
and would be relieved if the fetus was not affected. As F1 said: "It is of course always an advantage if you receive the confirmation that your child is healthy." Five women stated that the test provides the possibility to prepare for the support of a child that might face problems: "I think for you as a parent, it is nice to be able to have that clarity already. You know okay, this is coming, and you can take it into account, and prepare yourself" (F5). Only two participants (F3 and F6) mentioned the option of termination of pregnancy (TOP) as a benefit of screening. Interestingly, three other interviewees firmly stated that they would disagree with offering pregnant women the possibility for TOP because of a fetal SCT.

All women summed up a number of disadvantages of screening for SCTs. Being informed about a disorder in pregnancy with unclear consequences for the life of their future child was a disadvantage that was reported by the majority of the women (5/8). Following a positive NIPT result, women would no longer have a worry-free pregnancy, or would not be without worries during the childhood of their future child (7/8). They would receive a prenatal test result about a disorder with unclear consequences for the future child's life (5/8), and for which they would take no further actions, nor during pregnancy, nor during childhood (4/8). F2 said: "I think this entails a lot of worries, making the pregnancy and the time when the child is born less pleasant. Since I think these are relatively mild disorders, I wonder if you should do this". One woman mentioned that she may feel guilty in case of a continued pregnancy if problems would occur during the child's life.

\section{Advantages and disadvantages of prenatal screening for the future child}

Two participants brought up that knowing the diagnosis at the start of life could increase the acceptance and understanding of the own behavior and difficulties, and in case of Klinefelter syndrome the child could be treated for its infertility in time. F2 said: "Maybe if you know this in advance, you let it be part of who you are, without it being a kind of shock at that moment [when diagnosed at later age]". In contrast to this statement, two interviewees indicated that knowing about the SCT at the start of life could be detrimental for the future child, because it could lead to stigmatization, a damaged parent-child relationship, and possible distress due to the infertility: "I think you receive a certain label as a child. No, I do not believe that I would want to know this as a parent. Maybe if we would not know the child would develop in a normal way, while if it is known by the parents and the environment, the child is treated differently in advance" (F4). 


\section{The fetal sex is known}

All participants wanted to be informed about the fetal sex. Three women stated that a consequence of taking the test is knowing the sex, and that pregnant women should be aware of this prior to testing. None of them would screen for SCTs only to know the fetal sex.

\subsubsection{Theme 2: Specific aspects of cell-free DNA testing}

\section{Safety and timing of NIPT}

Almost all women (7/8) praised that NIPT is a test without risk for mother and child that can be conducted early in pregnancy.

\section{The limited positive predictive value}

The limited positive predictive value of NIPT for SCT was well understood by the vast majority of the interviewees (7/8). Most women mentioned potential unnecessary anxiety while waiting for the definitive answer: "I think it causes unnecessary stress for the pregnant woman. I didn't go through it myself, but I know people with a positive nuchal translucency measurement. This was a stressful phase for them. Later, it turned out that everything was fine. So, yes, I think a predictive value of $50 \%$ of a positive test is low and a disadvantage" (F4). Half of the participants preferred confirmation after birth, instead of a follow-up invasive test during pregnancy, because of its additional miscarriage risk.

\section{Detection of maternal Triple $X$ syndrome}

The possibility to detect maternal Triple $X$ syndrome was well understood by the majority of the participants as well (7/8). None of them would refrain from NIPT because of the possibility to receive the diagnosis of Triple $X$ syndrome themselves during pregnancy.

\subsubsection{Theme 3: Postnatal screening for SCTs}

Postnatal screening for SCTs as a part of the new-born blood spot screening program was proposed by the interviewer as a hypothetical alternative, while discussing the disadvantages of prenatal screening for SCTs. Three interviewees stated that new-born screening for SCTs could be a good alternative to prenatal screening if TOP was not allowed or not preferred by the future parents. Only two interviewees preferred newborn screening above prenatal screening because stress during pregnancy is avoided 
in this scenario, while timely support of the child, and for testosterone administration in the case of Klinefelter syndrome is still possible. For example, F5 said: "I think I would be happier to know the diagnosis after the pregnancy. Because during pregnancy it brings just too much turmoil and uncertainty. While it would be no reason for me to terminate a pregnancy". Three participants mentioned violation of the autonomy right of the future parents, because of the loss of the option of TOP. The couple brought up that also the autonomy right of the child is violated, since it does not have the right not to know.

\subsubsection{Theme 4: Pre-test and post-test informed decision-making}

The topics our participants wished to be informed about during pre-test counseling, are summarized in Table 6.3. All women requested a face-to-face pre-test consultation, preferably with their own obstetrician or midwife. It was suggested that pre-test information should be repeated more than once.

Table 6.3 Pre-test informed decision making

\begin{tabular}{ll}
\hline Prior to NIPT, pregnant women request to be informed about & $\mathbf{n}$ out of $\mathbf{8 ~ F}$ \\
\hline The health and expected quality of life of children with SCTs & 8 \\
The positive and negative predictive value & 6 \\
The possibility to find maternal Triple X syndrome & 6 \\
All further steps in the screening process & 5 \\
The risks for the mother and child of the screening test itself & 3 \\
Is termination of the pregnancy an option? & 3 \\
The possibility to confirm a positive NIPT result with an invasive procedure & 3 \\
The additional miscarriage risk of a confirmatory invasive procedure & 3 \\
Potential stress and anxiety during pregnancy following a positive NIPT result & 2 \\
The prevalence of SCTs & 1 \\
The fetal sex will be known early in pregnancy & 1 \\
What is the legal abortion timeframe? & 1 \\
\hline
\end{tabular}

After a positive NIPT result, all women wanted to be informed again about the consequences for their future child and the further steps in the screening process. Support was requested during the decision of undergoing a follow-up invasive test $(3 / 8)$, during the decision about TOP $(3 / 8)$, during the rest of the pregnancy $(5 / 8)$, and after birth (1/8). For post-test information, half of the interviewees preferred their own obstetrician as the central contact person. 


\subsubsection{Theme 5: Prenatal screening in general}

When asked to deliberate on which disorders should be screened for by NIPT, most interviewees answered that these should be early-onset disorders, that shorten life or that substantially limit the quality of life. Four pregnant women requested from the government a list of diseases serious enough to warrant prenatal screening. The couple and two other women requested such a list of conditions to warrant selective abortion. Remarkably, the majority of interviewees mentioned concerns about eugenics and pursuing a perfect child. Two participants worried about the message that certain groups are not welcome in society.

\subsubsection{Theme 6: Individualized choice}

All women believed that participation and all further steps in the screening process should be voluntary and based on adequate information. Four interviewees expressed the belief that pregnant women undergoing NIPT should be given the opportunity to indicate which specific outcomes they do not want to be informed about. As one interviewee put it: "Maybe people should be given the choice in advance. They can fill out a list: I do want to screen for these disorders, and I don't want to screen for these disorders" (F2).

\subsection{Discussion}

To explore the opinion of pregnant women about including SCTs in the NIPT panel in a public health setting, semi-structured interviews were conducted with eight pregnant women. Similar to a previous study, our participants were unfamiliar with SCTs. ${ }^{22}$ However, after explanation of the SCTs and possibilities and limitations of NIPT for SCTs, all participants were able to formulate possible advantages and disadvantages, and discuss the themes brought up by the investigator. Although we had a limited sample size, saturation was reached. We have interviewed a representative group of women that opt for prenatal screening, and were able to obtain very different opinions. Lack of knowledge about SCTs and preferring not to think about any genetic disorder in their fetus after being reassured by the screening for autosomal aneuploidy, were the main arguments for not participating. Most likely, the hypothetical character of the study, where women had to imagine how they would feel about a screening offer that in reality is not available for them, has contributed to the limited sample size. It is likely that the low response rate (32\%) had some effects 
on the conclusions drawn from this paper. Our article did not include the opinion of pregnant women that do not want to undergo the currently offered prenatal screening, because we assumed that these women also would not opt for prenatal screening for SCTs. Although all of the interviewees were in favor of screening for trisomies 13, 18 and 21, only four of them would also undergo screening for SCTs. This is not in agreement with two recent studies that found that the majority of pregnant women supports NIPT for fetal SCA. ${ }^{22,23}$ One possible explanation for this difference is that we have limited our interviews to the SCTs, which are milder chromosome aneuploidies than for example Turner syndrome $(45, \mathrm{X})$. Furthermore, either questionnaires or focus groups were used in the other studies. We believe that individual interviews, as used in our study are the best medium to investigate this subject, in order to identify detailed perceptions, opinions, beliefs, and attitudes.

The SCTs were perceived as less severe than the autosomal trisomies by the majority of the interviewees, because of the normal lifespan of children with SCTs and the limited negative effect on the quality of life of the future parents. Benefits of screening for SCTs brought up by the participants were receiving additional information about their fetus, being reassured by a negative test result, and the option to prepare for the support of their future child. Our study identified several potential disadvantages: receiving a prenatal test result about a disorder with unclear consequences for the future child's life and for which they would take no further actions, a less worry-free pregnancy and childhood, and possible guilt about continuation of pregnancy. Negative effect on emotions during pregnancy and childbirth have been reported by pregnant women after an incidental finding of fetal sex chromosome aneuploidy. ${ }^{24}$ Two participants mentioned the option of TOP as a benefit of screening, while others firmly stated that they disagreed with offering pregnant women the possibility to terminate the pregnancy because of a fetal SCT. Cultural and societal factors play a role in the parental decision about TOP because of a fetal SCA. ${ }^{25}$ Internationally, a decreasing trend of abortions for SCTs is observed. ${ }^{14}$ In continuing pregnancies, the early knowledge of the diagnosis may positively affect the child's cognitive and physiological development. ${ }^{11}$ However, knowing about the SCT at the start of life could be detrimental for the future child, because it could lead to stigmatization, a damaged parent-child relationship, and possible distress due to the infertility.

All interviewees were positive about NIPT in general. The limited positive predictive value was perceived as a negative aspect of NIPT for SCTs. In concordance with previous studies not all participants agreed to undergo confirmatory invasive testing 
for these conditions during pregnancy, because of its additional miscarriage risk. ${ }^{23}$ None of the interviewees thought that it was a problem that the fetal sex was known early in pregnancy. The detection of maternal Triple $X$ during pregnancy was perceived as not important or even as an advantage of the test. It would allow personal life experiences and potential struggles to be seen in a different perspective. For simplicity reasons, maternal mosaicism, e.g. for monosomy $\mathrm{X}$, was not discussed with the participants.

All participants requested to be well-informed about every condition in the NIPT panel prior to testing and brought up that participation and all further steps in the screening process should be voluntary and based on adequate information. Similar to previous studies, the participants emphasized the importance of acquiring pre-test and posttest information and support from their obstetric provider. ${ }^{22,26}$ Without being explicitly asked, all interviewees in this study brought up aspects of individualized choice, in which women decide for themselves what prenatal test strategy best fits their personal values and preferences, in contrast to a fixed prenatal screening program for everyone. ${ }^{27,28}$ They expressed the belief that, based on adequate information, women are able to choose which conditions they want to screen for, if they want to undergo confirmatory invasive testing, and if they choose for TOP. While voluntary choices about follow up testing and TOP are guaranteed, opt-in and opt-out options are only limited possible at the moment.

\subsection{Conclusion}

A plurality of opinions about screening for SCTs asks for an individualized prenatal screening trajectory. All participants requested adequate information before undergoing NIPT and the possibility to choose for themselves which screening strategy best fit their personal values and preferences 


\subsection{References}

1. Bianchi DW, Wilkins-Haug L. Integration of noninvasive DNA testing for aneuploidy into prenatal care: what has happened since the rubber met the road? Clin Chem 2014;60:78-87.

2. Gil MM, Quezada MS, Revello R, Akolekar R, Nicolaides KH. Analysis of cell-free DNA in maternal blood in screening for fetal aneuploidies: updated meta-analysis. Ultrasound Obstet Gynecol 2015;45:249266.

3. Norton ME, Jacobsson B, Swamy GK, Laurent LC, Ranzini AC, Brar H, Tomlinson MW, Pereira L, Spitz JL, Hollemon D, Cuckle H, Musci TJ, Wapner RJ. Cell-free DNA analysis for noninvasive examination of trisomy. N Engl J Med 2015;372:1589-1597.

4. Song Y, Huang S, Zhou X, Jiang Y, Qi Q, Bian X, Zhang J, Yan Y, Cram DS, Liu J. Non-invasive prenatal testing for fetal aneuploidies in the first trimester of pregnancy. Ultrasound Obstet Gynecol 2015;45:55-60.

5. Hooks J, Wolfberg AJ, Wang ET, Struble CA, Zahn J, Juneau K, Mohseni M, Huang S, Bogard P, Song K, Oliphant A, Musci TJ. Non-invasive risk assessment of fetal sex chromosome aneuploidy through directed analysis and incorporation of fetal fraction. Prenat Diagn 2014;34:496-499.

6. Nicolaides KH, Musci TJ, Struble CA, Syngelaki A, Gil MM. Assessment of fetal sex chromosome aneuploidy using directed cell-free DNA analysis. Fetal Diagn Ther 2014;35:1-6.

7. Porreco RP, Garite TJ, Maurel K, Marusiak B; Obstetrix Collaborative Research Network, Ehrich M, van den Boom D, Deciu C, Bombard A. Noninvasive prenatal screening for fetal trisomies 21, 18, 13 and the common sex chromosome aneuploidies from maternal blood using massively parallel genomic sequencing of DNA. Am J Obstet Gynecol 2014;211:365.e1-12.

8. Yao H, Jiang F, Hu H, Gao Y, Zhu Z, Zhang H, Wang Y, Guo Y, Liu L, Yuan Y, Zhou L, Wang J, Du B, Qu N, Zhang R, Dong $Y, X u H$, Chen F, Jiang H, Liu Y, Zhang L, Tian Z, Liu Q, Zhang C, Pan X, Yang S, Zhao L, Wang W, Liang Z. Detection of fetal sex chromosome aneuploidy by massively parallel sequencing of maternal plasma DNA: initial experience in a Chinese hospital. Ultrasound Obstet Gynecol 2014;44:1724.

9. Bianchi DW, Parsa S, Bhatt S, Halks-Miller M, Kurtzman K, Sehnert AJ, Swanson A. Fetal sex chromosome testing by maternal plasma DNA sequencing: clinical laboratory experience and biology. Obstet Gynecol 2015;125:375-382.

10. Linden MG, Bender BG, Robinson A. Genetic counseling for sex chromosome abnormalities. Am J Med Genet 2002;110:3-10.

11. Pieters JJ, Verhaak CM, Braat DD, van Leeuwen E, Smits AP. Experts' opinions on the benefit of an incidental prenatal diagnosis of sex chromosomal aneuploidy: a qualitative interview survey. Prenat Diagn 2012;32:1151-1157.

12. Morris JK, Alberman E, Scott C, Jacobs P. Is the prevalence of Klinefelter syndrome increasing? Eur J Hum Genet 2008;16:163-170.

13. Tartaglia NR, Howell S, Sutherland A, Wilson R, Wilson L. A review of trisomy X $(47, X X X)$. Orphanet J Rare Dis 2010;5:8.

14. Boyd PA, Loane M, Garne E, Khoshnood B, Dolk H; EUROCAT working group. Sex chromosome trisomies in Europe: prevalence, prenatal detection and outcome of pregnancy. Eur J Hum Genet 2011;19:231234.

15. Visootsak J, Ayari N, Howell S, Lazarus J, Tartaglia N. Timing of diagnosis of 47,XXY and 48,XXYY: a survey of parent experiences. Am J Med Genet A 2013;161A:268-272.

16. Ratcliffe S. Long-term outcome in children of sex chromosome abnormalities. Arch Dis Child 1999;80:192-195.

17. Linden MG, Bender BG. Fifty-one prenatally diagnosed children and adolescents with sex chromosome abnormalities. Am J Med Genet 2002;110:11-18.

18. Nieschlag E. Klinefelter syndrome: the commonest form of hypogonadism, but often overlooked or untreated. Dtsch Arztebl Int 2013;110:347-353. 
19. Kalafat E, Seval MM, Turgay B, Koç A. Non-invasive prenatal testing for sex chromosome abnormalities: a source of confusion. BMJ Case Rep. 2015 Jan 28;2015.

20. McNamara CJ, Limone LA, Westover T, Miller RC. Maternal source of false-positive fetal sex chromosome aneuploidy in noninvasive prenatal testing. Obstet Gynecol 2015;125:390-392.

21. Wang Y, Chen Y, Tian F, Zhang J, Song Z, Wu Y, Han X, Hu W, Ma D, Cram D, Cheng W. Maternal mosaicism is a significant contributor to discordant sex chromosomal aneuploidies associated with noninvasive prenatal testing. Clin Chem 2014;60:251-259.

22. Agatisa PK, Mercer MB, Leek AC, Smith MB, Philipson E, Farrell RM. A first look at women's perspectives on noninvasive prenatal testing to detect sex chromosome aneuploidies and microdeletion syndromes. Prenat Diagn 2015;35:692-698.

23. Lau TK, Chan MK, Salome Lo PS, Chan HY, Chan WK, Koo TY, Ng HY, Pooh RK. Non-invasive prenatal screening of fetal sex chromosomal abnormalities: perspective of pregnant women. J Mater Fetal Neonatal Med 2012;25:2616-2619.

24. Pieters JJ, Kooper AJ, Eggink AJ, Verhaak CM, Otten BJ, Braat DD, Smits AP, van Leeuwen E. Parents' perspectives on the unforeseen finding of a fetal sex chromosomal aneuploidy. Prenat Diagn 2011;31:286-292.

25. Jeon KC, Chen LS, Goodson P. Decision to abort after a prenatal diagnosis of sex chromosome abnormality: a systematic review of the literature. Genet Med 2012;14:27-38.

26. Farrell RM, Mercer MB, Agatisa PK, Smith MB, Philipson E. It's more than a blood test: patients' perspectives on noninvasive prenatal testing. J Clin Med 2014;3:614-631.

27. Mersy E, de Die-Smulders CE, Coumans AB, Smits LJ, de Wert GM, Frints SG, Veltman JA. Advantages and Disadvantages of Different Implementation Strategies of Non-Invasive Prenatal Testing in Down Syndrome Screening Programmes. Public Health Genomics 2015;18:260-271.

28. Bunnik EM, de Jong A, Nijsingh N, de Wert GM.The new genetics and informed consent: differentiating choice to preserve autonomy. Bioethics 2013;27:348-355. 

Supplemental data Chapter 6 


\section{Additional written and oral information}

Original: Dutch. Translated into English for publication.

\section{What is NIPT?}

In the blood of a pregnant woman, her own DNA is present, as well as DNA from the child she is carrying. DNA contains the code that determines our genetic characteristics. Drawing blood from the pregnant woman to test the unborn child's DNA, is called noninvasive prenatal testing, abbreviated to NIPT. [picture illustrating maternal and fetal cell-free DNA]

\section{Chromosomes}

The DNA in our body is folded into chromosomes. There are two copies of each chromosome. Only the sex chromosomes differ for men and women ( $X$ and $Y$ ). $A$ woman has two $X$ chromosomes, and a man has one $X$ chromosome and one $Y$ chromosome. [picture illustrating the karyotypes $46, X X$ and $46, X Y$ ]

\section{Currently in the Netherlands}

Today in the Netherlands, the DNA of the unborn child is tested by NIPT for Down syndrome (3 times chromosome 21), Edwards syndrome (3 times chromosome 18), Patau syndrome (3 times chromosome 13). The NIPT is only offered to women that have a high risk of one of these chromosome disorders following the combined test (a risk of 1 in 200 or higher). The combined test consists of two parts: a blood test and an ultrasound to measure the nuchal translucency of the child.

\section{NIPT of sex chromosome aneuploidy}

Foreign commercial laboratories also offer NIPT. Currently, these companies may also test for other genetic disorders using NIPT, because this is technically easy to do so. This is not done in the Netherlands yet. However, we are wondering what pregnant couples in the Netherlands think of this option. In this study, we want to investigate what your opinion is about expanding the existing NIPT to also screen for sex chromosome disorders. Additional information is provided below on sex chromosome disorders, which you may take into account when forming your opinion.

\subsection{What is a sex chromosome disorder?}

In a sex chromosome disorder, a change in the number of sex chromosomes occurs. We limit ourselves in this study to the two most common disorders: an extra $X$ chromosome in a woman (Triple $X$ syndrome) and an extra $X$ chromosome in a man (Klinefelter syndrome). [picture illustrating the karyotypes 47, XXX and 47,XXY]

\subsection{Consequences for the unborn child}

The effect of an extra $X$ chromosome is usually mild. People have a normal life span 
and little or no external characteristics. Children with Klinefelter syndrome and Triple $X$ syndrome rarely have an intellectual disability, although the IQ may be 10-15 points lower than in siblings. There is more risk of a mild impairment in speech and language development (this occurs in $50-80 \%$ of cases). In addition, learning problems in school are seen (in $>70 \%$ cases). Therapy and support for these problems are the same as in children without sex chromosome disorders. Psychological or psychiatric problems may occur (in $25 \%$ of cases), such as attention deficit hyperactivity disorder (ADHD) or depression. The main problem of boys with Klinefelter syndrome is their infertility. No or very few sperm cells are produced. In addition, these boys have small testes after puberty and extra administration of testosterone (male hormone) may be required. Girls with triple $X$ syndrome are normally fertile.

\subsection{What does NIPT for sex chromosome disorders offer?}

1) Reassurance. If the NIPT shows no extra $X$ chromosome, then the pregnant woman can be reassured: her baby will not have a change in the number of sex chromosomes.

2) An increased risk of Klinefelter syndrome or Triple $X$ syndrome. If the NIPT shows an extra $X$ chromosome, in half the cases, the baby still does not have Klinefelter syndrome or Triple $X$ syndrome. One reason is that the extra $X$ chromosome comes from the pregnant woman herself. In the blood of a pregnant woman, her own DNA and the DNA of her unborn child are present. The NIPT will examine all DNA simultaneously. It is possible that the pregnant woman does not know she has Triple $X$ syndrome, because it often causes no symptoms. If the NIPT shows an extra $X$ chromosome, a follow-up test by chorionic villus sampling or amniocentesis is required, along with a maternal blood test. The follow-up test takes an extra week (with a rapid test). The risk of miscarriage is $0.3-0.5 \%$.

3) Knowing the diagnosis during pregnancy and at the beginning of life. On the one hand, knowing that the child has an extra $X$ chromosome can be stressful for the pregnant couple during pregnancy and birth. During the time after birth parents can sometimes have doubts about the development of the child. It may also be difficult for parents if an when they decide to tell their child about the condition. On the other hand, parents may appreciate the clarity that comes with an earlier diagnosis during pregnancy. Finally, parents are faced with the decision whether to continue or terminate the pregnancy. This can be difficult, because it is uncertain whether or not the child will have problems and to what extent.

4) The sex. If the test is carried out the sex of the child will be known by the laboratory. This does not have to be communicated to the parents in case of a normal result (no extra X chromosome). 


\section{Interview guide}

\section{Part 1. Exploring question}

1. What is your opinion about the evolution that more disorders are included in the NIPT screening test?

Open question

Part 2. The interviewer asks about the possible motives and considerations concerning NIPT for sex chromosome trisomy

2. What is your opinion about the severity of the sex chromosomal trisomies? Are they, according to you, equally severe or more or less severe than the trisomies that are currently screened for?

Open question + question with three possible answers

3. Are there, according to you, advantages of screening for sex chromosome trisomy during your pregnancy?

Open question (When participant has elaborated on advantages for other women, ask what the advantages for herself are).

4. Are there, according to you, disadvantages of screening for sex chromosome trisomy during your pregnancy?

Open question (When participant has elaborated on disadvantages for other women, ask what the disadvantages for herself are).

5. What is your opinion about the accuracy of NIPT?

Open question (When needed, explain again the meaning of positive and negative predictive value, and mention the limited positive predictive value of NIPT for sex chromosome trisomy).

6. What do you think about the fact that the result of the NIPT might be an altered number of sex chromosomes in yourself?

Open question, only for pregnant woman (When needed, explain again how this is possible. Specifically ask if the pregnancy is an appropriate time to find out.)

7. What is your opinion about the fact that NIPT is a prenatal test and that, following confirmation of a positive result, a choice about continuation or termination of the pregnancy can be made?

Open question. Topics that can be suggested by the interviewer are: knowledge of the disorder at the time of birth, guidance during pregnancy, new-born screening as alternative.

8. What do you think about knowing the sex of the fetus following NIPT? 
Open question

9. Should NIPT for SCTs be added to the current NIPT assay? Why?

Yes/No question + open question

This was the final question of the part of the interview about your opinion about NIPT for SCTs. To control that I understood you correctly, I will give a short summary of your answers. Was the summary correct and complete? Do you want to add anything?

Part 3. The interviewer asks about the wishes of the couples concerning patient education and counseling (20-30 $\mathrm{min})$

10. If the test would be offered, what information should be explained during pre-test counseling?

Open question. Topics that can be suggested by the interviewer are: the phenotype, the variability of the phenotype, the positive and negative predictive values, the possibility to find maternal sex chromosome trisomy, the possibility of a choice between continuation or termination of the pregnancy, the potential stress and anxiety during pregnancy and after birth.

11. How would you like to obtain pre-test information?

Open question. Topics that can be suggested by the interviewer are: website, booklet, movie, consultation with a clinical geneticist/midwife/gynecologist.

12. If the NIPT would be positive, what information should be explained during posttest counseling?

Open question.

13. How would you like to obtain post-test information?

Open question.

This was the final question of the part of the interview about patient information and guidance. To control that I understood you correctly, I will give a short summary of your answers. Was the summary correct and complete? Do you want to add anything?

Part 4. The interviewer asks again about the wishes of the couples concerning expansion of the disorders included in the NIPT panel

14. If you would be able to choose, which disorders should be screened for during pregnancy?

Open question.

\section{Part 5. End of the interview}

15. Do you want to add anything concerning this topic that was not yet discussed during the interview? Open question. 



\section{Chapter 7}

General discussion and future perspectives 
In 1997, Lo et al. discovered the presence of fetal cell-free DNA (cfDNA) in the blood circulation of pregnant women. ${ }^{1}$ Since then, cfDNA has increasingly been used in prenatal care, and in prenatal screening and diagnosis of genetic disorders. Safe, noninvasive cfDNA tests, require simply a maternal venous blood sampling. In prenatal care, fetal blood group genotyping in the cfDNA of alloimunised pregnant women has replaced the invasive procedures in the prevention of hemolytic disease in the fetus and newborn. ${ }^{2,3}$ Furthermore, when a genetic determination of the fetal sex is required during pregnancy, a blood sample of the pregnant woman is now routinely drawn. ${ }^{4,5}$ Another goal has been to replace the invasive procedures by cfDNA testing for the detection of genetic disorders. This has led to the use of cfDNA in prenatal screening and diagnosis. ${ }^{6}$ In prenatal diagnosis, the cfDNA test offers women at increased risk for a genetic condition in the fetus, a definite answer to the question whether the genetic condition is present in the fetus. These noninvasive prenatal diagnostic tests are abbreviated as NIPD. In prenatal screening, the cfDNA test identifies pregnant women at high risk for a genetic condition in the fetus. These screening tests are referred to as noninvasive prenatal testing (NIPT). In this thesis, noninvasive prenatal screening and diagnosis of genetic disorders through analysis of fetal cfDNA in maternal blood was investigated. Furthermore, part of my research aimed at contributing to a further responsible implementation of NIPT.

In Part I the use of cfDNA for prenatal genetic diagnostic testing was explored. This part comprised the design of in-house noninvasive diagnostic tests for fetal sex determination as well as single-gene mutation detection. In this final chapter, the results of part I are discussed along the following themes: (1) improving noninvasive fetal sex determination, (2) noninvasive evaluation of cell-free RNA (cfRNA) levels in maternal plasma, (3) development and implementation of NIPD of single-gene disorders.

Part II investigated the responsible application of cfDNA in prenatal screening. The diagnostic accuracy and clinical implementation of trisomy 21 screening was examined. Additionally, the opinion of pregnant women regarding the inclusion of fetal sex trisomies in the NIPT panel, was explored within the broader context of the expansion of the scope of screening. In this general discussion chapter, the results of part II are discussed in these topics: (1) NIPT of trisomies 13, 18 and 21 from 2011 until now, (2) broadening the scope of noninvasive prenatal screening, (3) false positive and false negative NIPT results, and (4) autonomous reproductive choice. 


\subsection{Part I: Design of noninvasive prenatal diagnostic tests - results in perspective}

\subsubsection{Improving noninvasive fetal sex determination}

Sex determination was one of the first clinical applications of fetal cfDNA testing and is routinely used in European countries. ${ }^{4}$ In the Netherlands, it has been offered as a prenatal diagnostic test for clinical purpose since the beginning of $2003 .{ }^{5}$ This test is only available for a small group of pregnant women with a clinical indication for prenatal determination of the fetal sex. These are women carrying a fetus that presents with ambiguous genitalia during ultrasound examination, and women carrying a fetus that is at risk of an X-linked disorder, or a fetus at risk of the autosomal recessive disorder congenital adrenal hyperplasia, where masculinization of the external genitalia of girls occurs. ${ }^{7-9}$ Up until now the blood from pregnant women with a clinical indication for prenatal diagnosis of the fetal sex in the clinical genetics department of the Maastricht UMC+, and our collaborating clinical genetics department of the Radboud UMC, is sent to Sanquin in Amsterdam. ${ }^{5}$ Sanquin is the national reference laboratory for noninvasive prenatal sex determination. However, in case of a female fetus the testing at Sanquin can take more than a week, and sometimes fails sometimes to provide a clear result.

To address these problems, a novel noninvasive fetal sex determination assay was developed and tested in 75 pregnant women who were between 9-34 weeks of gestation (Chapter 2). In this novel single-tube assay amplification of $Y$ chromosomederived cfDNA, derived from Y-linked amelogenin (AMELY), is combined with reverse transcription PCR (RT-PCR) of trophoblast-derived cfRNA. A remarkable stability of cfRNA in blood was seen, possibly due to protection against enzymatic degradation by vesicle-like structures. ${ }^{10}$ In our assay, the cfRNA functions as a specific marker for fetoplacentally derived nucleic acids in the plasma sample. This fetoplacental marker is part of the NIPD assay, and sex-independent. The fetal sex was correctly determined in all 75 pregnant women without failure or false results (this thesis). The assay can compete with the current noninvasive fetal sex determination assays in that it is a cheap single-tube assay that can determine the fetal sex within one or two days. For the same reasons, it is a useful addition to the next-generation sequencing (NGS) workflow and it can also be conducted in laboratories that do not have access to NGS facilities. 
One could question if the presence of the fetoplacental RNA marker actually means that there is also an adequate amount of fetal cfDNA in the plasma. Our proof-ofprinciple study results all indicate that the presence of the fetoplacental cfRNA marker is strongly correlated with the presence of an adequate amount of fetal cfDNA for noninvasive sex determination. Moreover, our study shows that cfDNA and cfRNA are equally stable and both require storage at $-80^{\circ} \mathrm{C}$ and a minimal number of freeze/thaw cycles to ensure optimal conservation. A limitation of our test is that $\mathrm{Y}$ chromosome determination is based on $A M E L Y$ only, because too many primer interactions in the multiplex RT-PCR were seen when additional $Y$ chromosome gene markers were added (data not shown). Deletion of $A M E L Y$ could result in allelic dropout, and consequently, a false negative result. However, the frequency of $A M E L Y$ deletions is low $0.018 \%$ in Europe, $0.02 \%$ in Australia, $1.85-2.36 \%$ in India). ${ }^{11,12}$ Furthermore, sex determination based on $A M E L Y$ detection is widely accepted for genetic sex determination, e.g., in the forensic field, prenatal diagnosis, and preimplantation genetic diagnosis. In conclusion, I expect that this theoretical limitation does not hinder the implementation of the test. Clearly, this proof-of-principle study needs further replication before entering the diagnostic arena. Our novel assay will now be compared to the Sanquin test, in all pregnant women with a clinical indication for prenatal determination of fetal sex in Maastricht. If the assay continues to show $100 \%$ accuracy and provides a faster answer, the assay can be offered in the clinical genetics department of the Maastricht UMC+, as well as other laboratories. Furthermore, I recommend testing more samples from pregnant women between 7 and 10 weeks of pregnancy, before offering the test that early in pregnancy.

\subsubsection{Noninvasive evaluation of cfRNA levels in maternal plasma}

Multiplex RT-PCR assays, targeting specific fetal transcripts, or transcriptome analysis by NGS (RNA sequencing) could provide more information than simply the presence of fetal nucleic acids. ${ }^{13}$ CfRNA levels in maternal plasma are variable and reflect differential expression during fetal development. ${ }^{14}$ It is known that the majority of circulating fetal transcripts in third-trimester maternal blood are related to the sensory and central nervous system development, sense of smell and the ability to mount an inflammatory response. ${ }^{15}$ The cfRNA in amniotic fluid in pregnancies with twin-to-twin transfusion syndrome, fetal hydrops and fetuses with trisomies 18 and 21 has been analysed. ${ }^{16-18}$ In these disorders, diseases-specific upregulation of genes was identified. Furthermore, an association between upregulation of corticotrophinreleasing hormone cfRNA and preeclampsia, a pregnancy related disorder 
characterized by hypertension and proteinuria, has been demonstrated. ${ }^{19}$ These findings have not been translated into prenatal care at the moment. Possibly, fetal transcriptome analysis in maternal blood could be used in the future to noninvasively monitor the fetus and provide insight in placental and fetal development. ${ }^{15,20}$ Detection of abnormal patterns of gene expression could identify fetuses at risk of developmental delay, intra-uterine growth restriction and congenital heart defect, in particular when abnormalities are observed on ultrasound scan. ${ }^{21}$ Other placental transcripts in maternal blood could serve as biomarkers for preeclampsia.

\subsubsection{Development and implementation of NIPD of single-gene disorders}

\section{A. Noninvasive prenatal diagnosis of single-gene disorders: challenges}

A few years after the discovery of fetal cfDNA in the plasma of pregnant women, the first studies aimed at diagnosing single-gene disorders in cfDNA were published. Single-gene disorders can have recessive, dominant or X-linked Mendelian inheritance patterns. In approximately 4600 of these disorders, the causative gene is currently known. ${ }^{22}$ NGS has been used for the development of reliable noninvasive assays of all types of single-gene disorders since 2012. Disorders that have been detected in the cfDNA using NGS include achondroplasia and thanatophoric dysplasia, Huntington disease, beta-thalassemia, congenital adrenal hyperplasia, Wilson disease, congenital deafness, and Duchenne and Becker muscular dystrophies (Chapter 1, Table 1.1). ${ }^{23-34}$

Two of the greatest technical challenges in the development of noninvasive tests for single-gene disorders are the predominance of maternal cfDNA in the plasma sample, and the difficulty to reliably distinguish fetal cfDNA fragments from maternal cfDNA fragments. ${ }^{35,36}$ Consequently, noninvasive prenatal determination of single-gene disorders depends on the relative proportions of normal and mutated cfDNA. In Figure 7.1 different inheritance patterns and their consequences for the noninvasive determination of single-gene disorders are described. Due to the "maternal background" problem it is more straightforward to detect either paternally inherited mutations or de novo mutations than to detect maternally inherited mutations. In the case of maternal inheritance, the maternal mutation is already present in most cfDNA sequences in the maternal plasma, and the NIPD assay has to determine whether or not the mutation is also present in the fetal cfDNA. However, even in the case of paternal inheritance or a de novo mutation, sensitive detection of the low level of mutant alleles is required. Another challenge is the low concentration of total and fetal cfDNA. $^{37,38}$ Additionally, prenatal diagnosis for single-gene disorders is mostly 
requested early in pregnancy, when the fetal fraction is at its lowest. Last, due to the short cfDNA fragments, direct mutation detection is not eligible for all disorders, such as repeat expansion disorders and large deletions. ${ }^{39,40}$

In addition to the technical challenges, it is problematic to collect a large cohort of pregnant women requesting prenatal diagnosis for an individual single-gene disorder, due to the low prevalence of these disorders. This makes it difficult to validate a novel assay.

Notwithstanding the technical difficulties, the NGS-based noninvasive assays for single-gene disorders can provide a definite answer to the question whether the disorder is present in the fetus, without the need for an invasive follow-up test to confirm the result (NIPD). NIPD provides early in pregnancy a safe alternative to the invasive procedures. There are several reasons why NIPD is possible for single-gene disorders: (1) Due to targeted deep sequencing of regions of interest, these tests are less influenced by the fetal fraction than chromosome tests. (2) Methods are being developed to reduce incorrect variant calling by NGS because of PCR mistakes and sequencing mistakes. ${ }^{41}$ (3) Usually, the mutation(s) in the family is (are) known, and the fetus has often a very high risk to inherit the disorder, e.g. $25 \%$ or $50 \%$. The high chance of the examined pregnant women to actually carry a fetus with the disorder, will lead to a higher positive predictive value, i.e. the chance that a positive test result is a true test result is high. (4) In case of single-gene disorders, no placental mosaicism (possibly leading to false positive NIPD results) has been described. (5) No unexpected maternal chromosome abnormalities may confound results. ${ }^{42}$ 
A. Autosomal dominant

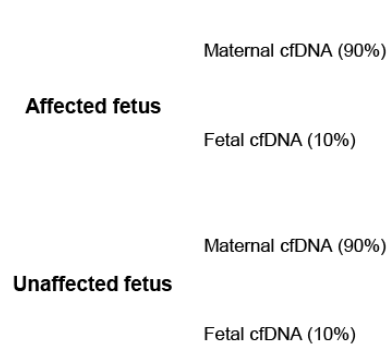

Affected mother (C>A)

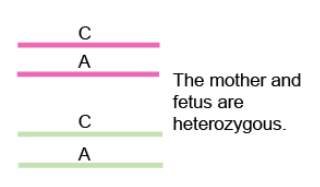

\begin{tabular}{cl}
\hline C & The mother is \\
heterozygous. & \\
C & The fetus is \\
homozygous for \\
the wild-type allele.
\end{tabular}

Affected father (C>A)

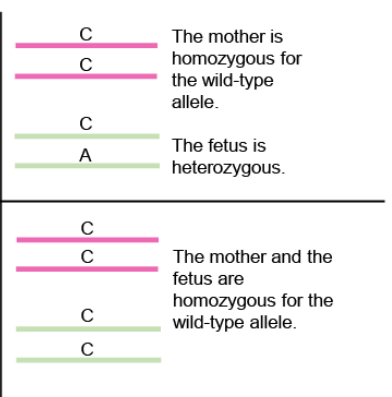

\section{B. Autosomal recessive}

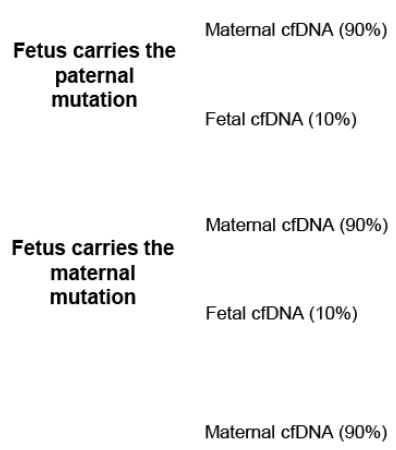

Affected fetus

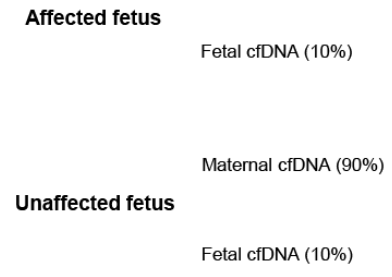

\begin{tabular}{|c|c|c|c|c|}
\hline \multicolumn{2}{|c|}{$\begin{array}{l}\text { Same mutation in } \\
\text { mother and father }(C>A)\end{array}$} & \multicolumn{3}{|c|}{$\begin{array}{l}\text { Different mutation in mother } \\
(\mathrm{C}>\mathrm{A}) \text { and father }(\mathrm{G}>\mathrm{T})\end{array}$} \\
\hline C & \multirow{4}{*}{$\begin{array}{l}\text { The mother and } \\
\text { fetus are } \\
\text { heterozygous. }\end{array}$} & C & G & \multirow{2}{*}{$\begin{array}{l}\text { The mother is } \\
\text { heterozygous. }\end{array}$} \\
\hline A & & A & G & \\
\hline C & & C & $\mathrm{T}$ & \multirow{2}{*}{$\begin{array}{l}\text { The fetus is } \\
\text { heterozygous for the } \\
\text { paternal mutated allele }\end{array}$} \\
\hline A & & C & G & \\
\hline C & \multirow{4}{*}{$\begin{array}{l}\text { The mother and } \\
\text { fetus are } \\
\text { heterozygous. }\end{array}$} & C & $\mathrm{G}$ & \multirow{4}{*}{$\begin{array}{l}\text { The mother and } \\
\text { fetus are } \\
\text { heterozygous for } \\
\text { the maternal } \\
\text { mutated allele. }\end{array}$} \\
\hline A & & A & G & \\
\hline C & & C & G & \\
\hline A & & A & G & \\
\hline C & \multirow{2}{*}{$\begin{array}{l}\text { The mother is } \\
\text { heterozygous. }\end{array}$} & C & G & \multirow{2}{*}{$\begin{array}{l}\text { The mother is } \\
\text { heterozygous. }\end{array}$} \\
\hline A & & A & G & \\
\hline A & \multirow{2}{*}{$\begin{array}{l}\text { The fetus is } \\
\text { homozygous for the } \\
\text { mutated allele. }\end{array}$} & C & $\mathrm{T}$ & \multirow{2}{*}{$\begin{array}{l}\text { The fetus is compound } \\
\text { heterozygous for both } \\
\text { mutated alleles. }\end{array}$} \\
\hline A & & A & G & \\
\hline C & \multirow{2}{*}{$\begin{array}{l}\text { The mother is } \\
\text { heterozygous. }\end{array}$} & C & G & \multirow{2}{*}{$\begin{array}{l}\text { The mother is } \\
\text { heterozygous. }\end{array}$} \\
\hline A & & A & G & \\
\hline C & \multirow{2}{*}{$\begin{array}{l}\text { The fetus is } \\
\text { homozygous for the } \\
\text { wild-type allele. }\end{array}$} & C & G & \multirow{2}{*}{$\begin{array}{l}\text { The fetus is } \\
\text { homozygous for the } \\
\text { wild-type allele. }\end{array}$} \\
\hline C & & C & G & \\
\hline
\end{tabular}

Figure 7.1 Detection of causal mutations in autosomal dominant $(A)$ and autosomal recessive disorders (B) in cell-free DNA (cfDNA). Noninvasive prenatal detection of the fetal inheritance depends on the relative proportions of normal and mutated cfDNA. In this example the fetal fraction is $10 \%$.

There is a significant demand for NIPD of single-gene disorders, and the continuing advances in technology and data analysis facilitate the expansion of the NIPD test repertoire. ${ }^{43}$ Dutch and international researchers nowadays attempt to design NIPD assays for a broader range of single-gene disorders. Both direct and indirect haplotype- 
based methods have been developed (Chapter 1, Table 1.1). The goal is to provide as many pregnant women as possible that carry a fetus at risk of a specific single-gene disorder the possibility to undergo NIPD instead of an invasive procedure.

A current challenge is developing NIPD assays for the detection of nucleotide repeat expansions. Nearly thirty hereditary disorders in humans are known to result from an increase in the number of copies of simple repeats in genomic DNA. ${ }^{44,45}$ This specific class of disorders is a common indication for prenatal diagnosis. In Chapter $\mathbf{3}$ we presented a novel assay for NIPD of myotonic dystrophy type 1 (DM1), caused by expansion of a CTG trinucleotide repeat in the dystrophia myotonica protein kinase gene $(D M P K) .{ }^{46,47}$ In a proof-of-principle study, we tested the cfDNA obtained from a plasma sample from a pregnant woman carrying a fetus that inherited DM1 from its affected father. In this assay single molecule molecular inversions probes (smMIPs) were designed and optimized for targeted NGS of DMPK repeat surrounding single nucleotide polymorphisms (SNPs). ${ }^{41}$ First, a trio (pregnant woman, affected father and previous affected child) was sequenced, to detect twelve informative SNP loci for the disease status of the father and the fetus. Subsequently, the plasma cfDNA was sequenced to determine the fetal inheritance, calculated from the percentage of the informative SNPs in the cfDNA reads. Ten SNPs unequivocally reported the presence of the mutated paternal allele in the cfDNA. Five of them proved the presence of the paternal risk allele in the plasma, while the remaining five showed that the paternal wild type allele was not present in the plasma. The fetal fraction was determined based on unique paternal variations. The results of this proof-of-principle study are promising.

We are the first to use smMIPs for NIPD. Molecular inversion probes represent an attractive platform for targeted capture because of their very low per-sample cost, workflow simplicity, target-set modularity and low sample input requirement. ${ }^{41}$ Direct measurements of the mutations can also benefit from additional haplotyping to provide a reliable combined direct and indirect NIPD assay. For this purpose, it could be ideal to design smMIPs to target the coding regions of disease genes, as well as common SNPs flanking these regions. As a result, this NIPD assay can be used for all autosomal dominant disorders, and paternal as well as maternal mutations may be detected. Obviously, more evaluation and optimization is required of the smMIPs NIPD approach for different disorders in the coming period.

In the case of haplotype-based NIPD assays for prenatal diagnosis of a repeat expansion disorder, only the mutated allele, carrying the repeat, can be detected. The 
exact repeat length in the fetus cannot be determined in cfDNA because of the degraded fragment size of the cfDNA. However, repeat expansion disorders are often characterized by anticipation: in successive generations within a family, affected family members are at risk for further expansion of the repeat, which can result in decreasing age of onset and increasing severity. ${ }^{48}$ Therefore, it is of clinical relevance to know the length of the repeat during pregnancy. Following a haplotype-based NIPD assay that reveals inheritance of the mutated allele in the fetus, pregnant women can opt for an invasive procedure to know the repeat length during pregnancy, or for testing after birth. Some groups have attempted direct detection of the repeat expansion mutation, mostly in Huntington's disease. ${ }^{33,49,50}$ Direct detection of repeat expansion mutations has been possible for small repeats that have a size of one to three times the average size of cfDNA fragments. ${ }^{33}$ This suggests that in case of repeat expansion disorders larger cfDNA fragments may be present in the maternal plasma. It has been suggested that plasma cfDNA fragments are derived from the enzymatic processing of DNA from apoptotic placenta cells. ${ }^{39}$ The length of the fetal and total cfDNA fragments resemble the nuclease cleaving in between the nucleosomes, where the double stranded DNA is wrapped around a histone core, as a part of the apoptotic process. ${ }^{39,51}$ DNA repeats seem to be predisposed to expansion because they have unusual structural features, which disrupt the cellular replication, repair and recombination machineries. ${ }^{44,45}$ It is unknown whether the structural DNA changes in repeat expansion regions prevent normal nuclease cleaving during apoptosis, leading to longer cfDNA fragments. Theoretically this may explain why direct repeat expansion mutation detection in some patients reveal cfDNA fragments that are longer than predicted during apoptosis. Further investigation of this phenomenon will provide insight about the possibility to predict increase of repeat size in the cfDNA. This happens in parallel with further improvements in NGS technology. The ideal sequencing platform in this context would work on a single cfDNA molecule without any need for DNA fragmentation and pre-amplification. ${ }^{52}$ Single molecule long read sequencing technology comes most close to this ideal platform and the first proof of concept study for repeat expansions has already been published. ${ }^{52-54}$

In the coming years a further parallel development of NGS technologies and targeted and more broad tests for all types of single-gene disorders early in pregnancy is to be expected. 


\section{B. Implementation of NIPD assays for single-gene disorders and future perspectives}

A translation into clinical practice of a NGS-based NIPD assay for some single-gene disorders has already occurred in the United Kingdom (Chapter 1, 1.5.3). ${ }^{43,55}$ For selected diseases couples can undergo NIPD from 9 weeks of gestation onwards. ${ }^{56}$ When a skeletal dysplasia is identified by ultrasound scan, e.g. achondroplasia or thanatophoric dysplasia, NIPD can be used to confirm the diagnosis. It is currently not possible for this laboratory to offer NIPD for maternal inheritance or for repeat expansion disorders. In the near future, it can be expected that for more single-gene disorders a noninvasive prenatal diagnostic test will be offered to pregnant women, also in the Netherlands.

In the coming years NIPD assays will be developed for all disorders for which at the moment conventional prenatal diagnosis, pre-implantation genetic diagnosis (PGD) and preconception or prenatal carrier screening is offered. PGD could be offered in combination with NIPD to reassure couples during pregnancy that an embryo without the disorder was selected for transfer to the woman's uterus. Probably, some couples will prefer early NIPD, if possible in the future, instead of PGD, because the latter demands in vitro fertilization/intracytoplasmic sperm injection (IVF/ICSI) treatment and the chance of conception with IVF/ICSI/PGD is limited even among normally fertile couples. ${ }^{57}$ Carrier screening of the parents before or during pregnancy could also be offered in combination with NIPD. ${ }^{58}$ Ethical considerations of this combination of carrier screening and NIPD are discussed further in detail in this general discussion chapter while discussing cfDNA-based screening.

NGS-based NIPD assays with disease-focused panels of candidate genes in case of prenatal ultrasound anomalies will most likely be offered in the near future. ${ }^{22}$ Examples are panels containing genes for Noonan syndrome in case of an increased fetal nuchal translucency, or skeletal dysplasia panels to differentiate between the different skeletal dysplasias in case of skeletal abnormalities seen on the fetal anomaly scan. $^{22}$

Before a widespread implementation of diagnostic cfDNA-based tests for women at high-risk for single-gene disorders, it is important to consider its costs and ethical implications. ${ }^{42,58}$ The costs of NIPD are dependent upon the complexity of the testing technique required. ${ }^{42}$ For that reason, it has been predicted that for autosomal dominant conditions the NIPD costs would be lower than those of the invasive procedure, while for autosomal recessive and X-linked conditions the NIPD costs 
would be higher than those of the invasive procedures. However, universal indirect methods, using SNP-based haplotyping, such as our smMIPs NIPD assay, have similar costs for all types of single-gene disorders. With further developments in NGS, the costs to detect all conditions will be declining rapidly in the coming period. Furthermore, it is perfectly possible to test several different conditions and include multiple causative mutations in a single assay, which also lowers the costs. There is no reason to restrict NIPD assays to a specific inheritance pattern. However, we can expect an increase in uptake in comparison to the invasive tests when NIPD assays will be offered to high-risk pregnant women. ${ }^{42}$ In particular, future parents with a fetus at risk for a single-gene disorder that have no intention to terminate the pregnancy may now request cfDNA-based testing while in the past they would not opt for invasive testing, due to the miscarriage risk. This will give the parents the opportunity to prepare for the birth of an affected child. However, for late onset genetic disorders, parents should be discouraged to do so, as continuing a pregnancy of an affected child will violate the autonomy of the future child to choose for a predictive test or not. The simplicity and safety of the tests could lead to more autonomous decision-making for pregnant women, but it could also lead to increased pressure on women to take up prenatal diagnostic testing. ${ }^{58}$ Health professionals in the United Kingdom, where NIPD is already implemented for some disorders, fear this increased pressure to test during pregnancy and even to terminate a pregnancy. ${ }^{59}$ However, they also felt that this could be overcome with thorough pre- and post-test counseling.

Most likely, detection of single-gene disorders will not remain an option only for pregnant women with an indication, at risk of passing on an inherited disorder. It will be technically possible within the foreseeable future to offer to all pregnant women a comprehensive noninvasive NGS-based screening test for a broad range of autosomal recessive, autosomal dominant and $\mathrm{X}$-linked single-gene disorders. Possible applications and ethical concerns of prenatal screening tests for single-gene disorders are discussed further in this general discussion chapter while discussing the possible broader range of heritable and congenital conditions for which prenatal screening could be offered. 


\subsection{Part II: Noninvasive prenatal screening for fetal chromosome disorders - Results in perspective}

\subsubsection{NIPT of trisomies 13, 18 and 21 from 2011 until now}

The search for a noninvasive prenatal test that could reliably detect fetal trisomies 13 , 18 and 21 started very soon after the discovery of fetal cfDNA in maternal plasma, and has been compared in the literature to the search for the Holy Grail. ${ }^{60}$ This drive originates in the fact that these chromosome imbalances have always been important indications for invasive prenatal diagnosis. In 2008 it was suggested to use NGS to calculate the over- or underrepresentation of any chromosome in the cfDNA. ${ }^{61,62}$ Since then it has been possible to reliably detect fetal chromosome imbalances in maternal plasma. In 2011, at the time I started the research upon which this doctoral dissertation is based, the first diagnostic accuracy studies were published using NGS to detect fetal trisomies 13, 18 and 21 in maternal plasma (Chapter 1, Table 1.2). ${ }^{63-72}$ This was accompanied by the first commercial release of NIPT in Hong Kong in August 2011, and in the United States (US) in October $2011 .^{73}$

In Chapter 4 we performed a systematic review of all studies evaluating the diagnostic accuracy of molecular techniques for noninvasive detection of trisomy 21 between 1997 and the beginning of 2012. In this systematic review, seven studies examined the sensitivity and specificity of NGS-based cfDNA testing of fetal trisomy $21.64-66,68,69,72,74$ We evaluated the diagnostic parameters and the quality of the studies (potential bias and applicability) using the revised tool for Quality Assessment of Diagnostic Accuracy (QUADAS-2). ${ }^{75}$ The important diagnostic parameters that are evaluated in diagnostic accuracy studies are listed in Table 7.1.

Table 7.1 Diagnostic parameters in noninvasive fetal trisomy detection

\begin{tabular}{ll}
\hline Sensitivity & $\begin{array}{l}\text { How likely is the cfDNA-based test to detect the presence of } \\
\text { trisomy when the pregnant woman carries a fetus with a trisomy? } \\
\text { Specificity }\end{array}$ \\
$\begin{array}{l}\text { How likely is the cfDNA-based test to detect the absence of trisomy } \\
\text { when the pregnant woman carries no fetus with a trisomy? }\end{array}$ \\
$\begin{array}{l}\text { Positive predictive } \\
\text { value (PPV) }\end{array}$ & $\begin{array}{l}\text { How likely is a pregnant woman with a positive cfDNA-based test } \\
\text { result to actually carry a fetus with the trisomy? }\end{array}$ \\
$\begin{array}{l}\text { Negative predictive } \\
\text { value (NPV) }\end{array}$ & $\begin{array}{l}\text { How likely is a pregnant woman with a negative cfDNA-based test } \\
\text { result to actually not carry a fetus with a trisomy? }\end{array}$ \\
\hline
\end{tabular}


In these NGS-based studies the sensitivity and specificity were compared with the gold standard karyotyping, in mainly high-risk pregnant women. We concluded that sensitivity and specificity in these seven studies was high: sensitivities were between 98.58\% [95\% confidence interval (Cl) 95.9-99.5\%] and 100\% (95\% Cl 96-100\%) and specificities were between $97.95 \%$ (95\% Cl 94.1-99.3\%) and 100\% (95\% Cl 99.1-100\%).

Nevertheless, in our review, and in other literature, it was clear that these tests would not be diagnostic tests, replacing the invasive procedures. ${ }^{76}$ In the beginning years, cfDNA testing companies did not always report information about the positive and negative predictive values of their test. Therefore, we calculated the positive predictive value and negative predictive value for different prevalence conditions for the seven NGS-based studies in our systematic review. We stated that NIPT of fetal trisomy 21 exhibits an excellent negative predictive value (100\%) in conditions with disease odds from 1:1500 to 1:200 (the a priori risk of a 20-year-old pregnant woman and the a priori risk of a 38-year-old pregnant woman, respectively). However, we reported for the first time that the positive predictive value showed large variation. Immediately upon publication of Chapter 4, the variable positive predictive value was reported by others. ${ }^{76}$ The reasons behind the variable positive predictive value are explained more in detail further in this general discussion chapter. In general, if the consequences of a false positive result of a test have detrimental effects on patients, a test with a high positive predictive value is essential. If the disorder may not be missed, a test with a high negative predictive value is chosen, if the consequences of a false positive result, e.g. treatment, in case of no disease are not harmful for the patient. Since a false positive NIPT result can lead to abortion of a healthy fetus, an invasive procedure followed by rapid aneuploidy detection or karyotyping is recommended by the International Society for Prenatal Diagnosis to confirm suspicion of fetal trisomy following a positive cfDNA-based test result. ${ }^{6,77}$ At that time the term "noninvasive prenatal testing" (NIPT) was formulated, referring to cfDNA-based tests that are used as a screening test and require a confirmation by a follow-up test.

In the last years, large prospective studies allowed more precise estimates about sensitivity, specificity and predictive values in high-risk and low-risk pregnancies (Chapter 1, Table 1.2). ${ }^{78-96}$ The efforts of commercial companies to validate NIPT assays have been huge. ${ }^{97}$ Thousands of plasma samples have been tested in many large cohort studies evaluating NIPT for trisomy 21, as well as for trisomies 13 and 18. In these studies, only minor technical alterations and bioinformatics improvements were made to the original studies. The focus was mainly on including large cohorts of 
low-risk pregnant women early in pregnancy, as NIPT would be a screening test. It was shown that cfDNA-based tests using NGS can detect fetal trisomy in high-risk and in low-risk pregnant women from 10 weeks of gestation onwards with a sensitivity and specificity of more than $99 \%$ and a negative predictive value of almost $100 \%$. However, a variation in the positive predictive value was still observed. The positive predictive value drops especially when the a priori chance of carrying a fetus with a trisomy declines. ${ }^{85}$ The positive predictive value varies between approximately $60 \%$ and $95 \%$ in a high-risk population (risk of 1 in 200), drops to $50 \%$ to $80 \%$ in a more general population, and may even fall below $50 \%$ in young, low-risk pregnant women.

A rapid global implementation of the screening test was seen. In 2015 commercial NIPT was already offered in over 60 countries throughout six continents, although a recent market report shows that the US account for $64.5 \%$ of global NIPT revenue, followed by Europe. ${ }^{73}$ The goal since 2011 has been to replace current screening tests, such as the first trimester combined test (FCT), with NIPT, or to offer NIPT as a second tier screening test. Although NGS cfDNA-based tests may have failed to provide the final answer on whether a trisomy is present in the fetus, they proved to be much better screening tests that the traditional biochemical screening tests so far. ${ }^{85,92}$ For example, the FCT is estimated to have a sensitivity of $89.0 \%$ and a specificity of $95.4 \%$ for fetal trisomy 21 detection, if considering women of all age categories and a risk threshold of 1 in $200 .{ }^{98}$ This is considerably lower than the sensitivity and specificity of the NIPT, that both exceed $99 \%$.

Nowadays, the option of NIPT for fetal aneuploidy screening has reached most pregnant women in the Western world through the internet, traditional media, family and friends, as well as through information provided by gynecologists. Several countries are working on the implementation of NIPT in their prenatal trisomy screening program. ${ }^{99-101}$ In the last years, the clinical utility, cost-effectiveness and ethical consequences of plausible NIPT implementation strategies have been evaluated. ${ }^{101-107}$ In addition, the attitudes of pregnant women and obstetricians and gynecologists towards NIPT have been studied through questionnaires and interviews. ${ }^{108-112}$ In Chapter 5 we compared different implementation strategies of NIPT for trisomy 21. For this, a quantitative analysis of different NIPT implementation strategies was conducted. We suggested that the most favorable screening program may be a program in which NIPT is offered to all women at 13 weeks of gestation as the first screening test (13-week NIPT). In this case, a minimal number of fetal chromosome disorders is missed since NIPT is offered to all women. Additionally, 
women only have to make a decision about whether or not they want to undergo an invasive test based on the result of one screening test, which is the least confusing scenario for the women. At 13 weeks of gestation, NIPT is offered when the risk for spontaneous miscarriage has declined remarkably. Furthermore, following a positive 13-week NIPT, timely confirmatory amniocentesis is possible. A last benefit of NIPT at 13 weeks of gestation is that women are offered some more time for adequate counseling and for reflection before they decide to undergo NIPT. Earlier in pregnancy, women may speak to their midwife or obstetrician for the first time. In practice, NIPT for fetal trisomy 21 is always conducted together with NIPT for fetal trisomies 13 and 18. Furthermore, most assays also detect submicroscopic chromosome aberrations and fetal sex chromosome disorders. The conclusions of Chapter 5, drawn for the implementation of trisomy 21, are also applicable for broad NIPT assays targeting trisomies 13 and 18, and submicroscopic chromosome aberrations and fetal sex chromosome disorders.

An acceptable alternative to our proposed NIPT implementation strategy in Chapter $\mathbf{5}$ is reflex prenatal screening. In this scenario two blood samples are collected together at a prenatal visit at 11-13 weeks of gestation. ${ }^{113}$ The first one for a FCT and the second one for NIPT in case of a high risk predicted by the FCT, e.g. > 1:800. Women are offered only one combined screening result and it avoids causing distress to women by recalling them for a second test and sample collection. The greatest advantage of this strategy is that in the case of a NIPT failure, which has been reported in 1.3-5\%, women can base their decision of follow-up testing on the result of the FCT. ${ }^{83,114-116}$ NIPT failure is an important factor to consider while organizing implementation, since it has been suggested that the prevalence of fetal aneuploidy is higher in the NIPT failure group than in the overall population. ${ }^{92,117}$ If no FCT is conducted, it should be clarified to women with a failed NIPT that it is highly recommended to repeat the NIPT or to undergo invasive prenatal diagnosis.

\subsubsection{Broadening the scope of noninvasive prenatal screening}

\section{A. Defining the scope of prenatal screening}

It will be technically possible to offer to all healthy pregnant women a broad noninvasive screening test that is able to screen for all frequent recessive and dominant single-gene disorders, as well as for imbalances of whole chromosomes and parts of chromosomes. What disorders should be included in a broad screening test? The European and the American Society of Human Genetics (ESHG and ASHG) 
recommend to offer prenatal screening only for serious congenital and childhood disorders, following sound validation studies and a comprehensive evaluation of all relevant aspects. ${ }^{118}$ They suggest limiting the scope to a range of well-defined disorders, and avoiding traits with little or variable medical morbidity or reporting variants of unknown significance.

In the next years, we can expect studies exploring the technical possibilities to expand the scope of NIPT, accompanied by validation studies, ethical reflections, costeffectiveness analyses, and more qualitative studies investigating the opinion of experts and potential users.

\section{B. Genome-wide analysis for fetal chromosome disorders}

Genome-wide NGS-based NIPT allows sequencing all cfDNA fragments in the maternal plasma to evaluate whether there is an excess or deficiency of fragments, which would be indicative for an imbalance of any of the autosomal or sex chromosomes. The imbalances can either be a chromosomal aneuploidy, a segmental imbalance, or a submicroscopic chromosome imbalance. Since 2013, some NIPT assays can detect submicroscopic chromosomal abnormalities and sex chromosome imbalances. ${ }^{119-128}$ Clinically significant microdeletion and microduplication syndromes can now be detected, such as DiGeorge syndrome (22q11.2 deletion). The sex chromosome disorders that can be detected include monosomy $X$ and sex chromosome trisomies (SCTs; 47,XXX; 47,XXY and 47,XYY). Extension of cfDNA screening to detect rare autosomal trisomies and inherited deletion and duplication copy-number variations is currently being investigated. ${ }^{129}$

It can be argued that NIPT for genome-wide chromosome imbalances currently does not meet the generally accepted criteria for a worthwhile screening test: a welldefined disorder, established performance characteristics and acceptable patient management steps following a positive result. ${ }^{130}$ According to the recommendations of the ESHG and ASHG, genome-wide cfDNA-based screening tests for chromosome disorders should only target the chromosome abnormalities with known phenotypes.

Critics may argue that NIPT for sex chromosome aneuploidy is also beyond the scope suggested by the ESHG and ASHG, because of the mild and variable phenotype. In Chapter 6 we assessed Dutch pregnant women's opinions about NIPT for SCTs within the broader context of the expansion of disorders included in the NIPT panel. Although all of the interviewees were in favor of screening for trisomies 13,18 and 21 , only half of them would also like to undergo screening for SCTs. Our study identified several 
potential disadvantages of NIPT for SCTs, beyond the technical issues leading to false negative and false positive results: receiving a prenatal test result about a disorder with unclear consequences for the future child's life and for which they would take no further actions, a less worry-free pregnancy and childhood, possible guilt about continuation of pregnancy, and possible insecurity about parenting. Some of the participants firmly stated that they disagreed with offering the possibility to terminate the pregnancy because of a fetal SCT. Furthermore, knowing about the SCT at the start of life could be detrimental for the future child, because it could lead to stigmatization, a damaged parent-child relationship, and possible distress due to the probable occurrence of infertility.

\section{Genome-wide analysis for single-gene disorders}

Postnatally, it is possible to sequence an entire genome in a few days. ${ }^{22}$ Are we heading towards noninvasive prenatal whole genome sequencing (WGS) and whole exome sequencing (WES) in the cfDNA? Will this be the future diagnostic or even screening test? There is limited experience with WGS and WES in fetal cells obtained by an invasive amniocentesis or chorionic villus sampling in ongoing pregnancies, and in fetal cells in terminated pregnancies. ${ }^{22,131,132}$ The entire genome can also be sequenced in the cfDNA. In 2010, genome-wide deep sequencing (up to 65-fold haploid genome coverage) of a plasma sample revealed that both the entire fetal and maternal genome is represented in cfDNA, at a constant relative proportion. ${ }^{39}$ In 2012, another group used genome-wide deep sequencing of a maternal plasma sample to a deeper extent (78-fold haploid genome coverage), in combination with haplotype-resolved genome sequencing of the mother and shotgun genome sequencing of the father, to detect both inherited variations and de novo mutations in the fetal cfDNA. ${ }^{133}$

Both the costs and the amount of labor needed to analyze the fetal genome noninvasively, currently preclude its clinical applications. ${ }^{22}$ Interpretation of variants in postnatal WGS and WES form a huge challenge, because of incomplete penetrance, modifier genes and variable clinical presentation. Even more challenges and ethical considerations arise when offering WES and WGS for noninvasive prenatal diagnosis and screening: it is prenatally too time consuming to filter sequencing variants to identify pathogenic ones, incidental findings can be found in the parents while trio sequencing, variants of unknown significance cannot be translated into a phenotype in prenatal post-test counseling, and it is practically impossible to provide detailed information on all possible results and genetic conditions that a diagnostic WGS or WES can harvest. ${ }^{22}$ For these reasons I think that it would not be wise to offer WGS 
and WES of fetal cfDNA for diagnostic or screening purposes.

In my opinion, single-gene disorders that could be included in a broad cfDNA-based prenatal screening test are disorders with complete penetrance, a clear genotypephenotype correlation, early onset of disease (congenital and childhood), and either severe clinical implications or treatment options. Disorders with incomplete penetrance and a broad variety of clinical consequences should only be included after more research is done to draw the phenotypical map. Prenatal screening for recessive disorders with a high carrier frequency in the society (e.g. cystic fibrosis) could be offered as the combination of parental carrier screening before conception or during pregnancy, with prenatal noninvasive fetal testing in case of positive carrier status. In that case specific ethical concerns come up. ${ }^{58}$ Women who are newly diagnosed as carriers may be particularly vulnerable to a routine offer of this noninvasive test, thereby possibly undermining informed consent. There is also the possibility of a conflict of the moral rights of a woman and her partner. For example, if the father refuses carrier screening, and the pregnant woman undergoes carrier screening and a cfDNA-based screening test for the fetus, the father may know his own carrier status.

\subsubsection{False positive and false negative NIPT results}

In pre-test counseling it should be explained that both false positive and false negative NIPT predictions, discordant to the actual fetal karyotype, have been reported. ${ }^{6,134-144}$ False positive results will be detected by the confirmatory diagnostic test following an invasive procedure. In case of a negative NIPT result, the condition will be missed. The positive and negative predictive value of trisomies 13, 18 and 21 are currently best known. ${ }^{134-136}$ Also for submicroscopic chromosome aberrations and fetal sex chromosome disorders this is now being evaluated. ${ }^{121-124,137-139}$ Especially for trisomy 13 and the submicroscopic chromosome aberrations a high number of false positive results have been reported. ${ }^{124,140}$ An important factor correlating with test success and reliability of interpretation, is the "fetal fraction", i.e. the fetal cfDNA subfraction from the total maternal and fetal cfDNA in the plasma. ${ }^{141}$ The fetal fraction can be $<4 \%$ in the first trimester, which can lead to missed cases of fetal trisomy (false negative predictions). ${ }^{141-143}$ In addition, the statistical algorithms used to distinguish a trisomic pregnancy from a non-trisomic pregnancy could be improved. A biological reason of false reassurance by NIPT is a trisomic rescue in the fetoplacental trophoblast cells, the source of fetal cfDNA, while the trisomy persists in the fetus. ${ }^{6}$

More frequent are the false positive predictions $(0.1-0.2 \%)$, leading to the lower 
positive predictive value. ${ }^{6} \mathrm{~A}$ biological explanation of the false positive predictions is a trisomy only occurring in the fetoplacental trophoblast cells and not in the fetus itself (confined placental mosaicism), due to either rescue mechanisms in fetal development or post-zygotic errors during placental mitosis. ${ }^{6,140,144}$ Only placental mosaicism limited to the chorionic stroma/mesenchymal cells will not influence a NIPT result, as these cells do not release cfDNA in the maternal plasma. ${ }^{140}$ Another biological cause for a false-positive NIPT is a vanishing twin with a chromosome abnormality. Furthermore, maternal copy-number variations, maternal mosaicism in blood cells, and cfDNA sequences with chromosomal aberrations that are released from a maternal malignancy can lead to false-positive results. ${ }^{140,145}$

Moreover, the positive and negative predictive values are not general characteristics of the test. The values are only true if the NIPT is conducted in the exact same way as published in the same well-defined population. The predictive values are strongly dependent on the prevalence of a disorder in the population. As a result, the low positive predictive value is mostly a consequence of the low a priori chance of the examined pregnant women to actually carry a fetus with a trisomy. The lower that chance, the harder it is for the cfDNA-based test to give the correct result, and the higher the chance for a false positive result. This is illustrated in the following example. The prevalence of fetal Down syndrome in women of all reproductive ages in the European and US population at 10 weeks of gestation is $0.2 \%$ (weighted mean of European and US population, calculated in Chapter 5). ${ }^{146,147}$ If we now assume a population of 100000 pregnant women, undergoing a NIPT assay with a sensitivity of $99.3 \%$ and a specificity of $99.8 \%$, then the diagnostic parameters can be calculated as in Table 7.2. 
Table 7.2 Hypothetical example of the accuracy of a NIPT assay for fetal Down syndrome in a population with a prevalence of $0.2 \%$.

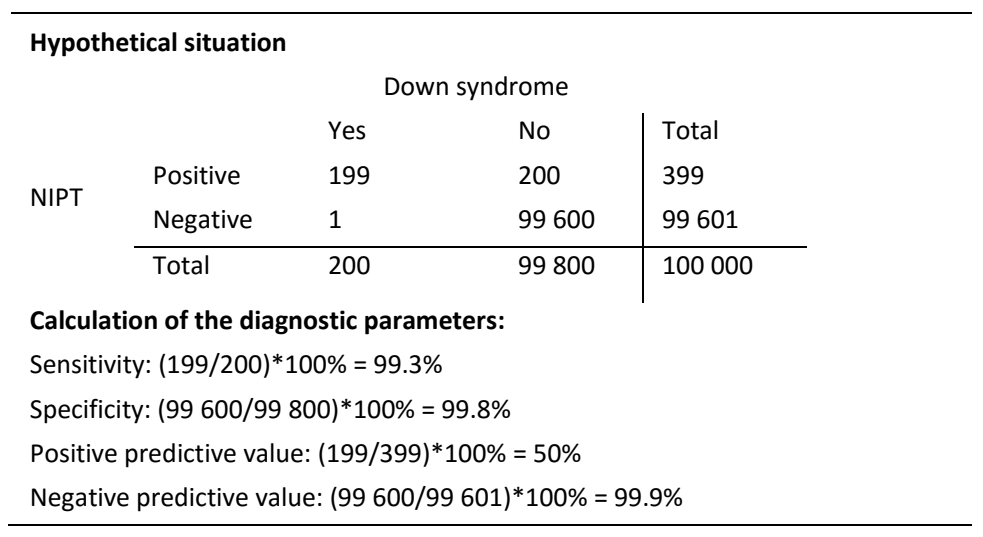

As seen in the above example, a NIPT assay can have both a high sensitivity and specificity while in only half of the positive results the fetus actually has Down syndrome, if the predictive values are calculated only based on the prevalence. It is nevertheless a good screening test for the condition. However, it is known that testspecific characteristics, such as the height of the z-score indicating that the fetus has a trisomy, or the fetal fraction, also have an influence on the positive and negative predictive value of the test. ${ }^{6} \mathrm{~A}$ positive NIPT result in a fetal fraction of $20 \%$ and a $z$ score of 8 is most likely to be a true result, even if the pregnant woman only has a chance of 1 in 1000 to carry a child with Down syndrome, based on her age. Because of all of these different aspects influencing the predictive values, I would recommend all laboratories to provide next to a positive or negative result of the NIPT, also the positive and negative predictive value specific for the tested pregnant woman and the precise test characteristics This can for example be done with this calculator developed at the university of Groningen (Figure 7.2). In post-test counseling, after receiving a positive NIPT result, pregnant women can have a more accurate idea of how great the chance is that they actually carry a child with a trisomy. This is helpful for an informed decision about undergoing an invasive confirmatory diagnostic test for a positive NIPT result. The pregnant women and caretakers may use other online calculators providing the positive and negative predictive value of the different commercially offered NIPT assays for a specific a priori risk, age and gestational age. ${ }^{148,149}$ However, these calculators may underestimate the positive predictive value and overestimate the negative predictive value, because they are mainly based on the prevalence of the trisomy, and not on the test characteristics. 

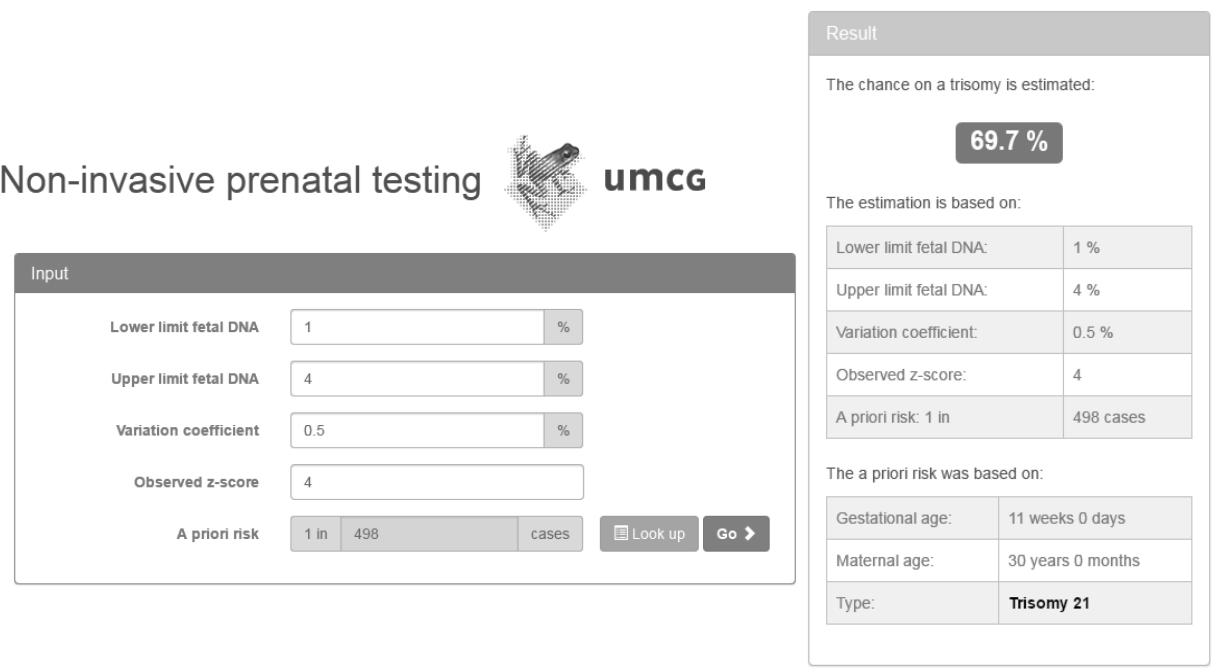

Figure 7.2 Calculator of the positive predictive value (https://molgenis60.target.rug.nl/). On the right an example of the positive predictive value of a positive NIPT test for a woman of 30 years old, undergoing NIPT at 11 weeks of gestation without undergoing first the FCT, with a maximum of $4 \%$ fetal fraction and a z-score of 4 .

\subsubsection{Autonomous reproductive choice}

International guidelines recommend offering prenatal screening in a non-directive way in order to provide an informed and autonomous reproductive choice to pregnant women. ${ }^{150}$ In this non-directive framework, health services adopt a position of neutrality, do not convey a discriminatory message about individuals with disabilities, and provide pregnant couples with free pre-test and post-test choices.

In view of the primary aim of prenatal screening, i.e. the provision of autonomous reproductive choice, it can be argued that women should, as far as reasonably possible, be given the opportunity to decide for themselves whether or not to undergo prenatal screening and if so which prenatal screening strategy best fits their personal values and preferences. This strategy is termed individualized choice. ${ }^{151}$ In Chapter 5 we described individualized choice for women that opt for NIPT for Down syndrome, more specifically concerning its timing in pregnancy and its combination with other tests. In Chapter 6, while discussing prenatal screening for sex chromosome trisomies, pregnant women expressed the belief that based on adequate information, women are able to choose which conditions if any they want to screen for, if they want to 
undergo confirmatory invasive testing, and if they wish to continue or terminate the pregnancy. So, what is reasonably possible? I will discuss possible adaptions in pre-test counseling and the laboratory flow in order to obtain individualized choice.

\section{A. Informed consent}

Informed decision-making is based on sufficient knowledge and is consistent with the pregnant women's values. ${ }^{152}$ Offering sufficient knowledge to pregnant women is the first challenge in pre-test counseling. In the light of the increased number of conditions for which women can undergo noninvasive prenatal screening, a generic counseling model could be offered. ${ }^{152}$ Generic consent emphasizes broader concepts and common-denominator issues in genetic screening, such as the type of information sought (e.g. fetal chromosome disorders that can result in birth defects, intellectual disability and shortened life expectancy of the baby), limitations of screening (e.g. false positive and false negative NIPT predictions have been described), the possible need for a follow-up test to establish a definitive diagnosis, the reproductive options that might have to be considered, the costs of screening, and social issues, including confidentiality and the possibility of social stigmatization. The key concept is that detailed information about any specific test or disorder would be given only if a condition was detected, although patients would still have the opportunity to receive more detailed information by requesting at any time. A generic consent model may lead to less information overload during pre-test counseling. However, this does not address the request from the pregnant women in Chapter 6 to be well-informed for every condition included in the test panel, in order to make a decision about which disorders they want to screen for. I believe that, although some aspects of NIPT could be explained in a more general fashion (e.g. the possibility of test failure or the confirmation of a positive screening result with an invasive procedure), a generic counseling model should be avoided while discussing the clinical consequences of the different conditions before the decision to undergo prenatal screening.

In Table 7.3 suggested counseling points to guide pre-test conversations with women who are considering NIPT for trisomies 13, 18 and 21, and sex chromosome aneuploidies are summarized. ${ }^{153}$ 
Table 7.3 Pre-test counseling points for noninvasive prenatal testing ${ }^{a}$

\section{Testing is optional}

\section{Define screening}

3. Clinical features and variability of conditions

4. Describe technology

5. Explain the reporting format

6. Sensitivity

7. False positive rate and confirmation of abnormal results

\section{Positive and negative predictive values}

\section{Limitations}

\section{Incidental findings}

11. Timing
All screening and diagnostic testing for fetal aneuploidy is optional. Women should be given an opportunity to consider the potential implications of test results. The decision to proceed should depend on how each individual perceives the benefits of obtaining information about aneuploidy when weighed against the potential emotional and physical risk of testing.

Clarify that NIPT is a screening test. It cannot diagnose or eliminate the chance that a fetus has a particular chromosome condition; rather it separates women into higher or lower risk categories.

Describe the clinical features of each condition included in the screen using sensitive, neutral language.

The specific testing methods vary by laboratory.

Women should be told when and how their results will be provided. The chance for a non-reportable result should be discussed too.

Describe the sensitivity for the different conditions.

A karyotype or microarray of cultured chorionic villi or amniocytes is necessary for confirmation of an abnormal NIPT result.

A NIPT assay can have both a high sensitivity and specificity without being a good predictor of whether the fetus actually has fetal aneuploidy. The predictive values are dependent of the prevalence of the disorder and test-specific characteristics. If a calculator is used to report the pregnant woman's individual positive predictive value, this should be discussed as well.

Emphasize that while NIPT screens for several of the more common aneuploidies, diagnostic testing through chorionic villus sampling or amniocentesis can test for all aneuploidies, can distinguish between full trisomy and trisomy caused by a chromosomal rearrangement, can detect mosaicism, microdeletions, microduplications, single-gene disorders and neural tube defects.

Incidental findings include maternal chromosome differences, in particular sex chromosome aneuploidies, maternal malignancies and fetal or placental chromosome differences other than the aneuploidies specifically targeted by NIPT.

Discuss the earliest time at which NIPT can be performed, the laboratory-specific turnaround time, the local legal limit for pregnancy termination and the turnaround time for amniocentesis results.

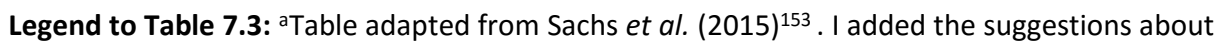
the positive and negative predictive values from this general discussion chapter to the table. 
A second challenge is to offer to women the opportunity to make autonomous decisions about undergoing screening and all further steps in the screening process consistent with their values. In the context of prenatal screening, autonomous choice does not mean that the pregnant woman is not influenced by others. ${ }^{154}$ On the contrary, relationships do play a role in decision-making regarding pregnancy testing. Women prefer to discuss the options, especially with their partners, but also with family and friends. Taking decisions compatible with their responsibilities and their ties with others can help women to feel more comfortable with their final choice. Health services should offer this time to discuss screening with others. I suggest a two-step counseling system with timely offering of pre-test counseling for NIPT to pregnant women in a first visit, and the decision about which disorders she would like to screen for in the second visit. In between the two visits written information, e.g. patient leaflets or websites, helps to make the decision. This decision-making process would be easier if women are already well informed about DNA, genetic disorders, and prenatal screening and diagnosis in the preconception phase. Well-informed pregnant women could already discuss the options with others, before talking to their obstetrician or midwife for the first time about screening. In that case, a second visit would probably not be necessary. Perhaps, decision-aids may help in the process. ${ }^{155}$

Finally, opt-in and opt-out options for the genetic conditions in the NIPT panel are reasonable. Women should not be obligated to screen for a genetic condition in their fetus because they want to screen for another one. Today, in the Netherlands it is not allowed to only screen for the more severe trisomies 13 and 18 . It is obligated to combine screening for these conditions with screening for trisomy 21 . It is however allowed to only screen for trisomy $21 .{ }^{156}$ Future parents should be explained that even if they thick all the boxes of every available screening test, a negative result will never exclude all possible congenital abnormalities in their fetus.

\section{B. Laboratory flow}

If prenatal screening is offered to provide future parents an informed decision, than one should not be overprotective of the current laboratory flows. These should be organized to support the individualized choice and to be flexible for opt-in and opt-out options. The performance (sensitivity and specificity) of NIPT in a general obstetrical population is equivalent to its performance in high-risk pregnant women. No bioinformatics or technical adjustments are required in low-risk women in comparison to high-risk women. Consequently, for all women, either tested early in pregnancy, pre-screened by the FCT or following the fetal anomaly scan, the NIPT result can be 
reported within the same turnaround time. However, as suggested earlier in this general discussion chapter, the result of the NIPT could be reported in combination with the specific positive and negative predictive value for the pregnant woman. Within a certain time frame, the timing of the NIPT can be flexible. The time frame is determined by two factors. Too early in pregnancy, the fetal fraction can be too low for a reliable test. ${ }^{142,143}$ Most laboratories do not offer the result before 10 weeks of gestation. Too late in pregnancy, women would no longer have a reproductive choice. NIPT should be performed so that the result is known before the legal time of abortion (<24 weeks in most countries)..$^{157}$

Efforts should be made to develop generic NIPT assays. In these tests, a broad panel of disorders to screen for can be offered to the pregnant women. As discussed earlier, these are preferably early-onset disorders with clear clinical consequences. To promote opt-in and opt-out choices, a filter should be available allowing to only visualize the results that are requested for by the future parents. Consequently, the laboratory staff and the clinicians are not informed about a disorder in the fetus that the parents do not want to know, avoiding a possible moral dilemma. The current NIPT assay, in which the panel of genetic disorders comprises trisomies 13, 18, 21, sex chromosome aneuploidy and microdeletions and duplications, is an example of a test for which this filter is possible. It is relatively easy to only filter the autosomal trisomies and not any of the other aberrations the assay can detect.

\subsection{Concluding remarks}

The analysis of fetal cfDNA in the maternal blood circulation provides a safe alternative to the invasive procedures for the prenatal diagnosis of single-gene disorders. Furthermore, it offers the possibility for a highly reliable screening test for fetal aneuploidy. In the coming years, cfDNA and cfRNA might be used to noninvasively monitor the fetus, to provide insight in placental and fetal development, and to offer pregnant women a prenatal screening test for a broader range of conditions. The aim of this thesis was to develop novel noninvasive prenatal diagnostic tests as well as to investigate the responsible application of cfDNA-based testing in prenatal screening. The latter investigation is at least as important as the exploration of what can be detected in the cfDNA. Parallel with technical innovations, further research is required, e.g. into the preferences of pregnant women, and the optimal path to informed decision making. 


\subsection{References}

1. Lo YM, Corbetta N, Chamberlain PF, Rai V, Sargent IL, Redman CW, Wainscoat JS. Presence of fetal DNA in maternal plasma and serum. Lancet 1997;350:485-487.

2. Lo YM, Hjelm NM, Fidler C, Sargent IL, Murphy MF, Chamberlain PF, Poon PM, Redman CW, Wainscoat JS. Prenatal diagnosis of fetal RhD status by molecular analysis of maternal plasma. N Engl J Med 1998;339:1734-1738.

3. Faas BH, Beuling EA, Christiaens GC, von dem Borne AE, van der Schoot CE. Detection of fetal RHDspecific sequences in maternal plasma. Lancet 1998;352:1196.

4. Wright CF, Wei Y, Higgins JP, Sagoo GS. Non-invasive prenatal diagnostic test accuracy for fetal sex using cell-free DNA a review and meta-analysis. BMC Res Notes 2012;5:476.

5. Scheffer PG, van der Schoot CE, Page-Christiaens GC, Bossers B, van Erp F, de Haas M. Reliability of fetal sex determination using maternal plasma. Obstet Gynecol 2010;115:117-126.

6. Bianchi DW, Wilkins-Haug L. Integration of noninvasive DNA testing for aneuploidy into prenatal care: what has happened since the rubber met the road? Clin Chem 2014;60:78-87.

7. Rijnders RJ, van der Schoot CE, Bossers B, de Vroede MA, Christiaens GC. Fetal sex determination from maternal plasma in pregnancies at risk for congenital adrenal hyperplasia. Obstet Gynecol 2001;98:374e8.

8. Chitty LS, Chatelain P, Wolffenbuttel KP, Aigrain Y. Prenatal management of disorders of sex development. J Pediatr Urol 2012;8:576-584.

9. Iruretagoyena JI, Grady M, Shah D. Discrepancy in fetal sex assignment between cell free fetal DNA and ultrasound. J Perinatol 2015;35:229-230.

10. Tsui NB, Ng EK, Lo YM. Stability of endogenous and added RNA in blood specimens, serum, and plasma. Clin Chem 2002;48:1647-1653.

11. Lattanzi W, Di Giacomo MC, Lenato GM, Chimienti G, Voglino G, Resta N, Pepe G, Guanti G. A large interstitial deletion encompassing the amelogenin gene on the short arm of the $Y$ chromosome. Hum Genet 2005;116:395-401.

12. Mitchell RJ, Kreskas M, Baxter E, Buffalino L, Van Oorschot RA. An investigation of sequence deletions of amelogenin (AMELY), a Y-chromosome locus commonly used for gender determination. Ann Hum Biol 2006;33:227-240.

13. Wong FC, Lo YM. Prenatal Diagnosis Innovation: Genome Sequencing of Maternal Plasma. Annu Rev Med 2016;67:419-432

14. Chiu RW, Lui WB, Cheung MC, Kumta N, Farina A, Banzola I, Grotti S, Rizzo N, Haines CJ, Lo YM. Time profile of appearance and disappearance of circulating placenta-derived mRNA in maternal plasma. Clin Chem 2006;52:313-316.

15. Bianchi DW. From prenatal genomic diagnosis to fetal personalized medicine: progress and challenges. Nat Med 2012;18:1041-1051.

16. Larrabee PB, Johnson KL, Lai C, Ordovas J, Cowan JM, Tantravahi U, Bianchi DW. Global gene expression analysis of the living human fetus using cell-free messenger RNA in amniotic fluid. JAMA 2005;293:836842.

17. Slonim DK, Koide K, Johnson KL, Tantravahi U, Cowan JM, Jarrah Z, Bianchi DW. Functional genomic analysis of amniotic fluid cell-free mRNA suggests that oxidative stress is significant in Down syndrome fetuses. Proc Natl Acad Sci U S A 2009;106:9425-9429.

18. Koide K, Slonim DK, Johnson KL, Tantravahi U, Cowan JM, Bianchi DW. Transcriptomic analysis of cellfree fetal RNA suggests a specific molecular phenotype in trisomy 18. Hum Genet 2011;129:295-305.

19. Ng EK, Leung TN, Tsui NB, Lau TK, Panesar NS, Chiu RW, Lo YM. The concentration of circulating corticotropin-releasing hormone mRNA in maternal plasma is increased in preeclampsia. Clin Chem 2003;49:727-731. 
20. Maron JL, Johnson KL, Slonim D, Lai CQ, Ramoni M, Alterovitz G, Jarrah Z, Yang Z, Bianchi DW. Gene expression analysis in pregnant women and their infants identifies unique fetal biomarkers that circulate in maternal blood. J Clin Invest. 2007;117:3007-3019.

21. Farina A. The Role of RNAs and microRNAs in Non-Invasive Prenatal Diagnosis. J Clin Med 2014;3:440452.

22. van den Veyver IB, Eng CM. Genome-Wide Sequencing for Prenatal Detection of Fetal Single-Gene Disorders. Cold Spring Harb Perspect Med 2015;5:a023077.

23. Lam KW, Jiang P, Liao GJ, Chan KC, Leung TY, Chiu RW, Lo YM. Noninvasive prenatal diagnosis of monogenic diseases by targeted massively parallel sequencing of maternal plasma: application to $\beta$ thalassemia. Clin Chem 2012;58:1467-1475.

24. New MI, Tong YK, Yuen T, Jiang P, Pina C, Chan KC, Khattab A, Liao GJ, Yau M, Kim SM, Chiu RW, Sun L, Zaidi M, Lo YM. Noninvasive prenatal diagnosis of congenital adrenal hyperplasia using cell-free fetal DNA in maternal plasma. J Clin Endocrinol Metab 2014;99:e1022-1030.

25. Ma D, Ge H, Li X, Jiang T, Chen F, Zhang Y, Hu P, Chen S, Zhang J, Ji X, Xu X, Jiang H, Chen M, Wang W, $\mathrm{Xu} Z$ Z. Haplotype-based approach for noninvasive prenatal diagnosis of congenital adrenal hyperplasia by maternal plasma DNA sequencing. Gene 2014;544:252-258.

26. Lv W, Wei X, Guo R, Liu Q, Zheng Y, Chang J, Bai T, Li H, Zhang J, Song Z, Cram DS, Liang D, Wu L. Noninvasive prenatal testing for Wilson disease by use of circulating single-molecule amplification and resequencing technology (cSMART). Clin Chem 2015;61:172-181.

27. Yoo SK, Lim BC, Byeun J, Hwang H, Kim KJ, Hwang YS, Lee J, Park JS, Lee YS, Namkung J, Park J, Lee S, Shin JY, Seo JS, Kim JI, Chae JH. Noninvasive prenatal diagnosis of duchenne muscular dystrophy: comprehensive genetic diagnosis in carrier, proband, and fetus. Clin Chem 2015;61:829-837.

28. Xu Y, Li X, Ge HJ, Xiao B, Zhang YY, Ying XM, Pan XY, Wang L, Xie WW, Ni L, Chen SP, Jiang WT, Liu P, Ye H, Cao Y, Zhang JM, Liu Y, Yang ZJ, Chen YW, Chen F,Jiang H, Ji X. Haplotype-based approach for noninvasive prenatal tests of Duchenne muscular dystrophy using cell-free fetal DNA in maternal plasma. Genet Med 2015;17:889-896.

29. Meng M, Li X, Ge H, Chen F, Han M, Zhang Y, Kang D, Xie W, Gao Z, Pan X, Dai P, Chi F, Chen S, Liu P, Zhang $\mathrm{C}$, Cao J, Jiang $\mathrm{H}, \mathrm{Xu} \mathrm{X,} \mathrm{Wang} \mathrm{W,} \mathrm{Duan} \mathrm{T.} \mathrm{Noninvasive} \mathrm{prenatal} \mathrm{testing} \mathrm{for} \mathrm{autosomal} \mathrm{recessive}$ conditions by maternal plasma sequencing in a case of congenital deafness. Genet Med 2014;16:972976.

30. Chitty LS, Mason S, Barrett AN, McKay F, Lench N, Daley R, Jenkins LA. Non-invasive prenatal diagnosis of achondroplasia and thanatophoric dysplasia: next-generation sequencing allows for a safer, more accurate, and comprehensive approach. Prenat Diagn 2015;35:656-662.

31. Xiong L, Barrett AN, Hua R, Tan TZ, Ho SSY, Chan JKY, Zhong M, Choolani M. Non-invasive prenatal testing for $\beta$-thalassaemia using cell-free DNA and next generation sequencing. Prenat Diagn 2015;35:258-265.

32. Hill M, Twiss P, Verhoef TI, Drury S, McKay F, Mason S, Jenkins L, Morris S, Chitty LS. Non-invasive prenatal diagnosis for cystic fibrosis: detection of paternal mutations, exploration of patient preferences and cost analysis. Prenat Diagn 2015;35:950-958.

33. van den Oever JM, Bijlsma EK, Feenstra I, Muntjewerff N, Mathijssen IB, Bakker E, van Belzen MJ, Boon EM. Noninvasive prenatal diagnosis of Huntington disease: detection of the paternally inherited expanded CAG repeat in maternal plasma. Prenat Diagn 2015;35:945-949.

34. Parks M, Court S, Cleary S, Clokie S, Hewitt J, Williams D, Cole T, MacDonald F, Griffiths M, Allen S. Noninvasive prenatal diagnosis of Duchenne and Becker muscular dystrophies by relative haplotype dosage. Prenat Diagn 2016;36:312-320.

35. Lo YM, Tein MS, Lau TK, Haines CJ, Leung TN, Poon PM, Wainscoat JS, Johnson PJ, Chang AM, Hjelm NM. Quantitative analysis of fetal DNA in maternal plasma and serum: implications for noninvasive prenatal diagnosis. Am J Hum Genet 1998;62:768-775.

36. Lun FM, Chiu RW, Chan KC, Leung TY, Lau TK, Lo YM. Microfluidics digital PCR reveals a higher than expected fraction of fetal DNA in maternal plasma. Clin Chem 2008;54:1664-1672. 
37. Chiu RW, Poon LL, Lau TK, Leung TN, Wong EM, Lo YM. Effects of blood-processing protocols on fetal and total DNA quantification in maternal plasma. Clin Chem 2001;47:1607-1613.

38. Manokhina I, Singh TK, Peñaherrera MS, Robinson WP. Quantification of cell-free DNA in normal and complicated pregnancies: overcoming biological and technical issues. PLoS One 2014;9:e101500.

39. Lo YM, Chan KC, Sun H, Chen EZ, Jiang P, Lun FM, Zheng YW, Leung TY, Lau TK, Cantor CR, Chiu RW. Maternal plasma DNA sequencing reveals the genome-wide genetic and mutational profile of the fetus. Sci Transl Med 2010;2:61ra91.

40. Fan HC, Blumenfeld YJ, Chitkara U, Hudgins L, Quake SR. Analysis of the size distributions of fetal and maternal cell-free DNA by paired-end sequencing. Clin Chem 2010;56:1279-1286.

41. Hiatt JB, Pritchard CC, Salipante SJ, O'Roak BJ, Shendure J. Single molecule molecular inversion probes for targeted, high-accuracy detection of low-frequency variation. Genome Res 2013;23:843-854.

42. Verhoef TI, Hill M, Drury S, Mason S, Jenkins L, Morris S, Chitty LS. Non-invasive prenatal diagnosis (NIPD) for single gene disorders: cost analysis of NIPD and invasive testing pathways. Prenat Diagn 2016;36:636-642.

43. Lench N, Barrett A, Fielding S, McKay F, Hill M, Jenkins L, White H, Chitty LS. The clinical implementation of non-invasive prenatal diagnosis for single-gene disorders: challenges and progress made. Prenat Diagn 2013;33:555-562.

44. Orr HT, Zoghbi HY. Trinucleotide repeat disorders. Annu Rev Neurosci 2007;30:575-621.

45. Mirkin SM. Expandable DNA repeats and human disease. Nature 2007;447:932-940.

46. Brook JD, McCurrach ME, Harley HG, Buckler AJ, Church D, Aburatani H, Hunter K, Stanton VP, Thirion JP, Hudson T, et al. Molecular basis of myotonic dystrophy: expansion of a trinucleotide (CTG) repeat at the $3^{\prime}$ end of a transcript encoding a protein kinase family member. Cell 1992;69:385.

47. Mahadevan M, Tsilfidis C, Sabourin L, Shutler G, Amemiya C, Jansen G, Neville C, Narang M, Barceló J, O'Hoy K, et al. Myotonic dystrophy mutation: an unstable CTG repeat in the 3' untranslated region of the gene. Science 1992;255:1253-1255.

48. Ho G, Cardamone M, Farrar M. Congenital and childhood myotonic dystrophy: Current aspects of disease and future directions. World J Clin Pediatr 2015;4:66-80.

49. González-González MC, Trujillo MJ, Rodríguez de Alba M, García-Hoyos M, Lorda-Sánchez I, DíazRecasens J, Ayuso C, Ramos C. Huntington disease-unaffected fetus diagnosed from maternal plasma using QF-PCR. Prenat Diagn 2003;23:232-234.

50. Bustamante-Aragones A, Trujillo-Tiebas MJ, Gallego-Merlo J, Rodriguez de Alba M, Gonzalez-Gonzalez C, Cantalapiedra D, Ayuso C, Ramos C. Prenatal diagnosis of Huntington disease in maternal plasma: direct and indirect study. Eur J Neurol 2008;15:1338-1344.

51. Elmore S. Apoptosis: a review of programmed cell death. Toxicol Pathol 2007;35:495-516

52. Buermans HP, den Dunnen JT. Next generation sequencing technology: Advances and applications. Biochim Biophys Acta 2014;1842:1932-1941.

53. McFarland KN, Liu J, Landrian I, Godiska R, Shanker S, Yu F, Farmerie WG, Ashizawa T. SMRT Sequencing of Long Tandem Nucleotide Repeats in SCA10 Reveals Unique Insight of Repeat Expansion Structure. PLoS One. 2015;10:e0135906.

54. Laver T, Harrison J, O'Neill PA, Moore K, Farbos A, Paszkiewicz K, Studholme DJ. Assessing the performance of the Oxford Nanopore Technologies MinION. Biomol Detect Quantif 2015;3:1-8.

55. http://www.rapid.nhs.uk/guides-to-nipd-nipt/nipd-for-single-gene-disorders/

56. Lewis $\mathrm{C}$, Hill M, Chitty LS. Non-invasive prenatal diagnosis for single gene disorders: experience of patients. Clin Genet 2014;85:336-342.

57. Derks-Smeets IA, Gietel-Habets JJ, Tibben A, Tjan-Heijnen VC, Meijer-Hoogeveen M, Geraedts JP, van Golde R, Gomez-Garcia E, van den Bogaart E, van Hooijdonk M, de Die-Smulders CE, van Osch LA. Decision-making on preimplantation genetic diagnosis and prenatal diagnosis: a challenge for couples with hereditary breast and ovarian cancer. Hum Reprod 2014;29:1103-1112. 
58. Deans Z, Hill M, Chitty LS, Lewis C. Non-invasive prenatal testing for single gene disorders: exploring the ethics. Eur J Hum Genet 2013;21:713-718.

59. Hill M, Karunaratna M, Lewis C, Forya F, Chitty L. Views and preferences for the implementation of non-invasive prenatal diagnosis for single gene disorders from health professionals in the United Kingdom. Am J Med Genet A 2013;161A:1612-1618.

60. Bianchi DW, Maron JL, Johnson KL. Insights into fetal and neonatal development through analysis of cell-free RNA in body fluids. Early Hum Dev 2010;86:747-752.

61. Fan HC, Blumenfeld YJ, Chitkara U, Hudgins L, Quake SR. Noninvasive diagnosis of fetal aneuploidy by shotgun sequencing DNA from maternal blood. Proc Natl Acad Sci U S A 2008;105:16266-16271.

62. Chiu RW, Sun H, Akolekar R, Clouser C, Lee C, McKernan K, Zhou D, Nicolaides KH, Lo YM. Maternal plasma DNA analysis with massively parallel sequencing by ligation for noninvasive prenatal diagnosis of trisomy 21. Clin Chem 2010;56:459-463.

63. Chen EZ, Chiu RW, Sun H, Akolekar R, Chan KC, Leung TY, Jiang P, Zheng YW, Lun FM, Chan LY, Jin Y, Go AT, Lau ET, To WW, Leung WC, Tang RY, Au-Yeung SK, Lam H, Kung YY, Zhang X, van Vugt JM, Minekawa $\mathrm{R}$, Tang MH, Wang J, Oudejans CB, Lau TK, Nicolaides KH, Lo YM. Noninvasive prenatal diagnosis of fetal trisomy 18 and trisomy 13 by maternal plasma DNA sequencing. PLoS One 2011;6:e21791.

64. Chiu RW, Akolekar R, Zheng YW, Leung TY, Sun H, Chan KC, Lun FM, Go AT, Lau ET, To WW, Leung WC, Tang RY, Au-Yeung SK, Lam H, Kung YY, Zhang X, van Vugt JM, Minekawa R, Tang MH, Wang J, Oudejans CB, Lau TK, Nicolaides KH, Lo YM. Non-invasive prenatal assessment of trisomy 21 by multiplexed maternal plasma DNA sequencing: large scale validity study. BMJ 2011;342:c7401.

65. Ehrich M, Deciu C, Zwiefelhofer T, Tynan JA, Cagasan L, Tim R, Lu V, McCullough R, McCarthy E, Nygren AO, Dean J, Tang L, Hutchison D, Lu T, Wang H, Angkachatchai V, Oeth P, Cantor CR, Bombard A, van den Boom D. Noninvasive detection of fetal trisomy 21 by sequencing of DNA in maternal blood: a study in a clinical setting. Am J Obstet Gynecol 2011;204:205e1-11.

66. Palomaki GE, Kloza EM, Lambert-Messerlian GM, Haddow JE, Neveux LM, Ehrich M, van den Boom D, Bombard AT, Deciu C, Grody WW, Nelson SF, Canick JA. DNA sequencing of maternal plasma to detect Down syndrome: An international clinical validation study. Genet Med 2011;13:913-920.

67. Sehnert AJ, Rhees B, Comstock D, de Feo E, Heilek G, Burke J, Rava RP. Optimal detection of fetal chromosomal abnormalities by massively parallel DNA sequencing of cell-free fetal DNA from maternal blood. Clin Chem 2011;57:1042-1049.

68. Bianchi DW, Platt LD, Goldberg JD, Abuhamad AZ, Sehnert AJ, Rava RP. Genome-wide fetal aneuploidy detection by maternal plasma DNA sequencing. Obstet Gynecol 2012;119:890-901.

69. Ashoor G, Syngelaki A, Wagner M, Birdir C, Nicolaides KH. Chromosome-selective sequencing of maternal plasma cell-free DNA for first-trimester detection of trisomy 21 and trisomy 18. Am J Obstet Gynecol 2012;206:322.e1-5.

70. Jiang F, Ren J, Chen F, Zhou Y, Xie J, Dan S, Su Y, Xie J, Yin B, Su W, Zhang H, Wang W, Chai X, Lin L, Guo H, Li Q, Li P, Yuan Y, Pan X, Li Y, Liu L, Chen H, Xuan Z, Chen S, Zhang C, Zhang H, Tian Z, Zhang Z, Jiang H, Zhao L, Zheng W, Li S, Li Y, Wang J, Wang J, Zhang X. Noninvasive Fetal Trisomy (NIFTY) test: an advanced noninvasive prenatal diagnosis methodology for fetal autosomal and sex chromosomal aneuploidies. BMC Med Genomics 2012;5:57.

71. Lau TK, Chen F, Pan X, Pooh RK, Jiang F, Li Y, Jiang H, Li X, Chen S, Zhang X. Noninvasive prenatal diagnosis of common fetal chromosomal aneuploidies by maternal plasma DNA sequencing. J Matern Fetal Neonatal Med 2012;25:1370-1374.

72. Norton ME, Brar H, Weiss J, Karimi A, Laurent LC, Caughey AB, Rodriguez MH, Williams J 3rd, Mitchell ME, Adair CD, Lee H, Jacobsson B, Tomlinson MW, Oepkes D, Hollemon D, Sparks AB, Oliphant A, Song K. Non-invasive chromosomal evaluation (NICE) study: results of a multicenter prospective cohort study for detection of fetal trisomy 21 and trisomy 18. Am J Obstet Gynecol 2012; 207:137.e1-8.

73. Allyse M, Minear MA, Berson E, Sridhar S, Rote M, Hung A, Chandrasekharan S. Non-invasive prenatal testing: a review of international implementation and challenges. Int J Womens Health 2015;7:113126. 
74. Dan S, Wang W, Ren J, Li Y, Hu H, Xu Z, Lau TK, Xie J, Zhao W, Huang H, Xie J, Sun L, Zhang X, Wang W, Liao S, Qiang R, Cao J, Zhang Q, Zhou Y, Zhu H, Zhong M, Guo Y, Lin L, Gao Z, Yao H, Zhang H, Zhao L, Jiang F, Chen F, Jiang H, Li S, Li Y, Wang J, Wang J, Duan T, Su Y, Zhang X. Clinical application of massively parallel sequencing-based prenatal noninvasive fetal trisomy test for trisomies 21 and 18 in 11,105 pregnancies with mixed risk factors. Prenat Diagn 2012;32:1225-1232.

75. Whiting PF, Rutjes AW, Westwood ME, Mallett S, Deeks JJ, Reitsma JB, Leeflang MM, Sterne JA, Bossuyt PM. QUADAS-2: a revised tool for the quality assessment of diagnostic accuracy studies. Ann Intern Med 2011;155:529-536.

76. Morain S, Greene MF, Mello MM: A new era in noninvasive prenatal testing. N Engl J Med 2013;369:499-501.

77. Benn P, Borrell A, Chiu R, Cuckle H, Dugoff L, Faas B, Gross S, Huang T, Johnson J, Maymon R, Norton M, Odibo A, Schielen P, Spencer K, Wright D, Yaron Y. Position Statement from the Chromosome Abnormality Screening Committee on Behalf of the Board of the International Society for Prenatal Diagnosis. Downloaded from http://www.ispdhome.org/, 26 April 2015.

78. Nicolaides KH, Syngelaki A, Ashoor G, Birdir C, Touzet G. Noninvasive prenatal testing for fetal trisomies in a routinely screened first-trimester population. Am J Obstet Gynecol 2012; 207:374.e1-6.

79. Palomaki GE, Deciu C, Kloza EM, Lambert-Messerlian GM, Haddow JE,Neveux LM, Ehrich M, van den Boom D, Bombard AT, Grody WW, Nelson SF, Canick JA. DNA sequencing of maternal plasma reliably identifies trisomy 18 and trisomy 13 as well as Down syndrome: an international collaborative study. Genet Med 2012;14:296-305.

80. Ashoor G, Syngelaki A, Wang E, Struble C, Oliphant A, Song K, Nicolaides KH. Trisomy 13 detection in the first trimester of pregnancy using a chromosome-selective cell-free DNA analysis. Ultrasound Obstet Gynecol 2013; 41:21-25.

81. Guex N, Iseli C, Syngelaki A, Pescia G, Nicolaides KH, Xenarios I, Conrad B. A robust second-generation genome-wide test for fetal aneuploidy based on shotgun sequencing cell-free DNA in maternal blood. Prenat Diagn 2013;33:707-710.

82. Liang D, Lv W, Wang H, Xu L, Liu J, Li H, Hu L, Peng Y, Wu L. Non-invasive prenatal testing of fetal whole chromosome aneuploidy by massively parallel sequencing. Prenat Diagn 2013;33:409-415.

83. Song Y, Liu C, Qi H, Zhang Y, Bian X, Liu J. Noninvasive prenatal testing of fetal aneuploidies by massively parallel sequencing in a prospective Chinese population. Prenat Diagn 2013;33:700-706.

84. Verweij EJ, Jacobsson B, van Scheltema PA, de Boer MA, Hoffer MJ, Hollemon D, Westgren M, Song K, Oepkes D. European Non-Invasive Trisomy Evaluation (EU-NITE) study: a multicenter prospective cohort study for non-invasive fetal trisomy 21 testing. Prenat Diagn 2013;22:1-6.

85. Bianchi DW, Parker RL, Wentworth J, Madankumar R, Saffer C, Das AF, Craig JA, Chudova DI, Devers PL, Jones KW, Oliver K, Rava RP, Sehnert AJ; CARE Study Group. DNA sequencing versus standard prenatal aneuploidy screening. N Engl J Med 2014;370:799-808.

86. Pergament E, Cuckle H, Zimmermann B, Banjevic M, Sigurjonsson S, Ryan A, Hall MP, Dodd M, Lacroute P, Stosic M, Chopra N, Hunkapiller N, Prosen DE, McAdoo S, Demko Z, Siddiqui A, Hill M, RabinowitzM. Single-nucleotide polymorphism-based noninvasive prenatal screening in a high-risk and low-risk cohort. Obstet Gynecol 2014;124:210-218.

87. Porreco RP, Garite TJ, Maurel K, Marusiak B; Obstetrix Collaborative Research Network, Ehrich M, van den Boom D, Deciu C, Bombard A. Noninvasive prenatal screening for fetal trisomies 21, 18, 13 and the common sex chromosome aneuploidies from maternal blood using massively parallel genomic sequencing of DNA. Am J Obstet Gynecol 2014;211:365.e1-12.

88. Shaw SW, Hsiao CH, Chen CY, Ren Y, Tian F, Tsai C, Chen M, Cheng PJ. Noninvasive prenatal testing for whole fetal chromosomal aneuploidies: a multicenter prospective cohort trial in Taiwan. Fetal Diagn Ther 2014;35:13-17. 
89. Stumm M, Entezami M, Haug K, Blank C, Wüstemann M, Schulze B, Raabe-Meyer G, Hempel M, Schelling M, Ostermayer E, Langer-Freitag S, Burkhardt T, Zimmermann R, Schleicher T, Weil B, Schöck $U$, Smerdka P, Grömminger S, Kumar Y, Hofmann W. Diagnostic accuracy of random massively parallel sequencing for non-invasive prenatal detection of common autosomal aneuploidies: a collaborative study in Europe. Prenat Diagn 2014;34:185-191.

90. Quezada MS, Gil MM, Francisco C, Oròsz G, Nicolaides KH. Screening for trisomies 21, 18 and 13 by cell-free DNA analysis of maternal blood at 10-11 weeks' gestation and the combined test at 11-13 weeks. Ultrasound Obstet Gynecol 2015;45:36-41.

91. Song $Y$, Huang S, Zhou X, Jiang Y, Qi Q, Bian X, Zhang J, Yan Y, Cram DS, Liu J. Non-invasive prenatal testing for fetal aneuploidies in the first trimester of pregnancy. Ultrasound Obstet Gynecol 2015;45:55-60.

92. Norton ME, Jacobsson B, Swamy GK, Laurent LC, Ranzini AC, Brar H, Tomlinson MW, Pereira L, Spitz JL, Hollemon D, Cuckle H, Musci TJ, Wapner RJ. Cell-free DNA analysis for noninvasive examination of trisomy. N Engl J Med 2015;372:1589-1597.

93. Stokowski R, Wang E, White K, Batey A, Jacobsson B, Brar H, Balanarasimha M, Hollemon D, Sparks A, Nicolaides K, Musci TJ. Clinical performance of non-invasive prenatal testing (NIPT) using targeted cellfree DNA analysis in maternal plasma with microarrays or next generation sequencing (NGS) is consistent across multiple controlled clinical studies. Prenat Diagn 2015;35:1243-1246.

94. Zhang H, Gao Y, Jiang F, Fu M, Yuan Y, Guo Y, Zhu Z, Lin M, Liu Q, Tian Z, Zhang H, Chen F, Lau TK, Zhao L, Yi X, Yin Y, Wang W. Non-invasive prenatal testing for trisomies 21, 18 and 13: clinical experience from 146,958 pregnancies. Ultrasound Obstet Gynecol 2015;45:530-538.

95. Ryan A, Hunkapiller N, Banjevic M, Vankayalapati N, Fong N, Jinnett KN, Demko Z, Zimmermann B, Sigurjonsson S, Gross SJ, Hill M. Validation of an Enhanced Version of a Single-Nucleotide Polymorphism-Based Noninvasive Prenatal Test for Detection of Fetal Aneuploidies. Fetal Diagn Ther. 2016 Mar 31. [Epub ahead of print]

96. Koumbaris G, Kypri E, Tsangaras K, Achilleos A, Mina P, Neofytou M, Velissariou V, Christopoulou G, Kallikas I, González-Liñán A, Benusiene E, Latos-Bielenska A, Marek P, Santana A, Nagy N, Széll M, Laudanski P, Papageorgiou EA, loannides M, Patsalis PC. Cell-Free DNA Analysis of Targeted Genomic Regions in Maternal Plasma for Non-Invasive Prenatal Testing of Trisomy 21, Trisomy 18, Trisomy 13, and Fetal Sex. Clin Chem 2016;62:848-855.

97. Agarwal A, Sayres LC, Cho MK, Cook-Deegan R, Chandrasekharan S. Commercial landscape of noninvasive prenatal testing in the United States. Prenat Diagn 2013;33:521-531.

98. Kagan KO, Wright D, Baker A, Sahota D, Nicolaides KH. Screening for trisomy 21 by maternal age, fetal nuchal translucency thickness, free beta-human chorionic gonadotropin and pregnancy-associated plasma protein-A. Ultrasound Obstet Gynecol 2008;31:618-624.

99. Hui L, Hyett J. Noninvasive prenatal testing for trisomy 21: challenges for implementation in Australia. Aust N Z J Obstet Gynaecol 2013;53:416-424.

100. Hill M, Wright D, Daley R, Lewis C, McKay F, Mason S, Lench N, Howarth A, Boustred C, Lo K, Plagnol V, Spencer K, Fisher J, Kroese M, Morris S, Chitty LS. Evaluation of non-invasive prenatal testing (NIPT) for aneuploidy in an NHS setting: a reliable accurate prenatal non-invasive diagnosis (RAPID) protocol. BMC Pregnancy Childbirth 2014;14:229.

101. Beulen L, Grutters JP, Faas BH, Feenstra I, van Vugt JM, Bekker MN. The consequences of implementing non-invasive prenatal testing in Dutch national health care: a cost-effectiveness analysis. Eur J Obstet Gynecol Reprod Biol 2014;182:53-61.

102. de Jong A, Dondorp WJ, Frints SG, de Die-Smulders CE, de Wert GM. Non-invasive prenatal diagnosis for aneuploidy: toward an integral ethical assessment. Hum Reprod 2011;26:2915-2917.

103. Deans Z, Newson AJ. Ethical considerations for choosing between possible models for using NIPD for aneuploidy detection. J Med Ethics 2012;38:614-618.

104. Song K, Musci TJ, Caughey AB. Clinical utility and costs of non-invasive prenatal testing with cfDNA analysis in high-risk women based on a US population. J Matern Fetal Neonatal Med 2013;26:11801185 . 
105. Nicolaides KH, Wright D, Poon LC, Syngelaki A, Gil MM. First-trimester contingent screening for trisomy 21 by biomarkers and maternal blood cell-free DNA testing. Ultrasound Obstet Gynecol 2013;42:4150.

106. Cuckle H, Benn P, Pergament E. Maternal cfDNA screening for Down syndrome - a cost sensitivity analysis. Prenat Diagn 2013;33:636-642.

107. Twiss $P$, Hill M, Daley R, Chitty LS. Non-invasive prenatal testing for Down syndrome. Semin Fetal Neonatal Med 2014;19:9-14.

108. van Schendel RV, Kleinveld JH, Dondorp WJ, Pajkrt E, Timmermans DR, Holtkamp KC, Karsten M, Vlietstra AL, Lachmeijer AM, Henneman L. Attitudes of pregnant women and male partners towards non-invasive prenatal testing and widening the scope of prenatal screening. Eur J Hum Genet 2014;22:1345-1350.

109. Hill M, Fisher J, Chitty LS, Morris S. Women's and health professionals' preferences for prenatal tests for Down syndrome: a discrete choice experiment to contrast noninvasive prenatal diagnosis with current invasive tests. Genet Med 2012;14:905-913.

110. Lewis C, Hill M, Chitty LS. Women's Experiences and Preferences for Service Delivery of Non-Invasive Prenatal Testing for Aneuploidy in a Public Health Setting: A Mixed Methods Study. PLoS One 2016;11:e0153147.

111. Verweij EJ, Oepkes D, de Vries M, van den Akker ME, van den Akker ES, de Boer MA. Non-invasive prenatal screening for trisomy 21: what women want and are willing to pay. Patient Educ Couns 2013;93:641-645.

112. Benn P, Chapman AR, Erickson K, Defrancesco MS, Wilkins-Haug L, Egan JF, Schulkin J. Obstetricians and gynecologists' practice and opinions of expanded carrier testing and noninvasive prenatal testing. Prenat Diagn 2014;34:145-152.

113. Wald NJ, Huttly WJ, Bestwick JP, Aquilina J, Peregrine E. Reflex antenatal DNA screening for Down syndrome. Prenat Diagn. 2015;35:1154.

114. Futch T, Spinosa J, Bhatt S, de Feo E, Rava RP, Sehnert AJ. Initial clinical laboratory experience in noninvasive prenatal testing for fetal aneuploidy from maternal plasma DNA samples. Prenat Diagn 2013;33:569-574.

115. Taylor JB, Chock VY, Hudgins L. NIPT in a clinical setting: an analysis of uptake in the first months of clinical availability. J Genet Couns 2014;23:72-78.

116. Gil MM, Quezada MS, Bregant B, Ferraro M, Nicolaides KH. Implementation of maternal blood cell-free DNA testing in early screening for aneuploidies. Ultrasound Obstet Gynecol 2013;42:34-40.

117. Yaron Y. The implications of non-invasive prenatal testing failures: a review of an under-discussed phenomenon. Prenat Diagn 2016;36:391-396.

118. Dondorp W, de Wert G, Bombard Y, Bianchi DW, Bergmann C, Borry P, Chitty LS, Fellmann F, Forzano F, Hall A, Henneman L, Howard HC, Lucassen A, Ormond K, Peterlin B, Radojkovic D, Rogowski W, Soller M, Tibben A, Tranebjærg L, van El CG, Cornel MC. Non-invasive prenatal testing for aneuploidy and beyond: challenges of responsible innovation in prenatal screening. Eur J Hum Genet. 2015;23:1438 1450.

119. Zhao C, Tynan J, Ehrich M, Hannum G, McCullough R, Saldivar JS, Oeth P, van den Boom D, Deciu C. Detection of fetal subchromosomal abnormalities by sequencing circulating cell-free DNA from maternal plasma. Clin Chem 2015;61:608-616.

120. Bayindir B, Dehaspe L, Brison N, Brady P, Ardui S, Kammoun M, Van der Veken L, Lichtenbelt K, Van den Bogaert K, Van Houdt J, Peeters H, Van Esch H, de Ravel T, Legius E, Devriendt K, Vermeesch JR. Noninvasive prenatal testing using a novel analysis pipeline to screen for all autosomal fetal aneuploidies improves pregnancy management. Eur J Hum Genet 2015;23:1286-1293.

121. Snyder MW, Simmons LE, Kitzman JO, Coe BP, Henson JM, Daza RM, Eichler EE, Shendure J, Gammill HS. Copy-number variation and false positive prenatal aneuploidy screening results. N Engl J Med 2015;372:1639-1645. 
122. Helgeson J, Wardrop J, Boomer T, Almasri E, Paxton WB, Saldivar JS, Dharajiya N, Monroe TJ, Farkas DH, Grosu DS, McCullough RM. Clinical outcome of subchromosomal events detected by wholegenome noninvasive prenatal testing. Prenat Diagn 2015;35:999-1004.

123. Straver R, Sistermans EA, Holstege H, Visser A, Oudejans CB, Reinders MJ. WISECONDOR: detection of fetal aberrations from shallow sequencing maternal plasma based on a within-sample comparison scheme. Nucleic Acids Res 2014;42:e31.

124. Valderramos SG, Rao RR, Scibetta EW, Silverman NS, Han CS, Platt LD. Cell-free DNA Screening in Clinical Practice: Abnormal Autosomal Aneuploidy and Microdeletion Results. Am J Obstet Gynecol. 2016 Jun 28. [Epub ahead of print]

125. Hooks J, Wolfberg AJ, Wang ET, Struble CA, Zahn J, Juneau K, Mohseni M, Huang S, Bogard P, Song K, Oliphant A, Musci TJ. Non-invasive risk assessment of fetal sex chromosome aneuploidy through directed analysis and incorporation of fetal fraction. Prenat Diagn 2014;34:496-499.

126. Nicolaides KH, Musci TJ, Struble CA, Syngelaki A, Gil MM. Assessment of fetal sex chromosome aneuploidy using directed cell-free DNA analysis. Fetal Diagn Ther 2014;35:1-6.

127. Yao H, Jiang F, Hu H, Gao Y, Zhu Z, Zhang H, Wang Y, Guo Y, Liu L, Yuan Y, Zhou L, Wang J, Du B, Qu N, Zhang R, Dong $Y, X u H$, Chen F, Jiang H, Liu Y, Zhang L, Tian Z, Liu Q, Zhang C, Pan X, Yang S, Zhao L, Wang W, Liang Z. Detection of fetal sex chromosome aneuploidy by massively parallel sequencing of maternal plasma DNA: initial experience in a Chinese hospital. Ultrasound Obstet Gynecol 2014;44:1724.

128. Bianchi DW, Parsa S, Bhatt S, Halks-Miller M, Kurtzman K, Sehnert AJ, Swanson A. Fetal sex chromosome testing by maternal plasma DNA sequencing: clinical laboratory experience and biology. Obstet Gynecol 2015;125:375-382.

129. Pescia G, Guex N, Iseli C, Brennan L, Osteras M, Xenarios I, Farinelli L, Conrad B. Cell-free DNA testing of an extended range of chromosomal anomalies: clinical experience with 6,388 consecutive cases. Genet Med. 2016 Jun 30. [Epub ahead of print]

130. Benn P. Expanding non-invasive prenatal testing beyond chromosomes 21, 18, 13, X and Y. Clin Genet. 2016 Jun 10. [Epub ahead of print]

131. Talkowski ME, Ordulu Z, Pillalamarri V, Benson CB, Blumenthal I, Connolly S, Hanscom C, Hussain N, Pereira S, Picker J, Rosenfeld JA, Shaffer LG, Wilkins-Haug LE, Gusella JF, Morton CC. Clinical diagnosis by whole-genome sequencing of a prenatal sample. N Engl J Med 2012;367:2226-2232.

132. Filges I, Nosova E, Bruder E, Tercanli S, Townsend K, Gibson WT, Röthlisberger B, Heinimann K, Hall JG, Gregory-Evans CY, Wasserman WW, Miny P, Friedman JM. Exome sequencing identifies mutations in KIF14 as a novel cause of an autosomal recessive lethal fetal ciliopathy phenotype. Clin Genet 2014;86:220-228.

133. Kitzman JO, Snyder MW, Ventura M, Lewis AP, Qiu R, Simmons LE, Gammill HS, Rubens CE, Santillan DA, Murray JC, Tabor HK, Bamshad MJ, Eichler EE, Shendure J.Noninvasive whole-genome sequencing of a human fetus. Sci Transl Med 2012;4:137ra76.

134. Verweij EJ, de Boer MA, Oepkes D. Non-invasive prenatal testing for trisomy 13: more harm than good? Ultrasound Obstet Gynecol 2014;44:112-114.

135. Smith M, Lewis KM, Holmes A, Visootsak J. A case of false negative NIPT for down syndrome-lessons learned. Case Rep Genet 2014;2014:823504.

136. Hochstenbach R, Nikkels PG, Elferink MG, Oudijk MA, van Oppen C, van Zon P, van Harssel J, SchuringBlom H, Page-Christiaens GC. Cell-free fetal DNA in the maternal circulation originates from the cytotrophoblast: proof from an unique case. Clin Case Rep 2015;3:489-491.

137. Kalafat E, Seval MM, Turgay B, Koç A. Non-invasive prenatal testing for sex chromosome abnormalities: a source of confusion. BMJ Case Rep 2015 Jan 28;2015.

138. McNamara CJ, Limone LA, Westover T, Miller RC. Maternal source of false-positive fetal sex chromosome aneuploidy in noninvasive prenatal testing. Obstet Gynecol 2015;125:390-392. 
139. Wang Y, Chen Y, Tian F, Zhang J, Song Z, Wu Y, Han X, Hu W, Ma D, Cram D, Cheng W. Maternal mosaicism is a significant contributor to discordant sex chromosomal aneuploidies associated with noninvasive prenatal testing. Clin Chem 2014;60:251-259.

140. Brady P, Brison N, Van Den Bogaert K, de Ravel T, Peeters H, Van Esch H, Devriendt K, Legius E, Vermeesch JR. Clinical implementation of NIPT - technical and biological challenges. Clin Genet 2016;89:523-530.

141. Palomaki GE, Kloza EM, Lambert-Messerlian GM, van den Boom D, Ehrich M, Deciu C, Bombard AT, Haddow JE. Circulating cell free DNA testing: are some test failures informative? Prenat Diagn 2015;35:289-293.

142. Ashoor G, Poon L, Syngelaki A, Mosimann B, Nicolaides KH. Fetal fraction in maternal plasma cell-free DNA at 11-13 weeks' gestation: effect of maternal and fetal factors. Fetal Diagn Ther 2012;31:237-243.

143. Ashoor G, Syngelaki A, Poon LC, Rezende JC, Nicolaides KH. Fetal fraction in maternal plasma cell-free DNA at 11-13 weeks' gestation: relation to maternal and fetal characteristics. Ultrasound Obstet Gynecol 2013;41:26-32.

144. Mardy A, Wapner RJ. Confined placental mosaicism and its impact on confirmation of NIPT results. Am J Med Genet C Semin Med Genet 2016;172:118-122.

145. Lo YMD. Noninvasive prenatal testing complicated by maternal malignancy: new tools for a complex problem. npj Genomic Medicine 2016;1:15002.

146. Loane M, Morris JK, Addor MC, Arriola L, Budd J, Doray B, Garne E, Gatt M, Haeusler M, Khoshnood B, Klungsøyr Melve K, Latos- Bielenska A, McDonnell B, Mullaney C, O'- Mahony M, Queisser-Wahrendorf A, Rankin J, Rissmann A, Rounding C, Salvador J, Tucker D, Wellesley D, Yevtushok L, Dolk H. Twentyyear trends in the prevalence of Down syndrome and other trisomies in Europe: impact of maternal age and prenatal screening. Eur J Hum Genet 2013;21:27-33.

147. Resta RG. Changing demographics of advanced maternal age (AMA) and the impact on the predicted incidence of Down syndrome in the United States: implications for prenatal screening and genetic counseling. Am J Med Genet A 2005;133A:31-36.

148. https://www.perinatalquality.org/Vendors/NSGC/NIPT/

149. http://mombaby.org/nips_calculator.html

150. Stapleton G. Qualifying choice: ethical reflection on the scope of prenatal screening. Med Health Care Philos. 2016 Sep 8. [Epub ahead of print]

151. Bunnik EM, de Jong A, Nijsingh N, de Wert GM. The new genetics and informed consent: differentiating choice to preserve autonomy. Bioethics 2013;27:348-355.

152. Ormond KE, Iris M, Banuvar S, Minogue J, Annas GJ, Elias S. What do patients prefer: informed consent models for genetic carrier testing. J Genet Couns 2007;16:539-550.

153. Sachs A, Blanchard L, Buchanan A, Norwitz E, Bianchi DW. Recommended pre-test counseling points for noninvasive prenatal testing using cell-free DNA: a 2015 perspective. Prenat Diagn 2015;35:968 971.

154. van den Berg M, Timmermans DR, ten Kate LP, van Vugt JM, van der Wal G.Informed decision making in the context of prenatal screening. Patient Educ Couns 2006;63:110-117.

155. Beulen L, van den Berg M, Faas BH, Feenstra I, Hageman M, van Vugt JM, Bekker MN. The effect of a decision aid on informed decision-making in the era of non-invasive prenatal testing: a randomised controlled trial. Eur J Hum Genet 2016 [Epub ahead of print]

156. Gezondheidsraad. Wet op het bevolkingsonderzoek: niet-invasieve prenatale test bij verhoogd risico op trisomie. Den Haag: Gezondheidsraad, 2013; publicatienr. 2013/35. ISBN 978-90-5549-984-7

157. United Nations Population Division. Abortion policies: a global review. 2002. 


\section{Summary}


Fetal cell-free DNA (cfDNA) is present in the blood circulation of pregnant women. Fetal cfDNA has increasingly been used in prenatal care, and in prenatal screening and diagnosis of genetic disorders. The analysis of fetal cfDNA in maternal plasma offers the possibility for a safe and highly reliable screening test for fetal aneuploidy. Furthermore, it provides a safe alternative to the invasive procedures for prenatal diagnosis of single-gene disorders. In this thesis, prenatal detection of genetic disorders through analysis of fetal cfDNA in maternal plasma was investigated, from bench to clinic. The aims of this thesis were to develop novel noninvasive prenatal diagnostic tests (Part I) and to investigate the responsible application of cfDNA-based testing in prenatal screening (Part II).

Chapter 1 defines the terms prenatal screening and diagnosis and provides a historical overview of the applications of cfDNA from its discovery until today. The aims of this thesis are presented with an outline of the two parts, subdivided in individual chapters.

\section{Part I: Design of noninvasive prenatal diagnostic tests}

Sex determination was one of the first clinical applications of fetal cfDNA testing and is routinely used in European countries. Delay of the test result or even failure of the test can occur, particularly when the presence of fetal cfDNA in the plasma sample cannot be proven. In Chapter $\mathbf{2}$ the development is described of a novel fast singletube noninvasive fetal sex determination assay, in which a gender-independent fetoplacental marker is incorporated in the test, requiring no extra time or expenses by the laboratory. The assay combines amplification of Y-linked amelogenin (AMELY) cfDNA with one-step reverse transcription PCR of trophoblast-derived cell-free RNA (cfRNA). In a proof-of-principle study, 75 blinded plasma samples from pregnant women were tested to find out whether the fetal sex could be determined and whether cfRNA was a reliable fetoplacental marker in this process. The fetal sex was correctly determined in all 75 pregnant women without failure or false results. It was concluded that amplification of trophoblast-derived cfRNA is a reliable marker for the confirmation of the presence of fetoplacentally derived nucleic acids in noninvasive fetal sex determination.

A current challenge is developing universal noninvasive prenatal diagnostic (NIPD) assays for the detection of single-gene disorders, and in particular disorders caused by nucleotide repeat expansions. In Chapter 3 a novel assay is presented for NIPD of myotonic dystrophy type 1 (DM1) in the cfDNA. DM1 is a single-gene disorder, caused 
by expansion of a CTG trinucleotide repeat in the dystrophia myotonica protein kinase gene $(D M P K)$. Single molecule molecular inversion probes (smMIPs) containing common repeat flanking single nucleotide polymorphisms (SNPS) in the targeted sequence were designed for targeted next-generation sequencing (NGS). We are the first to use smMIPs for haplotype-based NIPD. SmMIPs enable precise quantification of the variation in the cfDNA and are robust to relatively small amounts and poor quality of source DNA. As a proof of concept, the smMIP NIPD assay was applied to cfDNA isolated from the plasma of a woman carrying a fetus affected with DM1, as diagnosed by invasive prenatal testing. After sequencing the SNP markers from the pregnant woman, and from the father and a previous child (= reference) with DM1, informative SNPs for the mutated allele of the father and reference were selected. Subsequently, the cfDNA was sequenced to determine the fetal inheritance, calculated from the percentage of the informative SNPs in the cfDNA reads. In this study, it was demonstrated that the assay could detect the paternal mutated DMPK allele in the fetal cfDNA.

\section{Part II: Noninvasive prenatal screening for fetal chromosome disorders}

The search for a noninvasive prenatal test that could reliably detect fetal trisomies 13 , 18 and 21 started very soon after the discovery of fetal cfDNA in maternal plasma. The use of NGS, allowing to identify the chromosomal origin of each sequenced cfDNA molecule, and to calculate the over- or underrepresentation of any chromosome in maternal plasma led to a practical screening test that could be used routinely. In 2011 the first diagnostic accuracy studies were published using NGS to detect fetal trisomies 13, 18 and 21 in maternal plasma. In Chapter $\mathbf{4}$ an overview is provided of all studies evaluating the diagnostic accuracy of molecular techniques for noninvasive detection of trisomy 21 between 1997 and the beginning of 2012. The quality of the studies and the diagnostic parameters were evaluated using the QUADAS-2 tool. We noted that NGS-based detection of fetal trisomy 21 in the cfDNA exhibits a high sensitivity and specificity and an excellent negative predictive value. However, we also reported for the first time that the positive predictive value shows large variation between pregnant women, and can be as low as $50 \%$ in case of a low a priori probability for having a fetus with trisomy 21 . Furthermore, we concluded that additional large prospective studies would allow more precise estimates about sensitivity, specificity and predictive values in high-risk and low-risk pregnancies. Finally, we predicted that noninvasive detection of trisomy 21 in the cfDNA was likely to be implemented as a replacement for the current serum screening test. 
Immediately after publication of Chapter 4, the variable positive predictive value was also reported by others. Since a false positive result can lead to the abortion of a healthy fetus, independent validation by an invasive procedure followed by rapid aneuploidy detection or karyotyping is recommended by the International Society for Prenatal Diagnosis. In the chorionic villi or amniocytes, rapid aneuploidy detection, karyotyping or array can confirm the presence of an aneuploidy in the fetus. The term "noninvasive prenatal testing" (NIPT) was formulated, referring to cfDNA-based tests that are used as a screening test and require a confirmation by a follow-up test. In the years following our publication, large prospective studies have allowed more precise estimates about sensitivity, specificity and predictive values in high-risk and low-risk pregnancies. As we predicted, the goal since 2011 has been to replace current screening tests, such as the first trimester combined test (FCT), with NIPT, or to offer NIPT as a second tier screening test. A rapid global use of NIPT for fetal aneuploidy was seen, mostly offered in a commercial setting. Since 2013 , some NIPT assays can detect submicroscopic chromosomal abnormalities and sex chromosome imbalances. Clinically significant microdeletion and microduplication syndromes can now be detected, such as DiGeorge syndrome (22q11.2 deletion). The sex chromosome disorders that can be detected include monosomy $X$ and sex chromosome trisomies $(47, X X X ; 47, X X Y$ and $47, X Y Y)$.

Nowadays, several countries are working on the implementation of NIPT in their prenatal trisomy screening program. In Chapter $\mathbf{5}$ different hypothetical NIPT implementation strategies are compared for such a national screening program. For this, a quantitative analysis was conducted. Decision trees were created to illustrate all plausible implementation strategies in a theoretical cohort of 100000 pregnant women. This resulted in five screening programs: classical screening by the FCT, preselection of high-risk women prior to NIPT by the FCT, NIPT as the first screening test at 10 weeks and at 13 weeks, and the simultaneous conductance of NIPT and the FCT. Our results suggested that the most favorable screening program may be a program in which NIPT is offered to all women at 13 weeks of gestation as the first screening test (13-week NIPT). The conclusions of Chapter 5, drawn for the implementation of trisomy 21 screening, are also applicable for broad NIPT assays targeting trisomies 13 and 18, and submicroscopic chromosome aberrations and fetal sex chromosome disorders.

In some countries, NIPT for sex chromosome disorders is not available yet. Furthermore, critics may argue that NIPT for sex chromosome aneuploidy is beyond 
the scope of a worthwhile prenatal screening test, given that these abnormalities often result in a very mild phenotype. In Chapter 6, we assess pregnant women's opinions about NIPT for sex chromosome trisomies (SCTs) within the broader context of the expansion of disorders included in the NIPT panel. Individual semi-structured interviews were conducted with eight pregnant women that only have access to NIPT in case of an increased risk for trisomy 13, 18 or 21 after the FCT or on the basis of their personal history, through a national public health setting. Before the start of the interview, information was provided about SCTs and the possibilities and limitations of NIPT for SCTs. After ascertaining that the information about SCTs and NIPT for SCTs was clear for the participants, their ideas regarding NIPT for SCTs and the expansion of the spectrum of detectable disorders by NIPT were explored. The interviewees expressed a variety of opinions concerning NIPT for SCTs. Four of them agreed with adding SCTs to the NIPT panel. The overall opinion of these women was that they wanted to choose for themselves which disorders in the NIPT panel they wished to screen for, and which conditions they wanted to confirm by invasive testing.

In Chapter 7 the results of the individual studies are put into perspective. The results of Part I are discussed along the following themes: 1 ) improving noninvasive fetal sex determination, 2) noninvasive evaluation of cell-free RNA levels in maternal plasma, 3) development and implementation of NIPD of single-gene disorders. The results of Part II are discussed in these topics: 1) NIPT of trisomies 13, 18 and 21 from 2011 until now, 2) broadening the scope of noninvasive prenatal screening, 3) false positive and false negative NIPT results, and 4) autonomous reproductive choice. It is concluded that the investigation of responsible application of cfDNA-based testing in prenatal screening is at least as important as the exploration of what can be detected in the cfDNA. Parallel with technical innovations, further empirical research is required, in particular with regard to the organization and implementation of NIPT and NIPD in the different national health systems, the preferences of pregnant couples, and the optimal path to informed decision making. 



\section{Samenvatting}


In het bloed van zwangere vrouwen is celvrij DNA aanwezig dat afkomstig is van de foetus. De analyse van foetaal celvrij DNA wordt in toenemende mate gebruikt voor prenatale screening en diagnostiek van genetische aandoeningen. Het analyseren van foetaal celvrij DNA in een maternaal plasmamonster biedt de mogelijkheid voor een betrouwbare foetale aneuploïdie screeningstest. Bovendien is het een veilig alternatief zonder risico voor de foetus voor invasieve procedures (vlokkentest en vruchtwaterpunctie) bij prenatale diagnostiek van monogene aandoeningen. Wij bestudeerden de prenatale detectie van genetische aandoeningen via het analyseren van foetaal celvrij DNA in het maternaal plasma, van het laboratorium tot in de klinische praktijk. De doelstellingen van deze thesis waren het ontwikkelen van nieuwe niet-invasieve prenatale diagnostische testen (Deel I) en het bestuderen van de verantwoorde toepassing van de analyse van celvrij foetaal DNA voor prenatale screening (Deel II).

In Hoofdstuk 1 worden de termen prenatale screening en diagnostiek uitgelegd en wordt een historisch overzicht gegeven van de toepassingen van de analyse van foetaal celvrij DNA, sinds de ontdekking ervan tot op heden. De doelstellingen van deze thesis worden beschreven, met een overzicht van de twee delen en de individuele hoofdstukken.

\section{Deel I: De ontwikkeling van niet-invasieve prenatale diagnostische testen}

Foetale geslachtsbepaling was één van de eerste klinische toepassingen van de analyse van foetaal celvrij DNA. Het wordt routinematig uitgevoerd in Europese landen als er kans is op een geslachtsgebonden aandoening of als er een ambigue genitaal wordt gezien tijdens prenatale echografie. Wanneer de aanwezigheid van foetaal celvrij DNA in het plasmamonster niet bewezen kan worden, kunnen de testresultaten van de reguliere test niet of vertraagd afgegeven worden. In Hoofdstuk 2 wordt de ontwikkeling van een nieuwe niet-invasieve test voor foetale geslachtsbepaling, volledig uitgevoerd in één pipetteerbuisje, beschreven. Een geslachtsonafhankelijke foetoplacentaire marker is ingebouwd in de test, wat geen extra tijd of uitgaven van het laboratorium vraagt om de aanwezigheid van foetoplacentaire nucleïnezuren aan te tonen in het maternaal plasma. Onze nieuwe test combineert amplificatie van celvrij DNA van het gen $A M E L Y$, afkomstig van het $Y$-chromosoom, met one-step reverse transcription PCR van celvrij RNA, afkomstig van de trofoblast van de placenta. In een proof of principle studie werden 75 plasmamonsters van zwangere vrouwen getest om te onderzoeken of het geslacht juist bepaald kon worden, en of het celvrij RNA een 
betrouwbare marker was voor de aanwezigheid van foetaal materiaal tijdens dit proces. Het foetaal geslacht werd correct bepaald bij alle 75 zwangere vrouwen zonder testfalen. De conclusie was dat amplificatie van celvrij RNA, afkomstig van de trofoblast van de placenta, een betrouwbare marker was voor het bevestigen van de aanwezigheid van foetoplacentaire nucleïnezuren tijdens niet-invasieve foetale geslachtsbepaling.

Een uitdaging in de huidige tijd is het ontwikkelen van universele niet-invasieve prenatale diagnostische (NIPD) testen voor de detectie van monogene aandoeningen, en in het bijzonder aandoeningen veroorzaakt door een nucleotide repeat expansie. In Hoofdstuk 3 wordt een nieuwe test besproken voor NIPD van myotone dystrofie type 1 (DM1). DM1 is een monogene aandoening die veroorzaakt wordt door een expansie van een CTG trinucleotide repeat in het dystrophia myotonica protein kinase gen (DMPK). Er werden single molecule molecular inversion probes (smMIPs) ontworpen met een frequente repeat flankerende single nucleotide polymorfisme (SNP) in hun doelsequentie. Hiermee konden we NIPD uitvoeren middels op nextgeneration sequencing (NGS) gebaseerde haplotypering. We zijn de eerste onderzoeksgroep die smMIPs gebruiken voor NIPD. SmMIPs laten precieze kwantificatie van een variant in het celvrij DNA toe, en zijn robuust, ook voor relatief kleine hoeveelheden en slechte kwaliteit van het DNA. Als proof of concept werd de smMIPs NIPD test toegepast op cfDNA dat geïsoleerd werd uit het plasma van een vrouw die zwanger was van een foetus met DM1. Na het sequencen van de SNP markers van de zwangere vrouw, en van de vader en een eerder kind (= index patiënt) met DM1, werden informatieve SNPs voor het gemuteerde allel van de vader en de index geselecteerd. Vervolgens werd het cfDNA gesequencet voor het bepalen van de foetale overerving, wat berekend wordt uit de percentages van de informatieve SNPS in de cfDNA reads. In deze studie werd aangetoond dat de smMIPs NIPD test de paternaal overgeërfde DMPK mutatie kon aantonen in het moederlijk bloedplasma. 


\section{Deel II: Niet-invasieve prenatale screening voor foetale chromosoom aandoeningen}

De zoektocht naar een niet-invasieve prenatale test die betrouwbaar de foetale trisomieën 13, 18 en 21 kan detecteren, werd snel na het ontdekken van celvrij DNA gestart. NGS laat het toe om de chromosomale origine van elke gesequencete DNA molecule te identificeren, en zo een teveel of te weinig van elk chromosoom in het maternale plasma te bepalen. In 2011 werden de eerste diagnostische studies gepubliceerd waarin NGS werd gebruikt voor de detectie van de foetale trisomieën 13, 18 en 21 in het maternale plasma. In Hoofdstuk 4 wordt een overzicht gegeven van alle van 1997 tot 2012 gepubliceerde studies die de diagnostische waarde van een moleculaire techniek voor de niet-invasieve detectie van trisomie 21 evalueerden. De kwaliteit en de diagnostische parameters van de studies werden beoordeeld, via de QUADAS-2 beoordeling. We vonden dat de detectie van foetale trisomie 21 in het celvrij DNA op basis van NGS zowel een hoge sensitiviteit als een hoge specificiteit, en een uitstekende negatieve voorspellende waarde had. We rapporteerden echter ook voor het eerst dat de positieve voorspellende waarde veel variatie tussen zwangere vrouwen vertoonde, en dat deze zelfs kleiner dan $50 \%$ kan zijn bij een laag a priori risico op een foetus met trisomie 21 . We concludeerden dat grotere prospectieve studies nodig waren om meer precieze inschattingen te maken van de sensitiviteit, specificiteit, en voorspellende waardes in hoog-risico en laag-risico zwangerschappen. Ten slotte voorspelden we dat niet-invasieve detectie van trisomie 21 in het celvrij DNA waarschijnlijk geïmplementeerd zou worden als vervanging voor de huidige serum screening test.

Onmiddellijk na het publiceren van het artikel uit Hoofdstuk 4, werd de variabele positief voorspellende waarde van niet-invasieve detectie van trisomie 21 ook gerapporteerd door anderen. Aangezien een vals positief resultaat kan leiden tot het aborteren van een gezonde foetus, is een onafhankelijke validatie nodig in foetaal materiaal, verkregen via een invasieve procedure. In de vlokken of het vruchtwater kan snelle aneuploïdie detectie, karyotypering, of array diagnostiek aantonen of er werkelijk sprake is van een aneuploïdie. Dit advies is vastgelegd in een richtlijn van de International Society for Prenatal Diagnosis. De term "niet-invasief prenataal testen" (NIPT) werd vervolgens gepreciseerd, verwijzend naar testen op basis van celvrij DNA die gebruikt worden als screeningstest en een bevestiging met een follow-up test vragen. Het is sinds 2011 de bedoeling om de huidige screeningstesten, zoals de eerste trimester combinatie test (CT) te vervangen door NIPT, of om NIPT aan te bieden als 
tweede screeningstest bij een verhoogd risico na de CT. Sinds 2013 kunnen sommige NIPT assays ook submicroscopische chromosomale afwijkingen en numerieke geslachtschromosoomafwijkingen detecteren. Klinisch significante microdeletie- en microduplicatiesyndromen kunnen nu getest worden, zoals DiGeorge syndroom (22q11.2 deletie). Tot de numerieke geslachtschromosoomafwijkingen die kunnen gevonden behoren monosomie $X$ en de trisomieën van de geslachtschromosoom $(47, X X X ; 47, X X Y ; 47, X Y Y)$.

Op dit moment werken verschillende landen aan de implementatie van NIPT in hun prenataal trisomie screeningsprogramma. In Hoofdstuk 5 worden verschillende hypothetische NIPT implementatie-strategieën voor een nationaal screeningsprogramma vergeleken. Hiervoor werd een kwantitatieve analyse uitgevoerd. Er werden beslisbomen ontworpen om mogelijke implementatiestrategieën te illustreren in een theoretisch cohort van 100000 zwangere vrouwen. Dit resulteerde in vijf hypothetische screeningsprogramma's: klassieke screening met behulp van de CT, selectie van hoog-risico vrouwen vóór NIPT met behulp van de CT, NIPT als de eerste screeningstest tijdens de 10e zwangerschapsweek of tijdens de $13 \mathrm{e}$ zwangerschapsweek, en het simultaan uitvoeren van NIPT en CT. Onze resultaten tonen aan dat het meest gunstige screeningsprogramma mogelijk een programma is waarin NIPT als eerste screeningstest wordt aangeboden aan alle vrouwen tijdens de 13e zwangerschapsweek. De conclusies van Hoofdstuk 5, die werden gebaseerd op screening voor trisomie 21, zijn ook van toepassing voor uitgebreidere NIPT voor bijvoorbeeld trisomie 13 en 18, submicroscopische chromosoomafwijkingen en numerieke geslachtschromosoomafwijkingen.

NIPT voor numerieke geslachtschromosoomafwijkingen is nog niet algemeen beschikbaar. Het is de vraag of NIPT voor geslachtschromosoomaneuploïdie binnen de reikwijdte van een prenatale screeningtest zou moeten vallen, aangezien de aandoeningen die het gevolg zijn van een aneuploïdie van de geslachtschromosomen vaak leiden tot een mild fenotype. In Hoofdstuk 6 onderzoeken we de mening van zwangere vrouwen over NIPT voor geslachtschromosoomtrisomieën, binnen de bredere context van de uitbreiding van het aantal aandoeningen dat in het NIPT panel geïncludeerd kunnen worden. Er werden individuele semi-gestructureerde interviews gehouden met acht zwangere vrouwen die op dit moment enkel toegang tot NIPT hebben bij een verhoogd risico op trisomie 13, 18 of 21, na de CT of op basis van hun voorgeschiedenis. Vóór aanvang van de interviews werd informatie gegeven over geslachtschromosoomtrisomieën en de mogelijkheden en beperkingen van NIPT voor 
deze aandoeningen. Nadat werd vastgesteld dat deze informatie duidelijk was voor de deelnemers, werden hun ideeën over NIPT voor deze aandoeningen en de uitbreiding van het spectrum van detecteerbare aandoeningen via NIPT geëxploreerd. De geïnterviewden hadden diverse meningen over NIPT voor geslachtschromosoomtrisomieën. Vier van hen vonden het toevoegen van geslachtschromosoomtrisomieën aan het NIPT panel een goed idee. De algemene opinie van deze vrouwen was dat zij zelf wilden kiezen voor welke aandoeningen in het NIPT panel zij wensten te laten screenen, en welke aandoeningen zij wilden laten bevestigen met een invasieve test.

In Hoofdstuk 7 worden de resultaten van de beschreven studies in perspectief geplaatst. De resultaten van Deel I worden bediscussieerd in de volgende thema's: 1) verbetering van niet-invasieve foetale geslachtsbepaling, 2) niet-invasieve analyse van celvrij RNA in maternaal plasma, 3) ontwikkeling en implementatie van NIPD van monogene aandoeningen. De resultaten van Deel II worden besproken in de volgende onderwerpen: 1) NIPT van trisomie 13, 18 en 21 vanaf 2011 tot nu, 2) het uitbreiden van de reikwijdte van niet-invasief prenataal screenen, 3) vals positieve en vals negatieve NIPT resultaten, en 4) autonome reproductieve keuze. We concluderen dat naast het ontwikkelen van nieuwe niet-invasieve prenatale diagnostische testen, het eveneens belangrijk is om het proces van verantwoorde prenatale screening met behulp van celvrij foetaal DNA te bestuderen. Parallel aan de technische innovaties, is er verder onderzoek noodzakelijk, in het bijzonder naar de organisatie en implementatie van NIPT en NIPD in verschillende nationale gezondheidszorgsystemen, de voorkeuren van zwangere koppels, en de optimale weg tot het maken van geïnformeerde keuzes. 
Addendum: valorization 
This addendum describes the valorization of the relevant findings from the research upon which this doctoral dissertation is based. This means that I translate these findings into available products for the society. The word "products" should be interpreted in a broad sense in this context, ranging from novel noninvasive prenatal diagnostic laboratory tests (Part I), to knowledge aiding the national debate and decision-making concerning noninvasive prenatal screening (Part II).

\section{Valorization of Part I: Design of noninvasive prenatal diagnostic tests}

Part I comprised the design of in-house noninvasive diagnostic tests for fetal sex determination as well as for single-gene mutation detection (Chapters $\mathbf{2}$ and $\mathbf{3}$ ).

A noninvasive fetal sex determination assay was developed and tested in 75 pregnant women from 9-34 weeks of gestation (Chapter 2 ). Noninvasive fetal sex determination in cell-free fetal DNA (cfDNA) in maternal blood is only available for a small group of pregnant women with a clinical indication. These are women carrying a fetus that presents with ambiguous genitalia during ultrasound examination, women carrying a fetus that is at risk of an X-linked disorder, or a fetus at risk of the autosomal recessive disorder congenital adrenal hyperplasia, where masculinization of the external genitalia of girls occurs. ${ }^{1-3}$ The fetal sex was correctly determined in all 75 pregnant women without failure or false results. For clinical application, the assay is competitive opposed to current assays: it is a non-expensive, fast, single-tube assay that can determine the fetal sex within one or two working days, with an equal turnaround time for boys and girls. Up until now the blood from pregnant women with a clinical indication for prenatal diagnosis of fetal sex was sent to Sanquin, the national reference laboratory for noninvasive prenatal sex determination. ${ }^{4}$ In case of a female fetus the test in Sanquin can take more than a week, and sometimes fails to provide a certain result.

After publication of Chapter 2, our noninvasive fetal sex determination assay was further validated in 13 pregnant women from 10-12 weeks of gestation (Addendum Table 1). ${ }^{5}$ Comparison of the results of our new assay with the results of invasive prenatal testing revealed that the fetal sex was correctly determined in all samples. Before the assay can be offered to pregnant women in the Clinical Genetics department of the Maastricht UMC+, further validation is required, especially early in pregnancy (8-10 weeks of gestation). Currently, approval by the Medical Ethics Committee of the Academic Hospital Maastricht and Maastricht University is requested for this validation in 100 pregnant women. Plasma will be obtained in two 
populations: (1) When a sample is sent to Sanquin for fetal sex determination, a second blood sample will be drawn for our new test. The results of the two sex determination assays will be compared. Annually, 5-10 samples are sent to Sanquin for X-linked disorders, and another 5-10 samples for ambiguous genitalia. (2) When blood is drawn for the first trimester fetal aneuploidy screening (combined test), an additional blood sample will be drawn. In these women, follow-up of the pregnancy should be guaranteed, e.g. by 20 weeks ultrasound or postnatal information, so that the fetal sex can be compared with the result of our assay.

Following implementation our new noninvasive fetal sex determination assay in the Clinical Genetics department of the Maastricht UMC+, pregnant women are provided a more robust and fast test, and the department can send an invoice to the health care insurers. In the future, after gaining some more experience and confidence conducting the test, our laboratory may even opt to establish itself as an additional national reference laboratory for noninvasive fetal sex determination.

Addendum Table 1 Further validation of the one-tube noninvasive prenatal sex determination assay

\begin{tabular}{|c|c|c|c|c|c|}
\hline \multicolumn{2}{|l|}{ Sample } & \multicolumn{3}{|c|}{ Noninvasive prenatal sex determination } & \multirow[t]{2}{*}{ Invasive testing } \\
\hline$\#$ & $\begin{array}{l}\text { Gestational age } \\
\text { (weeks + days) }\end{array}$ & CSH cfRNA & CGB cfRNA & $\begin{array}{l}\text { AMELY } \\
\text { cfDNA }\end{array}$ & \\
\hline 1 & $12+0$ & + & + & + & boy \\
\hline 2 & $12+1$ & + & + & + & boy \\
\hline 3 & $11+4$ & + & + & + & boy \\
\hline 4 & $12+4$ & + & + & + & boy \\
\hline 5 & $12+2$ & + & + & - & girl \\
\hline 6 & $11+2$ & + & + & + & boy \\
\hline 7 & $11+2$ & + & + & - & girl \\
\hline 8 & $11+2$ & + & + & - & girl \\
\hline 9 & $10+6$ & + & + & + & boy \\
\hline 10 & $12+3$ & + & + & + & boy \\
\hline 11 & $11+2$ & + & + & - & girl \\
\hline 12 & $12+3$ & + & + & - & girl \\
\hline 13 & $11+4$ & + & + & - & girl \\
\hline Sensitivity & $100 \%$ & & & & \\
\hline Specificity & $100 \%$ & & & & \\
\hline
\end{tabular}


The design of a newly developed in house NIPD assay for single-gene disorders was described in Chapter 3. Single molecule molecular inversion probes (smMIPs) were designed, together with the Human Genetics department of the Radboud UMC in Nijmegen, for targeted next-generation sequencing (NGS) for NIPD by haplotyping. ${ }^{6}$ We are the first to use smMIPs for NIPD of single-gene disorders. The designed MIPs were optimized for analysis of fetal cfDNA, which is fractionated and present in a low concentration. Adding single molecule tagging to the MIPs allows us to mark sequence reads derived from a common progenitor molecule (that is, the same genomic equivalent in source DNA). This results in counting of unique captured molecules, and tag-based consensus calling to minimize errors from PCR or sequencing. SmMIPs enable precise quantification of the variation in the cfDNA and are robust to relatively small amounts and poor quality of source DNA.

In Chapter 3 the first proof of concept was described. As a proof of concept, the smMIP NIPD assay was applied to cfDNA isolated from the plasma of a woman carrying a fetus affected with myotonic dystrophy type 1 (DM1), as diagnosed by invasive prenatal testing. DM1 is a single-gene disorder, caused by expansion of a CTG trinucleotide repeat. ${ }^{7,8}$ After sequencing the SNP markers from the pregnant woman, and from the father and a previous child (= reference) with DM1, informative SNPs for the mutated allele of the father and reference were selected. Subsequently, the cfDNA was sequenced to determine the fetal inheritance, calculated from the percentage of the informative SNPs in the cfDNA reads. In the proof of concept, it was demonstrated that the assay could detect the mutated DMPK allele, inherited from the father, in the fetal cfDNA.

Validation of the smMIPs NIPD assay is ongoing. Plasma samples are being collected in Maastricht and Nijmegen when a pregnant woman undergoes an invasive procedure for prenatal genetic diagnosis for one of the following indications: (1) a fetus at high risk of having inherited a dominant or recessive disorder of his/her affected parent(s), or (2) a fetus at risk of having a de novo disorder on the basis of ultrasound findings. Annually, 40-60 couples are referred for prenatal diagnosis of a single-gene disorder, both in Maastricht and Nijmegen. In anticipation of this study, smMIP assays have already been designed for three other single-gene disorders:

- autosomal dominant: spastic paraplegia 4 (SPG4, gene: SPAST)

- autosomal recessive: cystic fibrosis (CF, gene: CFTR)

- autosomal dominant, caused by a trinucleotide repeat expansion: Huntington's disease (HD, gene: HTT) 
For SPG4 and CF, smMIPs were developed to cover all exons and to target intronic and gene surrounding common SNPs (combined direct and indirect mutation detection by SNP-based haplotyping). For HD, as for DM1, smMIPs were designed to target common repeat flanking SNPs (only SNP-based haplotyping).

Because of the unique smMIPs design, especially adapted to fetal cfDNA testing, the first steps for the development of an international competitive NIPD assay were taken. We are heading towards an in-house NIPD for paternally and maternally inherited disorders, even X-linked disorders and repeat expansion disorders. By combining the unique knowledge of the Radboud UMC regarding next-generation sequencing, as well as of the Maastricht UMC+ regarding direct and indirect detection of all types of genetic disorders in pre-implantation genetic diagnosis, translation of the newly developed assay into prenatal diagnostic tests for pregnant women is realistic.

\section{Valorization of Part II: Noninvasive prenatal screening for fetal chromosome disorders}

In Part II the diagnostic accuracy and clinical implementation of trisomy 21 screening by NIPT were examined (Chapters 4 and 5). Additionally, the opinion of pregnant women regarding the inclusion of fetal sex trisomies in the NIPT panel was explored, within the broader context of the expansion of the scope of screening (Chapter 6).

In 2007, in the Netherlands a national prenatal screening program was introduced aiming to provide all pregnant women the option of prenatal screening for trisomies 13,18 and 21 with the first trimester combined test (FCT). ${ }^{9}$ The FCT combines a serum screening test with a nuchal translucency measurement in the first trimester of pregnancy. Traditionally, women with a risk of fetal trisomies 13, 18 or 21 of 1 in 200 or higher after the FCT were offered an invasive procedure to further investigate these fetal chromosome disorders.

In 2011, at the time I started the research upon which this doctoral dissertation is based, the first diagnostic accuracy studies were published of noninvasive prenatal testing (NIPT) for fetal trisomies 13, 18 and 21 in maternal plasma. ${ }^{10}$ In Chapter 4 a systematic review was conducted and an overview was provided of all studies evaluating the diagnostic accuracy of NIPT for trisomy 21 between 1997 and the beginning of $2012 .{ }^{10}$ We concluded that the positive predictive value of NIPT (How likely is a pregnant woman with a positive cfDNA-based test result to actually carry a fetus with the trisomy?) declines if the a priori risk for a fetus with a trisomy declines. 
NIPT requires a confirmation by a follow-up diagnostic test, for a definite diagnosis of fetal aneuploidy in the fetus. We predicted that NIPT was likely to replace the prenatal serum screening test that is currently combined with nuchal translucency measurement in the FCT. Due to the reduction in false-positive and false-negative results in comparison to the FCT, fewer trisomy cases would be missed at the first screening step and fewer invasive procedures would be needed, only to verify a positive NIPT result and to confirm non-inheritable or inheritable forms of Down syndrome, using the gold standard karyotyping. The results of our study were among others cited by the Nederlandse Vereniging voor Obsetrie en Gynaecologie (NVOG) in their opinion about NIPT in May 2013 ${ }^{11}$, and in the Wet op het bevolkingsonderzoek niet-invasieve prenatale test bij verhoogd risico op trisomie in December 2013, from the Health Council of the Netherlands Health Council, an advisory board of the Dutch Ministry of Health. ${ }^{12}$

The first commercial releases of NIPT were seen in Hong Kong in August 2011, and in the United States (US) in October 2011. ${ }^{13}$ Different companies offered commercial NIPT to high-risk pregnant women, such as the MaterniT21 $1^{\text {TM }}$ PLUS test from Sequenom (http://www.sequenom.com), the Praena-Test ${ }^{\circledR}$ from their European partner LifeCodexx (http://www.lifecodexx.com), the verifi ${ }^{\circledR}$ test from Verinata (http://www.verinata.com) and the Harmony ${ }^{\mathrm{TM}}$ prenatal test from Ariosa (http://www.ariosadx.com). During a 3 year-period after the first commercial release, the news about the option for NIPT had reached Dutch pregnant women through the internet, traditional media as well as family and friends. However, for them, it was not possible to undergo NIPT in The Netherlands. Following the publication of Chapter 4, we were approached for an interview for the newspaper NRC, in which we explained to pregnant women the principle of the NIPT, and when we expected the test to be available in the Netherlands. ${ }^{14}$

Since April 2014, a national implementation study has been organized in the Netherlands (the TRIDENT study). ${ }^{15}$ In this study, the genetic laboratories of the country collaborate to investigate the accuracy of NIPT and compare it to the published accuracy. Prenatal screening for trisomies 13, 18 and 21 by NIPT is offered as a part of the TRIDENT- 1 study to women with an increased risk based on the FCT ( $\geq$ 1:200), or based on their personal history. Also in Maastricht UMC+, pregnant women can undergo NIPT as a part of the TRIDENT-1 study. Recently, the Health Council, an advisory board of the Dutch Ministry of Health, advised to offer all pregnant women the choice for NIPT as the first screening test. ${ }^{16}$ In September 2016, the Minister of 
Health gave permission to start with the TRIDENT-2 study in April 2017. In the TRIDENT-2 study women can choose between three different scenarios: NIPT as the first screening test, the FCT as the first and only screening test, and pre-selection by the FCT prior to NIPT. ${ }^{15}$ At the moment, the Minister does not follow the suggestion of the Health Council that the NT measurement could be offered to pregnant women that only undergo NIPT. The university hospitals are allowed to offer these scenarios under the following conditions: adequate counseling about the advantages and disadvantages of these three scenarios, as well as counseling about incidental findings and the possibility to opt-out for incidental findings, scientific study of the impact of analysis filters (that preclude incidental findings) on the quality of NIPT, protecting the women's right not to know and avoiding routinization offer of NIPT.

In Chapter 5 different hypothetical NIPT implementation strategies were compared for a national screening program. Decision trees were created to illustrate all plausible alternatives in a theoretical cohort of 100000 pregnant women in five screening programs: classical screening by the first-trimester combined test (FCT), pre-selection of high-risk women prior to NIPT by the FCT, NIPT as the first screening test at 10 weeks and at 13 weeks, and the simultaneous conductance of NIPT and the FCT. We reflected upon the results of the quantitative analysis in the light of psychological and practical considerations, e.g. the chance that women are correctly reassured by a negative screening result, the chance of a correct positive screening result, the time until the result of the screening test, the time from the result of the screening test until the confirmation of a positive result by amniocentesis, the number of decision-making moments for women, etc. The results of Chapter $\mathbf{5}$ were presented in the European Human Genetics Conference (31 May- 3 June 2014, Milan, Italy). The results may be used for to inform pregnant couples about the advantages and disadvantages of the three programs of TRIDENT-2.

In Chapter 6, we assessed pregnant women's opinions about NIPT for sex chromosome trisomies (SCTs) within the broader context of the expansion of disorders included in the NIPT panel. Individual semi-structured interviews were conducted with eight pregnant women. The results of our study revealed several topics to consider when offering NIPT for SCTs or expanding the NIPT panel. Our study identified several potential disadvantages of NIPT for SCTs: receiving a prenatal test result about a disorder with unclear consequences for the future child's life and for which they would take no further actions, a less worry-free pregnancy and childhood, and possible guilt about continuation of pregnancy. Two participants mentioned the option of 
termination of pregnancy as a benefit of screening, while others firmly stated that they disagreed with offering pregnant women the possibility to terminate the pregnancy because of a fetal SCT. Furthermore, the limited positive predictive value was perceived as a negative aspect of NIPT for SCTs. In concordance with previous studies, not all participants agreed to undergo confirmatory invasive testing for these conditions during pregnancy, because of its additional miscarriage risk. All participants requested to be well-informed about every condition in the NIPT panel prior to testing and brought up that participation and all further steps in the screening process should be voluntary and based on adequate information. The overall opinion was that couples wanted to choose for themselves which disorders in the NIPT panel they wished to screen for, and which conditions they wanted to confirm by invasive testing. Hopefully, also this Chapter will have societal impact, contributing to the discussion about how NIPT should be offered to pregnant couples, and which conditions should be in the NIPT panel. 


\section{References}

1. Rijnders RJ, van der Schoot CE, Bossers B, de Vroede MA, Christiaens GC. Fetal sex determination from maternal plasma in pregnancies at risk for congenital adrenal hyperplasia. Obstet Gynecol 2001;98:374e8.

2. Chitty LS, Chatelain P, Wolffenbuttel KP, Aigrain Y. Prenatal management of disorders of sex development. J Pediatr Urol 2012;8:576-584.

3. Iruretagoyena JI, Grady M, Shah D. Discrepancy in fetal sex assignment between cell free fetal DNA and ultrasound. J Perinatol 2015;35:229-230.

4. Scheffer PG, van der Schoot CE, Page-Christiaens GC, Bossers B, van Erp F, de Haas M. Reliability of fetal sex determination using maternal plasma. Obstet Gynecol 2010;115:117-126.

5. Mersy E, Faas BH, Spierts S, Houben LM, Macville MV, Frints SG, Paulussen AD, Veltman JA. Cell-free RNA is a reliable fetoplacental marker in noninvasive fetal sex determination. Clin Chem 2015;61:15151523.

6. Hiatt JB, Pritchard CC, Salipante SJ, O'Roak BJ, Shendure J. Single molecule molecular inversion probes for targeted, high-accuracy detection of low-frequency variation. Genome Res 2013;23:843-854.

7. Brook JD, McCurrach ME, Harley HG, Buckler AJ, Church D, Aburatani H, Hunter K, Stanton VP, Thirion JP, Hudson T, et al. Molecular basis of myotonic dystrophy: expansion of a trinucleotide (CTG) repeat at the $3^{\prime}$ end of a transcript encoding a protein kinase family member. Cell 1992;69:385.

8. Mahadevan M, Tsilfidis C, Sabourin L, Shutler G, Amemiya C, Jansen G, Neville C, Narang M, Barceló J, O'Hoy K, et al. Myotonic dystrophy mutation: an unstable CTG repeat in the 3 ' untranslated region of the gene. Science. 1992;255:1253-1255.

9. Bakker M, Birnie E, Pajkrt E, Bilardo CM, Snijders RJ. Low uptake of the combined test in The Netherlands--which factors contribute? Prenat Diagn 2012;32:1305-1312.

10. Mersy E, Smits L, van Winden LA, de Die-Smulders CE; South-East Netherlands NIPT Consortium, Paulussen AD, Macville MV, Coumans AB, Frints SG: Noninvasive detection of fetal trisomy 21: systematic review and report of quality and outcomes of diagnostic accuracy studies performed between 1997 and 2012. Hum Reprod Update 2013;19:318-329.

11. http://www.nvogdocumenten.nl/index.php?pagina=/richtlijn/item/pagina.php\&id=28131\&richtlijn_id=930

12. Gezondheidsraad. Wet op het bevolkingsonderzoek: niet-invasieve prenatale test bij verhoogd risico op trisomie. Den Haag: Gezondheidsraad, 2013; publicatienr. 2013/35. ISBN 978-90-5549-984-7

13. Allyse M, Minear MA, Berson E, Sridhar S, Rote M, Hung A, Chandrasekharan S. Non-invasive prenatal testing: a review of international implementation and challenges. Int J Womens Health. 2015;7:113126.

14. Dagblad NRC, March 2013: Down: zekerheid over de grens, by Nienke van Trommel, https://www.nrc.nl/nieuws/2013/03/30/down-zekerheid-over-de-grens-1230219-a1137514

15. http://www.meerovernipt.nl/

16. Gezondheidsraad. Wet op het bevolkingsonderzoek: NIPT als eerste test voor de syndromen van Down, Patau en Edwards. Den Haag: Gezondheidsraad, 2016; publicatienr. 2016/10. 

Dankwoord 
Er zijn ontzettend veel mensen te bedanken bij het tot stand komen van dit proefschrift.

Ik wil in de eerste plaats mijn promotoren bedanken die mij en het project geadopteerd hebben en dit zonder aarzeling of enig voorbehoud hebben gedaan. Prof. dr. ir. Joris Veltman, halverwege ingestapt, en meteen gezocht naar een mooi evenwicht tussen een eigen stempel op het project drukken en geloven in wat al opgebouwd was. Tel daarbij een fijne samenwerking met jouw team in Nijmegen op, en het recept voor een vernieuwende test is geschreven. Prof. dr. Christine de DieSmulders, vanaf de start begaan met het project, een rots in de branding voor menig Maastrichtse PhD student, en uitstekend in het begrijpen en me uitleggen wat dit NIPT verhaal betekent voor de zwangere vrouwen. Christine en Joris, jullie unieke combinatie maakte dit proefschrift, waarin een brug wordt gelegd tussen laboratoriumwerk en de klinische praktijk, mogelijk.

Eveneens wil ik mijn copromotor dr. Suzanne Frints bedanken, die mij aangenomen heeft voor dit project. Suzanne, je hebt je steeds ingezet voor NIPT in Maastricht, en had al een enthousiast team verzameld toen ik aan mijn PhD project begon. Zonder de inzet van dit team was dit proefschrift niet tot stand gekomen.

Alle zwangere vrouwen die bloed gedoneerd hebben net voor het beëindigen van hun zwangerschap, die met me mee gefilosofeerd hebben over het invoeren van brede prenatale screeningstesten, die me deel lieten uitmaken van hun prenataal testmoment samen met hun aangedane partner, en alle andere zwangere vrouwen en partners die deelgenomen hebben tijdens één van onze studies, ook heel erg bedankt.

Daarnaast wil ik mijn paranimfen bedanken, dr. Muriel Draht en dr. Eline van Roekel. Muriel, vriendinnen sinds de eerste GROW Science Day, samen PhDvertegenwoordigers, elkaars supporter in het leven, nu ook elkaars paranimf. Welke taal we ook gebruiken tijdens onze gesprekken, we begrijpen elkaar wel. Eline, je sloot later aan bij de PhD-vertegenwoordigers, en voegde goede organisatie-skills, gezelligheid en enthousiasme aan het team toe. Op jou kan je rekenen, of het nu gaat over een workshop tot in de puntjes regelen, of de noodzaak voor een gezellig tapasavondje, je bent een rots. Muriel en Eline, dankjewel om ook tijdens het verdedigen van mijn proefschrift naast me te staan.

De collega's bij de afdelingen Klinisch Genetica en Obstetrie en Gynaecologie van het MUMC+, hartelijk dank voor het helpen verzamelen van bloedsamples, meedenken over protocollen en experimenten, en jullie interesse en steun gedurende het hele 
traject. In het bijzonder het reproductieve genetica team met dr. Merryn Macville, dr. Yvonne Arens, Nienke Muntjewerff, Nieke Houben, Melanie van Esch; het prenatale screening en diagnostiek team met dr. Salwan Al-Nasiry, dr. Audrey Coumans, Mijntje Pieters, dr. Christine Willekes, Ingrid Witters; de arts-assistenten van beide afdelingen; de analisten en de verloskundigen, dank voor jullie bijdrage aan dit proefschrift.

En als laatste wil ik hier mijn dank uitspreken voor iedereen in mijn drie thuissteden Kuurne, Gent en Maastricht, die met enthousiaste woorden, een luisterend oor of een geurende koffie mij zo weer vooruit hielpen. Samen door de studie geneeskunde, mogen oefenen en groeien in genetisch testen als student, het cytogenetica lab dat mij heeft opgenomen in hun team, alle PhD studenten tijdens onze workshops, mijn familie en vrienden, mijn mooie dochter Eleonora,... Te veel namen om op te noemen, maar ik hoef maar even na te denken en kan meteen verschillende uitspraken uit mijn mouw schudden die allemaal even behulpzaam waren: "Ik zie het in jou, je kan beginnen als thesisstudent."; "We hebben een PhD positie waar je heel erg geschikt voor bent, ik zal je voorstellen aan de PI."; "Ik heb een appartement voor ons gevonden, in het centrum van Maastricht, en het is groot!"; "Ik heb een zwangere voor de MAMOET studie!"; "Een PhD is volhouden, volhouden, volhouden."; "Vanavond naar II Fiore?"; "Er is een monogene, zal ik hem doen? Ik heb wel tijd, hoor.", "Je kan wel wat hebben."; "Mag je spreken in Milaan? Dat is leuk!"; "Cappuccino met wat cacaopoeder?"; "Noortje mag gerust bij ons eten hoor 's avonds, werk nog maar wat verder."; “Mama, werk je aan je boekje?”; “Mama, houvjou!”... 

Curriculum vitae 
Elke Mersy was born on 18 August 1986 in Kortrijk, Belgium.

After completing high school at the Spes Nostra Instituut in Kuurne, Belgium, in 2004, she studied Medicine at Ghent University, Belgium. Three years later, Elke obtained her Bachelor's degree and continued with a four-year Master of Medicine. During the 1st and 2nd year of her Master, Elke did a practical research internship in the DNA laboratory of the Centrum voor Medische Genetica in Ghent, under the supervision of prof. dr. E. De Baere and dr. F. Coppieters,

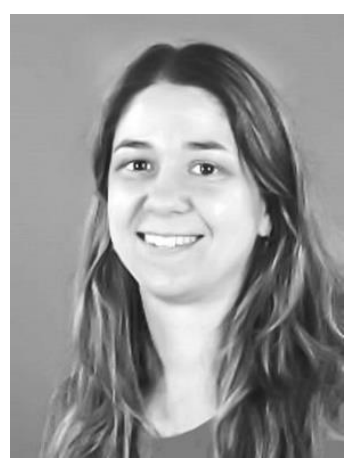
and wrote a Master thesis entitled: Screening of genes from the retinal transcriptional network in retinal dystrophies and optimization of a genetic test for the OPA1 gene in optic atrophy. In the final year of her master of Medicine, Elke chose the program with emphasis on clinical research. She did another research internship in the cytogenetics laboratory of the Centrum voor Medische Genetica in Ghent, under the supervision of prof. dr. ir. B. Menten and dr. ir. S. Vergult, and wrote a thesis entitled: Array-CGH after amniocentesis and chorionic villus sampling in fetuses with prenatal ultrasound abnormalities, and isolation and testing of cell-free fetal DNA in the plasma from the mothers of these fetuses.

After graduating in 2011, Elke started her PhD research at the department of Clinical Genetics from the cluster Genetics and Cell biology, at Maastricht University, the Netherlands. The research was conducted within the doctoral school GROW, School for Oncology and Developmental Biology. During the subsequent five-year period, she investigated the use of cell-free fetal DNA in maternal plasma in prenatal screening and diagnosis, under the supervision of prof. dr. ir. J.A. Veltman, prof. dr. C.E.M. de Die-Smulders and dr. S.G.M. Frints, which was the foundation of this thesis. She contributed to the implementation of NIPT in the department of Clinical Genetics of the Maastricht University Medical Center (MUMC+). During her PhD project, Elke was part of the GROW PhD representatives team, which organizes various research and social activities for other GROW PhD students.

Elke lives in Maastricht with her daughter Eleonora. 
Publications 


\section{Publications}

Mersy E, Faas BH, Spierts S, Houben LM, Macville MV, Frints SG, Paulussen AD, Veltman JA. Cell-free RNA is a reliable fetoplacental marker in noninvasive fetal sex determination. Clin Chem 2015;61(12):1515-23.

Mersy E, de Die-Smulders CE, Coumans AB, Smits LJ, de Wert GM, Frints SG, Veltman $J A$. Advantages and disadvantages of different implementation strategies of noninvasive prenatal testing in Down syndrome screening programmes. Public Health Genomics 2015;18(5):260-71.

Mersy E, Smits LJ, van Winden LA, de Die-Smulders CE; South-East Netherlands NIPT Consortium, Paulussen AD, Macville MV, Coumans AB, Frints SG. Noninvasive detection of fetal trisomy 21: systematic review and report of quality and outcomes of diagnostic accuracy studies performed between 1997 and 2012. Hum Reprod Update 2013;19(4):318-29.

\section{Presentations}

Mersy E, Faas BH, Spierts S, Macville MV, Frints SG, Paulussen AD, and Veltman JA. Non-invasive determination of fetal sex by simultaneous amplification of $Y$ chromosome DNA and trophoblast-specific RNA. 25 th Genetics Retreat, 22-24 April 2015, Kerkrade.

Mersy E, de Die-Smulders CE, Coumans A, Smits LJ, de Wert GM, Frints SG and Veltman JA. Scenarios for implementation of noninvasive prenatal testing (NIPT) for Down syndrome in a national health care system. European Human Genetics Conference, 31 May- 3 June 2014, Milan, Italy.

Mersy E, de Die-Smulders CE, Coumans A, Smits LJ, de Wert GM, Frints SG and Veltman JA. Scenarios for implementation of noninvasive prenatal testing (NIPT) for Down syndrome in a national health care system. $24^{\text {th }}$ Genetics Retreat, 20-21 March 2014, Kerkrade.

Mersy E, Stell A, Spierts S, Paulussen AD, Frints SG, Faas BH, Veltman JA. Non-invasive detection of cell-free $Y$ chromosome DNA and trophoblast-specific RNA in maternal plasma using OneStep RT-PCR. GROW Science Day, 14 November 2013, Maastricht. 


\section{Posters}

Mersy E, Smits LJ, van Winden LA, de Die-Smulders CE, South-East Netherlands NIPT Consortium, Paulussen AD, Macville MV, Coumans AB, Frints SG. Noninvasive detection of fetal trisomy 21: systematic review and report of quality and outcomes of diagnostic accuracy studies performed between 1997 and 2012, International Society of Prenatal Diagnosis 17th International Conference, 2-5 June 2013, Lisboa, Portugal.

Mersy E, Smits LJ, van Winden LA, de Die-Smulders CE, South-East Netherlands NIPT Consortium, Paulussen AD, Macville MV, Coumans AB, Frints SG. Noninvasive detection of fetal trisomy 21: systematic review and report of quality and outcomes of diagnostic accuracy studies performed between 1997 and 2012, European Human Genetics Conference, 8-11 June 2013, Paris, France.

Mersy E, Stell A, Spierts S, Paulussen AD, Frints SG, Faas BH, Veltman JA. Non-invasive detection of cell-free $Y$ chromosome DNA and trophoblastspecific RNA in maternal plasma using OneStep RT-PCR. GROW Science Day, 14 November 2013, Maastricht.

\section{Media}

Nataal, Vakmagazine voor pre- en postnatale zorgverlening, June 2014, edition 21 De NIPT voor iedereen?, by Maureen Baartman.

http://www.gynaecologie.nl/, April 2014: Veilige bloedtest spoort downsyndroom op.

Dagblad NRC, March 2013: Down: zekerheid over de grens, by Nienke van Trommel, https://www.nrc.nl/nieuws/2013/03/30/down-zekerheid-over-de-grens-1230219a1137514 
